\title{
SETTLEMENT OF SHALLOW FOOTINGS ON SAND: REPORT AND USER'S GUIDE FOR COMPUTER PROGRAM CSANDSET
}

\author{
by \\ Virginia R. Knowles \\ Information Technology Laboratory \\ DEPARTMENT OF THE ARMY
}

Waterways Experiment Station, Corps of Engineers

3909 Halls Ferry Road, Vicksburg, Mississippi 39180-6199

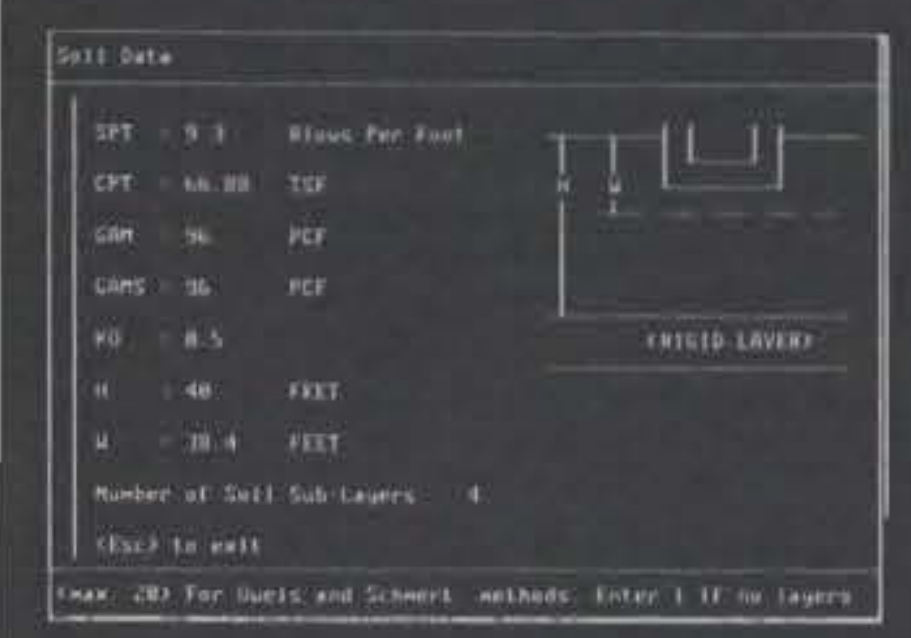

\section{US-CE-C PROPERTV OF THE
UNITED STATES GOVERMMENT}
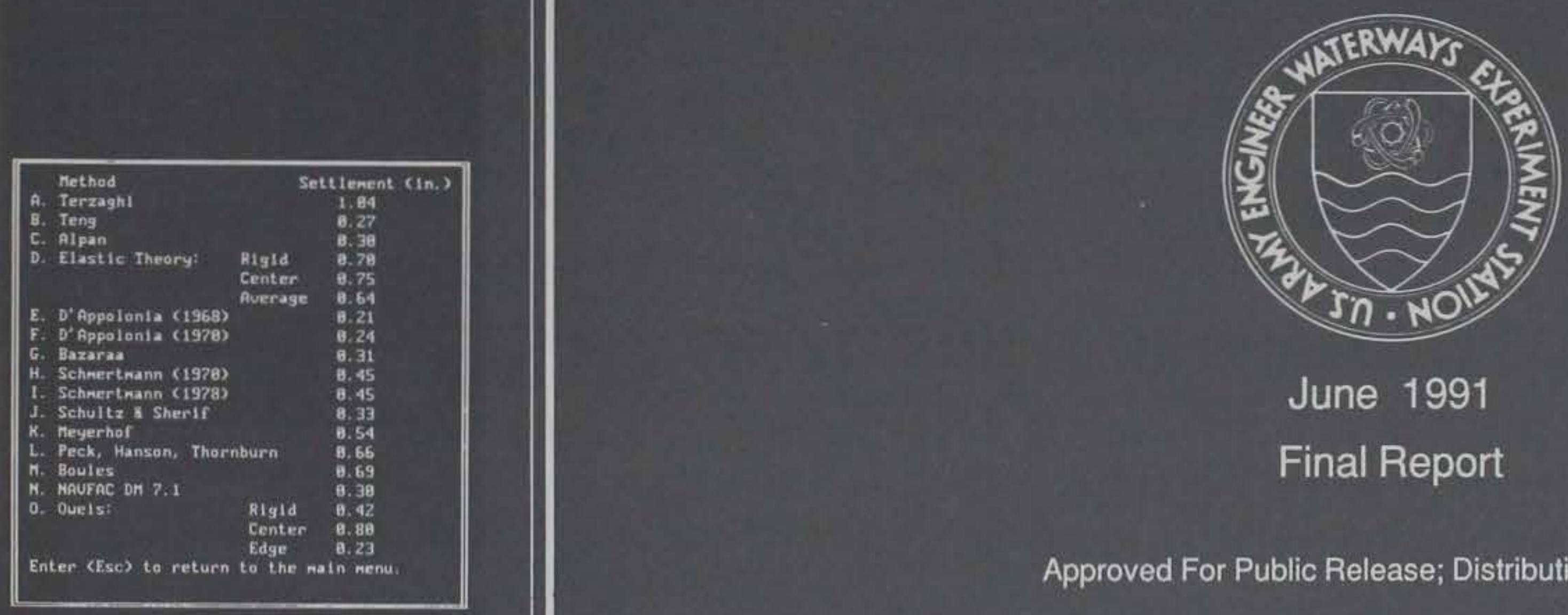

Approved For Public Release; Distribution Unlimited

RESEARCH LIBRARY

US ARMY ENGINEER WATERWAYS

EXPERIMENT STATION

VICKSEIIRG, MISSISSIPPI 
Public reporting burden for this collection of information is estimated to average 1 hour per response, including the time for reviewing instructions, searching existing data sources, gathering and maintaining the data needed, and completing and reviewing the collection of information. Send comments regarding this burden estimate or any other aspect of this coliection of information, including suggestions for reducing this burden, to Washington Headquarters Services, Directorate for information Operations and Reports, 1215 Jefferson Davis Highway, Suite 1204, Arlington, VA 22202-4302, and to the Office of Management and Budget, Paperwork Reduction Project (0704-0188), Washington, DC 20503.
\begin{tabular}{|l|l} 
1. AGENCY USE ONLY (Leave blank) & $\begin{array}{c}\text { 2. REPORT DATE } \\
\text { June } 1991\end{array}$ \\
\hline
\end{tabular}

June 1991
3. REPORT TYPE AND DATES COVERED Final report

4. TITLE AND SUBTITLE

Settlement of Shallow Footings on Sand: Report and

User's Guide for Computer Program CSANDSET

6. AUTHOR(S)

Virginia R. Knowles

7. PERFORMING ORGANIZATION NAME(S) AND ADDRESS(ES)

USAE Waterways Experiment Station

8. PERFORMING ORGANIZATION

Information Technology Laboratory

3909 Halls Ferry Road

Vicksburg, MS 39180-6199

5. FUNDING NUMBERS

9. SPONSORING/MONITORING AGENCY NAME(S) AND ADDRESS(ES)

US Army Corps of Engineers

Washington, DC 20314-1000

\section{SUPPLEMENTARY NOTES}

Available from National Technical Information Service, 5285 Port Royal Road, Springfield, VA 22161.

\begin{tabular}{|l|l|}
\hline 12a. DISTRIBUTION/AVAILABILITY STATEMENT & 12b. DISTRIBUTION CODE
\end{tabular}

Approved for public release; distribution unlimited.

\section{ABSTRACT (Maximum 200 words)}

The CSANDSET computer program calculates the settlement of shallow footings on sand from 15 different methods. This report provides a user's guide for this program and a theoretical section discussing aspects of sand settlement computations. Factors presented include the SPT blowcount and its correction, groundwater and embedment corrections, and elastic and empirical types of settlement methods. Each of the 15 settlement procedures is presented with a brief background summary and all related equations. Examples of handcalculated settlement by all the methods are shown in Appendix A and used for program verification.

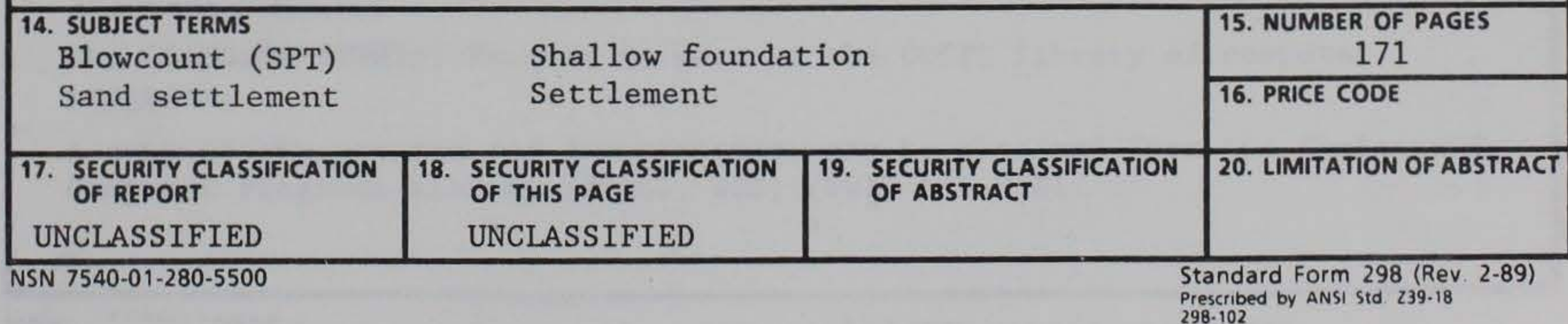




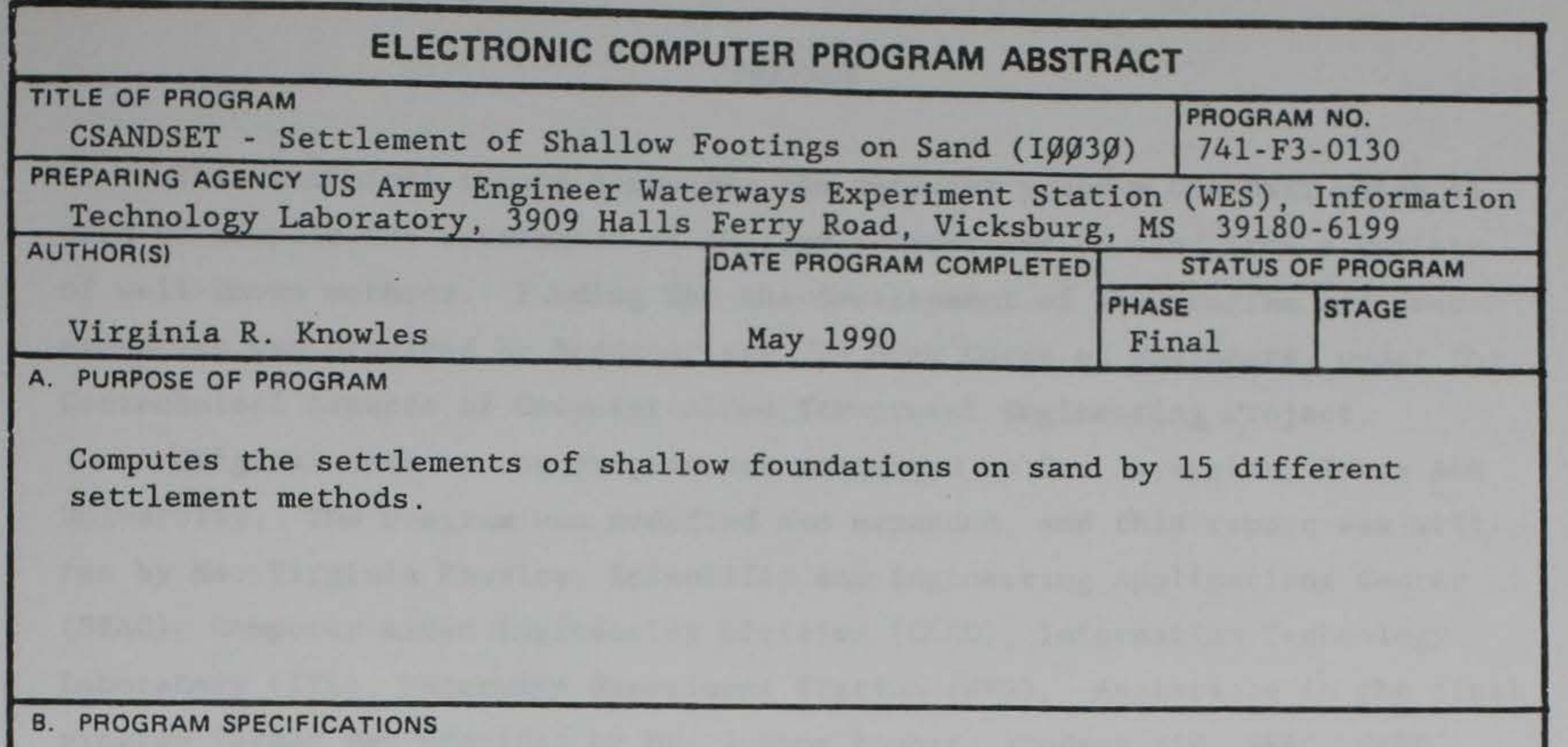

Menu-driven by $\mathrm{C}$-language programming. Calculations in FORTRAN.

C. METHODS

Settlements computed according to procedures given by: Terzaghi and Peck (1948); Teng (1962); Alpan (1964); D'Appolonia, D'Appolonia, and Brissette (1968); D'Appolonia, D'Appolonia, and Brissette (1970); Peck and Bazaraa (1969); Schmertmann (1970); Schmertmann, Hartman, and Brown (1978); Schultze and Sherif (1973); Meyerhof (1974); Peck, Hanson, and Thornburn (1974); Bowles (1977); Oweis (1979); NAVFAC DM 7.1 (1982); Elastic Theory.

D. EQUIPMENT DETAILS

IBM-AT compatible with EGA monitor.

E. INPUT-OUTPUT

INPUT - interactively through on-screen menus or by a prepared data file. OUTPUT - calculated settlements and statistical summary are listed on the monitor screen.

- input data may be written to a file.

F. ADDITIONAL REMARKS

The CSANDSET (I $\emptyset \emptyset 3 \emptyset$ ) Program is part of the CORPS Library of computer programs.

A copy of the program and documentation may be obtained from the Engineering Computer Programs Library (ECPL), WES; (601) 634-2581. 
This technical report documents the computer program CSANDSET which is used to compute the settlement of shallow foundations on sand from a variety of well-known methods. Funding for the development of the program and documentation was provided by Headquarters, US Army Corps of Engineers, under the Geotechnical Aspects of Computer-Aided Structural Engineering Project.

Original work on the program was performed by Dr. Jeyapalan, Texas A\&M University. The program was modified and expanded, and this report was written by Ms. Virginia Knowles, Scientific and Engineering Applications Center (SEAC), Computer-Aided Engineering Division (CAED), Information Technology Laboratory (ITL), Waterways Experiment Station (WES). Assistance in the final program format was provided by Mr. Joshua Booher, student aid, SEAC, CAED, ITL, WES.

The report was written under the general supervision of Dr. H. Wayne Jones, Chief, SEAC, ITL, WES, and Dr. N. Radhakrishnan, Chief, ITL, WES.

Permission to reprint figures was granted by Copyright owners, W. G. Holtz, Ralph B. Peck, American Society of Civil Engineers, Morgan-Grampian (Construction Press) Ltd., International Society for Soil Mechanics and Foundation Engineering, National Research Council of Canada, and the Department of Civil Engineering, Massachusetts Institute of Technology.

Commander and Director of WES was COL Larry B. Fulton, EN, and Technical Director was Dr. Robert W. Whalin. 
PREFACE . . . . . . . . . . . . . . . . . . . . . . . . . . . 1

LIST OF TABLES . . . . . . . . . . . . . . . . . . . . . . . . . . . . . 3

LIST OF FIGURES . . . . . . . . . . . . . . . . . . . . . . . . . . . . 4

CONVERSION FACTORS, NON-SI TO SI (METRIC)

UNITS OF MEASUREMENT . . . . . . . . . . . . . . . . . . . . . . . . . 6

PART I: REPORT OVERVIEW . . . . . . . . . . . . . . . . . . . . . . 7

Introduction . . . . . . . . . . . . . . . . . . . 7

Purpose of CSANDSET . . . . . . . . . . . . . . . . . . . . . . 8

Objectives . . . . . . . . . . . . . . . . . . . . . . . 8

Report Description . . . . . . . . . . . . . . . . . . . . . 8

PART II: SETTLEMENT THEORY AND CALCULATION . . . . . . . . . . . . . . . . 9

Background . . . . . . . . . . . . . . . . . . . . . 9

Settlement Models... . . . . . . . . . . . . . . . . 12

Standard Penetration Test . . . . . . . . . . . . . . . . . 15

Factors Affecting the SPT Value. . . . . . . . . . . . . . . . . 15

Embedment Effects on Settlement . . . . . . . . . . . . . . 21

Water Effects on Settlement . . . . . . . . . . . . . . . . . . . 24

Summary . . . . . . . . . . . . . . . . . . . . . . . 26

PART III: SETTLEMENT-COMPUTING METHODS . . . . . . . . . . . . . . . . 29

Terzaghi and Peck $(1948,1967)$. . . . . . . . . . . . . . . . 29

Teng (1962) . . . . . . . . . . . . . . . . . . 31

Alpan (1964) . . . . . . . . . . . . . . . . . . 32

Elastic Theory . . . . . . . . . . . . . . . . . . . 36

D'Appolonia, D'Appolonia, and Brissette (1968) . . . . . . . . . 41

D'Appolonia, D'Appolonia, and Brissette (1970) . . . . . . . . . 42

Peck and Bazaraa (1969). . . . . . . . . . . . . . . . . . . 44

Schmertmann (1970) . . . . . . . . . . . . . . . . . 45

Schmertmann, Hartman, and Brown (1978) . . . . . . . . . . . 48

Schultze and Sherif (1973) . . . . . . . . . . . . . . . 51

Meyerhof (1974) . . . . . . . . . . . . . . . . . . . 52

Peck, Hanson, and Thornburn (1974) . . . . . . . . . . . . . . . 54

Bowles $(1977,1982)$. . . . . . . . . . . . . . . . . . 55

Oweis (1979) . . . . . . . . . . . . . . . . . . . 56

NAVFAC DM 7.1 (Department of the Navy (1982)) . . . . . . . . . . 62

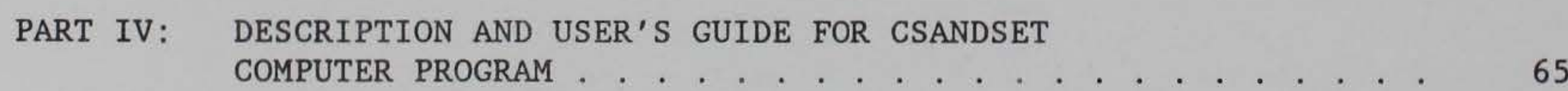

Overview of Program . . . . . . . . . . . . . . . . . . . . 65

Comments on Settlement Methods in CSANDSET . . . . . . . . . . . 66

User's Guide for CSANDSET . . . . . . . . . . . . . . . . . . . . 69

Preparation of Input Data File for CSANDSET . . . . . . . . . . . 77

REFERENCES . . . . . . . . . . . . . . . . . . . . . . . . 85 
Hand Calculations and Verification of CSANDSET . . . . . . . . . Al

Problem 1......................... . . . . . A2

Problem 2......................... . . . . A32

Problem 3... . . . . . . . . . . . . . . . . . . . $\mathrm{A} 51$

APPENDIX B: NOTATION .......................... . . . . . . . . . . .

\section{LIST OF TABLES}

No.

$\underline{\text { Page }}$

1 Correlation of Relative Density with SPT Blowcount . . . . . . . 10

2 Approximate Relation Between Blowcount, Relative Density, and Friction Angle for Sand . . . . . . . . . . . . . . . . . . 11

3 Overburden Correction Factors. . . . . . . . . . . . . . . . . . 18

4 Embedment Correction Factors . . . . . . . . . . . . . . . . . . 23

5 Water Correction Factors . . . . . . . . . . . . . . . . . . . . 27

6 Summary of Terms Used in Settlement Equations . . . . . . . . . . 29

7 Summary of Elasticity Influence Factors for Footing on Semi-infinite, Homogeneous, Linearly Elastic Medium . . . . . . 38

8 Equations for Stress-Strain Elastic Modulus, $E$, from SPT and CPT Test Methods . . . . . . . . . . . . . . . . . . 38

9 Range of Elastic Modulus, E . . . . . . . . . . . . . . . . . 39

10 Range of Values for Poisson's Ratio.. . . . . . . . . . . . . . 39

11 Chart for Use with Oweis Settlement Computations . . . . . . . . 58

12 Summary of Settlement Methods. . . . . . . . . . . . . . . . . . 64

A1 Summary of Results from Hand Calculations of Problem 1 . . . . . A24

A2 Summary of Results from Hand Calculations of Problem 2 . . . . . A49

A3 Summary of Results from Hand Calculations of Problem 3 . . . . . A72 
1 Relationship between SPT blowcount, relative density, and overburden pressure (Gibbs and Holtz 1957)

2 Relationships between footing width, $B$, and ratio of footing settlement to settlement of $1-\mathrm{ft}$ square plate under same load on sand (Terzaghi and Peck 1948)

Terzaghi and Peck's Design Chart for allowable bearing pressure, based on footing size and blowcount value (1948)

overburden correction factor for SPT blowcount from various authors

Embedment correction factor from various authors

Embedment correction factors from Schmertmann (1970) and Peck and Bazaraa (1969)

Embedment correction factors from Figures 5 and 6 . . . . . . . . 23

Depth correction factor by Fox (1948) for elastic methods (Bowles (1982))

Influence factors $\mu_{1}$ and $\mu_{0}$ from Janbu, Bjerrum, and Kjaernsli (1956) used in the D'Appolonia, D'Appolonia, and Brissette (1970) method.

D'Appolonia, D'Appolonia, and Brissette (1970) compressibility modulus

Strain influence factor diagram for Schmertmann (1970) settlement method

Strain influence factor diagram for Schmertmann, Hartman, and Brown (1978) settlement method

Factor $F_{c}$ for Schultze and Sherif (1973) settlement method blowcount

(1979) coefficient for stress increase in soil under loaded footing

Oweis' (1979) relation of secant modulus, $E / E_{\max }$ to strain

Vertical subgrade reaction modulus, $K_{\mathrm{v}}$, for the NAVFAC DM 7.1

(Department of the Navy (1982)) settlement method. 
37 Example data file

38 Example footing showing dimensions and terms for required

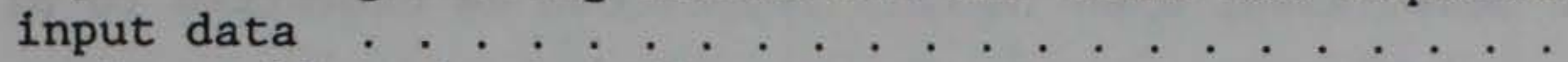

39 Example problem showing dimensions and terms for a layered soil system. . . . . . . . . . . . . . . . . . . . . 84

A1 Example Problem 1 . . . . . . . . . . . . . . . . . . . . . A2

A2 Input data for footing of Problem 1 . . . . . . . . . . . . . . . A25

A3 Input data for soil of Problem 1 . . . . . . . . . . . . . . . . A25

A4 Input of optional soil data for Problem 1. . . . . . . . . . . . A26

A5 Listing of all input data for Problem 1 . . . . . . . . . . . . . A26

A6 CSANDSET settlement calculations for Problem 1. . . . . . . . . . A27

A7 Listing of intermediate calculations from each method for Problem 1. . . . . . . . . . . . . . . . . . . A28

A8 Example Problem 2 . . . . . . . . . . . . . . . . . . . A32

A9 Listing of all input data for Problem 2 . . . . . . . . . . . . . A50

A10 CSANDSET settlement calculations for Problem 2 . . . . . . . . . A50

A11 Example Problem 3 . . . . . . . . . . . . . . . . . . . . . A52

A12 Input footing data for Problem 3 . . . . . . . . . . . . . . . . A73

A13 Input soil data for Problem 3 . . . . . . . . . . . . . . . . . . A73

A14 Input optional soil data for Problem 3 . . . . . . . . . . . . . A74

A15 Input soil layers corresponding to hand calculations for Schmertmann (1970) and Schmertmann, Hartman, and Brown (1978) methods. Depths to bottom of each layer include $D=0.23 \mathrm{ft}$

A18 Input soil layer data corresponding to hand calculations for Oweis (1979) method.

A19 CSANDSET settlement calculations for Oweis (1979) hand calculations 
Non-SI units of measurement used in this report can be converted to SI (metric) units as follows:

Multiply

\section{feet}

inches

kips (force) per square foot

pounds (force)

pounds (force) per square foot

pounds (force) per square inch

pounds (mass) per cubic foot

tons (mass) per cubic foot

tons per square foot
By

0.3048

2.54

47.88026

4.448222

47.88

$6,894.757$

16.01846

$32,036.9$

0.976486
To Obtain

meters

centimeters

kilopascals

newtons

pascals

pascals

kilograms per cubic meter

kilograms per cubic metre

kilograms per square centimeter 


\section{PART I: REPORT OVERVIEW}

\section{Introduction}

1. This report explains the use and background of the computer program CSANDSET, CORPS Library Program I0030. CSANDSET computes predictions of settlement for a loaded footing founded on sand. The footings of concern are "shallow" foundations, those where the depth of embedment is less than or equal to the width of the footing. There are many methods presented in literature and textbooks for predicting the settlement of shallow foundations on sand. Depending upon which method is used, this calculation can be a very simple one or can be moderately complex, and the resulting prediction can differ greatly. Fifteen of the many methods available for predicting settlement on sand are covered in this report. The methods are:

a. Terzaghi and Peck (1948, 1967).

b. Teng (1962).

c. Alpan (1964).

d. Elastic Theory.

e. D'Appolonia, D'Appolonia, and Brissette (1968).

f. D'Appolonia, D'Appolonia, and Brissette (1970).

g. Peck and Bazaraa (1969).

h. Schmertmann (1970).

i. Schmertmann, Hartman, and Brown (1978).

j. Schultze and Sherif (1973).

k. Meyerhof (1974).

1. Peck, Hanson, and Thornburn (1974).

m. Bowles (1977, 1982).

n. Oweis (1979).

o. NAVFAC DM 7.1 (Department of Navy 1982). 


\section{Purpose of CSANDSET}

2. Based on experience, an engineer may prefer one method over another for its reliability in predicting settlement for the types of footings or the region where he works. The purpose of this report is not to tell the engineer which method to use, but to present procedures and backgrounds so that the reader can make an engineering judgment of each.

\section{Objectives}

3. The objectives of the CSANDSET project are:

a. To present and describe some of the various methods found in engineering publications for computing the settlement of shallow foundations on sand.

b. To develop an easily usable computer program which computes settlement according to the methods in consideration.

c. To provide a brief theoretical background of various aspects involved in the settlement of shallow foundations on sand for the reader's use in assessing each method.

\section{Report Description}

4. Part II of this report discusses the theoretical background of sandsettlement computation. Factors and variables affecting settlement are presented. Correction factors found with the different methods of settlement computation are explained and compared.

5. The 15 settlement procedures chosen for study are described in Part III. For each of the methods, the background, the procedure, and all related equations and figures are presented.

6. Part IV describes the computer program CSANDSET. Special programming considerations of some of the settlement methods are discussed, and data entry for both interactive and data file input are explained.

7. Appendix A shows three example problems which have been worked by hand for each of the 15 settlement methods. These hand results are compared to CSANDSET results for verification of the program. 
8. The unanticipated settlement of a structure, whether total or differential, can have devastating effects on its performance. Settlement of the foundation must be accurately accounted for in foundation design. It is important to determine the magnitude of foundation settlement to assess and control differential movements or movements caused by changes in the loading or soil conditions.

9. Consolidation settlement of structures founded on clay-type soils is very slow. Terzaghi's one-dimensional consolidation theory is usually applied in engineering design for settlement predictions of clay. For structures founded on sand, settlement is relatively quick, often complete by the end of the construction period. Many different methods have been developed to calculate the settlement of a shallow foundation on sand. Most of these procedures are straightforward and involve brief computations. The difficulty comes in choosing the procedure to use. This part presents the basis of the theoretical computation of settlement on sand. Factors that affect settlement and the variables involved will be discussed so that a background for the methods presented in Part III is established.

\section{Background}

10. Settlement is inversely related to bearing capacity in the design and analysis of shallow foundations on sand. The key variables in these relations are the relative density of the soil, the footing width, and the magnitude of the load.

\section{Relative density}

11. Relative density is the degree of compactness of a sand deposit relative to its fully compacted state, as measured by the void ratio. In general, the magnitude of a footing settlement is inversely proportional to the relative density of the sand on which it is founded. Relative density was described in terms of the SPT (Standard Penetration Test) blowcount by Terzaghi and Peck (1948). This relation is shown in Table 1. Gibbs and Holtz (1957) expanded on this relation using results from laboratory tests in work at the United States Bureau of Reclamation (USBR). They showed the relationship of the blowcount to the overburden pressure at which the SPT was performed. They produced the well-known family of curves shown in Figure 1. 
TABLE 1. Correlation of Relative Density with SPT Blowcount

\begin{tabular}{|c|cccccc|}
\hline Relative Density & Very Loose & Loose & Medium & Dense & Very Dense \\
\hline SPT Blowcount Value & $0-4$ & $4-10$ & $10-30$ & $30-50$ & $>50$ \\
\hline
\end{tabular}

(After Terzaghi and Peck 1948. Numerical ranges for relative density not provided.)

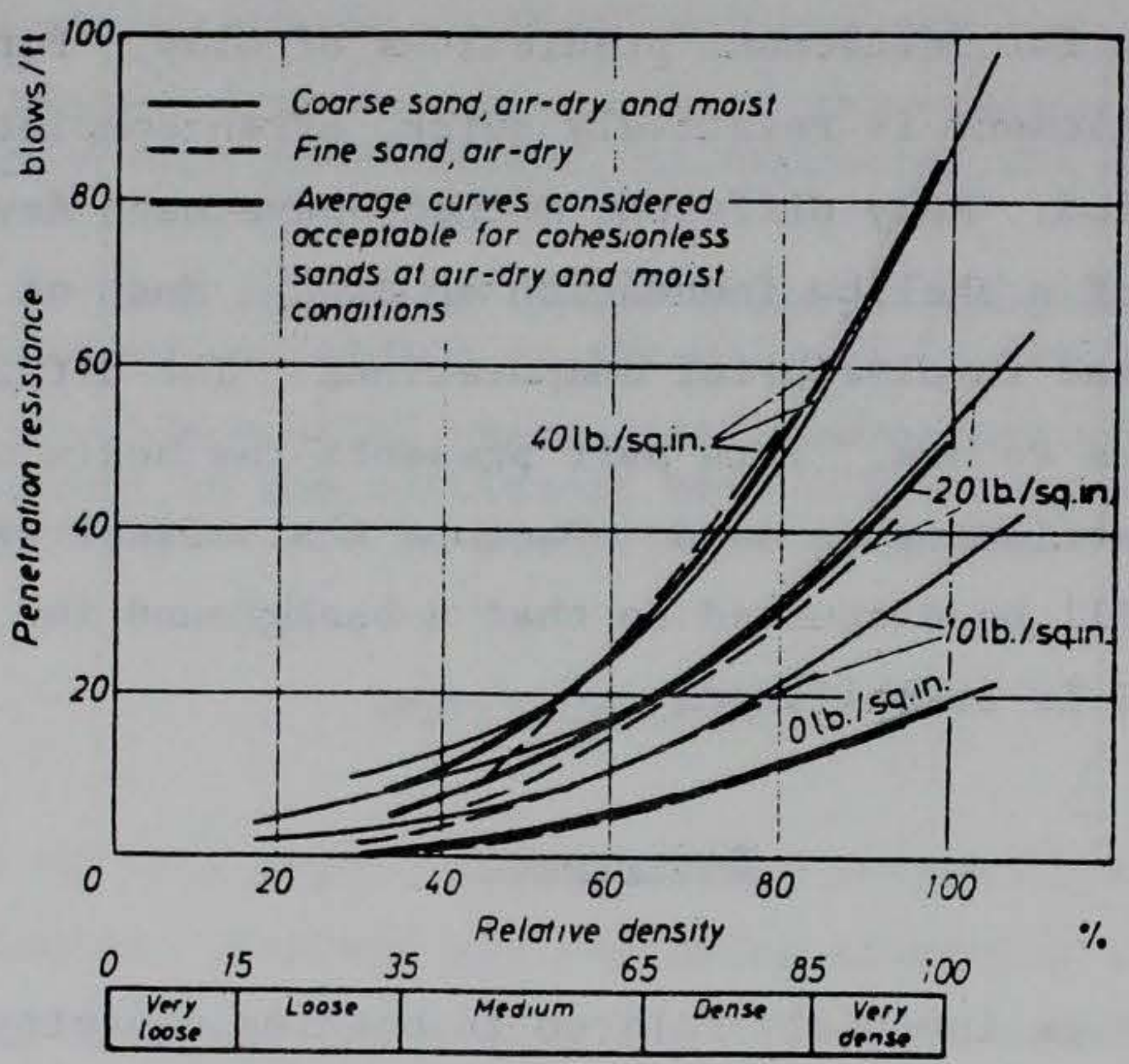

Figure 1. Relationship between SPT blowcount, relative density, and overburden pressure (Gibbs and Holtz 1957) (Permission to reprint granted by

W. G. Holtz)

Others (Bazaraa (1967); Schultze and Menzenbach (1961); Marcuson and Bieganousky $(1977 \mathrm{a}, \mathrm{b}))$ have also developed correlations between these variables. Another interpretation by Das (1985) is shown in Table 2.

\section{Footing width}

12. The relationship between settlement and footing width was described by Terzaghi and Peck (1948) from the results of numerous load tests on sand. This is shown in Figure 2. For the same load on the same soil, the 
Table 2. Approximate Relation Between Blowcount, Relative Density, and Friction Angle for Sand

\begin{tabular}{|ccc|}
\hline $\begin{array}{c}\text { Corrected } \\
\text { SPT Blowcount }\end{array}$ & $\begin{array}{c}\text { Relative } \\
\text { Density (\%) }\end{array}$ & $\begin{array}{c}\text { Internal Friction } \\
\text { Angle, (degrees) }\end{array}$ \\
\hline $0-5$ & $0-5$ & $26-30$ \\
$5-10$ & $5-30$ & $28-35$ \\
$10-30$ & $30-60$ & $35-42$ \\
$30-50$ & $60-95$ & $38-46$ \\
\hline
\end{tabular}

(after Das 1985)

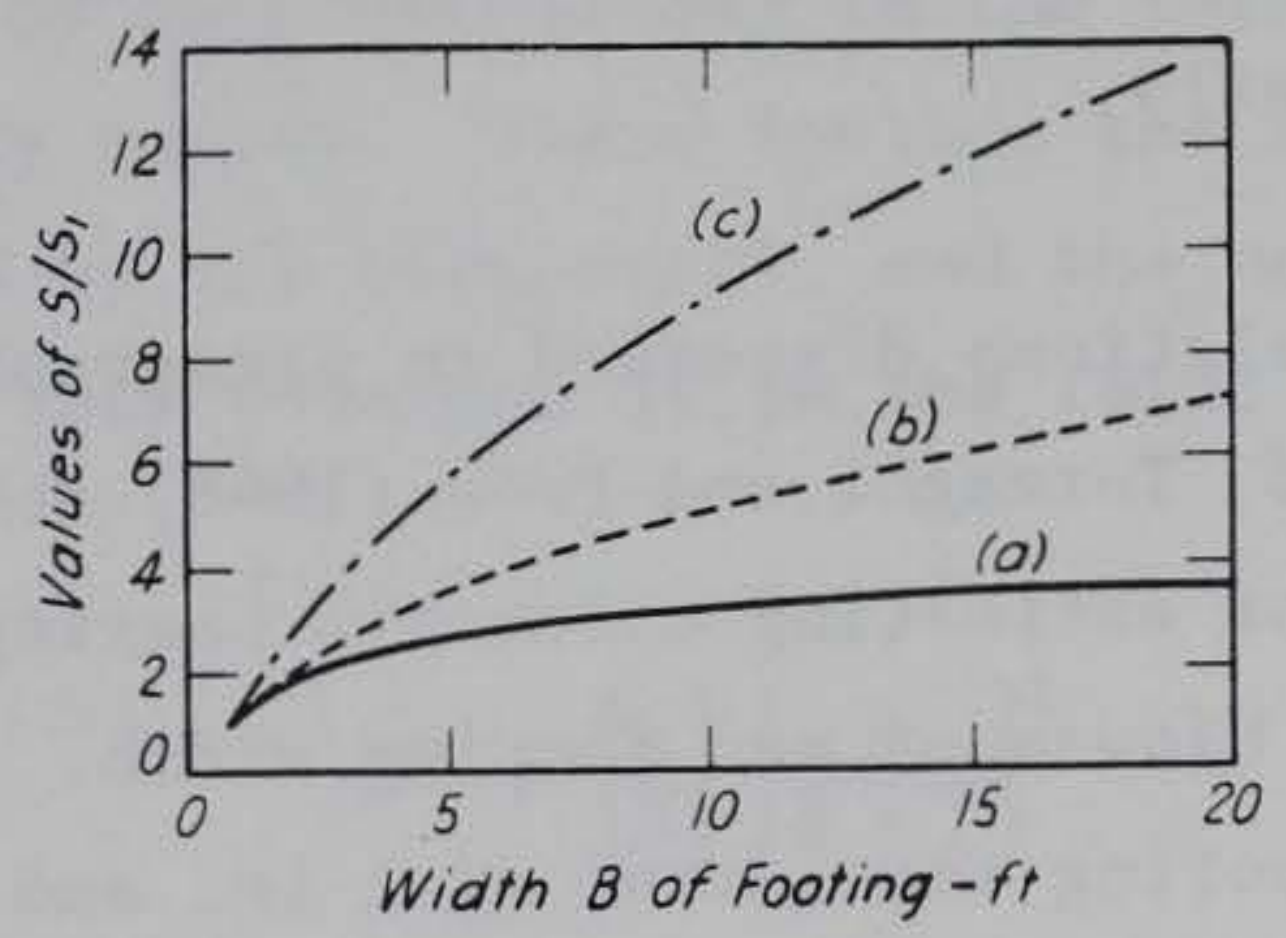

Figure 2. Relationships between footing width, $B$, and ratio of footing settlement to settlement of $1-\mathrm{ft}$ square plate under same load on sand (Terzaghi and Peck 1948) (Permission to reprint granted by Ralph B. Peck) 
settlement, $S$,* is related to the square of the footing width, $B$, through the settlement of a 1 -ft square plate, $S_{1}$, by:

$$
S=S_{1}\left(\frac{B}{B+1}\right)^{2}
$$

13. Some form of this relation is applied in many of the different settlement-computing methods.

Applied load

14. The magnitude of settlement is also directly proportional to the magnitude of the applied load up to the allowable bearing pressure, with all else constant. Loads above the allowable pressure will eventually cause failure, either in bearing, in settlement, or both, depending on the definition of failure for each case.

\section{Settlement Models}

15. Most of the settlement methods can be placed within one of two categories; some are modeled after the Terzaghi and Peck (1948) bearing capacity and settlement-footing width relationship, and others are modeled after elasticity methods. A few methods combine some aspects of both. The backgrounds for both the Terzaghi-based settlement methods and elastic-based settlement methods are described briefly.

\section{Terzaghi-based settlement}

16. Based on the relations discussed in paragraph 12 and from experience with footings on sand, Terzaghi and Peck (1948) developed the well-known design chart, Figure 3, for estimating allowable bearing pressures for shallow foundations on sand using blowcount and footing width. These design curves correspond to a maximum footing settlement of 1 in. and total differential settlement of $3 / 4 \mathrm{in.} * *$ Data was interpreted conservatively in the development of this chart. Often, practice has shown this method to produce very

* For convenience, symbols and definitions are listed and identified in the Notation (Appendix B).

** A table of factors for converting non-SI units of measurement to SI (metric) units is presented on page 6. 


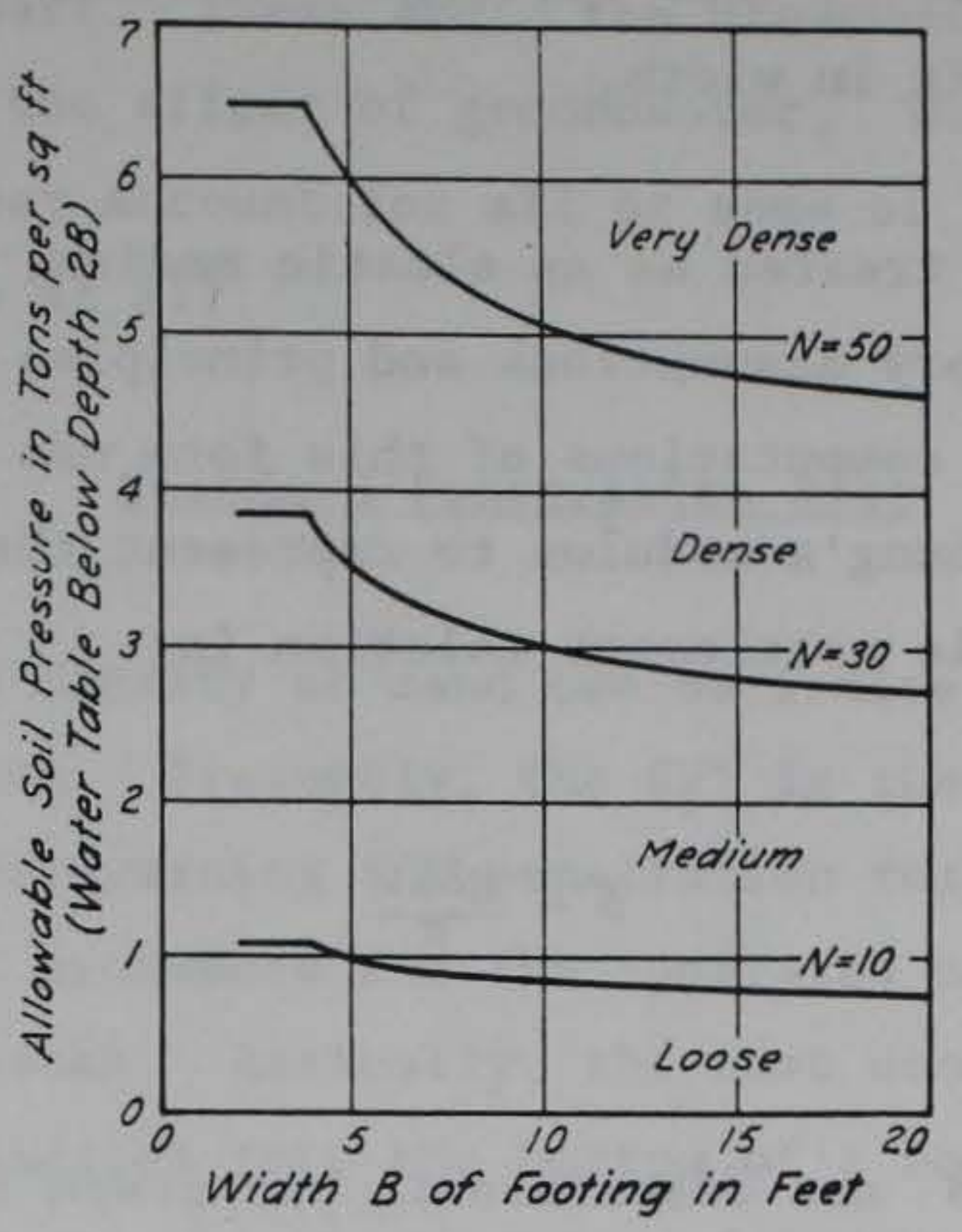

Figure 3. Terzaghi and Peck's Design Chart for allowable bearing pressure, based on footing size and blowcount value (1948) (Permission to reprint granted by Ralph B. Peck)

conservative values for bearing pressure. Modifications to these values for less conservatism have been made by many engineers and scientists in the practice of foundation design. The computation of settlement by the Terzaghi and Peck chart was defined by Meyerhof (1956) in the form of equations representing the bearing capacity curves. These include the footing width, the relative density (expressed by the blowcount), and the net applied load. A general expression for this relation is in the form:

$$
S=C\left(\frac{q}{N}\right)\left(\frac{B}{B+1}\right)^{2}
$$

where

$S=$ settlement

$q=$ net applied load

$B=$ footing width

$N=$ blowcount

$C=$ empirical constant determined by observation and/or experimentation 
Terzaghi's charts give $C=8$ for footings less than $4 \mathrm{ft}$, and $C=12$ for footings greater than $4 \mathrm{ft}$ in width.

\section{Elastic soil settlement}

17. Soil is often treated as an elastic medium, linear or non-linear, to which the elastic theory assumptions and principles of stress and strain are applied. Settlement computations of this form use the elastic properties of Poisson's ratio and Young's modulus to represent the soil. A general expression for the elastic settlement relation is:

$$
S \sim \frac{q B I v}{E}
$$

in which $S, q$, and $B$ are described in paragraph 16, and where

$v=$ Poisson's ratio

$E=$ elastic modulus

$I=$ influence factor based on footing shape, depth, and the extent of the elastic region of settlement

18. One main difference between the Terzaghi model and the elastic model is the relationship between footing width, and settlement. The elastic theory models a linear relation between settlement and footing width, while Terzaghi's work shows this to be a nonlinear relation as shown in Figure 2 . Elastic theory settlement methods can account for this nonlinear relationship through an appropriate use of the elastic or compressibility modulus based on the SPT value. D'Appolonia, D'Appolonia, and Brissette (1970) address this in their elastic settlement model.

\section{Summary}

19. Some procedures for computing settlement of shallow foundations on sand are modifications of Terzaghi and Peck (1948) work. Other procedures are based on elastic strain theory. Some are a combination of both. In general, the three basic components of most settlement-predicting techniques are: the applied load, some measure of the footing size or shape, and a representation of soil bearing strength.

20. There are many other factors affecting the settlement of a foundation on sand which should be included somehow in the settlement computation. of the three variables listed, usually the one with the most uncertainty is the soil strength. Factors dealing with the soil strength are presented in 
the remainder of this part. These are: the blowcount or SPT value, embedment of the foundation, and the effect of groundwater. The settlement methods presented in Part III may account for all or some of these factors, while others account for none at all.

\section{$\underline{\text { Standard Penetration Test }}$}

21. The relative density of sand can be indirectly determined by its resistance to penetration. Presently, the SPT is the most widely used test in the United States for determining the penetration resistance of soils. A description of the test procedure and the apparatus can be found in most foundation and soils text books. Basically, the test consists of driving the standard split-barrel sampler into the bottom of a boring for a distance of 18 in. The number of hammer blows needed to drive the sampler the last 12 in. is counted. This is referred to as the "blowcount" or SPT number. The hammer should weigh $140 \mathrm{lb}$ and drive the sampler by free-fall from a height of $30 \mathrm{in}$. The penetration resistance is used both directly and indirectly in almost all of the settlement procedures described in Part III.

22. The Cone Penetration Test (CPT) is another means of measuring the penetration resistance of a deposit. This test is widely used in Europe and is experiencing increased use in the United States. The CPT can be either a static test (pushed continuously into the soil) or a dynamic test (driven into the soil). The SPT is a dynamic test. Often, the CPT value is correlated with the SPT value. Some design methods use it directly. Specifically, Schmertmann (1970), Schmertmann, Hartman, and Brown (1978), and Meyerhof (1956 and 1974) incorporate the CPT value in their procedures and provide correlations with the SPT value. Robertson and Campanella (1983) discuss various aspects of the CPT, including SPT-CPT correlations, and its use in engineering practice for determining soil classification and certain parameters.

\section{Factors Affecting the SPT Value}

23. The blowcount value obtained from the field can be affected by a number of factors. Whether or not to correct the blowcount for these should be taken into consideration before a final representative blowcount is selected for design. A specific numeric correction factor is not always available for the consideration of each effect. In all cases engineering 
judgment should be exercised. Some of these aspects are briefly discussed in the following paragraphs and references are provided for additional review. Overburden pressure

24. One of the most influential and widely known of the factors affecting the measured SPT value is the overburden pressure. Since it is desired to determine the relative density of a sand from the blowcount, ideally the changes in the blowcount should represent the changes in relative density. This is not always the case. For example, in a homogeneous deposit where relative density and friction angle are constant with depth, an increasing blowcount is measured. This is due to increasing overburden and confining pressures which increase soil resistance to the sampler's penetration. For this reason, each measured SPT value should be corrected for the influence of its corresponding overburden pressure. Then a representative blowcount can determined. For a shallow foundation, a representative blowcount is often taken as the lowest average value of corrected blowcounts below the base of the footing over a depth approximately equal to the footing width.

25. There are many techniques available to correct the SPT value for overburden pressure. In general, it involves determining a correction factor, $C_{\mathrm{n}}$, based on the effective overburden pressure, $\sigma_{\mathrm{v}}^{\prime}$, and the field blowcount, $N$, so that $N$ is normalized to a standard reference overburden pressure. The corrected field blowcount, $N_{\mathrm{c}}$, is calculated as: $N_{\mathrm{c}}=N C_{\mathrm{n}}$. Blowcount correction factors for overburden developed by various authors are plotted in Figure 4. The corresponding equations are shown in Table 3.

26. Excluding the Teng (1962) curve, all the plots in Figure 4 are in close agreement in the range of effective overburden pressures greater than about 0.5 tsf. For pressures less than 0.5 tsf, the curves diverge into two general areas: in one group are Peck and Bazaraa (1969) with Liao and Whitman (1986); in the other group are Skempton (1986) with Peck, Hanson, and Thornburn (1974). The Teng (1962) curve is unrelated to the others due to the reference pressure used.

27. The reference pressure is the overburden pressure to which a correction factor normalizes the blowcount. This is the overburden pressure at which $C_{\mathrm{n}}=1$. Typically, 1 tsf is the reference pressure used. However, Peck and Bazaraa (1969) normalize to 0.75 tsf and Teng uses 40 psi, which is 2.88 tsf. The Terzaghi and Peck (1948) classification, Table 1, was based on blowcounts at an overburden pressure of approximately $0.75 \mathrm{tsf} . C_{\mathrm{n}}$ is greater than 1.0 


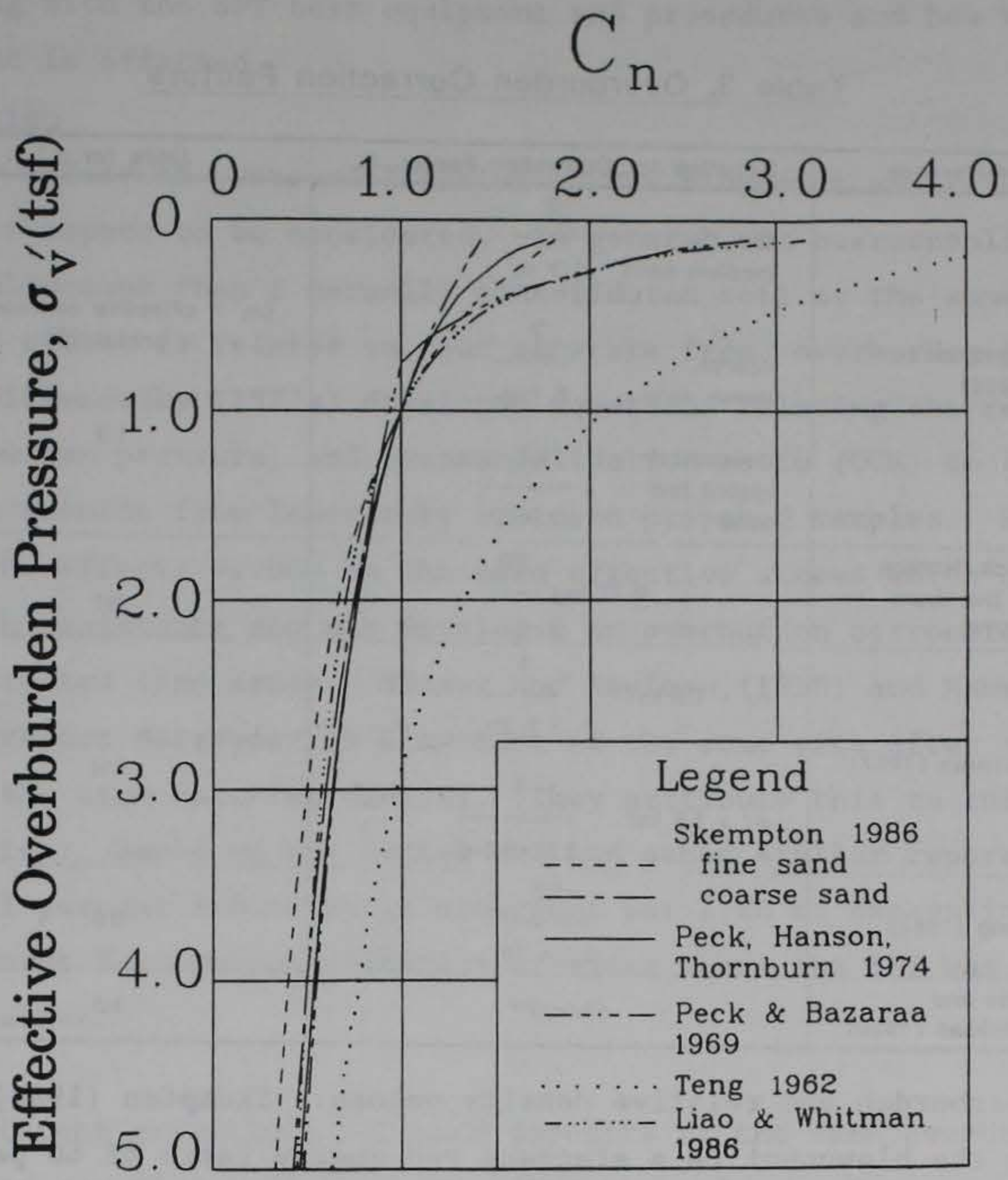

Figure 4. Overburden correction factor for SPT blowcount from various authors

for overburden pressures less than the reference pressure, and is less than 1.0 for overburden pressures greater than the reference pressure.

28. Some procedures for computing settlement do not advocate correcting the blowcount for overburden but use the blowcount values as obtained from the field. Most experiments and theories show that this correction is necessary, and recommend that the field blowcount be corrected for overburden. One of the relationships shown in Figure 4 (excluding Teng (1962) due to the reference pressure difference) is appropriate, or another which plots in the same region. The method by Peck, Hanson, and Thornburn (1974) is widely used in engineering practice.

\section{Testing/equipment}

29. In the SPT test itself, variations in the borehole diameter, rod length, and hammer release mechanism produce different blowcounts for sands at 


\section{Table 3. Overburden Correction Factors}

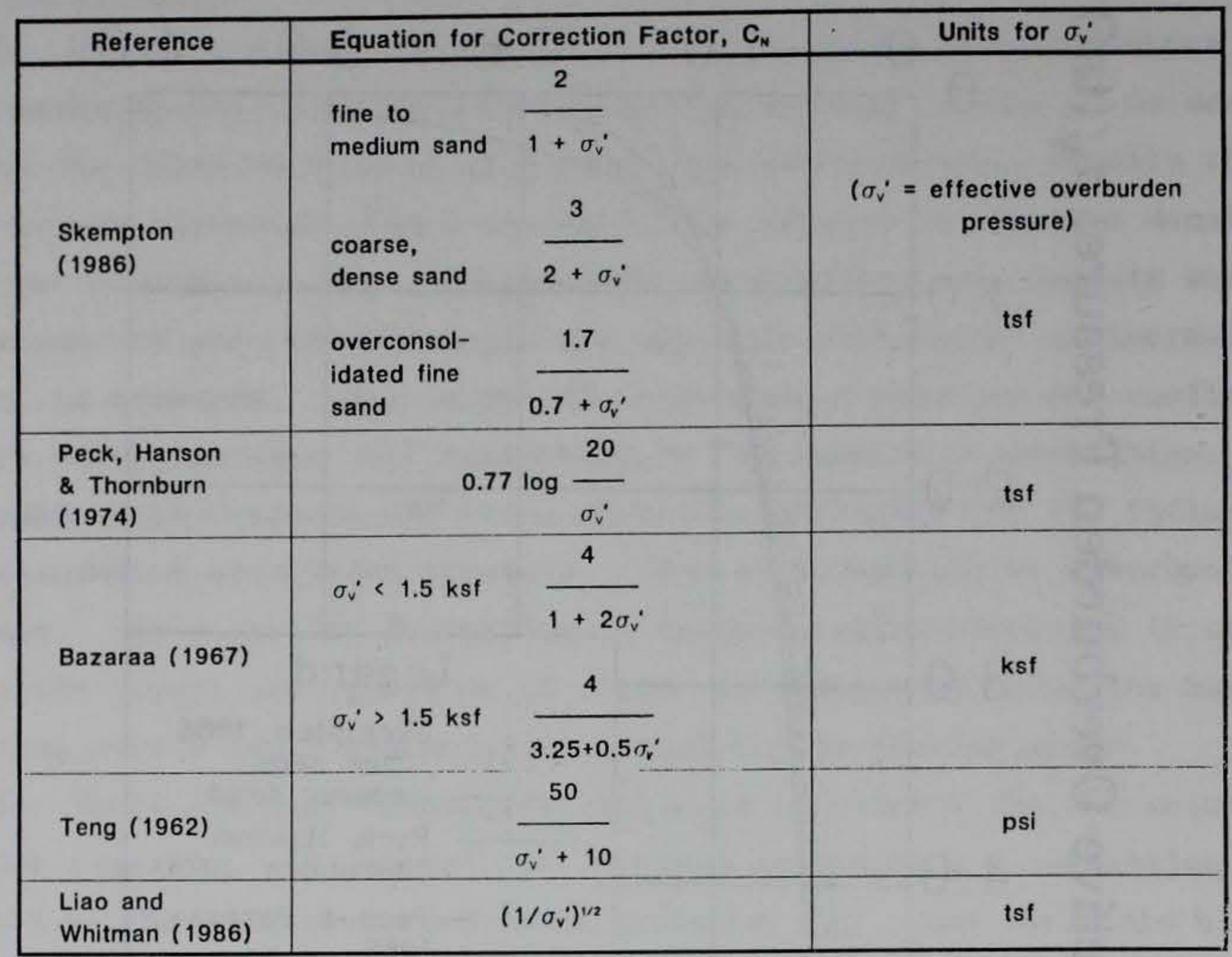

the same overburden and relative density values. Skempton (1986) suggests normalizing the blowcount to a standard rod energy ratio of 60 percent and provides corrections for this, as well as for the borehole diameter, the presence of a sampler liner, and differences in rod length. Gibbs and Holtz (1957) and Bazaraa (1967) also studied the effects of different rod lengths and rod weights on the blowcount value.

30. There are other conditions of the equipment and the test procedure which should be considered. For example, the height of the hammer fall (standard, $30 \mathrm{in.}$ ) and the weight of the hammer (standard, $140 \mathrm{lb}$ ) determine the energy imparted in the blow. Deviations from these standards produce blowcounts that are not applicable for analyses that were developed based on blowcounts from standard equipment and procedures. Other variations include whether or not the casing was cleaned before the blows started, differences in the length of the sampler used, and differences in the method of drilling. Fletcher (1965), Palmer and Stuart (1957), Skempton (1986), and NAVFAC DM 7.1 (Department of the Navy 1982) provide excellent discussions of these areas of 
concern dealing with the SPT test equipment and procedures and how the measured blowcount is affected.

\section{Overconsolidation}

31. The effect of overconsolidation on the blowcount and relative density is another aspect to be considered. In general, an overconsolidated soil has a higher blowcount than a normally consolidated soil at the same relative density. This effect is related to, but separate from, overburden pressure. Marcuson and Bieganousky (1977a) developed equations relating the relative density, overburden pressure, and overconsolidation ratio (OCR) to the blowcount based on results from laboratory tests on prepared samples. Skempton (1986) shows the effects of OCR on the mean effective stress which controls the penetration resistance and has developed an overburden correction factor for overconsolidated fine sands. Mansur and Kaufman (1958) and Mansur and Hunter (1970) report decreases in blowcount at the same site after an excavation at about the same relative density. They attribute this to the effect of overconsolidation. Based on the latter two and other similar reports, Mosher. (1984) used a 1-percent reduction in blowcount per $1 \mathrm{ft}$ of excavation to correct the blowcount for overconsolidation at sites where the SPT was performed prior to excavation.

Type of sand

32. Different gradations for sand deposits at the same overburden and relative density can also influence the blowcount values. Marcuson and Bieganousky (1977b) present a relationship between blowcount, overburden, relative density, and OCR, which also includes a uniformity coefficient term to account for minor blowcount differences observed from different types of sands tested. Some of the settlement predicting methods have individual equations for different categories of sands: Meyerhof (1956, 1965, 1974) and Skempton (1986) account for grain size in their correlations of blowcount to relative density. In general, increasing grain size increases the blowcount for sand at the same overburden pressure and relative density. Meigh and Nixon (1961) found that while the SPT gives reasonable estimates of bearing capacity for footings on fine sand, it underestimates the bearing capacity (overestimates settlement) of footings on sandy gravels and, to some extent, gravelly and well-graded sands. This is based on comparison of the SPT with plate load test results at the same site. 
33. In sand below the water table, the effective soil pressure and the confining pressure are less than in the sand above the water table. Water lubricates the soil grains lowering intergranular, frictional resistance to shear and increasing slip potential. These conditions allow the sampler to penetrate a loose saturated soil with less blows than required in the same soil when dry or moist. Also, moist soil above the water table exhibits a slight cohesion which may add to its measured resistance. This cohesive effect is lost below the water table.

34. The effect of groundwater on the measured blowcount value has been addressed by many. Bazaraa (1967) studied 11 sites and compared blowcounts measured $3 \mathrm{ft}$ above and $3 \mathrm{ft}$ below the water table in fairly uniform sand. The data shows little change in the blowcount: some of the SPT values measured below the water table were greater, while others were less, than those measured above the water table.

35. Terzaghi and Peck (1967) state that the SPT value is not significantly affected by submergence for soils of intermediate grain sizes.

Schultze and Menzenbach (1961) found an average decrease of 15 percent in the blowcount below the water table in fine sand. This reduction was especially pronounced for loose fine sand. Gibbs and Holtz (1957) evaluated USBR laboratory test data and compared blowcounts of moist sand to those of saturated sand. Their results show little reduction in blowcount for the coarse sand below water, but significant reduction for fine sands below water. Meyerhof $(1956,1965)$ holds that the blowcounts in sand below water have a lowered value from that in the same sand above water.

36. In a saturated, very fine or silty, dense sand, the blowcount values may be excessively large because this type of material tends to dilate upon shearing, and water movement becomes restricted among the fine densely packed grains. Terzaghi and Peck (1948) proposed a correction for this phenomenon for a sand with a blowcount less than 15 which meets these conditions. This is: $N_{\mathrm{c}}=15+0.5(N-15)$ where $N_{\mathrm{c}}$ is the corrected blowcount and $N$ is the measured value. Meyerhof (1956) also recommends using this procedure.

37. One other aspect of the submerged sand blowcount value relates to the SPT procedure itself. When performing the SPT below the groundwater table in very loose sand, the sand in the bottom of the borehole can boil and become "quick" if water is allowed to seep upward into the hole. The measured blows 
will be abnormally low. This may be corrected by maintaining the level of water in the borehole at the level of the adjacent groundwater table, as measured by peizometers.

\section{Embedment Effects on Settlement}

38. A footing embedded below the ground surface, can be expected to settle less than a footing at the surface. The soil above the base of the footing acts as a surcharge, increasing the confining pressure of the soil below the base of the footing. This provides greater bearing capacity and less settlement.

39. Figure 5 shows some of the settlement method embedment factors

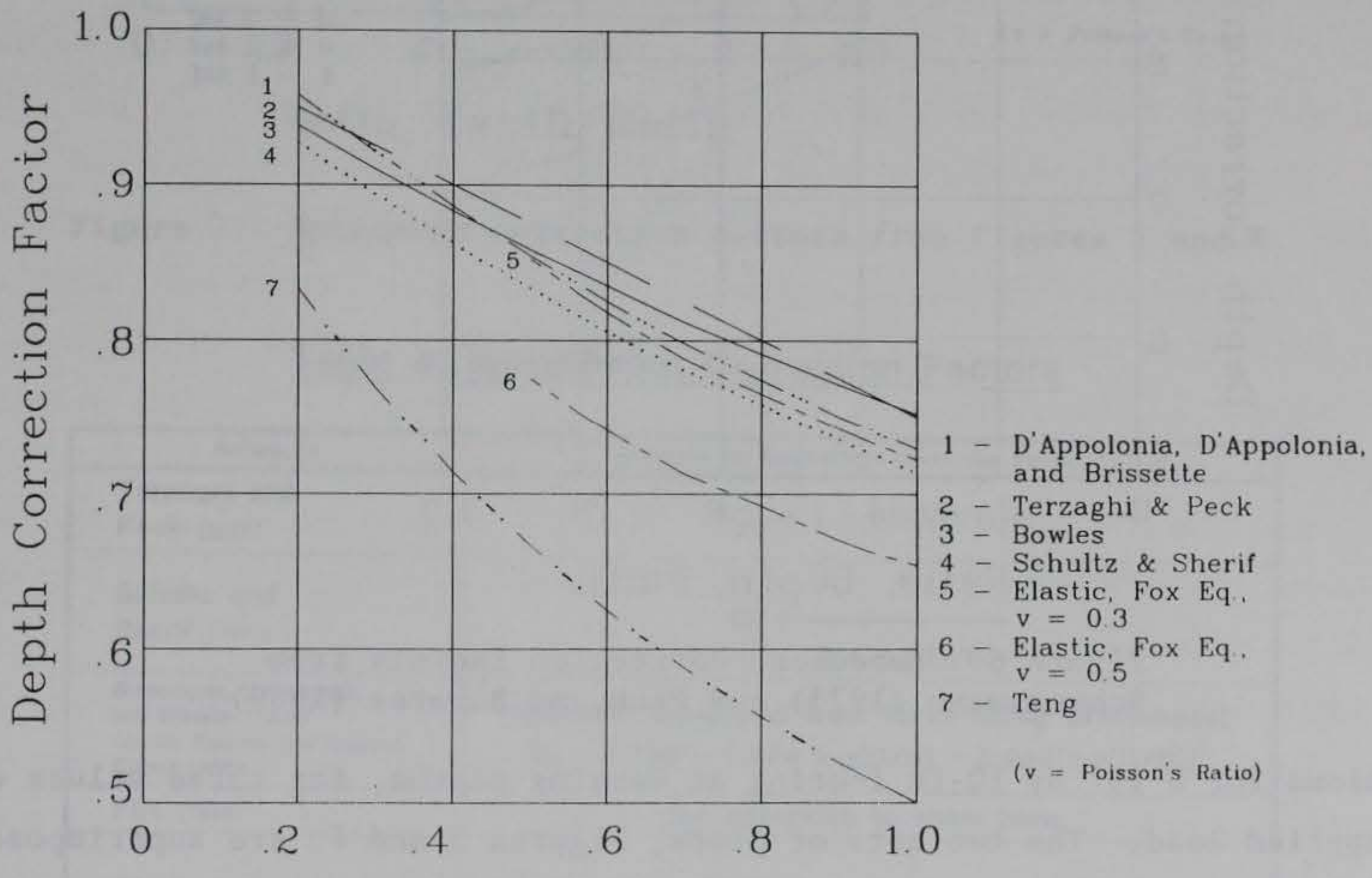

Ratio, Depth/Width

Figure 5. Embedment correction factor from various authors

plotted for various depths of embedment, $D$, normalized to footing width $(D / B)$. The Fox (1948) equations for embedment correction are based on elastic settlement, and plots are shown for two different values of the Poisson ratio, $v=0.3$ and $v=0.5$.

40. The depth correction factor reduces the calculated settlement to account for the increase in bearing capacity achieved by embedment. However, 
this assumes that the pressure applied by the original soil above the footing is replaced by the concrete mass and applied load. If this is not the case, the increase in bearing capacity due to the surrounding surcharge may be compensated for by a decrease in bearing immediately under the footing if there is a net loss of overburden. Therefore, depth correction factors for bearing or settlement should include some relation between the applied pressure and the released pressure. Bazaraa (1967) and Schmertmann (1970) use this principle in their embedment correction factors. Figure 6 plots their

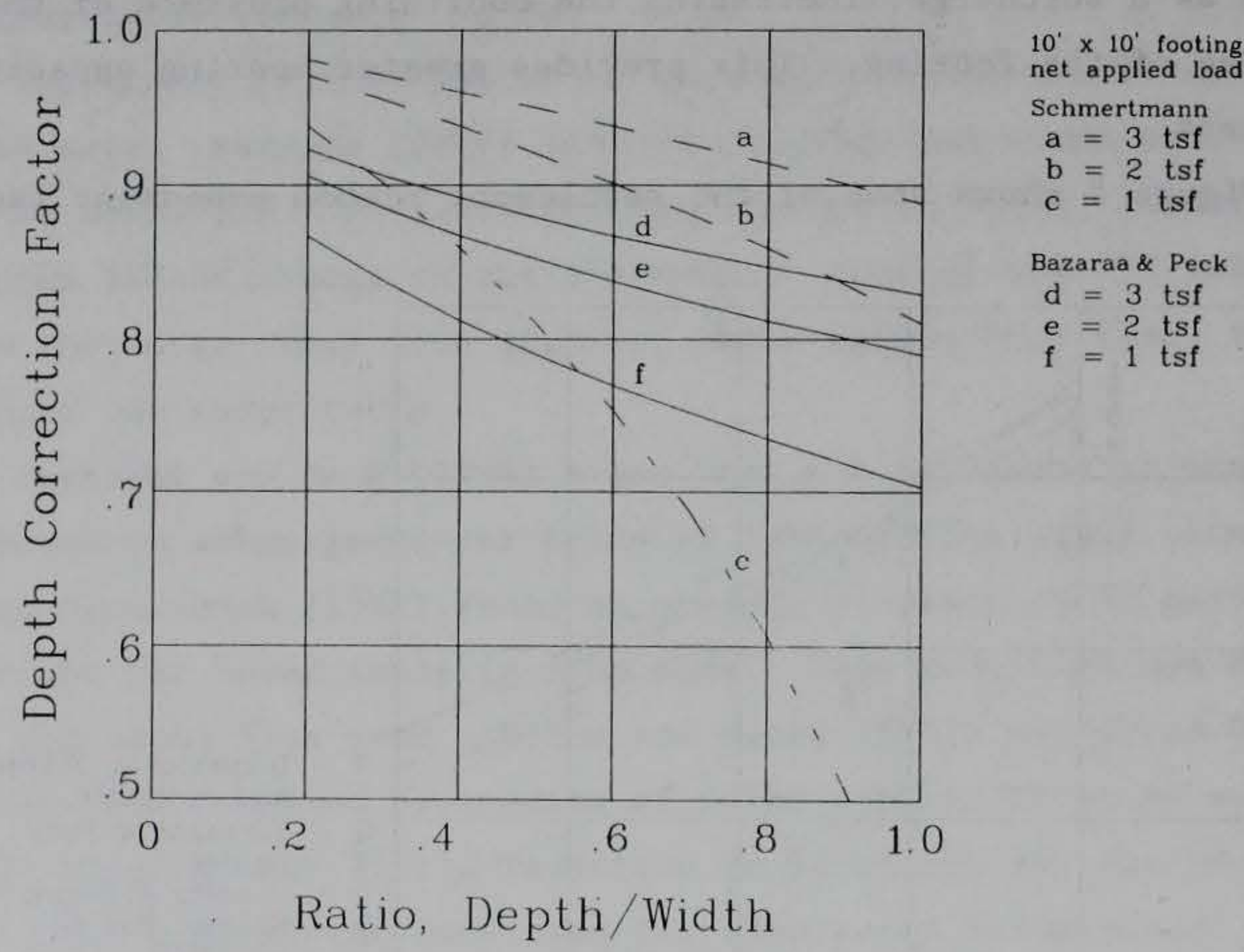

Figure 6. Embedment correction factors from Schmertmann (1973) and Peck and Bazaraa (1969)

equations for a 10 - by 10 -ft footing at varying depths, for three values of net applied load. The two sets of plots, Figures 5 and 6 , are superimposed in Figure 7. For the 10 - by 10 -ft footing, Bazaraa's relation plots reasonably close to the group of plots numbered (1) to (5) in Figure 5, and Schmertmann's relation is also consistent with this group for net loads between 1 and 2 tsf. All embedment equations are shown in Table 4. In general, there is very close agreement among all the embedment corrections except for Teng (1962) and Fox (1948) at Poisson's ratio of 0.5 (more representative of a cohesive soil than a granular soil). 


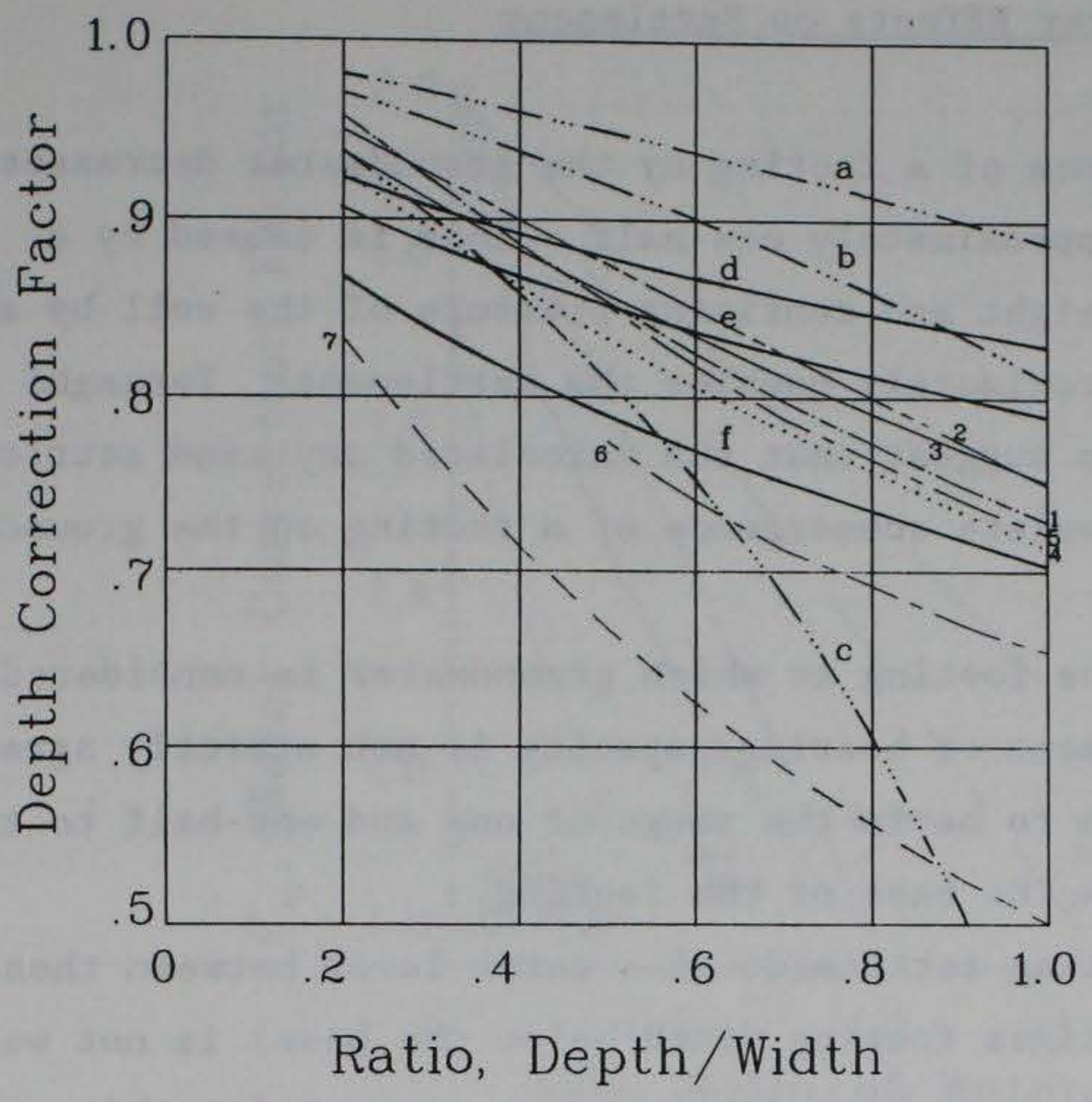

$10^{\circ} \times 10^{\prime}$ footing.

net applied load:

Schmertmann

$a=3 \mathrm{tsf}$

b $=2$ tsf

$c=1 \mathrm{tsf}$

\section{Bazaraa \& Peck}

$\mathrm{d}=3 \mathrm{tsf}$

$\mathrm{e}=2$ tsf

$f=1$ tsf

1 - D'Appolonia, D'Appolonia, and Brisselle

2 - Terzaghi \& Peck

3 - Bowles

4 - Schultz \& Sherif

5 - Elastic, Fox Eq. $\mathrm{v}=0.3$

6 - Elastic, Fox Eq. $\mathrm{v}=0.5$

7 - Teng

( $v$ = Poisson's Ratio)

Figure 7. Embedment correction factors from Figures 5 and 6

\section{Table 4. Embedment Correction Factors}

\begin{tabular}{|c|c|}
\hline Reference & Equation for Embedment Correction Factor, $\mathrm{C}_{0}$ \\
\hline $\begin{array}{l}\text { Terzaghi and } \\
\text { Peck (1967) }\end{array}$ & $C_{0}=1-0.25(D / B)$ \\
\hline $\begin{array}{l}\text { Schultz and } \\
\text { Sherif (1973) }\end{array}$ & $C_{0}=\frac{1}{1+0.4(D / B)}$ \\
\hline $\begin{array}{l}\text { D'Appolonia, D'Appolonia, } \\
\text { and Brissette (1970) } \\
\text { (Janbu, Bjerrum, and KJaernsli } \\
\text { Curves 1956) }\end{array}$ & $\begin{array}{l}\text { (equation developed from curve-fitting procedures) } \\
C_{0}=0.729-0.484 \log (D / B)-0.224[\log (D / B)]^{2}\end{array}$ \\
\hline Fox (1948) & too extensive to show here. \\
\hline Bowles (1977) & $C_{0}=\frac{1}{1+0.33(D / B)}$ \\
\hline Teng (1962) & $C_{0}=\frac{1}{1+D / B}$ \\
\hline Bazaraa (1969) & $\mathbf{C}_{0}=1-0.4\left[\frac{\gamma \mathrm{D}}{\mathrm{q}}\right]^{(1 / 2)}$ \\
\hline $\begin{array}{l}\text { Schmertmann (1970) } \\
\text { Schmertmann, Hartman, and } \\
\text { Brown (1978) }\end{array}$ & $\mathbf{C}_{0}=1-0.5\left[\frac{\gamma D}{q-D}\right]$ \\
\hline
\end{tabular}

Terms: $D=$ foundation depth, $B=$ foundation width, $q=$ loading pressure 
41. Complete submergence of a footing by the groundwater decreases the soil's bearing capacity by approximately one-half. This is caused by a decrease in effective unit weight and confining pressure of the soil by about one-half. In turn, this approximately doubles the settlement. Terzaghi and many others use this point to suggest that the calculated dry sand settlement be doubled in the case of complete submergence of a footing on the ground surface.

42. The depth below the footing at which groundwater is considered to have no effect on the settlement or bearing capacity is not strictly agreed upon. Generally, it is taken to be in the range of one and one-half to two times the footing width below the base of the footing.

43. The effect on footing settlement of a water level between these two depths (footing base to two times footing width below the base) is not well known. Many different methods have been developed to account for this. Terzaghi and Peck $(1948,1967)$ proposed a linear interpolation over this range. Other methods provide a nonlinear relationship. Meyerhof (1956) and others hold that the effect of water on the soil is reflected in the blowcount, which is lower below the water table, and do not correct the settlement for the effect of water. However, if the groundwater table rises from below after the SPT was conducted, the effect of water cannot be included in the blowcount. The bearing capacity of this material decreases and settlement problems could result.

44. The embedment of the footing is also important in determining the effect of the water table on settlement. According to Terzaghi and Peck (1948, 1967), submergence of a footing at a depth, $D$, equal to its width, $B$, increases the calculated dry settlement value by only 1.5 instead of by 2.0 for submerged surface footings. This is because the weight of the surcharge due to embedment partly accounts for the decrease in bearing capacity (increase in settlement) caused by the water.

45. All of the water correction factors for settlement used in the methods of Part III involve three variables: (a) depth of water, (b) depth of embedment, and (c) width of the footing. These correction factors are plotted in Figures $8 \mathrm{a}$ through $c$, for a range of the water table from 0 to $2 B$ below the ground surface, and for three different embedments of the footing: $D=0$ 


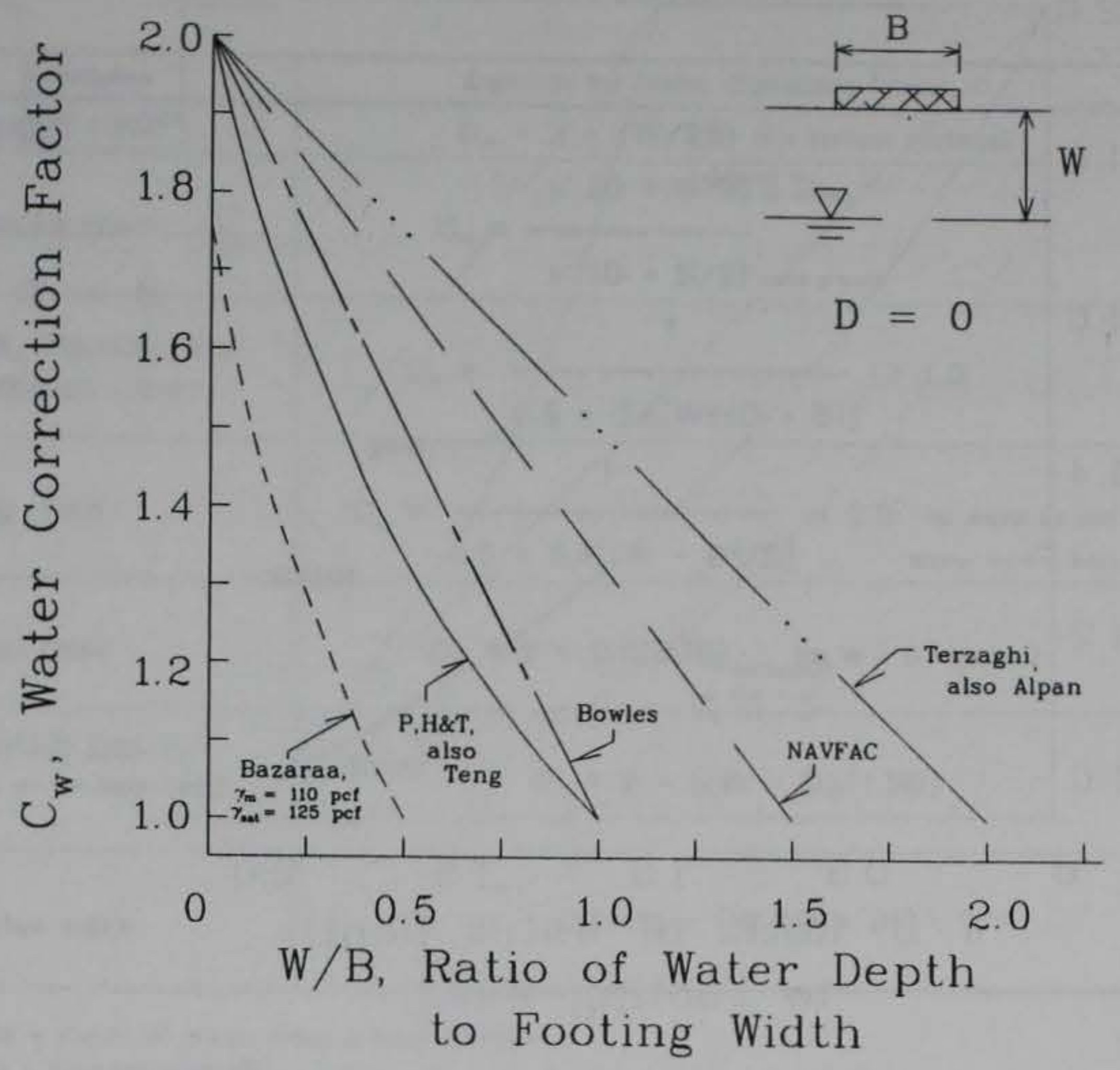

a. Footing at ground surface

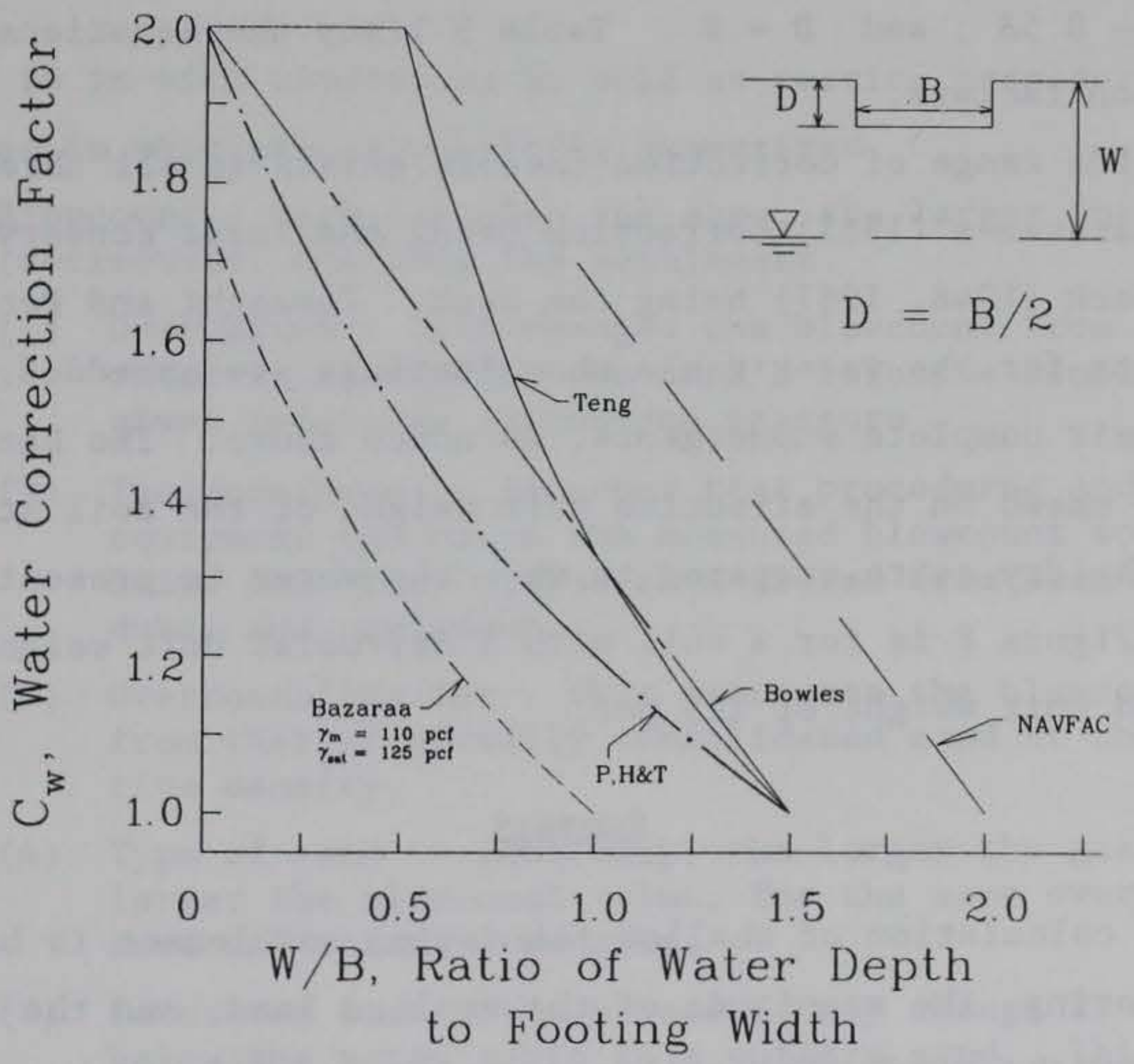

b. Embedment at one-half footing width

Figure 8. Water correction factors from various settlement methods (Continued) 


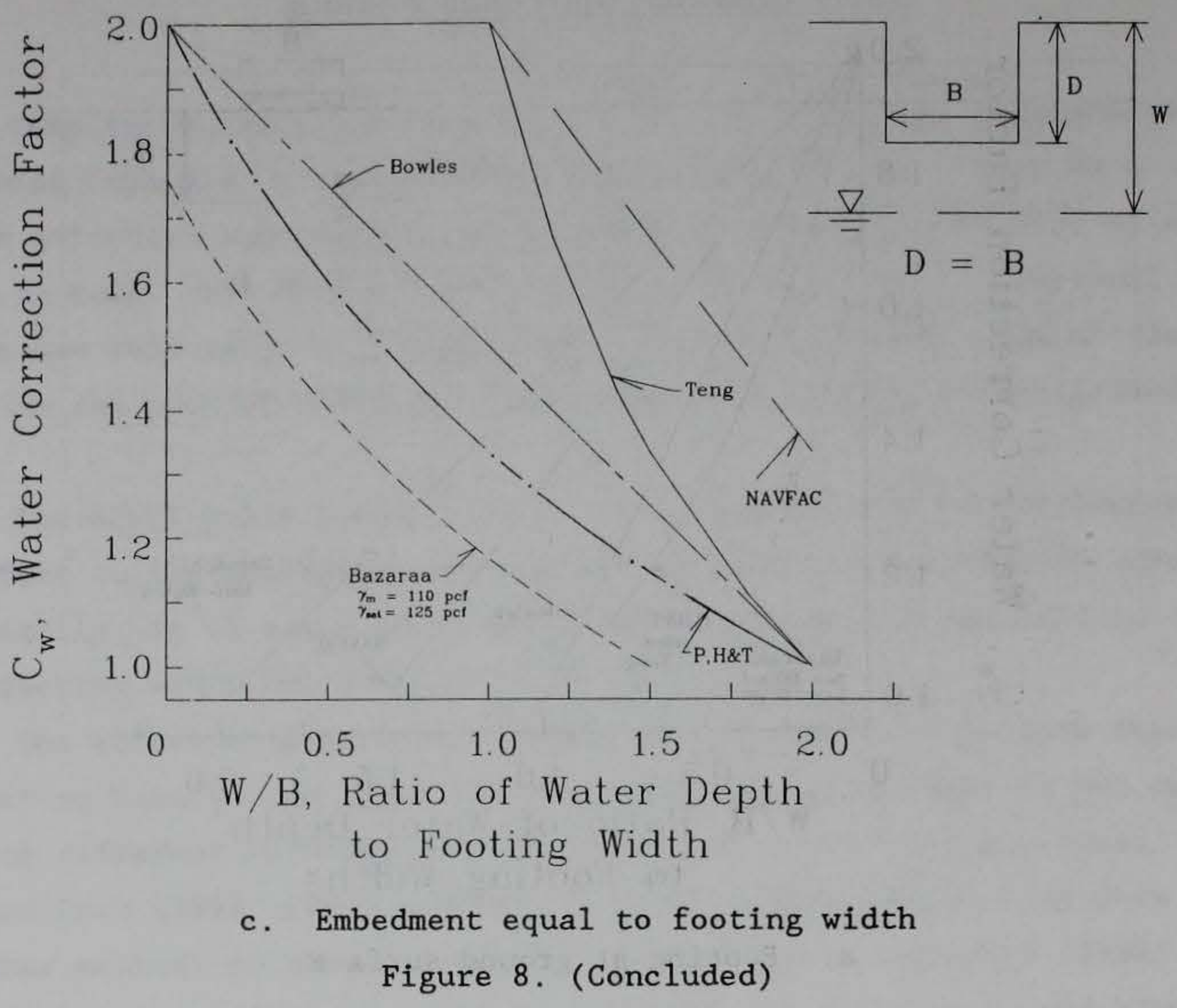

(surface), $D=0.5 B$, and $D=B$. Table 5 lists the equations of these water correction factors.

46. A wide range of correction factors exists in all three cases shown in Figure 8, Bazaraa's (1967) correction being the least conservative and Terzaghi and Peck $(1948,1967)$ being the most. Terzaghi and Peck do not provide corrections for the water table when footings are embedded, except for the case of their complete submergence, as noted above. The Bazaraa correction factor is based on the effective unit weight of the soil at a depth $D+0.5 B$ in the dry state compared to when the water is present. The Bazaraa plot shown in Figure 8 is for a soil with a dry/moist unit weight of 110 pcf and a saturated unit weight of 125 pcf.

\section{$\underline{\text { Summary }}$}

47. The calculation of shallow foundation settlement is based on the size of the footing, the magnitude of the applied load, and the capacity of the soil to bear the load. The soil's capacity is affected by a variety of 


\section{Table 5. Water Correction Factors}

\begin{tabular}{|c|c|}
\hline Reference & Equation for Water Correction Factor, $\mathrm{C}_{\mathrm{w}}$ \\
\hline Terzaghi (1967) & $C_{w}=2-(W / 2 B)$ (for surface footings) \\
\hline \multirow{2}{*}{ Bazaraa (1967) } & \multirow{2}{*}{$\mathbf{C}_{w}={\frac{\gamma^{\prime}(\mathbf{D}+\mathbf{B} / 2)}{\gamma^{\prime}(\mathbf{D}+\mathbf{B} / 2) \text { no water }}}_{\text {water present }}$} \\
\hline & \\
\hline \multirow{2}{*}{$\begin{array}{l}\text { Peck, Hanson, and } \\
\text { Thornburn (1974) }\end{array}$} & \multirow{2}{*}{$C_{w}=\frac{1}{0.5+0.5[W /(D+B)]}>1.0$} \\
\hline & \\
\hline \multirow{2}{*}{ Teng (1962) } & \multirow{2}{*}{$C_{w}=\frac{1}{0.5+0.5[(W-D) / B]}<2.0 \quad \begin{array}{l}\text { for water at and } \\
\text { below footing base }\end{array}$} \\
\hline & \\
\hline Alpan (1964) & $C_{w}=2-0.5(D / B) \quad$ for $W=D$ (approx.) \\
\hline $\begin{array}{l}\text { NAVFAC DM } 7.1 \\
\text { (Dept. of the Navy 1982) }\end{array}$ & $C_{w}=2-[(W-D) / 1.5 B]$ \\
\hline Bowles (1977) & $C_{w}=2-[W /(D+B)]$ \\
\hline
\end{tabular}

Terms: $W=$ depth of water from ground surface

$D=$ foundation depth

$B=$ foundation width

factors related to in situ conditions as well as testing procedures. Those factors discussed in this part are briefly summarized.

a. Blowcount - with all else the same, the larger the blowcount (corrected), the less the settlement.

(1) Overburden - this changes the blowcount from the value at which it represents the sand's relative density for a given reference overburden pressure.

(2) Test/equipment - improper test procedures and inconsistent equipment can cause the measured blowcount to be above or below the "true" value as measured from standard procedures and equipment.

(3) Overconsolidation - this increases the blowcount measured from that of normally consolidated sand at the same relative density.

(4) Type of sand - generally, the larger the grain size, the larger the blowcount value, for the same overburden pressure and relative density.

(5) Saturated sand - the blowcount may change from above to below the water table in a uniform sand. This change could be a slight decrease in a coarse sand, and a more notable decrease (up to 15 percent) in a fine sand. The blowcount may be sharply increased in a saturated, dense, 
very fine, or silty sand due to dilation of the grains upon shearing from the SPT.

b. Embedment - this decreases the settlement due to increased confinement from the soil surcharge, provided the removed surcharge pressure is replaced.

c. Water - this increases settlement when located in the range from the footing base or above to a depth of one and one-half to two times the footing width. This is caused by a decrease in the confining pressure and bearing capacity of the soil. 
48. In this part of the report, 15 methods of computing the settlement of a shallow foundation on sand are presented. For each method, the theoretical background is briefly discussed and the procedure is given.

49. Unless otherwise noted, the terms in the settlement equations shown in this part are used according to the definitions given in Table 6 .

\section{Table 6. Summary of Terms Used in Settlement Equations}

\begin{tabular}{|c|c|c|}
\hline Symbol & Definition & Units \\
\hline S & footing Settlement & inch \\
\hline q & net applied loading pressure & tsf (tons per square foot) \\
\hline B & footing width & feet \\
\hline L & footing length & feet \\
\hline D & $\begin{array}{l}\text { footing depth from } \\
\text { ground surface }\end{array}$ & feet \\
\hline H & $\begin{array}{l}\text { thickness of compressible } \\
\text { stratum, from ground surface } \\
\text { to rigid base }\end{array}$ & feet \\
\hline W & $\begin{array}{l}\text { depth to water table from } \\
\text { ground surface }\end{array}$ & feet \\
\hline N & $\begin{array}{l}\text { uncorrected SPT blowcount, } \\
\text { lowest average value over the } \\
\text { range } D \text { to } D+B \text {. }\end{array}$ & blows per foot \\
\hline $\mathrm{N}_{\mathrm{c}}$ & $\begin{array}{c}\text { corrected SPT blowcount, } \\
=\left(C_{N}\right) N\end{array}$ & blows per foot \\
\hline $\mathrm{C}_{\mathrm{N}}$ & blowcount correction factor & unitless \\
\hline $\mathrm{C}_{\mathrm{o}}$ & depth correction factor & unitless \\
\hline $\mathrm{C}_{\mathrm{w}}$ & water table correction factor & unitless \\
\hline $\mathbf{p}^{\prime}$ or $\sigma_{v}^{*}$ & effective overburden pressure & psf (pounds per square foot) \\
\hline$\gamma$ & unit weight of soil & pef \\
\hline$\nu$ & Poisson's Ratio & unitless \\
\hline E & Young's modulus of elasticity & tsf \\
\hline
\end{tabular}

\section{Terzaghi and Peck $(1948,1967)$}

50. The Terzaghi and Peck settlement method is based on the bearing capacity charts shown in Figure 3 of Part II. The equations shown were developed by Meyerhof (1956). The chart is used to determine the allowable bearing capacity for a range of footing widths and SPT blowcount values with maximum settlement not to exceed 1 in. and differential settlement not to exceed $3 / 4$ in. 
51. Field tests and the observance of structural settlements led to the development of the relation between bearing capacity and footing width (Figure 2). According to Terzaghi and Peck, square and strip footings of the same width show no significant difference in their settlements for the same load and soil.

52. The water correction factor for this method applies to cases where water is at or above the base of the footing (complete submergence). For partial submergence (water from depths $D$ to $D+B$ ), a correction factor is given for surface footings only (no embedment). In current practice, the water correction is often not used with the Terzaghi and Peck settlement, because the method is considered to be over conservative already. Applying the water correction factor makes it even more over conservative.

53. The depth correction factor following paragraph 54 is described in the text of Terzaghi and Peck (1967) and quantified by D'Appolonia, D'Appolonia, and Brissette (1970).

54. Calculation of settlement should not be attempted with Terzaghi's modulus of subgrade reaction theory. This is explicitly stated in his paper (Terzaghi 1955): the subgrade reaction modulus is reliable for computing stresses, bending moments, and the distribution of contact pressure in footings or mats, but not for the settlement of a foundation.

\section{Settlement expression}

$$
\begin{array}{ll}
S=\frac{8 q}{N}\left(C_{\mathrm{w}} C_{\mathrm{d}}\right) & \text { for } B \leq 4 \mathrm{ft} \\
S=\frac{12 q}{N}\left[\frac{B}{B+1}\right]^{2}\left(C_{\mathrm{w}} C_{\mathrm{d}}\right) & \text { for } B \geq 4 \mathrm{ft} \\
S=\frac{12 q}{N}\left(C_{\mathrm{w}} C_{\mathrm{d}}\right) & \text { for rafts }
\end{array}
$$


Water: $C_{w}=2-\left(\frac{W}{2 B}\right) \leq 2.0$ (for surface footings)

$$
C_{w}=2-0.5\left(\frac{D}{B}\right) \leq 2.0 \quad \begin{aligned}
& \text { (for a fully submerged, } \\
& \text { embedded footing; } W \leq D \text { ) }
\end{aligned}
$$

Depth: $C_{\mathrm{d}}=1-0.25\left(\frac{D}{B}\right)$

Blowcount: Use the measured SPT blowcount value. If the sand is saturated, dense, and very fine or silty, correct the blowcount by:

$$
N_{\mathrm{c}}=15+0.5(N-15) \text {, for } N \text { greater than } 15
$$

\section{Teng (1962)}

55. Teng's method for computing the settlement of shallow foundations on sand is an interpretation of the Terzaghi and Peck (1948) bearing capacity chart (Figure 3). Teng includes corrections for depth of embedment, the presence of water, and the blowcount. The blowcount correction equation is an approximation of the Gibbs and Holtz (1957) curves shown in Figure 1.

\section{Settlement expression}

$$
S=\frac{q}{720\left(N_{\mathrm{c}}-3\right)}\left[\frac{2 B}{B+1}\right]^{2} \frac{1}{\left(C_{\mathrm{w}}\right)\left(C_{\mathrm{d}}\right)}
$$

where

$$
q=\text { net pressure in psf }
$$




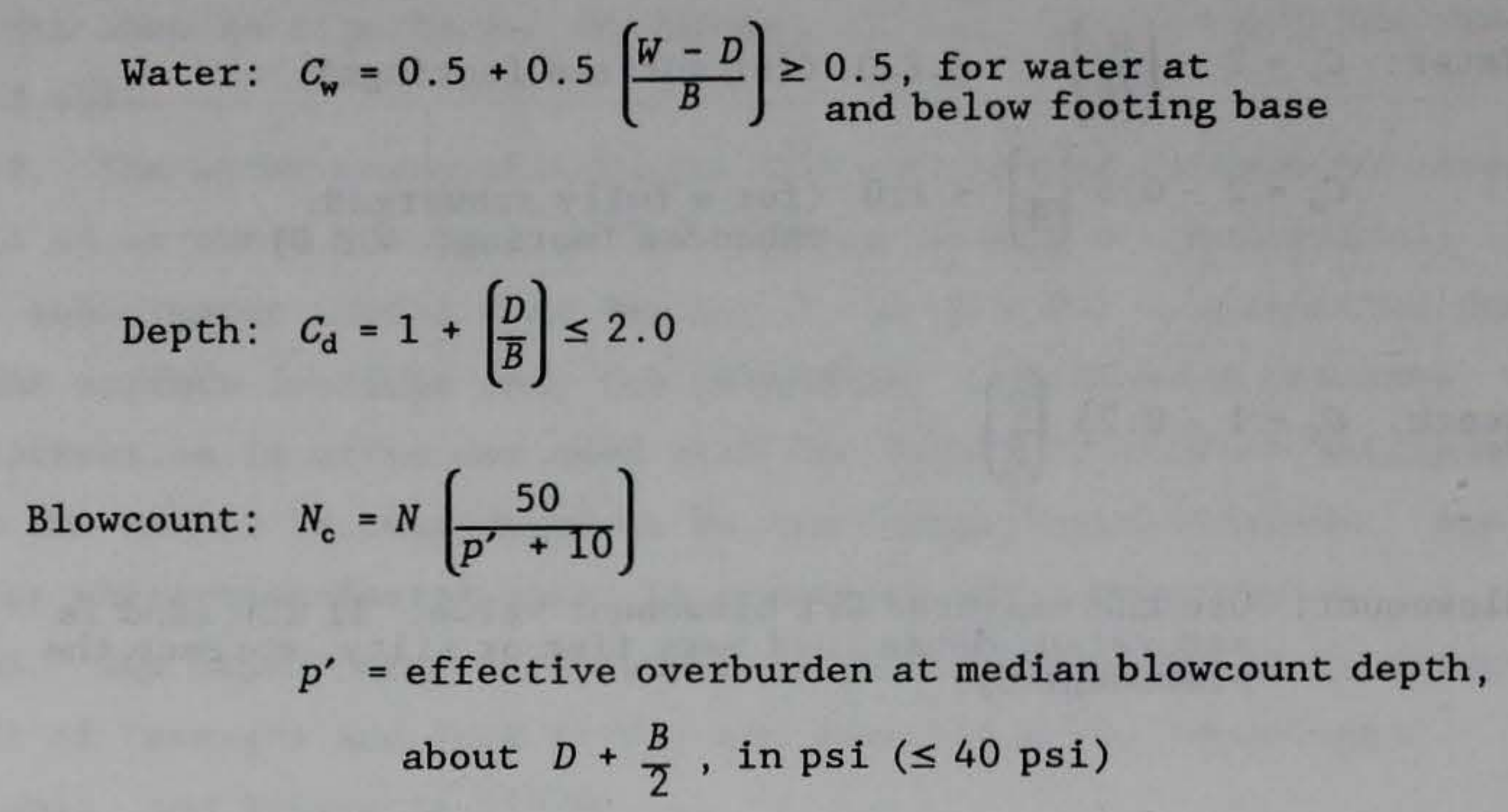

\section{Alpan (1964)}

56. Alpan's settlement method was derived from the Terzaghi and Peck (1948) method. However, instead of directly using the blowcount he developed a modulus of subgrade reaction based on the corrected blowcount. Alpan recommends correcting the blowcount with the Gibbs and Holtz (1957) chart of Figure 1. This chart was modified for easier use by Coffman (1960) as shown in Figure 9a. Use of the chart is explained in paragraph 57 and shown in Figure 9b. The "Terzaghi-Peck" curve in Figure 9b was added by Alpan.

57. Alpan also accounts for submerged soil conditions as well as the shape of the footing in his settlement prediction method. 


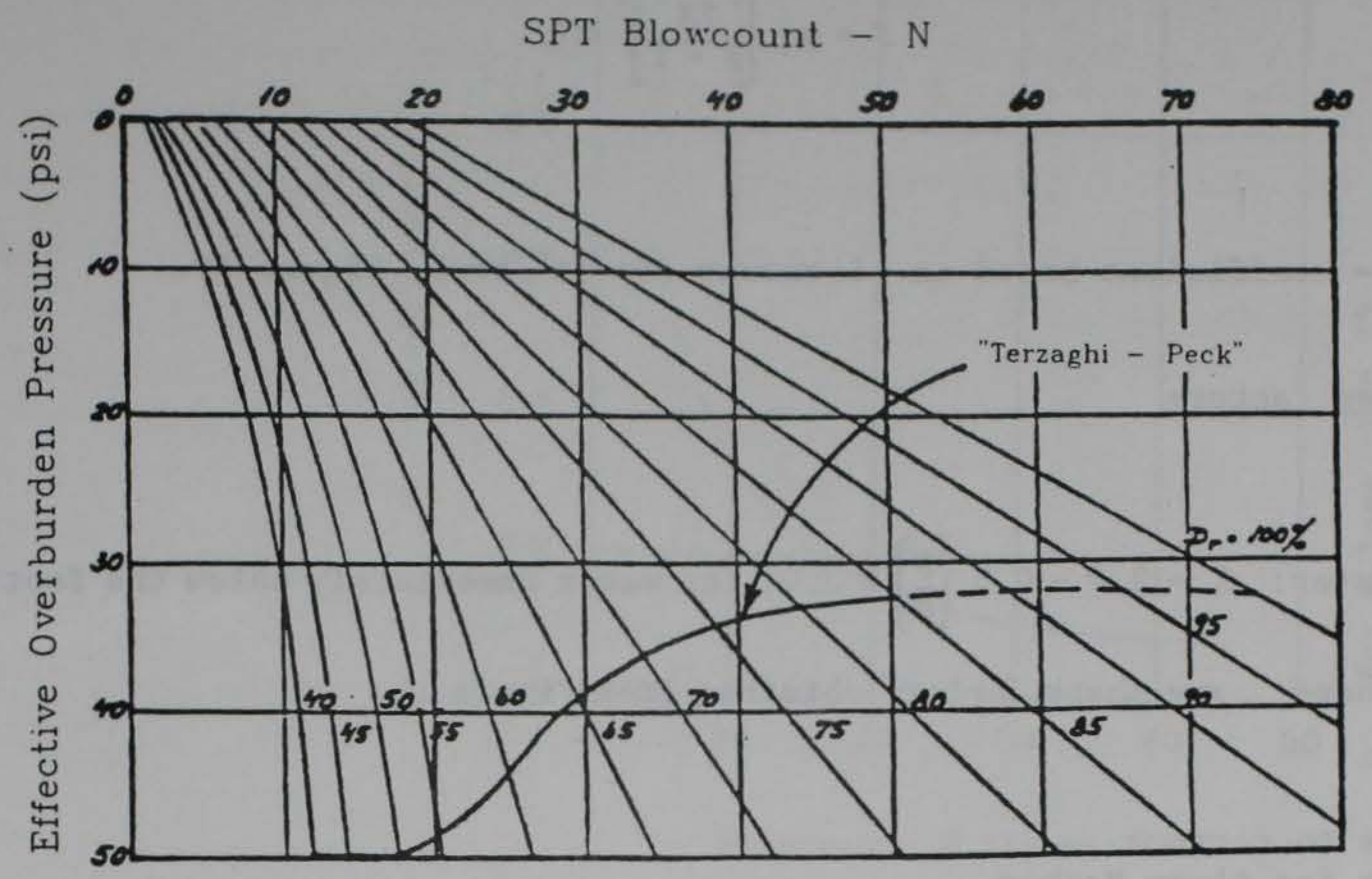

a. Blowcount correction based on Gibbs and Holtz (1957) chart

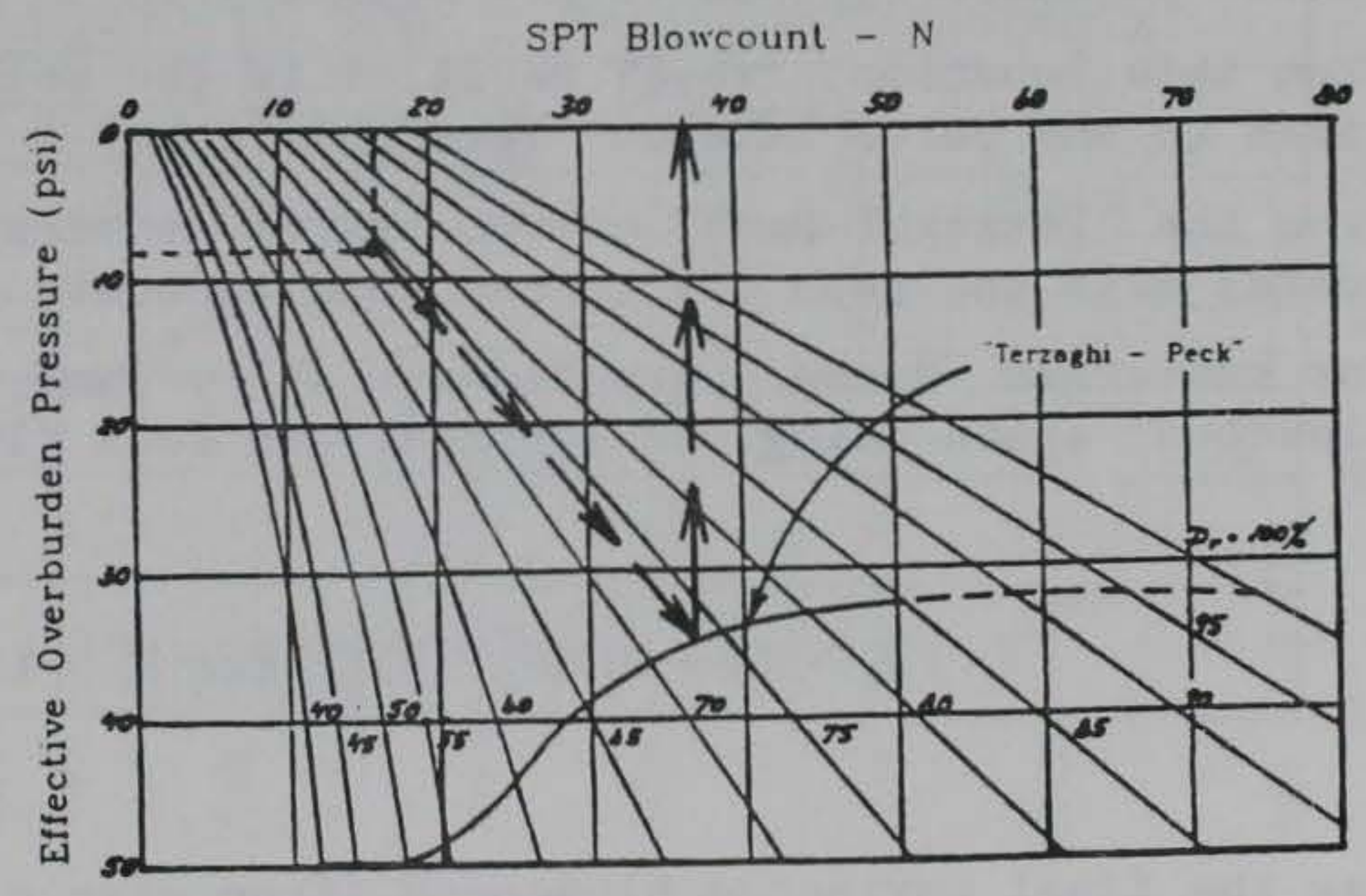

b. Example showing use of chart

Figure 9. Blowcount correction for use with Alpan's (1964) method (Permission to reprint granted by Morgan Grampian (Construction Press) Ltd.) 


$$
S=\alpha q\left[\frac{2 B}{B+1}\right]^{2} m C_{w}
$$

where

$\alpha=$ coefficient based on blowcount (in- $\mathrm{ft}^{2} /$ ton), Figure 10 .

\section{Correction factors}

Water: $C_{\mathrm{w}}=2.0-0.5\left(\frac{D}{B}\right) \leq 2.0$, for water immediately below the footing

Shape: $m=$ shape factor, obtained from Figure 11

Procedure to correct

blowcount for Alpan Method

58. These steps can be followed to arrive at a corrected blowcount for the Alpan (1966) Method.

a. Enter Figure $9(a)$ with field blowcount and corresponding overburden pressure (in pounds per square inch).

b. From this location, travel parallel to the relative density lines to the curve labeled "Terzaghi-Peck."

c. From the "Terzaghi-Peck" curve, travel vertically to the horizontal axis and read the corrected blowcount, $N_{\mathrm{c}}$.

d. For submerged, dense, very fine or silty sand, correct the blowcount again using the Terzaghi and Peck (1948) equation:

$$
N_{c}=15+0.5\left(N_{c}-15\right) \text {, for } N_{c}>15
$$

e. Use the final corrected blowcount (from step c or d) in Figure $10 \mathrm{a}$ or $\mathrm{b}$, to determine alpha, $\alpha$. 


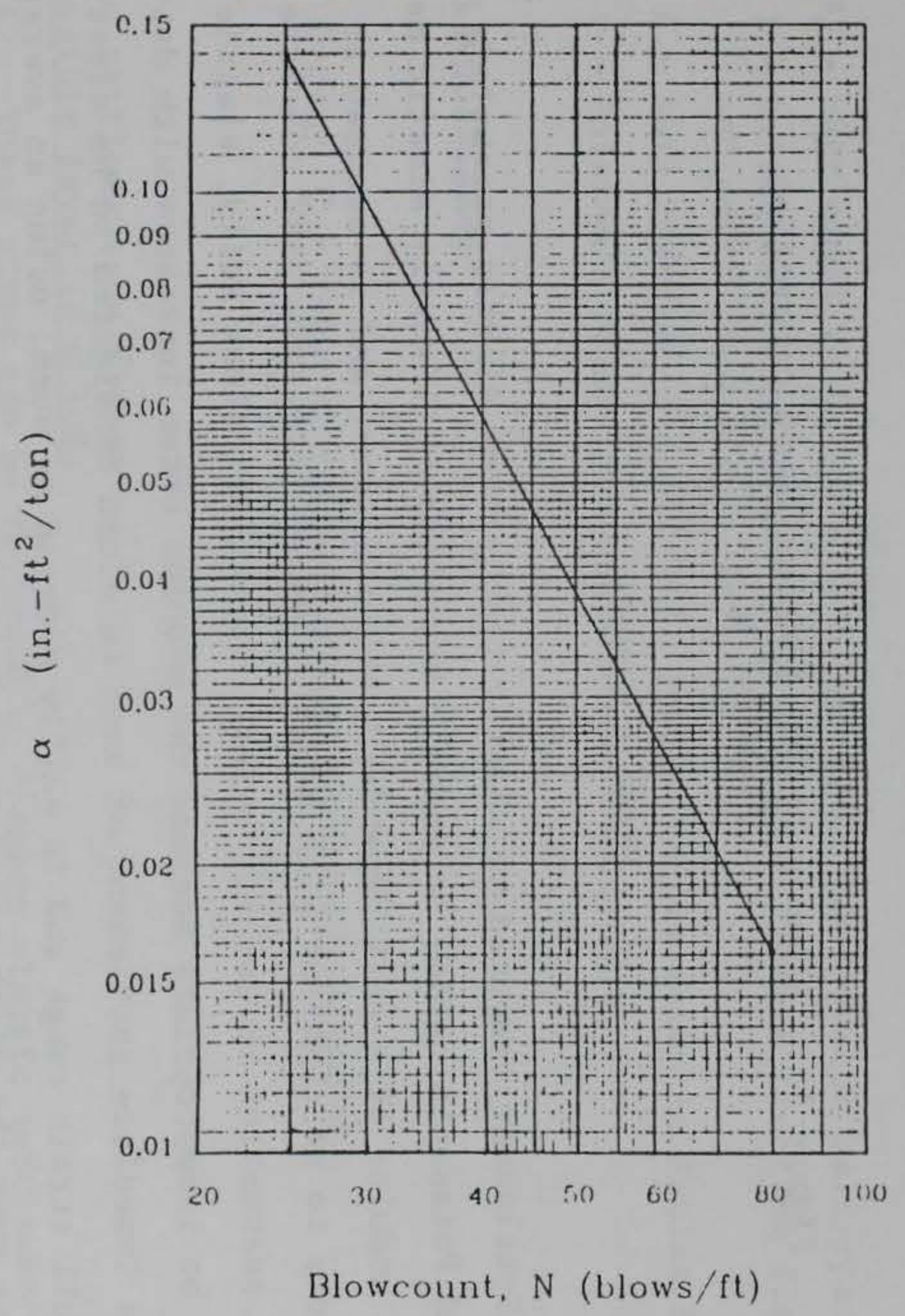

a. For $\mathrm{N}$ greater than 25

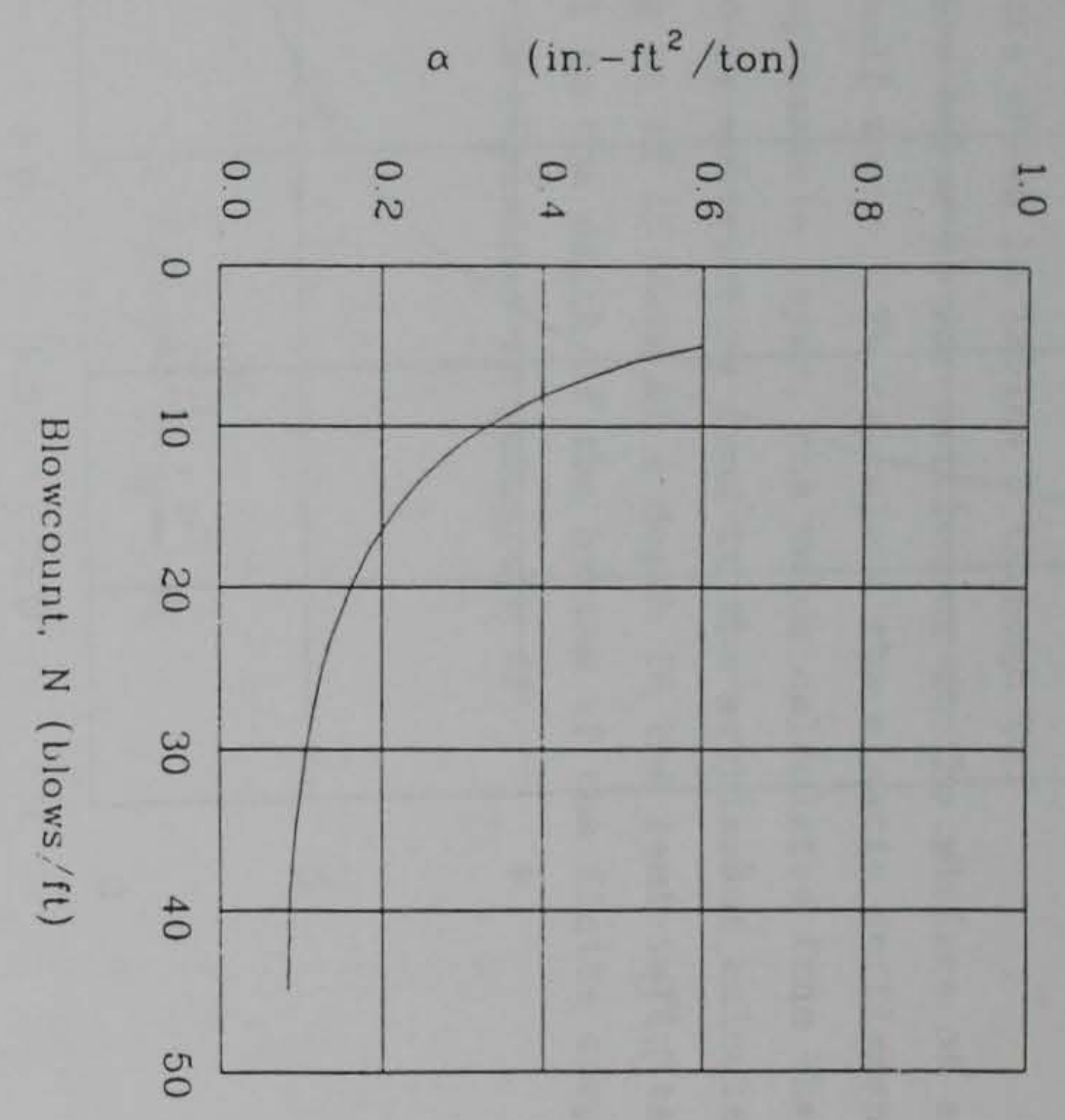

b. For $\mathrm{N}$ less than 25

Figure 10. Alpan's (1964) subgrade modulus coefficient 


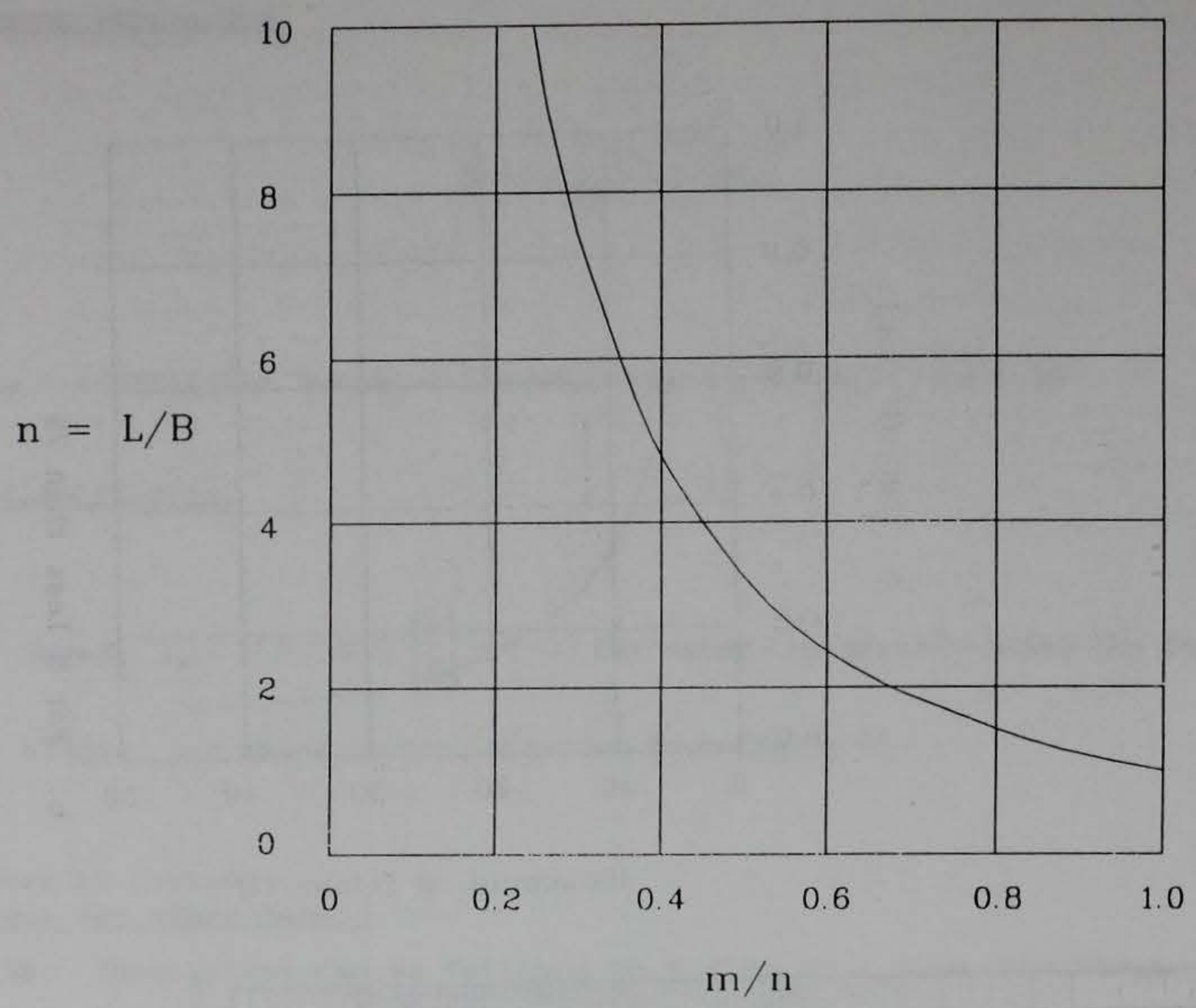

Figure 11. Alpan's (1964) footing shape correction factor, $m$

\section{Elastic Theory}

59. Settlement computed by elastic theory uses elastic parameters (modulus and Poisson's ratio) to model a homogeneous, linearly elastic medium. The elastic modulus of a soil depends upon confinement and is assumed in elastic theory to be constant with depth. For uniform saturated cohesive soils, this assumption is usually valid. For cohesionless soils, elastic methods can be inappropriate because the modulus often increases with depth. However, the immediate settlement of sand is often considered to be elastic within a small strain range and is easily modeled as such, using an average modulus value over the depth equal to $2 B$ below the footing base.

60. The elastic theory settlement calculation presented here uses equations found in the text of Das (1983) for the influence factor, and the charts by Fox (1948) for embedment. Tables of precalculated influence factors for elastic settlement on a semi-infinite stratum can be found in many texts for 
use in hand calculations. Table 7 summarizes these factors. Estimates of the modulus of elasticity and Poisson's ratio are also readily found in the literature. Some of these are shown in Tables 8 through 10 .

61. The expression below is for settlement at the surface of a semiinfinite, homogeneous half-space. To calculate the elastic settlement of a footing on a finite compressible layer, the value calculated from the following equation is reduced by subtracting from it the settlement calculated for the same loaded footing as if it were at a depth in the semi-infinite homogeneous half-space, equal to the depth of the bottom of the finite compressible layer. This procedure is explained in paragraph 62 .

\section{Settlement expression}

$$
S_{\mathrm{c}}=q B I \frac{\left(1-v^{2}\right)}{E} C_{\mathrm{d}}
$$

where

$$
\begin{aligned}
S_{\mathrm{c}}= & \text { settlement in } \underline{\mathrm{ft}} \text { on a semi-infinite, homogeneous half-space } \\
I= & \text { influence factor based on shape, aspect ratio, footing flexibility, } \\
& \text { and depth to a rigid base, Table } 7 \\
E= & \text { soil modulus of elasticity (tsf), values shown in Tables } 8 \text { and } 9 \\
v= & \text { Poisson's ratio, values shown in Table } 10
\end{aligned}
$$

\section{Correction factors}

Depth: $C_{\mathrm{d}}=$ value from Fox's chart (Figure 12) based on $v, L / B$, and $D / B$

Elastic settlement on finite

compressible layer $(H<10 B)$

62. These steps can be followed to compute elastic settlement of a footing on a finite layer instead of an infinite mass as shown in paragraph 61 (Das, 1983).

a. Compute $S_{\mathrm{c}}$, the settlement at the center of a flexible footing on a semi-infinite half-space, by the equation in paragraph 61 . 
TABLE 7. Summary of Elasticity Influence Factors for Footing on Semi-infinite, Homogeneous, Linearly Elastic Medium

\begin{tabular}{|c|ccc|}
\hline \multirow{2}{*}{ Length/Width } & \multicolumn{3}{|c|}{ Flexible Footing } \\
\hline Circle & 1.00 & 0.64 & 0.85 \\
1.0 & 1.122 & 0.561 & 0.951 \\
1.5 & 1.36 & 0.67 & 1.15 \\
2. & 1.532 & 0.766 & 1.299 \\
3. & 1.783 & 0.892 & 1.512 \\
5. & 2.105 & 1.053 & 1.785 \\
10. & 2.544 & 1.272 & 2.157 \\
20. & 2.985 & 1.493 & 2.531 \\
50. & 3.568 & 1.784 & 3.026 \\
100. & 4.010 & 2.005 & 3.400 \\
$1,000$. & 5.47 & 2.75 & 5.15 \\
\hline
\end{tabular}

(after Das 1983, and Winterkorn and Fang 1975)

Table 8. Equations for Stress-Strain Modulus, E from SPT and CPT Test Methods

\begin{tabular}{|lll|}
\hline Soil & SPT, units in $k P a *$ & CPT, units of $q_{c}$ \\
\hline Sand & $E=500(N+15)$ & $E=(2$ to 4$) q_{c}$ \\
& $E=18,000+750 N$ & $E=2\left(1+D_{r}^{2}\right) q_{c}$ \\
& $E=(15,200$ to 22,000$)$ In $N$ & \\
Clayey sand & $E=320(N+15)$ & $E=(3$ to 6$) q_{c}$ \\
Silty sand & $E=300(N+6)$ & $E=\left(1\right.$ to 2) $q_{c}$ \\
Gravelly sand & $E=1,200(N+6)$ & \\
Soft clay & & $E=\left(6\right.$ to 8) $q_{c}$ \\
\hline
\end{tabular}

* Divide $\mathrm{kPa}$ by 50 to get ksf

(after Bowles 1982) 
Table 9. Range of Elastic Modulus, E

\begin{tabular}{|cc|}
\hline Soil & $\begin{array}{c}\text { Young's Modulus, E } \\
\text { (psi) }\end{array}$ \\
\hline Soft Clay & $250-500$ \\
Hard Clay & $850-2,000$ \\
Loose Sand & $1,500-4,000$ \\
Dense Sand & $5,000-10,000$ \\
\hline
\end{tabular}

(after Das 1985)

Table 10. Range of Values for Poisson's Ratio

\begin{tabular}{|lc|}
\hline Soil & Poisson's Ratio \\
\hline Loose Sand & $0.2-0.4$ \\
Medium Sand & $0.25-0.4$ \\
Dense Sand & $0.3-0.45$ \\
Silty Sand & $0.2-0.4$ \\
Soft Clay & $0.15-0.25$ \\
Medium Clay & $0.2-0.5$ \\
\hline
\end{tabular}

(after Das 1985) 


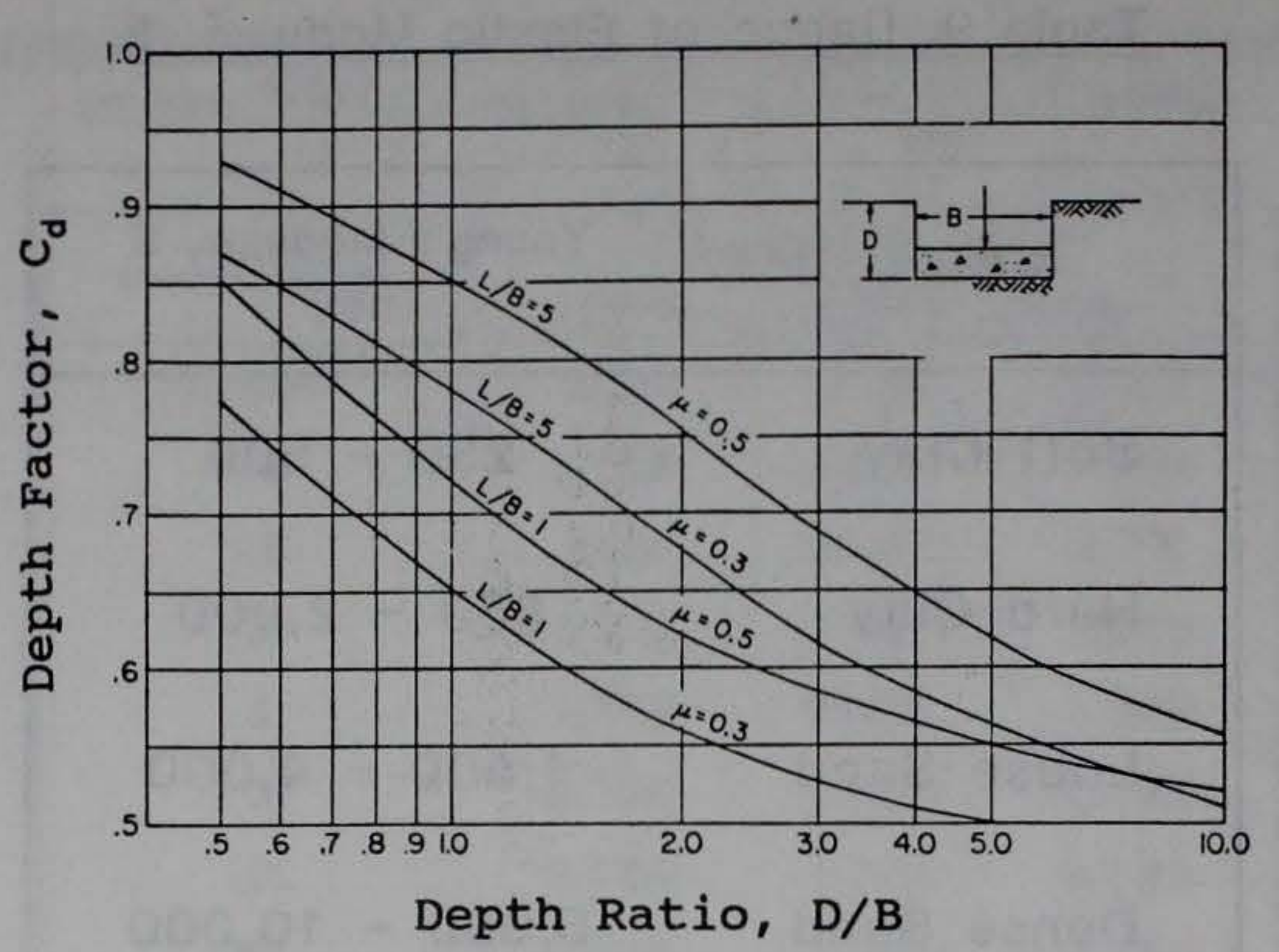

Figure 12. Depth correction factor by Fox (1948) for elastic methods (Bowles (1982)) (Permission to reprint granted by the International Society for Soil Mechanics and Foundation Engineering)

b. If desired, compute $S_{\mathrm{a}}$, the average settlement of the flexible footing, and $S_{r}$, the settlement of a rigid footing, on a semi-infinite half-space. This is calculated from $S_{c}$ by:

$$
S_{\mathrm{a}}=0.848\left(S_{\mathrm{c}}\right) \text { and } S_{\mathrm{r}}=0.93\left(S_{\mathrm{c}}\right)
$$

c. Compute $S^{\prime}$, settlement of one corner of the footing, at a depth equal to the bottom of the compressible layer $(H)$.

$$
S^{\prime}=\frac{q B^{\prime}}{2 E}\left(1-v^{2}\right)\left[I_{3}^{\prime}-\frac{(1-2 v)}{(1-v)} I_{4}^{\prime}\right]
$$


where

$$
\begin{aligned}
& B^{\prime}=\frac{B}{2} \\
& I_{3}^{\prime}=\frac{1}{\pi}\left[\ln \frac{\left(1+m^{2}+n^{2}\right)^{1 / 2}+m}{\left(1+m^{2}+n^{2}\right)^{1 / 2}-m}+m \ln \frac{\left(1+m^{2}+n^{2}\right)^{1 / 2}+1}{\left(1+m^{2}+n^{2}\right)^{1 / 2}-1}\right] \\
& I_{4}^{\prime}=\frac{n}{\pi} \tan ^{-1}\left[\frac{m}{n\left(1+m^{2}+n^{2}\right)^{1 / 2}}\right] \\
& m=\frac{L / 2}{B / 2} \text { and } \\
& n=\frac{H}{B / 2}
\end{aligned}
$$

The $\tan ^{-1}$ angle is in radians.

d. Compute $S_{c f}$, settlement at the center of a flexible footing on a finite compressible layer, by:

$$
S_{c f}=S_{c}-\left(4 \times S^{\prime}\right)
$$

e. Compute $S_{a f}$, average settlement of a flexible footing, and $S_{\text {rf }}$, settlement of a rigid footing, on a finite compressible layer, by:

$$
S_{\text {af }}=0.848\left(S_{\mathrm{cf}}\right) \text { and } S_{\mathrm{rf}}=0.93\left(S_{\mathrm{cf}}\right)
$$

\section{D'Appolonia, D'Appolonia, and Brissette (1968)}

63. In this paper, D'Appolonia, D'Appolonia, and Brissette (1968) report the results from an extensive study performed with the Terzaghi and Peck (1948, 1967) and Meyerhof $(1956,1965)$ settlement methods versus measured settlements. They concluded:

a. Use the Terzaghi equations with a 50-percent increase in bearing capacity (two-thirds decrease of settlement) as proposed by Meyerhof (1956). 
b. Correct the blowcount with the Gibbs and Holtz (1957) curves, Figure 1.

c. Do not correct for the water table with this procedure, also proposed by Meyerhof.

64. These conclusions are valid for overconsolidated, vibratory compacted, dune sand, on which the comparisons were made. Extrapolation to soils other than this may produce erroneous results. The depth correction factor shown below was not explicitly stated as part of this procedure. It is, however, part of Meyerhof's procedure, on which this one is based.

\section{Settlement expression}

$$
\begin{aligned}
& S=\frac{16 q}{3 N_{\mathrm{c}}} C_{\mathrm{d}} \text { for } B \leq 4 \mathrm{ft} \\
& S=\frac{8 q}{N_{\mathrm{c}}}\left(\frac{B+1}{B+1}\right)^{2} C_{\mathrm{d}} \text { for } B \geq 4 \mathrm{ft} \\
& S=\frac{8 q}{N_{\mathrm{c}}} C_{\mathrm{d}} \text { for rafts }
\end{aligned}
$$

\section{Correction factors}

Depth: $\quad C_{\mathrm{d}}=1-0.25\left(\frac{D}{B}\right)$, from Meyerhof (1956)

Blowcount: use $N_{c}$ value from Gibbs and Holtz (1957) curves (Figure 1)

\section{D'Appolonia, D'Appolonia, and Brissette (1970)}

65. This procedure was presented in the 1970 closure article to the authors' 1968 paper. It is similar to an elastic settlement method, using an elastic modulus of compressibility, $M$, that is determined from the field blowcount. A separate modulus of compressibility was developed for preloaded soil to account for the influence of stress history on soil behavior. A water 
table correction is not used in this method. The effect of groundwater on settlement (and bearing) is believed to be measured in the blowcount.

66. An influence factor, $I$, is computed as the product of $\mu_{0}$ and $\mu_{1}$ from Figure 13. These are factors developed by Janbu, Bjerrum, and Kjaernsli (1956) to account for the length and depth of the footing and the
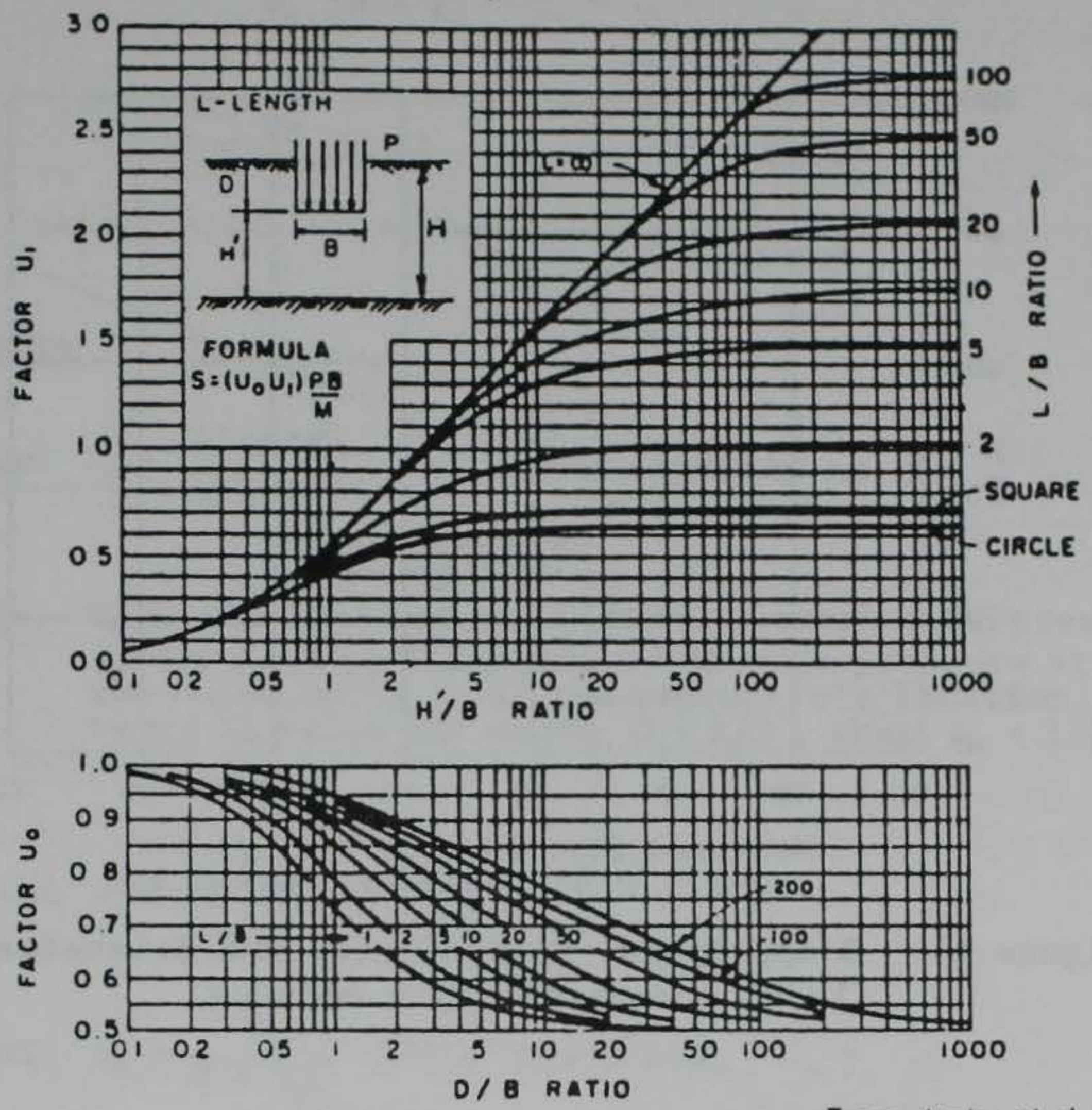

From Janbu ef al

Figure 13. Influence factors $\mu_{1}$ and $\mu_{\circ}$ from Janbu, Bjerrum, and Kjaernsli (1956) used in the D'Appolonia, D'Appolonia, and Brissette (1970) method (Permission to reprint granted by the National Research Council of Canada)

depth to a rigid base. These curves have been modified by Christian and Carrier (1978) to account for a wider range of Poisson's ratio. They differ from Janbu's curves for values of $H / B<5$. The original Janbu curves are those of Figure 13 .

\section{Settlement expression}

$$
S=\frac{q B I}{M}
$$


where

$S=\operatorname{settlement}(\underline{\mathrm{ft}})$

$I$ = influence factor based on footing shape and embedment and depth to a rigid base

$I=\left(\mu_{\mathrm{o}}\right)\left(\mu_{1}\right)$, see Figures $13 \mathrm{a}$ and $\mathrm{b}$

$M=$ modulus of compressibility (tsf), Figure 14

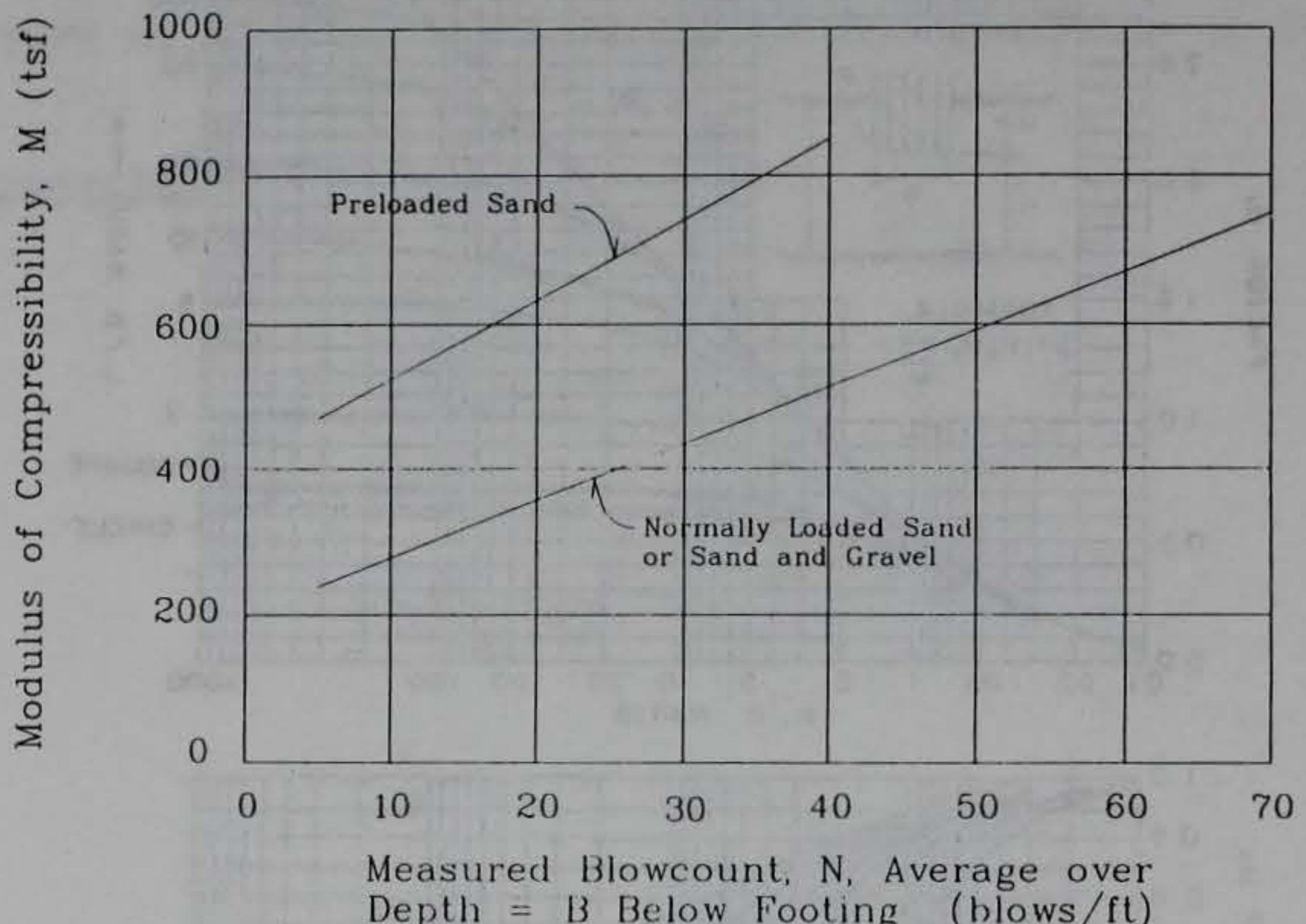

Figure 14. D'Appolonia, D'Appolonia, and Brissette (1970) compressibility modulus

\section{Peck and Bazaraa (1969)}

67. This method is similar to Terzaghi and Peck $(1948,1967)$ but predicts a less conservative settlement value and corrects the blowcount for overburden. In an extensive research effort, Bazaraa (1967) developed a means to correct the field blowcount for overburden effects. This was an effort to clear inconsistencies found with the Gibbs and Holtz (1957) method of blowcount correction (Figure 1). Also developed was a new bearing capacity chart which modifies the Terzaghi and Peck chart (Figure 3 ) to less conservative estimates by increasing the allowable bearing capacity by 50 percent. Water and depth effects were studied and corrections were developed for these factors as well. 
Settlement expression

$$
\begin{array}{ll}
S=\frac{16 q}{3 N_{\mathrm{c}}}\left(C_{\mathrm{d}} C_{\mathrm{w}}\right) & \text { for } B \leq 4 \mathrm{ft} \\
S=\frac{8 q}{N_{\mathrm{c}}}\left(\frac{B+1}{B+1}\right)^{2}\left(C_{\mathrm{d}} C_{\mathrm{w}}\right) & \text { for } B \geq 4 \mathrm{ft} \\
S=\frac{8 q}{N_{\mathrm{c}}}\left(C_{\mathrm{d}} D_{\mathrm{w}}\right) & \text { for rafts }
\end{array}
$$

\section{Correction factors}

Water: $C_{\mathrm{w}}=\frac{\sigma_{\mathrm{v}}^{\prime}(\text { dry })}{\sigma_{\mathrm{v}}^{\prime}(\text { wet })} . \quad \sigma_{\mathrm{v}}^{\prime}$ is computed at $D+\frac{B}{2}$

Note: $C_{\mathrm{w}}$ is the ratio of the effective overburden pressure at $D+B / 2$ of dry soil to effective overburden pressure at $D+B / 2$ when the water table is at the appropriate location. Therefore, if water is below the depth $D+B / 2$, then $C_{\mathrm{w}}=1.0$.

$$
\text { Depth: } \quad C_{\mathrm{d}}=1.0-0.4\left(\frac{\gamma D}{q}\right)^{1 / 2}
$$

$$
\text { Blowcount: } \begin{aligned}
N_{c} & =\frac{4 N}{1+2 p^{\prime}} \text { for } p^{\prime} \leq 1.5 \mathrm{ksf} \\
& =\frac{4 N}{3.25+0.5 p^{\prime}} \text { for } p^{\prime} \geq 1.5 \mathrm{ksf} \\
P^{\prime} & =\begin{array}{l}
\text { effective overburden pressure corresponding to the } \\
\text { blowcount (at approximately } D+B / 2 \text { ) }
\end{array}
\end{aligned}
$$

\section{Schmertmann (1970)}

68. Schmertmann proposes calculating total settlement by subdividing the compressible stratum and summing the settlements of each sublayer. The sublayer boundaries are defined by changes in the SPT or CPT profile. This profile is used to determine the elastic modulus as it changes with depth. If 
the SPT (or CPT) is fairly constant with depth (to depth $D+2 B$ ), then the elastic modulus will be constant with depth and the layered approach is not necessary. A simplified settlement expression for this case is provided in paragraph 70 .

69. This method is similar to elasticity procedures. Results from tests which studied vertical strain distribution below loaded footings were used to develop the vertical strain influence diagram shown in Figure 15 . The strain influence diagram models the strain distribution below the footing. This method applies to rigid footings as well as to flexible ones. The effect of creep settlement over a given period of time is included in the creep factor, $C_{\mathrm{t}}$.

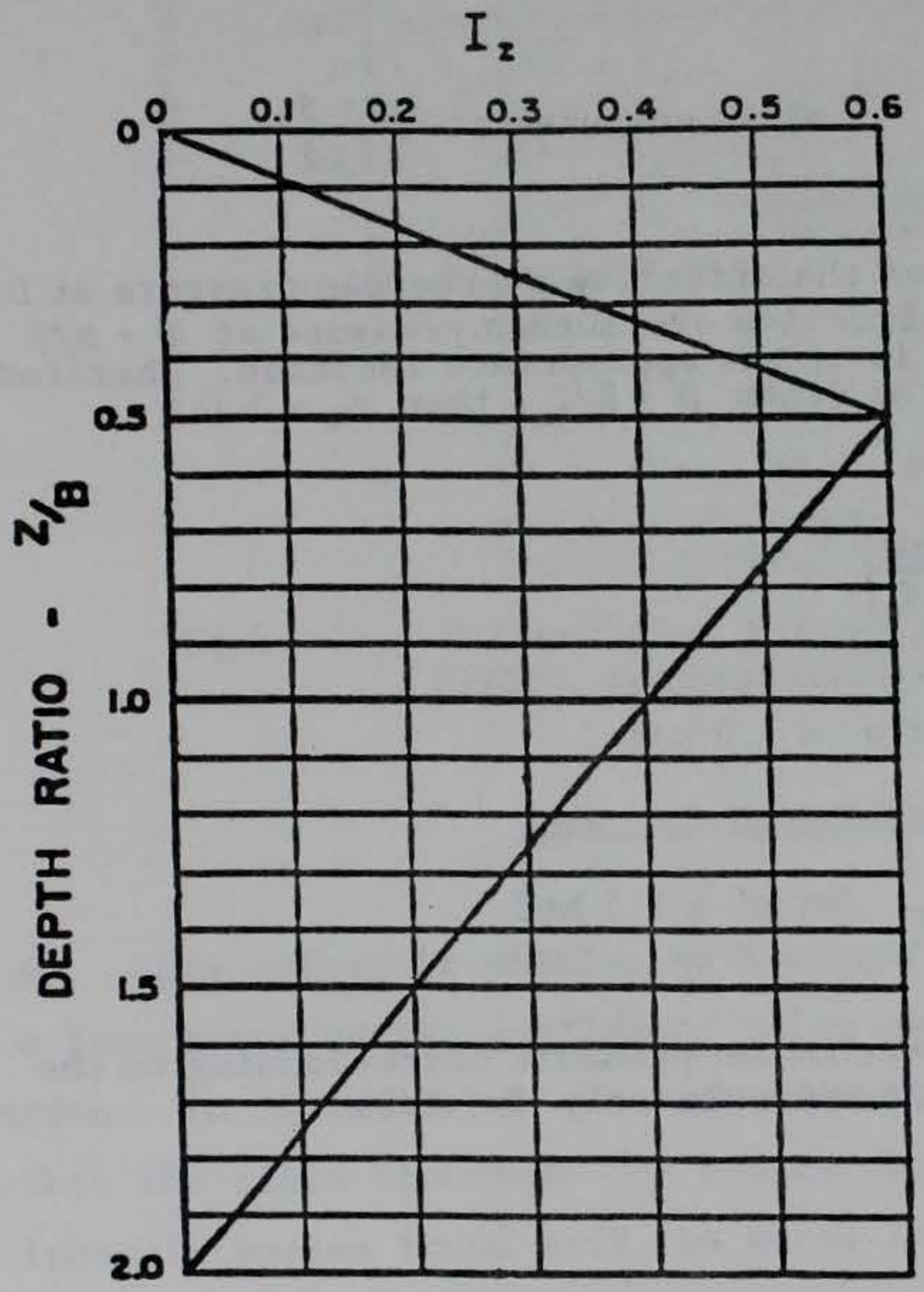

B = FOOTING WIDTH

\section{$Z$ = DEPTH BELOW BOTTOM OF FOOTING TO MIDPOINT OF SOIL LAYER}

Figure 15. Strain influence factor diagram for Schmertmann (1970) settlement method

70. The strain factor chart for this method (Figure 15), is often

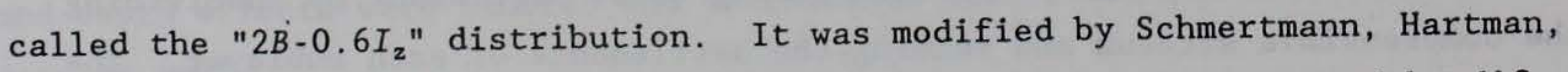
and Brown (1978) to model changes found in the strain diagram caused by different footing shapes and loading intensities. 


$$
S=q C_{\mathrm{d}} C_{\mathrm{t}} \sum_{\mathrm{i}=1}^{\mathrm{n}}\left(\frac{I_{\mathrm{z}}}{E_{\mathrm{s}}}\right)_{\mathrm{i}} z_{\mathrm{i}}
$$

where.

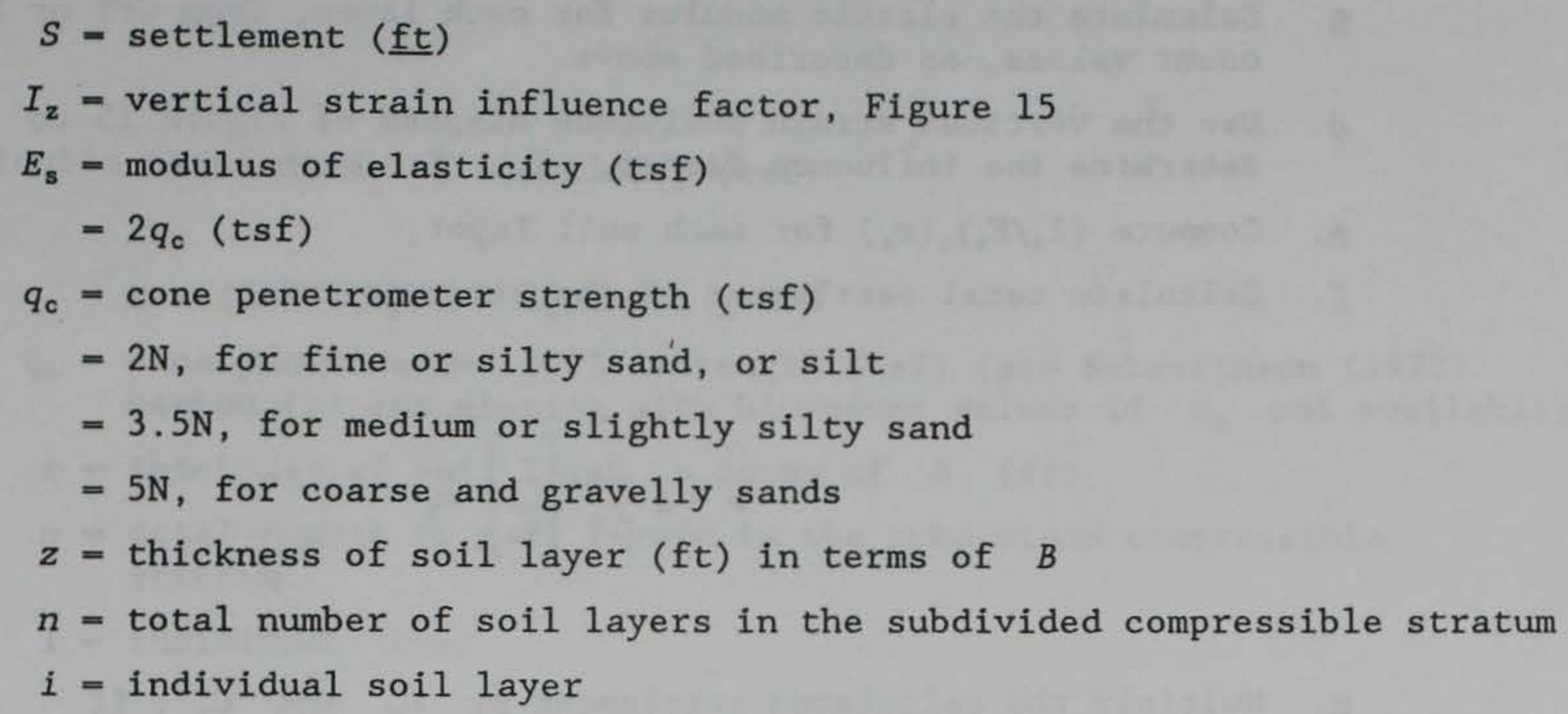

If $E_{\mathrm{s}}$ is constant over $2 B$ below the footing base (i.e., SPT or CPT values are constant) the simplified expression is:

$$
S=q C_{\mathrm{d}} C_{\mathrm{t}} \frac{0.6 B}{E_{\mathrm{s}}}
$$

where $0.6 B$ is the sum of the $\left(I_{z}\right)(z)$ area under the strain influence diagram in terms of $B$. No sublayers are needed.

\section{Correction factors}

Depth: $\quad C_{\mathrm{d}}=1.0-0.5\left(\frac{\gamma D}{q}\right) \geq 0.5$

Creep: $\quad C_{\mathrm{t}}=1.0+0.2 \log \left(\frac{t}{0.1}\right), \quad t=$ time period (years) 


\section{Procedure}

71. The following steps comprise the procedure for calculating total settlement.

a. Divide the compressible stratum into layers, based on a CPT or an SPT profile.

b. For each layer determine thickness, $z$, and depth (in terms of footing width, $B$ ) to the layer midpoint, $Z$, measured from the bottom of the footing.

c. Calculate the elastic modulus for each layer, from CPT or blowcount values, as described above.

d. Use the vertical strain influence diagram of Figure 15 to determine the influence factor, $I_{z}$, for each layer midpoint.

e. Compute $\left(I_{z} / E_{\mathrm{s}}\right)_{1}\left(z_{1}\right)$ for each soil layer.

f. Calculate total settlement of the stratum:

$$
S=q \sum_{i=1}^{\mathrm{n}}\left(\frac{I_{\mathrm{z}}}{E_{\mathrm{s}}}\right)_{i} z_{i}
$$

g. Multiply the calculated settlement by $C_{\mathrm{d}}$ and $C_{\mathrm{t}}$, if appropriate.

\section{Schmertmann, Hartman, and Brown (1978)}

72. This method differs from the Schmertmann (1970) method in that the strain influence diagram must be constructed for each individual case. Its dimensions are based on the shape of the footing, as measured by the lengthto-width ratio, $L / B$, and the net loading intensity, $q$. The diagram varies from square to strip footings, where $L / B=1$ to $L / B=10$, respectively. Another difference from the 1970 method is the computation of the elastic modulus for each soil layer. This also is based on $L / B$ as well as CPT or SPT values. 


$$
S=q C_{\mathrm{d}} C_{\mathrm{t}} \sum_{\mathrm{i}=1}^{\mathrm{n}}\left[\frac{I_{\mathrm{z}}}{E_{\mathrm{s}}}\right)_{1} z_{1}
$$

where

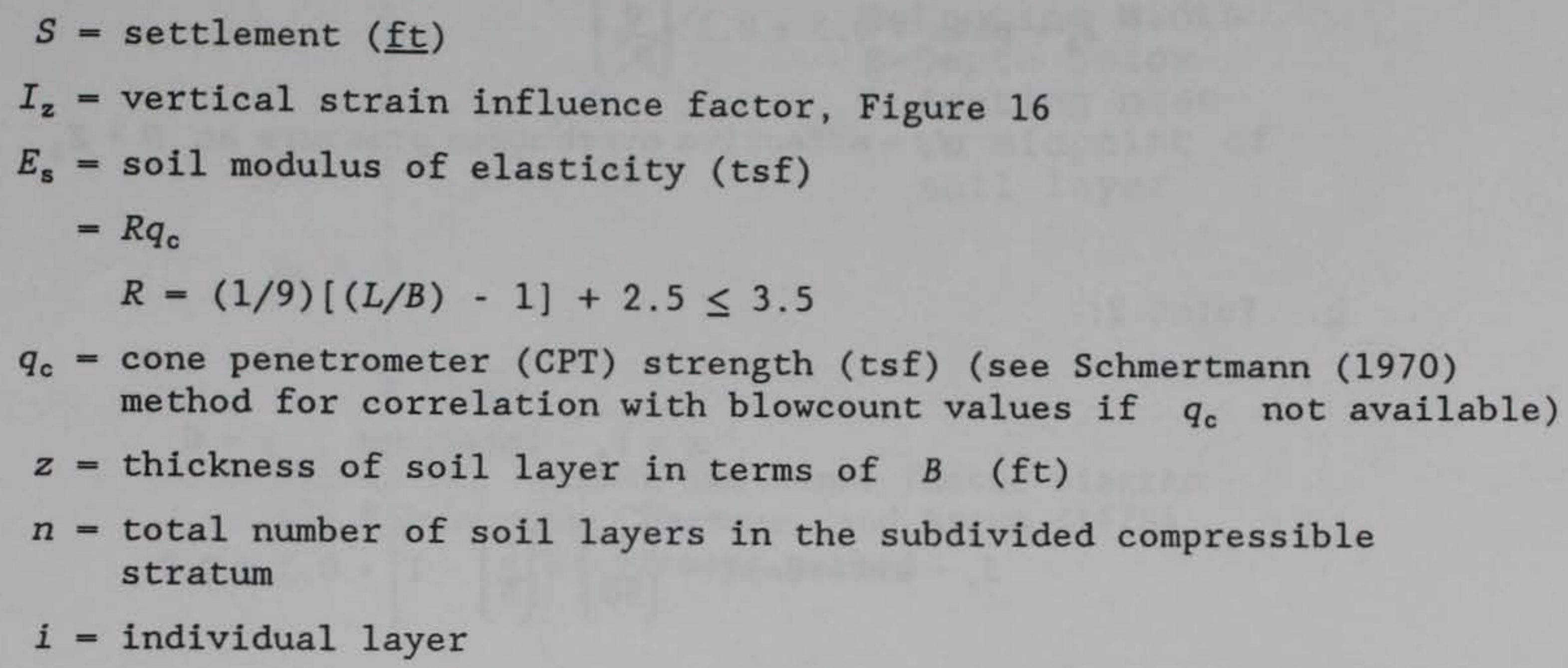

\section{Correction factors}

$$
\begin{aligned}
& \text { Depth: } C_{\mathrm{d}}=1.0-0.5\left(\frac{\gamma D}{q}\right) \geq 0.5 \\
& \text { Creep: } C_{\mathrm{t}}=1.0+0.2 \log \left(\frac{t}{0.1}\right), \quad t=\text { time (years) }
\end{aligned}
$$

\section{Procedure}

73. Three $(x, y)$ coordinate points are required to construct the straininfluence diagram. These are described in terms of $I_{z}$ and $Z / B$ coordinates for the $\mathrm{x}$ and $\mathrm{y}$ axes, respectively. Figure 16 shows the general form of this diagram. Note, $z$ = thickness of the sublayer, while $Z$ = depth from footing base to midpoint of the sublayer. 
a. Point 1:

$$
\begin{aligned}
x & =I_{z}-\text { peak }, \quad y=\frac{Z_{1}}{B} \\
\frac{Z_{1}}{B} & =\left(\frac{1}{18}\right)\left[\left(\frac{L}{B}\right)-1\right]+0.5 \leq 1.0 \\
I_{z}-\text { peak } & =0.5+0.1\left(\frac{q}{p^{\prime}}\right)^{1 / 2} \\
P^{\prime} & =\text { effective overburden pressure at } D+Z_{1}
\end{aligned}
$$

b. Point 2:

$$
\begin{array}{r}
x=I_{z}-\text { intercept }, \quad y=0 \\
I_{z}-\text { intercept }=\left(\frac{1}{90}\right)\left[\left(\frac{L}{B}\right)-1\right]+0.1 \leq 0.2
\end{array}
$$

c. Point 3:

$$
\begin{aligned}
& x=0, \quad y=\frac{Z_{2}}{B} \\
& \frac{Z_{2}}{B}=\left(\frac{2}{9}\right)\left[\left[\frac{L}{B}\right]-1\right]+2.0 \leq 4.0
\end{aligned}
$$

d. Draw the influence diagram through these three points as shown in Figure 16, then follow the procedure for the Schmertmann (1970) method, beginning with step 1 and using this vertical strain-influence diagram to obtain the $I_{z}$ values at layer midpoints, defined by $Z / B$.

e. If the elastic modulus is constant with depth (constant SPT or CPT), layers need not be formed. Simply sum the area under the influence diagram in terms of $B$, divide this by the modulus, and multiply by the load and correction factors:

$$
S=q C_{\mathrm{d}} C_{\mathrm{t}} \frac{(\text { sum }) B}{E_{\mathrm{s}}}
$$




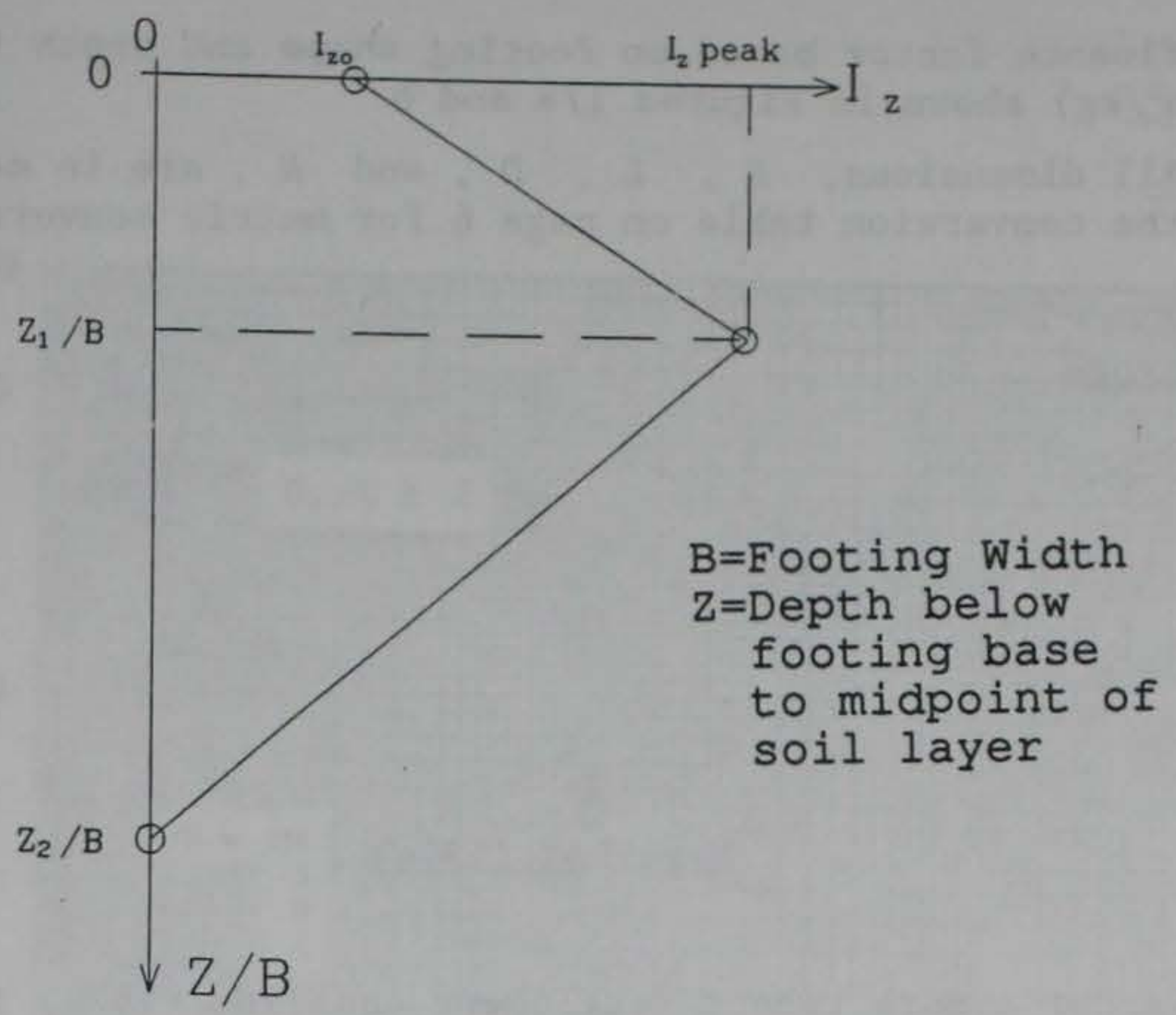

Figure 16. Strain influence factor diagram for Schmertmann, Hartman, and Brown (1978) settlement method

\section{$\underline{\text { Schultze and Sherif (1973) }}$}

74. Schultze and Sherif derived an empirical settlement calculation method from the results of a study of observed settlements from 48 sites. The reported accuracy of this method is \pm 40 percent. The exponent, 0.87 , on the blowcount value was determined from a statistical study of their results. The factor, $F_{c}$, accounts for footing shape and the depth of the compressible stratum.

\section{$\underline{\text { Settlement expression }}$}

$$
S=\frac{Q F_{\mathrm{c}}}{(N)^{0.87} C_{\mathrm{d}}}
$$

where

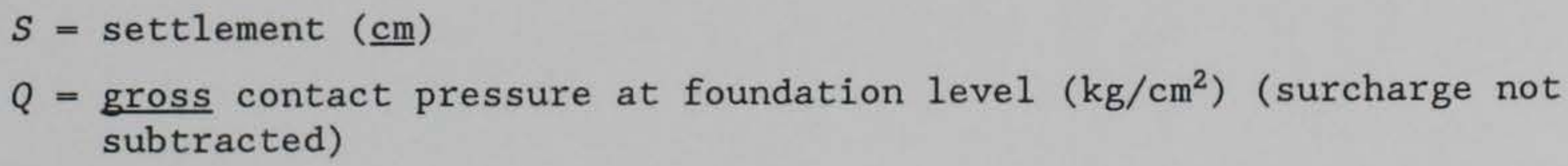
subtracted) 
$F_{c}=$ influence factor based on footing shape and depth to a rigid base $\left(\mathrm{cm}^{3} / \mathrm{kg}\right)$ shown in Figures $17 \mathrm{a}$ and $\mathrm{b}$

Note: All dimensions, $B, L, D$, and $H$, are in centimeters. See the conversion table on page 6 for metric conversion.

\section{Correction factors}

$$
\text { Depth: } C_{\mathrm{d}}=1+0.4\left(\frac{D}{B}\right) \leq 1.4
$$

\section{Meyerhof (1974)}

75. Meyerhof's more recent settlement equation (1974) is presented here. It is a modification of his earlier ones $(1956,1965)$, generally considered to be overconservative.

76. Meyerhof does not provide a correction factor for water, but claims that the presence of water is reflected in the field blowcount. That is, the blowcount is decreased in the presence of water and this causes the computed bearing capacity to be less than for dry soil. He does note that upon full submergence approximately 50 percent loss in bearing capacity occurs (or, twice the settlement) and that the engineer should consider this in the analysis.

77. In earlier reports, Meyerhof (1956, 1965) proposes using the Terzaghi and Peck (1948) correction to the field blowcount for submerged, compact, and dense, very fine, or silty sand. This correction is not included. with Meyerhof's (1974) method. A separate equation is provided for very fine or silty sands. 

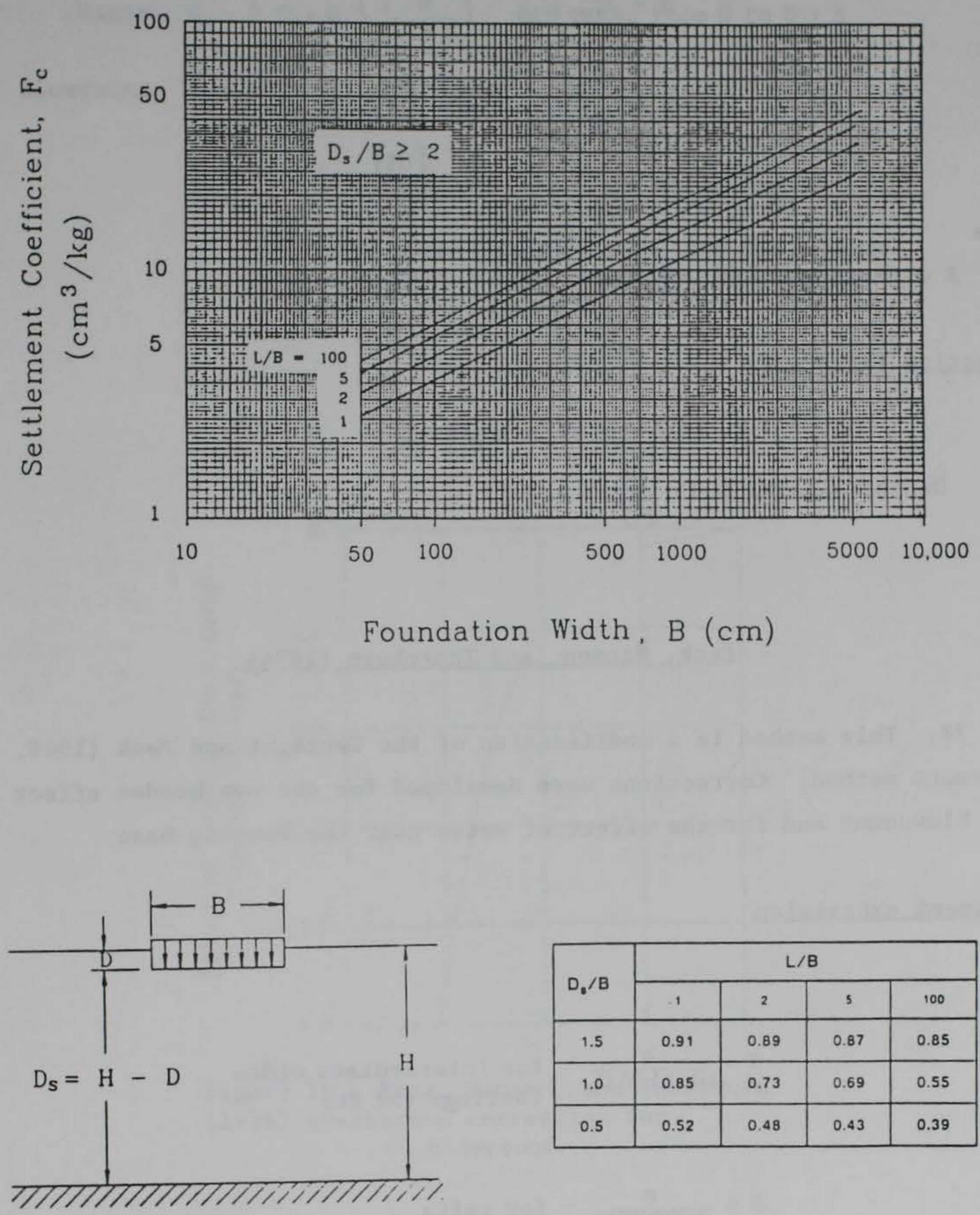

\begin{tabular}{|c|c|c|c|c|}
\hline \multirow{2}{*}{$D_{8} / B$} & \multicolumn{4}{|c|}{ L/B } \\
\cline { 2 - 5 } & 1 & 2 & 5 & 100 \\
\hline 1.5 & 0.91 & 0.89 & 0.87 & 0.85 \\
\hline 1.0 & 0.85 & 0.73 & 0.69 & 0.55 \\
\hline 0.5 & 0.52 & 0.48 & 0.43 & 0.39 \\
\hline
\end{tabular}

Figure 17. Factor $F_{c}$ for Schultze and Sherif (1973) settlement method 


$$
\begin{aligned}
& S=\frac{q \sqrt{B}}{2 N}\left(C_{\mathrm{d}}\right) \\
& S=\frac{q \sqrt{B}}{N}\left(C_{\mathrm{d}}\right), \text { for silty sand }
\end{aligned}
$$

where

$$
B=\text { footing width (in.) }
$$

\section{Correction factors}

$$
\text { Depth: } \quad C_{d}=1-0.25\left(\frac{D}{B}\right)
$$

$$
\text { Peck, Hanson, and Thornburn (1974) }
$$

78. This method is a modification of the Terzaghi and Peck $(1948,1967)$ settlement method. Corrections were developed for the overburden effect on field blowcount and for the effect of water near the footing base.

\section{Settlement expression}

$$
\begin{array}{ll}
S=\frac{q}{0.11 N_{c} C_{w}} & \begin{array}{l}
\text { for intermediate width } \\
\text { footings }(>2 \mathrm{ft})
\end{array} \\
S=\frac{q}{0.22 N_{\mathrm{c}} C_{\mathrm{w}}} & \text { for rafts }
\end{array}
$$




\section{Correction factors}

$$
\text { Water: } C_{\mathrm{w}}=0.5+0.5\left(\frac{W}{D+B}\right) \text { for water from } 0 \text { to } D+B
$$

Blowcount: $N_{\mathrm{c}}=N C_{\mathrm{n}}$

$$
\begin{aligned}
C_{\mathrm{n}}= & 0.77 \log \left(\frac{20}{p^{\prime}}\right) \\
p^{\prime}= & \text { effective overburden pressure for the measured } \\
& \text { blowcount at }(D+B / 2) \text { in tsf } \geq 0.25 \text { tsf. For } \\
& p^{\prime}<0.25, \text { use Figure } 18
\end{aligned}
$$

Correction Factor, $\mathrm{C}_{\mathrm{N}}$

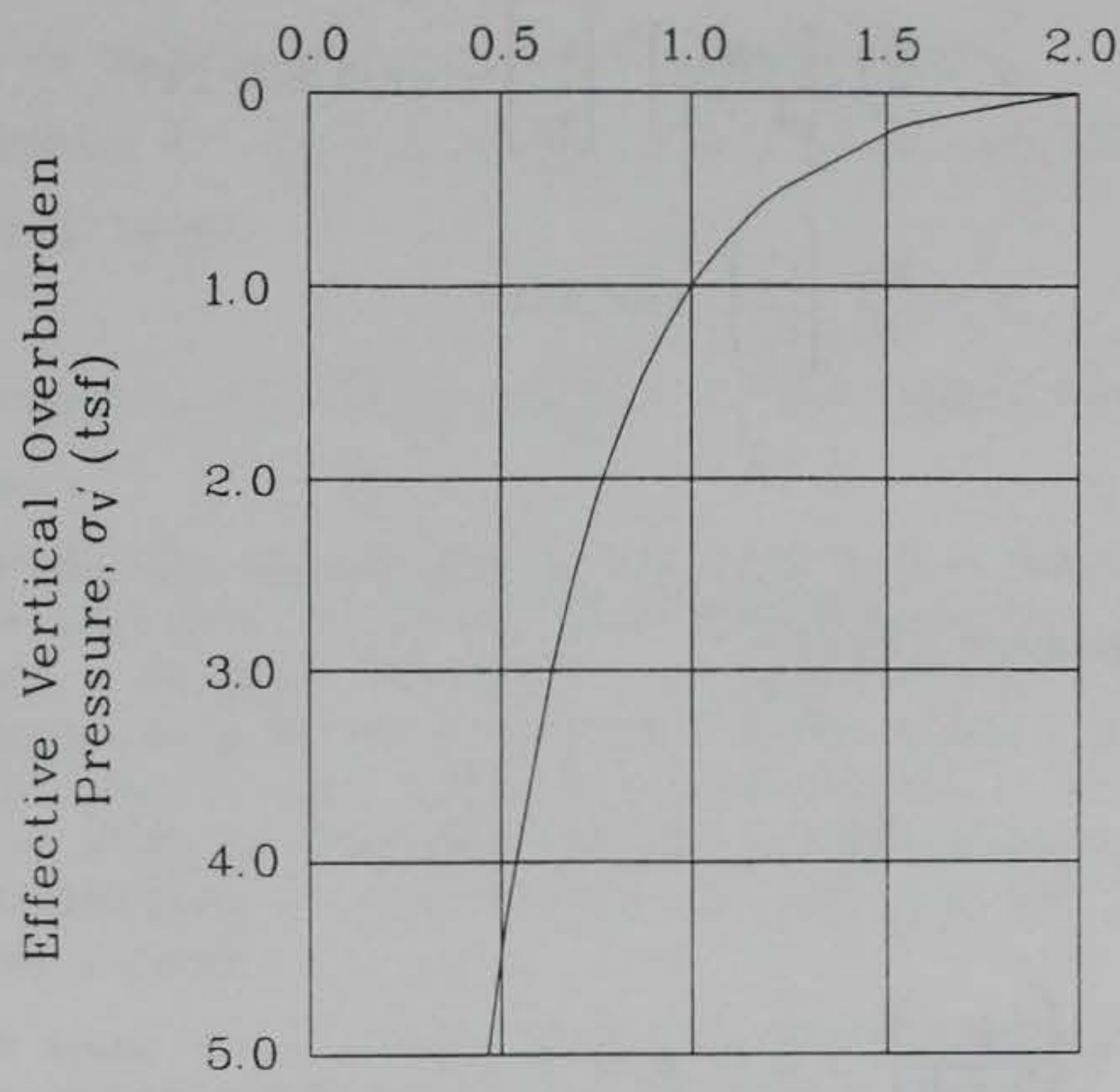

Figure 18. Peck, Hanson, and Thornburn (1974) overburden correction for blowcount

\section{Bowles (1977, 1982)}

79. Bowles' settlement method is based on the Terzaghi and Peck (1948, 1967) method, but is modified to produce results which are not as conservative. 
80. The water correction factor was interpreted from the text by the writer; the settlement doubles with water at the footing base, while the depth at which water has no influence is stated to be $[0.5 B \tan (45+\phi / 2)]$. This ranges from approximately $0.75 B$ to $1.0 B$ for typical values of $\phi$, the internal friction angle. To be conservative, this extent of water influence was taken to be $1 . O B$ below the footing base, and the correction factor was determined from this.

81. The blowcount is used directly as measured in the field.

\section{Settlement expression}

$$
\begin{aligned}
& S=\frac{2.5 q}{N}\left(\frac{C_{\mathrm{w}}}{C_{\mathrm{d}}}\right) \text { for } B \leq 4 \mathrm{ft} \\
& S=\frac{4 q}{N}\left(\frac{B}{B+1}\right)^{2}\left(\frac{C_{\mathrm{w}}}{C_{\mathrm{d}}}\right) \text { for } B \geq 4 \mathrm{ft} \\
& S=\frac{4 q}{N}\left(\frac{C_{\mathrm{w}}}{C_{\mathrm{d}}}\right) \text { for mats }
\end{aligned}
$$

where

$$
q=\text { applied pressure (ksf) }
$$

\section{$\underline{\text { Correction factors }}$}

$$
\begin{aligned}
& \text { Water: } C_{\mathrm{w}}=2-\left(\frac{W}{D+B}\right) \leq 2.0 \text { and } \geq 1.0 \\
& \text { Depth: } C_{\mathrm{d}}=1+0.33\left(\frac{D}{B}\right) \leq 1.33
\end{aligned}
$$

\section{Oweis (1979)}

82. This settlement prediction method called the "Equivalent Linear Model" involves computing settlement at the midheight of several sublayers of the stratum, then summing these to get the total settlement of the stratum. 
This technique is based on elastic theory and the emphasis is on the determination of the deformation (elastic) modulus, $E$, over the depth of the stratum. The procedure to calculate settlement is described in paragraph 83 . An example chart for keeping track of computations is shown as Table 11 .

\section{Settlement expression}

$$
S=q B \sum_{i=1}^{n} \frac{\Psi_{i}}{E_{i}}
$$

where

$S=\operatorname{set} t$ lement $(\mathrm{ft})$

$q=$ net applied pressure (ksf)

$\Psi=$ settlement factor

$E=$ modulus of elasticity at 0.001 strain (ksf)

$n=$ total number of layers in the subdivided compressible stratum

$i=$ individual layer

\section{Procedure}

83. A description of the procedure to calculate settlement is given in the following steps.

a. Divide the compressible stratum (to a depth of at least $D+2 B$ ) into layers. The layers need not be of equal thickness. It will be useful to define layers at locations of different soil properties, the water table, different blowcount or CPT values, and other distinct areas. If the stratum is uniform with no distinct property variations, the writer suggests subdividing a depth from $D$ to $D+2 B$ into at least four or five layers.

b. For each soil layer, correct the blowcount for the corresponding overburden using the Peck and Bazaraa (1969) correction in paragraph 67.

c. For each soil layer, calculate the effective vertical stress, $P^{\prime}$, from the ground surface to the midpoint of each layer if different from the corresponding midlayer overburden from step b. 
TABLE 11. Chart for Use With Oweis Settlement Computations

\section{For: (Center Edge Rigid) Settlement.}

\begin{tabular}{|c|c|c|c|c|c|c|c|c|c|c|c|c|c|c|c|c|c|c|c|}
\hline $\begin{array}{l}\text { Layer } \\
\text { No. }\end{array}$ & $\begin{array}{c}\text { Layer } \\
\text { Thickness } \\
h_{1}\end{array}$ & $\begin{array}{c}\text { blows } \\
\text { per foot, } \\
\text { N }\end{array}$ & $\begin{array}{c}\text { corrected } \\
\text { blowcount } \\
N_{c}\end{array}$ & $\begin{array}{l}\text { midlayer } \\
\sigma_{v} \\
\text { (psf) }\end{array}$ & $\begin{array}{l}\text { mean Init. } \\
\text { stress, } \sigma_{m} \\
\text { (psf) }\end{array}$ & $\frac{z \text {-midlayer }}{0.5 B}$ & $\begin{array}{l}\text { alpha } \\
\text { factor }\end{array}$ & $\underset{\text { (pst) }}{\Delta \sigma_{m}}$ & $\kappa_{\infty}$ & $\underset{\text { (kst) }}{E_{\text {sin }}}$ & $\frac{2-10 p}{0.5 B}$ & $\frac{z \text {-bottom }}{0.58}$ & $\begin{array}{c}\text { (top) } \\
F_{p-1-1}\end{array}$ & $\begin{array}{c}\text { (bottom) } \\
F_{1}\end{array}$ & $\psi_{1}$ & $\begin{array}{r}\lambda_{1} \\
(\mathbf{x})\end{array}$ & $\frac{E}{E_{-\infty}}$ & $\underset{\text { (kst) }}{E_{1}}$ & $\begin{array}{c}\delta_{1} \\
\text { (feet) }\end{array}$ \\
\hline 1 & & & & & & & & & & & & & & & & & & & \\
\hline 2 & & & & & & & & & & & & & & & & & & & \\
\hline 3 & & & & & & & & & & & & & & & & & & & \\
\hline 4 & & & & & & & & & & & & & & & & & & & \\
\hline 5 & & & & & & & & & & & & & & & & & & & \\
\hline 6 & & & & & & & & & & & & & & & & & & & \\
\hline & & & & & & & & & & & & & & & & & & & \\
\hline & & & & & & & & & & & & & & & & & & & \\
\hline & & & & & & & & & & & & & & & & & & & \\
\hline
\end{tabular}


d. Compute the mean effective normal stress of each layer:

$$
\sigma_{\mathrm{mo}}=\frac{1+2 K_{\mathrm{o}}}{3} p^{\prime}
$$

where

$$
\begin{aligned}
\sigma_{\mathrm{mo}} & =\text { mean effective normal stress (psf) } \\
K_{\mathrm{o}} & =\text { coefficient of horizontal earth pressure, at rest } \\
p^{\prime} & =\text { effective overburden pressure from step c (psf) }
\end{aligned}
$$

e. Calculate the change in the mean effective normal stress, $\Delta \sigma_{\mathrm{m}}$, at the midpoint of each layer, due to the applied load:

$$
\Delta \sigma_{\mathrm{m}}=\alpha q(p s f)
$$

where

$$
\begin{aligned}
\alpha= & \text { factor from curves of Figure } 19(Z=\text { depth to midpoint } \\
& \text { of layer, from footing base }) . \\
q= & \text { net applied pressure (psf) }
\end{aligned}
$$

Ratio of Stress Change to Applied Load, $\alpha$ $\left(\alpha=\Delta \sigma_{\mathrm{m}} / \mathrm{q}\right)$ for Flexible Circular Footing

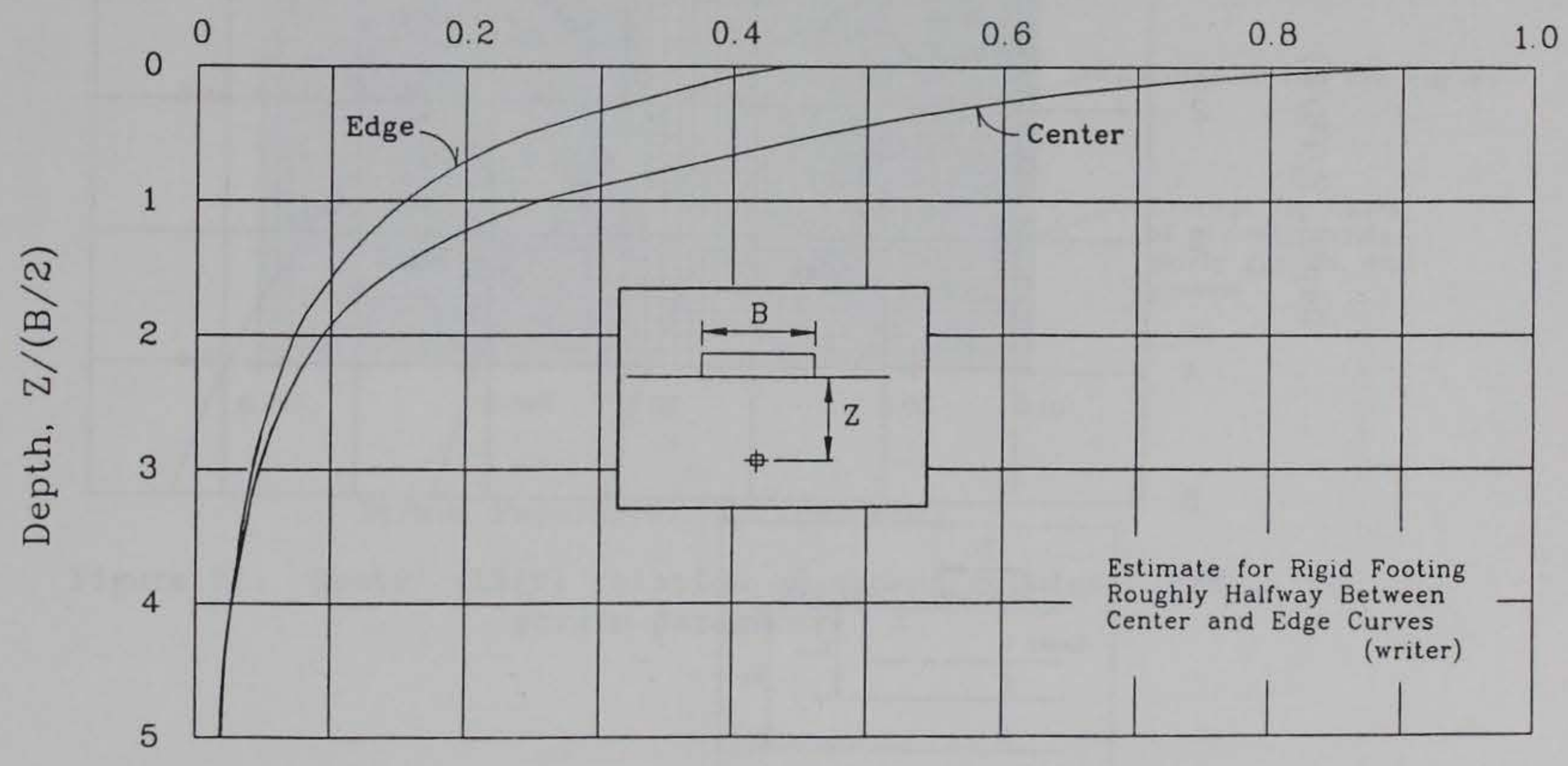

Figure 19. Oweis' (1979) coefficient for stress increase in soil under loaded footing 
f. Calculate the factor, $K_{\max }$, for each soil layer.

$$
K_{\max }=17.2\left(N_{c}\right)^{(0.42)}
$$

g. For each layer, calculate the maximum elastic modulus.

$$
E_{\max }=K_{\max } \sqrt{\left(\sigma_{\operatorname{mo}}+\Delta \sigma_{\mathrm{m}}\right)}
$$

$E_{\max }$ units are in kips per square foot, $\sigma_{\mathrm{mo}}$ and $\Delta \sigma_{\mathrm{m}}$ are in pounds per square foot.

h. Obtain settlement factors, $F$, for the top and bottom of each soil layer using Figure 20. $\left(F_{1-1}=\right.$ top, $F_{1}=$ bottom, $Z_{i-1}=$ depth to top of layer, $Z_{i}=$ depth to bottom of layer, measured from footing base).

Settlement Factor, F

(for Circular Footings)

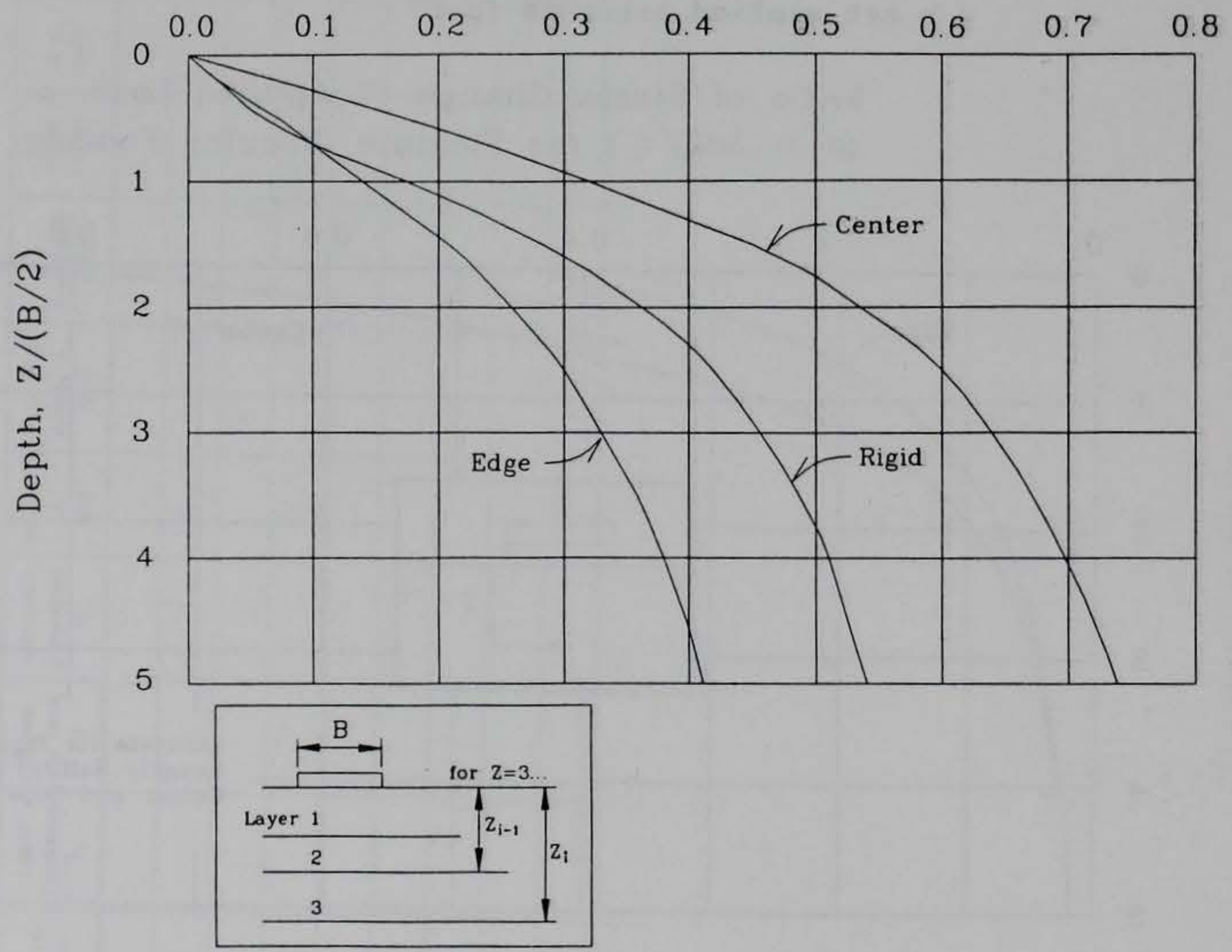

Figure 20. Oweis' (1979) settlement factor, F 
i. Compute $\Psi_{i}$ and $\lambda_{i}$ for each layer:

$$
\begin{aligned}
& \Psi_{1}=\left(F_{1}\right)-\left(F_{1-1}\right) \\
& \lambda_{1}=\frac{\Psi_{i} q B}{z E_{\max }}
\end{aligned}
$$

where,

$$
\begin{aligned}
z & =\text { layer thickness }(\mathrm{ft}) \\
q & =\text { net load }(\mathrm{ksf}) \\
E_{\max } & =\text { maximum modulus }(\mathrm{ksf}) \\
\lambda_{i} & =\text { strain parameter }
\end{aligned}
$$

i. Use Figure 21 with $\lambda_{i}$ to determine the ratio $\left(E / E_{\max }\right)_{i}$ for each soil layer.

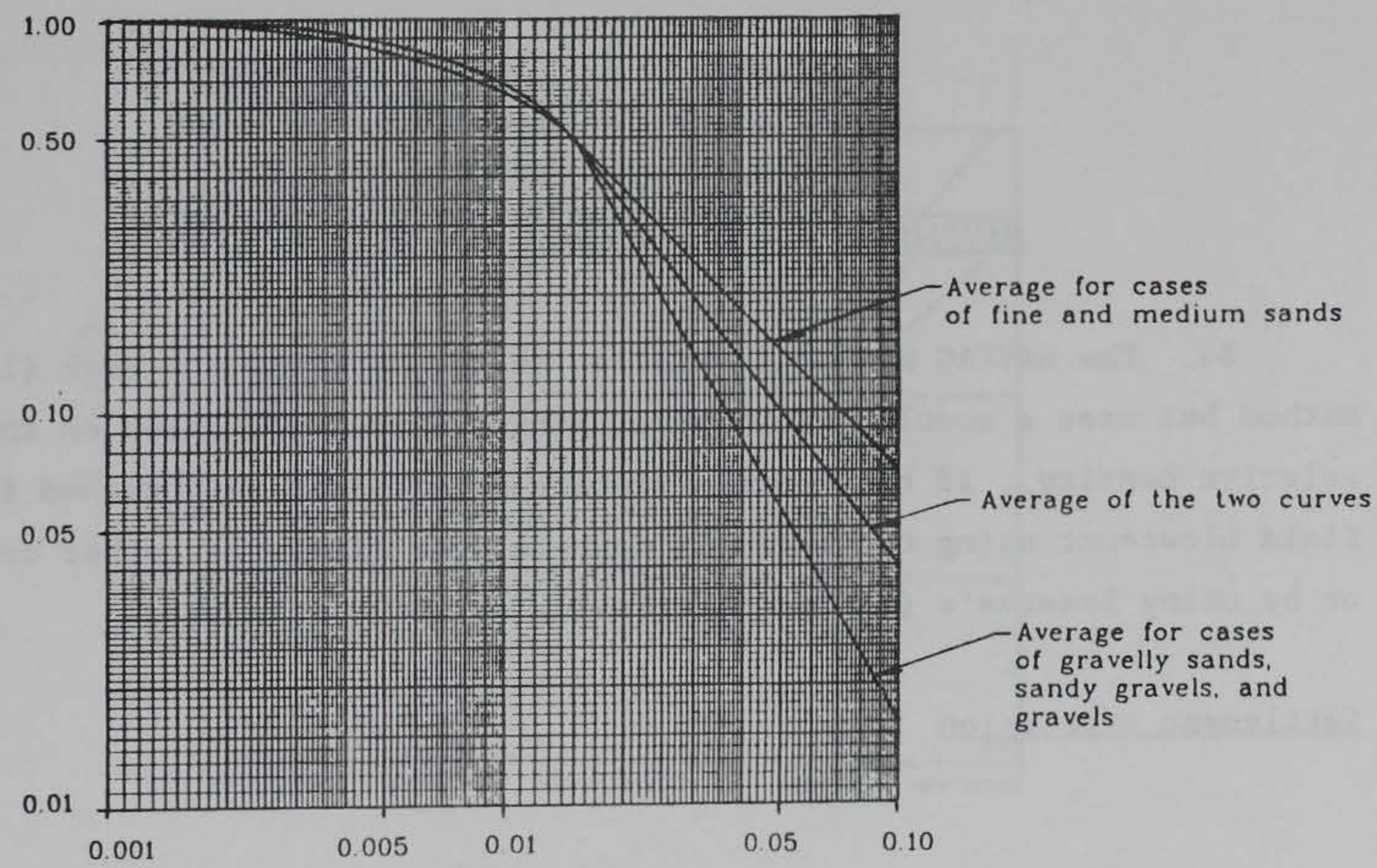

Strain Parameter, $\lambda$ (percent)

Figure 21. Oweis' (1979) relation of secant modulus, $E / E_{\max }$ to strain parameter, $\lambda$ 
k. Calculate the elastic modulus, $E_{1}$, for each soil layer:

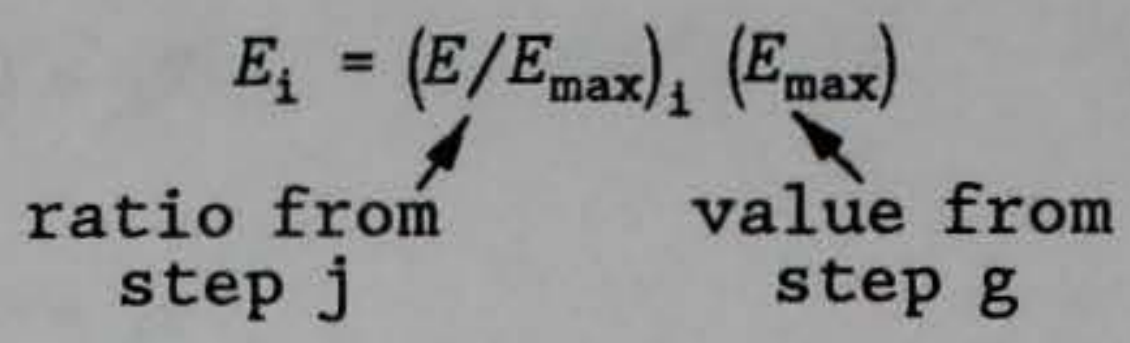

1. For each soil layer, calculate settlement:

$$
s_{i}=\left(\frac{q B}{E_{i}}\right) \Psi_{i}
$$

m. Compute the total settlement of the stratum,

$$
S=\sum_{i=1}^{\mathrm{n}} s_{\mathrm{i}}
$$

NAVFAC DM 7.1 (Department of the Navy (1982))

84. The NAVFAC method is similar to the Terzaghi and Peck $(1948,1967)$ method but uses a modulus of vertical subgrade reaction based on the soil's relative density. If not known, relative density can be obtained from the field blowcount using the Terzaghi correlations (Table 1), other correlations, or by using Bazaraa's (1967) equations.

\section{Settlement expression}

$$
S=\frac{C q}{K_{\mathrm{v}}}\left(\frac{B}{B+1}\right)^{2} C_{\mathrm{w}}
$$

where

$$
\begin{aligned}
S & =\text { settlement }(\mathrm{ft}) \\
K_{\mathrm{v}} & =\text { modulus of vertical subgrade reaction }(\mathrm{tcf}), \text { Figure } 22 \\
C & =\text { coefficient based on footing width } \\
& =4.0+(20-B) / 10, \text { for } 20 \mathrm{ft} \leq B \leq 40 \mathrm{ft}
\end{aligned}
$$


$=4.0$ for $B<20 \mathrm{ft}$

$=2.0$ for $B>40 \mathrm{ft}$

\section{Correction factors}

Water: $\quad C_{\mathrm{w}}=2.0-\left(\frac{W-D}{1.5 B}\right) \leq 2.0, \begin{aligned} & \text { for water to a depth of } \\ & 1.5 B \text { below the footing }\end{aligned}$

Shape: For a strip footing, double the calculated settlement. Strip footing is not quantified in this method. The writer suggests considering footings where $L / B \geq 10$ to be strip footings.

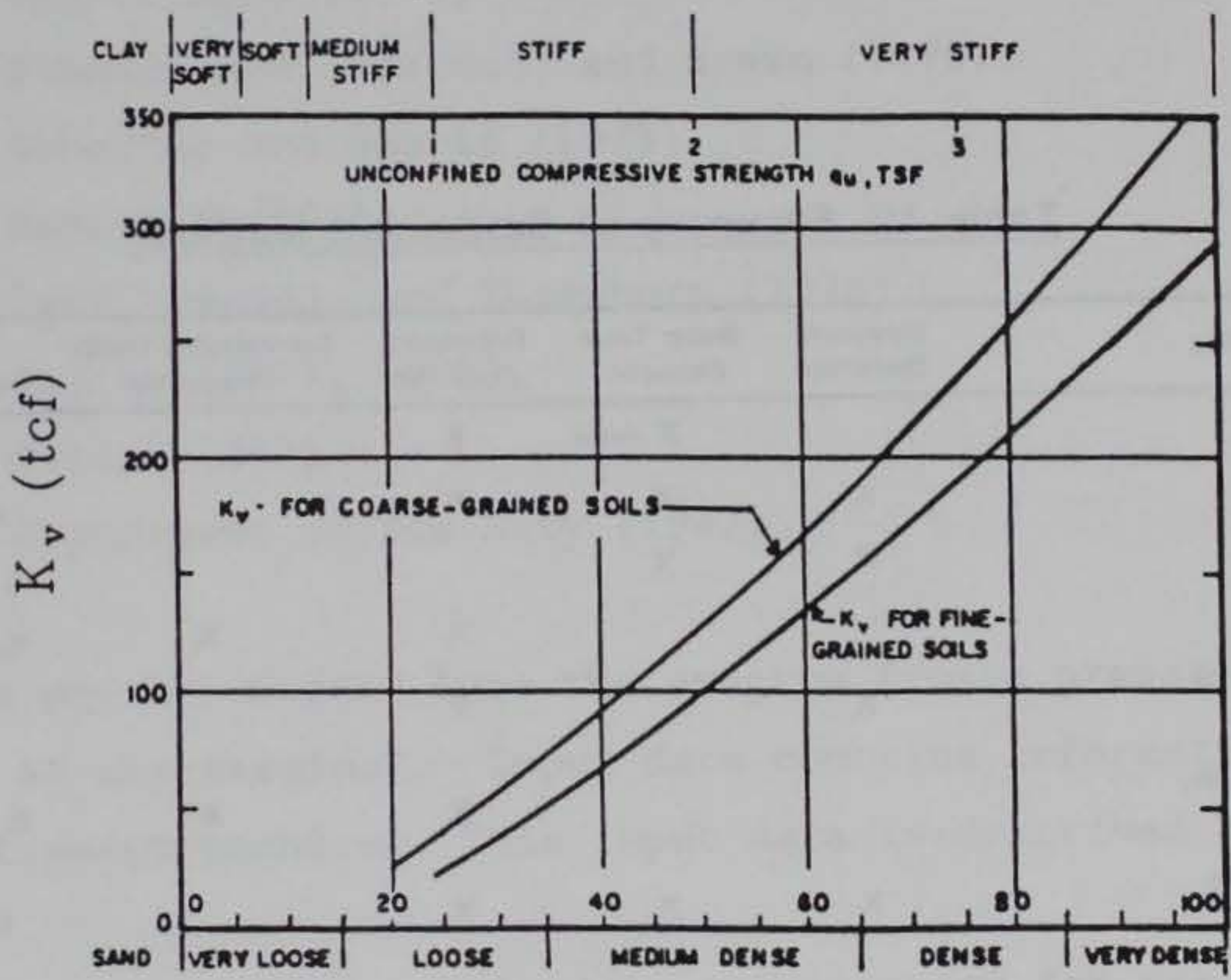

Relative Density $\mathrm{D}_{\mathrm{r}}$,

Figure 22. Vertical subgrade reaction modulus, $K_{\mathrm{v}}$, for the NAVFAC DM 7.1 (Department of the Navy (1982)) settlement method 


$$
\begin{aligned}
& D_{r}=\left[\frac{N}{20\left(1+2 p^{\prime}\right)}\right]^{1 / 2} \text { for } p^{\prime} \leq 1.5 \mathrm{ksf} \\
& D_{r}=\left[\frac{N}{20\left(3.25+0.5 p^{\prime}\right)}\right]^{1 / 2} \text { for } p^{\prime}>1.5 \mathrm{ksf}
\end{aligned}
$$

where

$D_{\mathrm{r}}=$ relative density (decimal number)

$p^{\prime}=$ effective overburden pressure corresponding to the blowcount (at approximately $\mathrm{D}+\mathrm{B} / 2$

85. Table 12 summarizes the settlement-predicting methods presented in

Part III in terms of variables and correction factors.

\begin{tabular}{|c|c|c|c|c|c|}
\hline Method & $\begin{array}{l}\text { Blowcount } \\
\text { Correction }\end{array}$ & $\begin{array}{l}\text { Water Table } \\
\text { Correction }\end{array}$ & $\begin{array}{l}\text { Embedment } \\
\text { Correction }\end{array}$ & $\begin{array}{l}\text { Compressible Depth } \\
\text { Considered }\end{array}$ & $\begin{array}{l}\text { Variables Required } \\
\text { (see Tab. } 6 \text { for definition) }\end{array}$ \\
\hline Terzaghi (1967) & & $\mathbf{X}$ (limited) & $x$ & & q, B, N, D, W \\
\hline Teng (1962) & $x$ & $x$ & $x$ & & q, B, N, D, W, $\gamma$ \\
\hline Alpan (1964) & $\mathrm{x}$ & 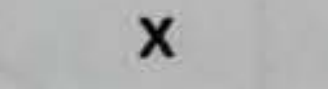 & & & q, B, L, N, D, W, $\gamma$ \\
\hline Elastic Theory & & & $x$ & $x$ & $\mathbf{q}, \mathbf{B}, \mathbf{L}, \mathbf{D}, \nu, \mathbf{E}, \mathbf{H}$ \\
\hline $\begin{array}{l}\text { D'Appolonia, D'Appolonia, } \\
\text { and Brissette (1968) }\end{array}$ & $x$ & & $x$ & & q, B, N, D, $\gamma$ \\
\hline $\begin{array}{l}\text { D'Appolonia, D'Appolonia, } \\
\text { and Brissette }(1970)\end{array}$ & & & $x$ & $x$ & q, B, N, D, L, E, H \\
\hline $\begin{array}{l}\text { Peck and Bazaraa } \\
\text { (1969) }\end{array}$ & $\mathrm{x}$ & $x$ & $x$ & & q, B, N, D, W, $\gamma$ \\
\hline $\begin{array}{l}\text { Schmertmann (1970) } \\
\text { Schmertmann, Hartman, and Brown (1978) }\end{array}$ & & & $\mathrm{x}$ & & $\mathbf{q}, \mathbf{B}, \mathbf{L}, \mathbf{q}_{\mathrm{c}}$ or $\mathbf{N}, \gamma$ \\
\hline $\begin{array}{l}\text { Schultze and } \\
\text { Sherif (1973) }\end{array}$ & & & $x$ & $\mathrm{x}$ & $\mathrm{q}, \mathrm{B}, \mathrm{L}, \mathrm{N}, \mathrm{D}, \mathrm{H}$ \\
\hline Meyerhof (1974) & & & $x$ & & q, B, N, D \\
\hline $\begin{array}{l}\text { Peck, Hanson, \& } \\
\text { Thornburn (1974) }\end{array}$ & $\mathrm{x}$ & $x$ & & & $\mathrm{q}, \mathrm{B}, \mathrm{N}, \mathrm{D}, \mathrm{W}, \gamma$ \\
\hline Bowles (1977/1982) & & $\mathrm{x}$ & $x$ & & $\mathrm{q}, \mathrm{B}, \mathrm{N}, \mathrm{D}, \mathrm{W}$ \\
\hline Oweis (1979) & $\mathrm{x}$ & & & & $\mathrm{q}, \mathrm{B}, \mathrm{N}, \mathrm{D}, \gamma, \mathrm{K}_{\mathrm{o}}$ \\
\hline $\begin{array}{l}\text { NAVFAC DM } 7.1 \\
\text { (Dept. of the Navy 1982) }\end{array}$ & & $x$ & & & q, B, L, N, D, W \\
\hline
\end{tabular}

\section{Table 12. Summary of Settlement Methods}




\section{PART IV: DESCRIPTION AND USER'S GUIDE FOR CSANDSET COMPUTER PROGRAM}

\section{Overview of Program}

86. CSANDSET is a computer program that computes the settlement of shallow foundations on sand from 15 different settlement methods. The methods listed are described in Part III.
a. Terzaghi and Peck (1948, 1967).
b. Teng (1962).
c. Alpan (1964).
d. Elastic Theory.
e. D'Appolonia, D'Appolonia, and Brissette (1968).
f. D'Appolonia, D'Appolonia, and Brissette (1970).
g. Peck and Bazaraa (1969).
h. Schmertmann (1970).
i. Schmertmann, Hartman, and Brown (1978).
i. Schultze and Sherif (1973).
k. Meyerhof (1974).
1. Peck, Hanson, and Thornburn (1974).
m. Bowles (1977, 1982).
n. Oweis (1979).
o. Department of the Navy (1982).

\section{Program input}

87. Data may be entered into the program from a prepared data file or interactively, at the terminal. Input data contains information about an individual settlement problem. This input data is described by three categories :

a. Required data. This data is necessary for program execution. It consists of information describing the foundation, the applied load, and the soil profile and properties.

b. Optional data. Optional data items are additional soil data which may be entered to enhance or give better accuracy to the computations in some of the settlement methods. Some, all, or none of the optional data may be entered for a given problem. For optional data not entered, the program computes default values. These are discussed in the user's guide for data file input, paragraph $118 \underline{d}$.

c. Soil layer data. Soil layer data are also optional data describing the soil properties of a layered system. It is 
beneficial to enter soil layers to model the compressible stratum when there are differences in the blowcount, unit weight, modulus, or other properties in the soil profile. Soil layers are needed in the settlement method of Oweis (1979) and can be used but are not required in the methods by Schmertmann (1970) and Schmertmann, Hartman, and Brown (1978). If layers are not entered by the user, the program automatically breaks the stratum into layers for use in the Oweis method. This is explained in paragraph 97.

\section{Program output}

88. Program output information consists of:

a. A listing of the input data

b. A listing of the intermediate calculations from each method, such as correction factors, values used from charts, etc.

c. A listing of the computed settlement from each of the 15 methods.

89. The input data 1 isting and settlement calculations are viewed at the terminal, and may be printed by pressing the Shift and Print Screen keys at the same time. Input data may be saved to a data file. The intermediate calculations are directed to a data file only, and may be printed after exiting the program.

\section{Comments on Settlement Methods in CSANDSET}

90. This section explains how some of the settlement methods are used in CSANDSET. Aspects of the programming such as assumptions and limitations, are discussed. The exact equations shown in Part III are used to calculate settlement for each method. For those methods in which curves or graphs are used to determine certain variables, an equation was derived to represent the curves. This was done by entering points from the curves into the Corps programs "Curvefit" (M0001) and "Multi-Graph." These programs use curve-fitting techniques to determine equations for a set of coordinate data points. All of the equations derived for the curves have correlation coefficients greater than 97.5 percent, with most being greater than 99 percent.

\section{Alpan (1964)}

91. Difficulties were encountered in obtaining and developing equations which accurately represent the Gibbs and Holtz (1957) curves (Figure 1 and Coffman (1960) version Figure 9a). Therefore, instead of internally calculating this corrected blowcount value in CSANDSET, the user must enter it in the optional data input section. The method for determining the Gibbs and 
Holtz corrected blowcount is described in the Alpan (1964) section of Part III, paragraph 58. If no corrected blowcount value is entered, the Alpan settlement is not computed. Equations for the other variables, alpha and $\mathrm{m} / \mathrm{n}$, were developed from the curves shown, Figures 10 and 11 , using curvefitting techniques.

D'Appolonia,

D'Appolonia, and Brissette (1968)

92. As with the Alpan method, this settlement is only calculated if the user enters the corrected blowcount from the Gibbs and Holtz (1957) chart.

D'Appolonia,

D'Appolonia, and Brissette (1970)

93. The D'Appolonia method uses a modulus of compressibility in the settlement equation. This modulus is related to the blowcount for both normally loaded and preloaded soils, Figure 14. The program will calculate the preloaded soil modulus if indicated in the optional input by the user, otherwise, the normally loaded soil modulus is computed. Equations for the Janbu, Bjerrum, and Kjaernsli (1956) curves, Figure 13, for the influence factor were developed using curve-fitting techniques with linear interpolation between curves.

Schmertmann (1970)

Schmertmann, Hartmam, and Brown (1978)

94. In both of the Schmertmann methods, the stratum is defined by soil layers based on changes in the CPT or SPT profile. The CPT or SPT profile is used to determine the soil modulus profile. However, if no soil layers are entered by the user, the modulus is assumed constant over the depth of the compressible zone, and the program simply computes the area under the $I_{z}--Z / B$ curve for both methods. If no modulus is entered, one is computed from CPT or SPT values according to the equations for the modulus given with the Schmertmann methods.

Schultze and Sherif (1973)

95. The value, $Q$, in the settlement equation of Schultze and Sherif, is defined as the full mean contact pressure, without reduction of the surcharge pressure, $\gamma D$. Therefore, in CSANDSET, the surcharge is added to the applied net pressure, $q$, entered by the user, and this sum is the value $Q$.

96. Equations for the settlement factor curves, $F_{c}$, of Figure 17a were developed by curve-fitting methods, with linear interpolation for values 
between the curves shown. The same was done for the $(H / B)$ reduction factor, Figure 17b, using the values shown in the chart.

Owe is (1979)

97. In CSANDSET, the user has the option of entering the soil layers or allowing the program to subdivide the stratum itself. If the user does not enter soil layers, CSANDSET breaks the stratum of thickness $H$ into substrata of thicknesses $0.25 B$, plus any remainder, from the base of the footing to depth $H$. A break is also defined at the water table if it is within this range. The properties assigned to each layer, unit weight, blowcount, etc., are the same as those input for the one soil stratum. The only difference will be the effective overburden pressure calculated at the midheight of each layer.

98. The Oweis (1979) settlement factor, $F_{i}$, is shown in graphical form in Figure 20 for the center of a flexible footing, the edge of a flexible footing, and for a rigid footing. The load factor alpha, of Figure 19, is only provided for the center and edge of flexible footings, and not for rigid footings. Therefore, a curve was interpolated for a rigid footing approximately midway between the two flexible footing curves.

99. For the value of $E / E_{\max }$, instead of using either the fine sand curve or the coarse sand curve, an average of the two curves was interpolated for use in CSANDSET. This plots half-way between the two lines as shown in Figure 21.

NAVFAC DM 7.1

(Department of the Navy (1982))

100. An equation was developed to represent the $K_{\mathrm{v}}$ versus $D_{\mathrm{r}}$ curve for coarse-grained soils of the NAVFAC method, Figure 22, using curve-fitting techniques. The user may enter a relative density value, $D_{\mathrm{r}}$, in the optional data. If not entered, $D_{r}$ is computed from the blowcount using the Bazaraa (1967) relations shown in paragraph 84.

General rules

101. Note, if layers are entered, they are only used in the Oweis and Schmertmann methods. Therefore, the soil properties entered under the soil data section are used in all the other settlement methods and must be representative of any soil layer differences immediately under the footing to a depth of approximately $2 \mathrm{~B}$ below the footing. That is, values like unit weights and blowcounts must be averaged for use in all the other settlement methods. 


\section{General comments}

102. Some general comments which apply to the use of the CSANDSET computer program are listed.

a. Each window or menu in the program has an information line at the bottom of the screen. This contains information about your selection, input values, units, cursor movement, etc.

b. During execution of the program, the escape key, $\langle E S C\rangle$, can be used to exit the current screen. The previous screen or the main menu will then appear. Escape from the main menu exits the program.

c. Use the arrow keys to move the cursor/highlight bar to various parts of the screen or menu. Press the enter key to enter a value or make a selection.

d. A complete description of the input data, its limitations, ranges, and the assumptions and defaults, is covered in the user's guide for data file preparation, paragraphs 113 through 118 .

e. At any time during the program, the current screen or menu may be printed by pressing the Shift and Print Screen keys at the same time.

\section{Starting the program}

103. If you have a hard disk system you may wish to copy the program and example files to a directory on your hard disk and run it from there. The program may also be run from a floppy disk drive. In either case, start the program by changing to the directory on which the program is located and type the program number, I0030, or type the full pathname to the directory where the program is located, ending with $\backslash 10030$.

104. The opening screen of CSANDSET is displayed in Figure 23. Press the escape key, $\langle E S C\rangle$, to continue.

Main menu

105. The main menu is shown in Figure 24. From the main menu, one can choose to:

a. Enter data from a prepared data file.

b. Enter data at the terminal, by typing at the keyboard.

c. View the current input data on one screen.

d. Calculate settlement from selected methods.

e. Save current data to a data file. 


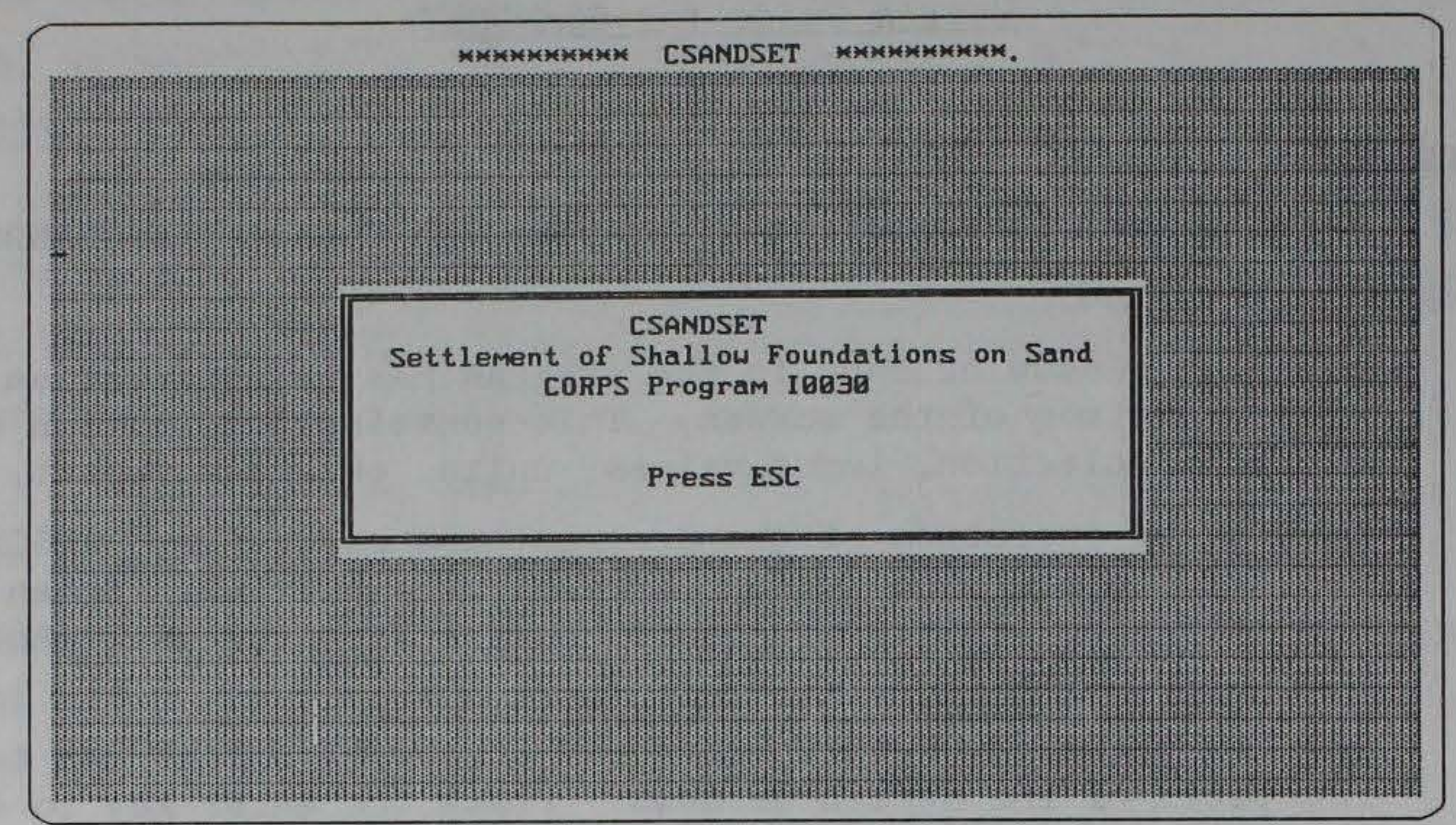

Figure 23. Opening screen of the CSANDSET program

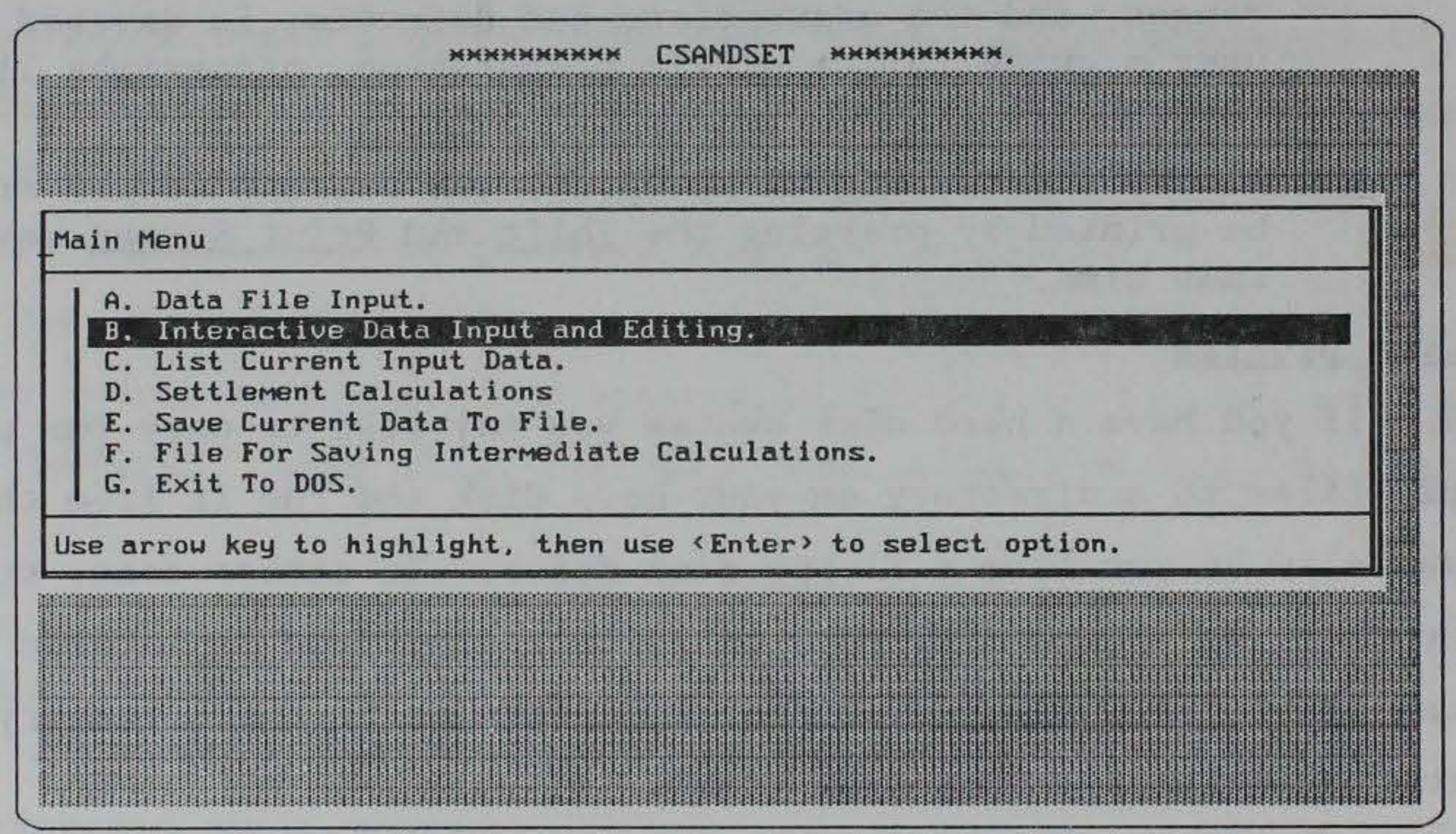

Figure 24. Main menu of CSANDSET

f. Save intermediate program calculations from each method to a file for printing.

g. Exit the program.

Each of these options and their submenus are discussed in the following text.

106. Data file entry. Figure 25 shows the window where the input data file name is entered. The file name can be as long as the spaces provided in the window. Preparation of a data file is explained in paragraphs 113 through 118 .

107. Keyboard data input. In the main menu, Figure 24, the choice to 


\begin{tabular}{|c|}
\hline |File $=$ \\
\hline Enter File Name \\
\hline
\end{tabular}

Figure 25. Window to enter input data file name

enter data interactively is shown highlighted. If this is selected, Figure 26 shows the menu which next appears. The first two choices, A and B as shown on this menu, the required data, must be entered before any optional data or soil layers are entered.

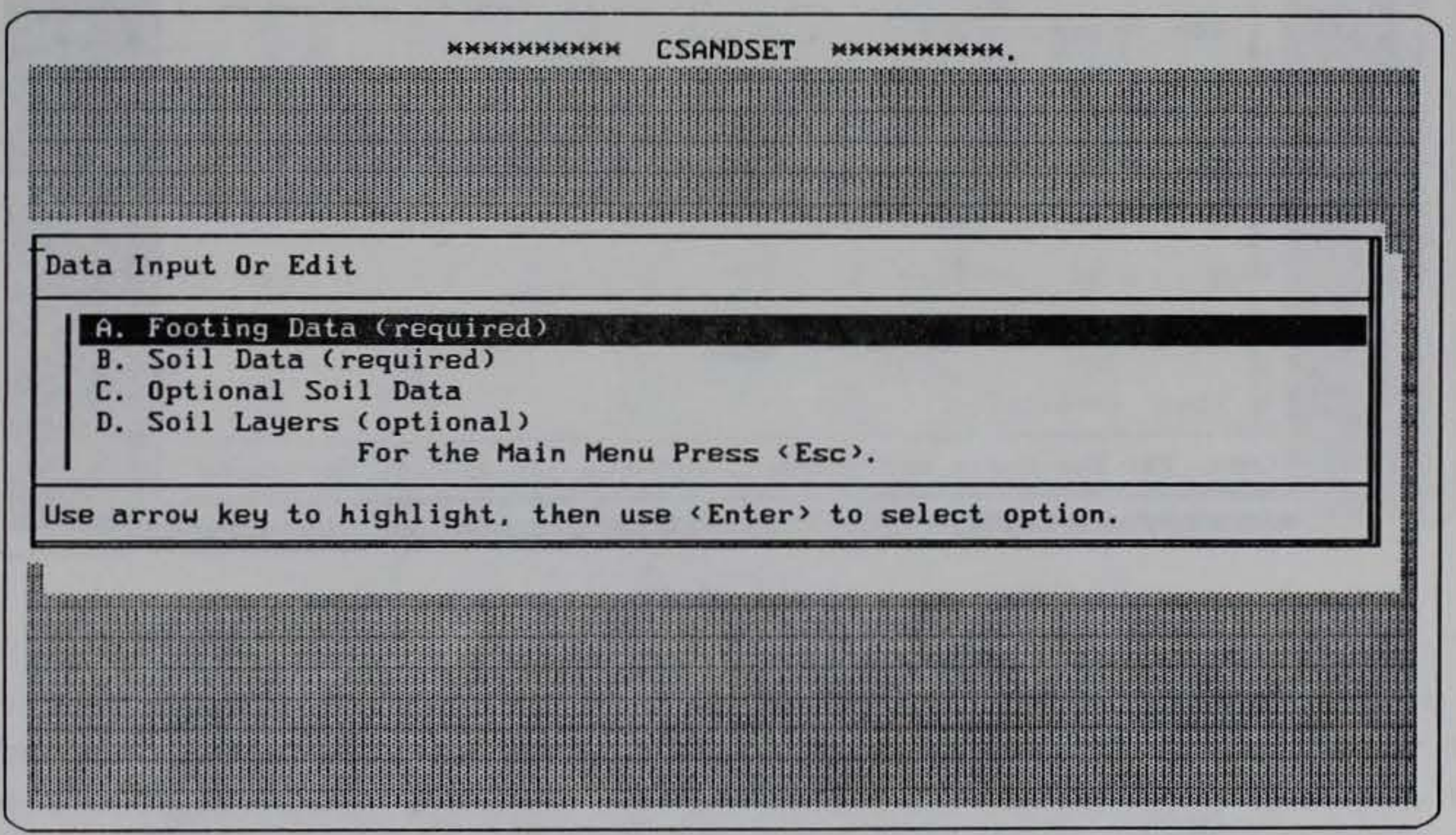

Figure 26. Data Input and Edit menu

a. Footing data. Figure 27 shows the screen for footing data entry. The information line on the bottom of the screen explains about each data item.

b. Soil data. The soil data input screen is shown in Figure 28 . If soil layers will be entered, indicate the number of layers on this screen. Again, information about each data item is listed on the bottom of the screen. 


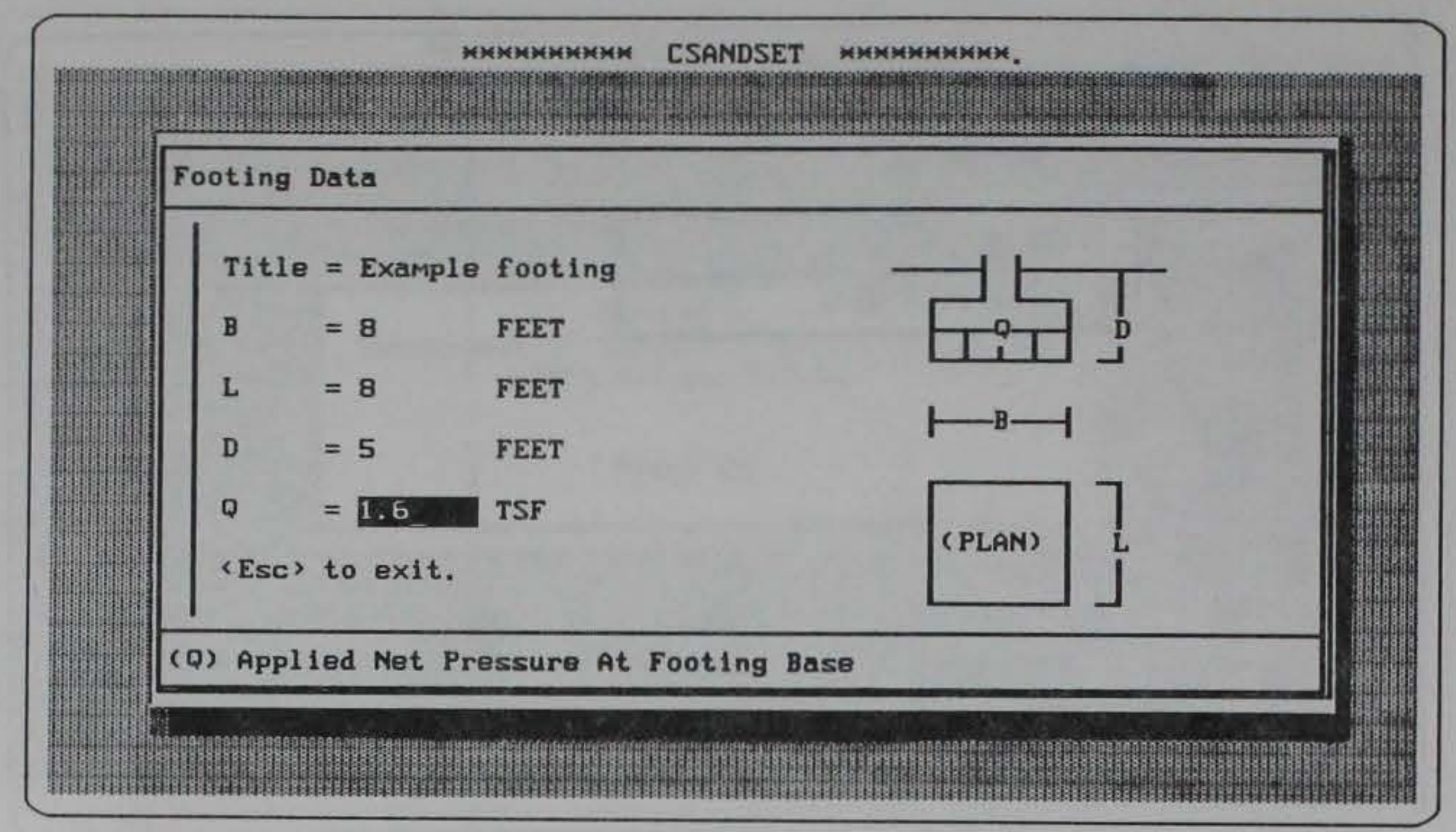

Figure 27. Footing data input screen

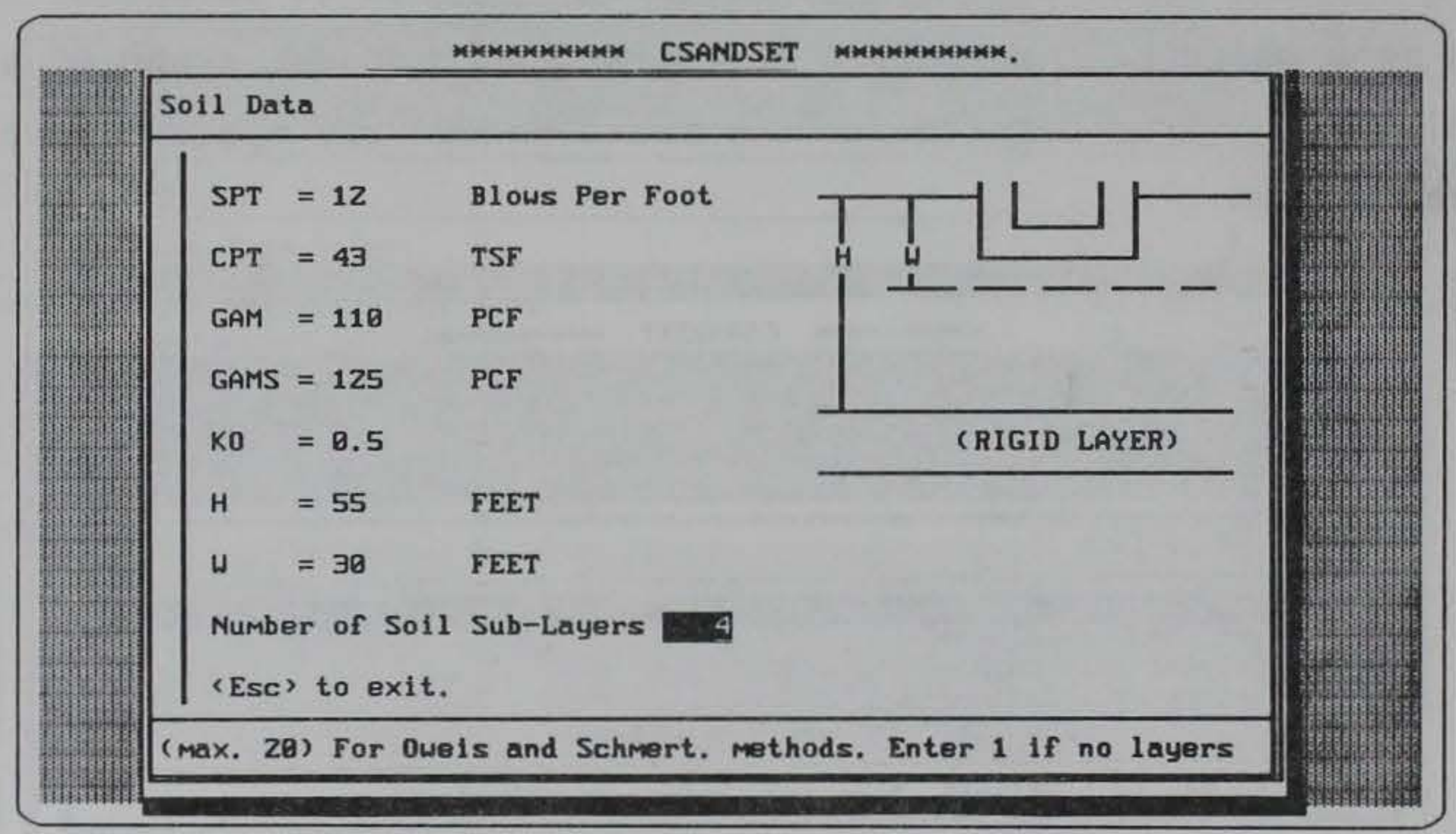

Figure 28. Soil data input screen

c. Optional soil data. Figure 29 shows the screen for entering optional data. Some of the default values are already set, such as Poisson's ratio (PR) and the unit weight of water (GAMW). The effective overburden pressure (OVER) at $D+B / 2$ will be internally calculated if it has the value of zero when this screen is exited. The defaults can be changed by typing over the values on the screen. The condition or result of allowing the default value to be set is explained on the right side of the screen and also in the data file user's guide in paragraph $118 \underline{\mathrm{b}}$.

d. Soil layers. The soil layer data entry screen is presented in Figure 30 . Note that the number of soil layers ( 1 to 20 ) must first be entered on the required soil data input screen, 


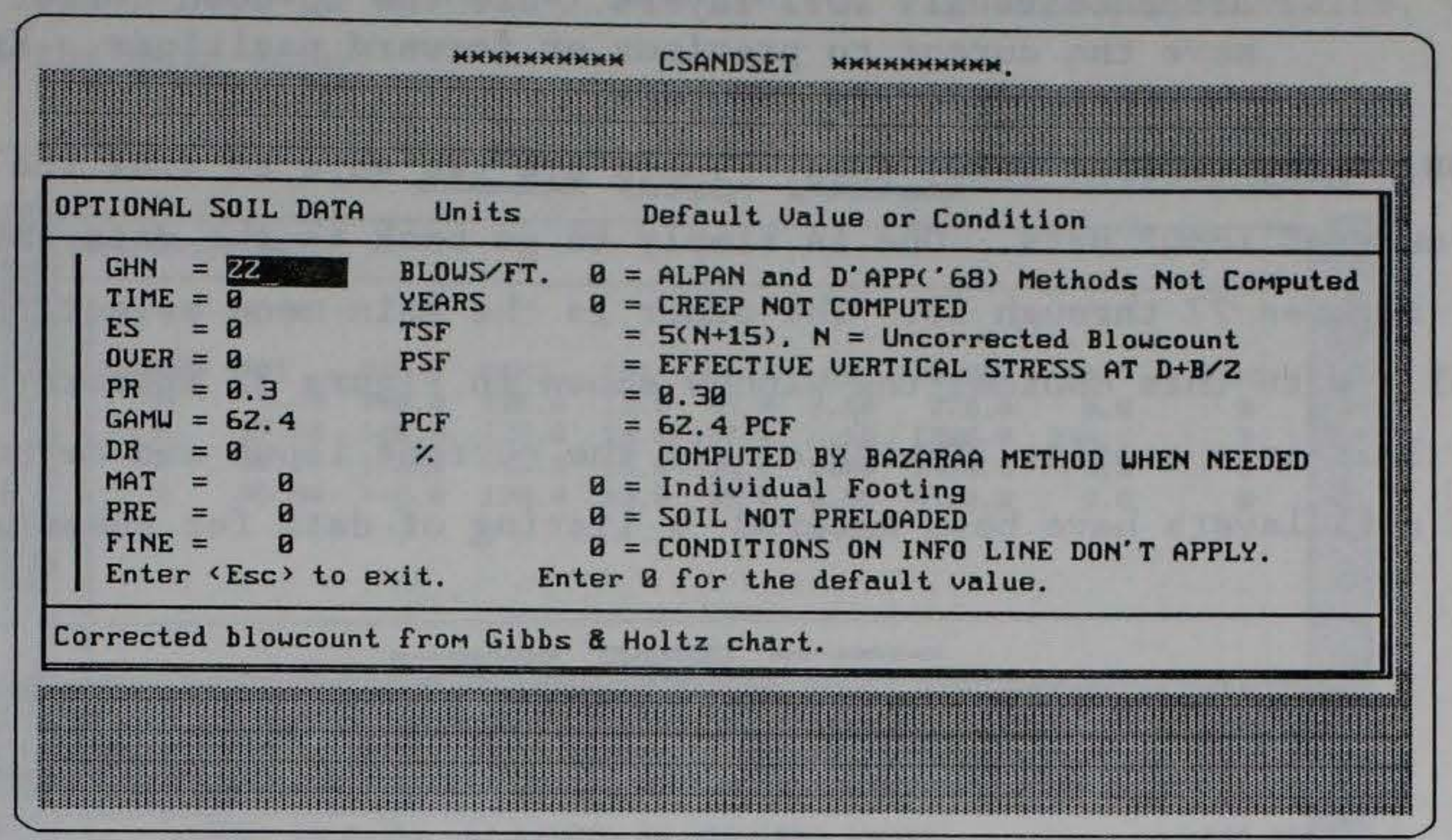

Figure 29. Optional data input screen

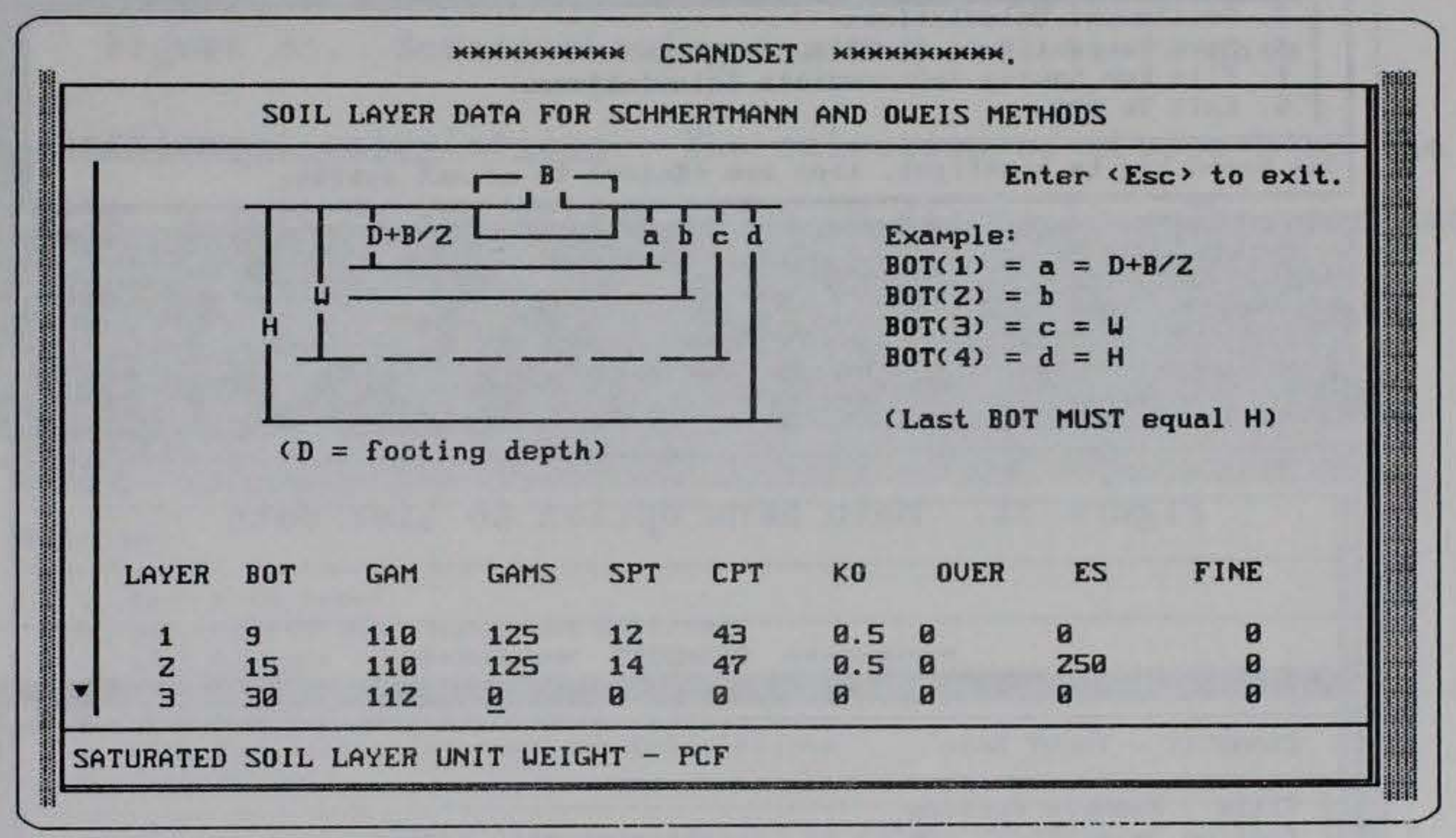

\section{Figure 30. Soil layer data input screen}

Figure 28. Effective overburden is calculated at the midheight of the layer in CSANDSET if the user enters 0 (zero) for this variable (OVER). Also, the elastic modulus (ES) can be entered as 0 and will be computed in the CSANDSET methods where required (Schmertmann (1970), Schmertman, Hartman, and Brown (1978), and Elastic Theory). The values of BOT, GAM, GAMS, and KO of the first soil layer are initially set to the values entered in the soil data screen, Figure 28. Type over these to change any. Note, the variable BOT of the last layer entered must equal the value of $H$ (depth of compressible layer) entered on the soil data screen. Enter data in the row for one soil layer at a time, starting with the top layer and ending with the bottom layer. The screen will scroll to 
accommodate all soil layers. Use the up-down cursor keys to move the cursor to previous or forward positions. Enter <ESC> when data entry is complete.

108. List Current input data. There are two ways to view the values of all the current input data. One is simply to go back to the data entry screens, Figures 27 through 30. The other is the main menu selection shown in Figure 31. With this choice, the window shown in Figure 32 appears on the screen. This is a concise listing of all the current input and default values. If soil layers have been entered, a listing of data for these appears on

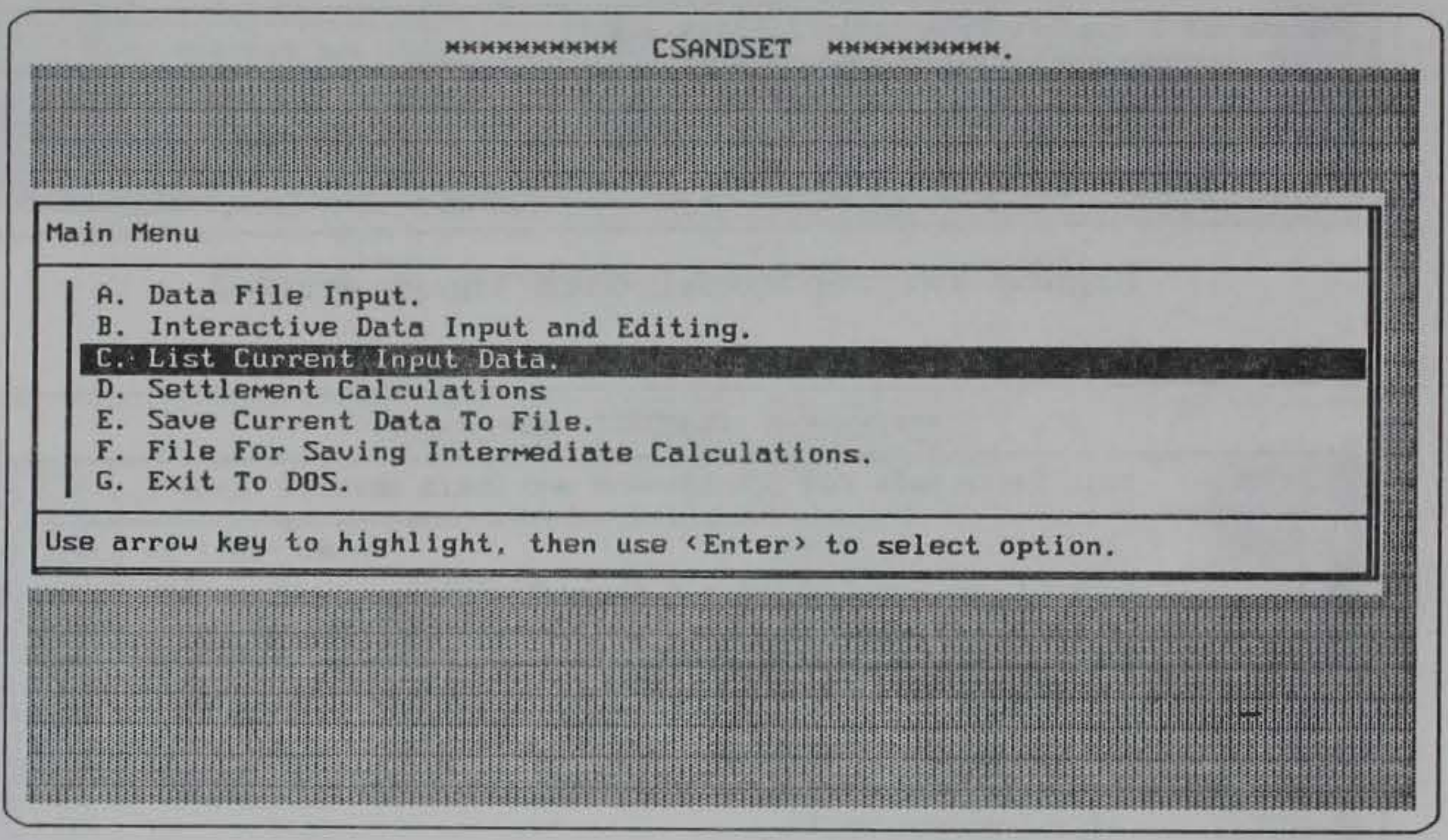

Figure 31. Main menu option to list data

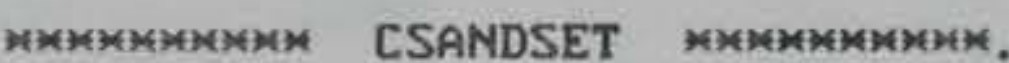

\begin{tabular}{|c|c|c|}
\hline & CSANDSET - INPUT DATA & \\
\hline$\nabla$ & 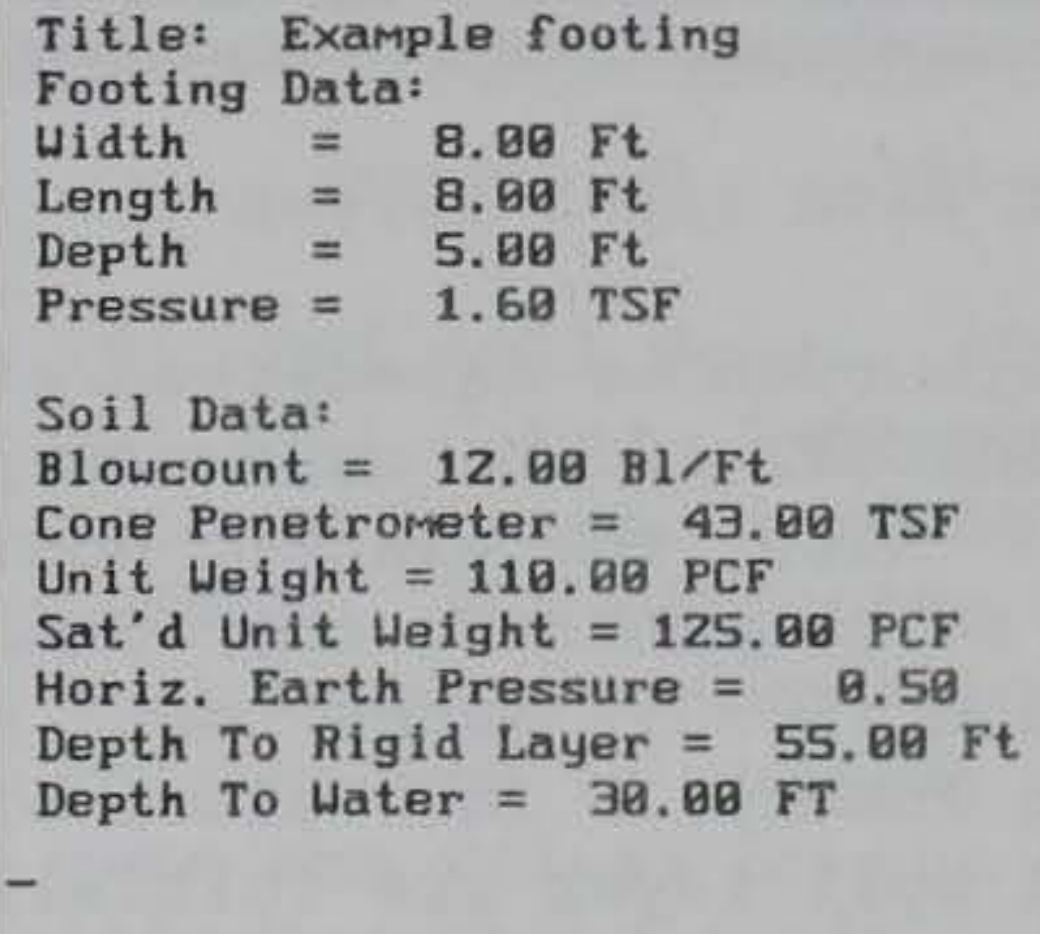 & 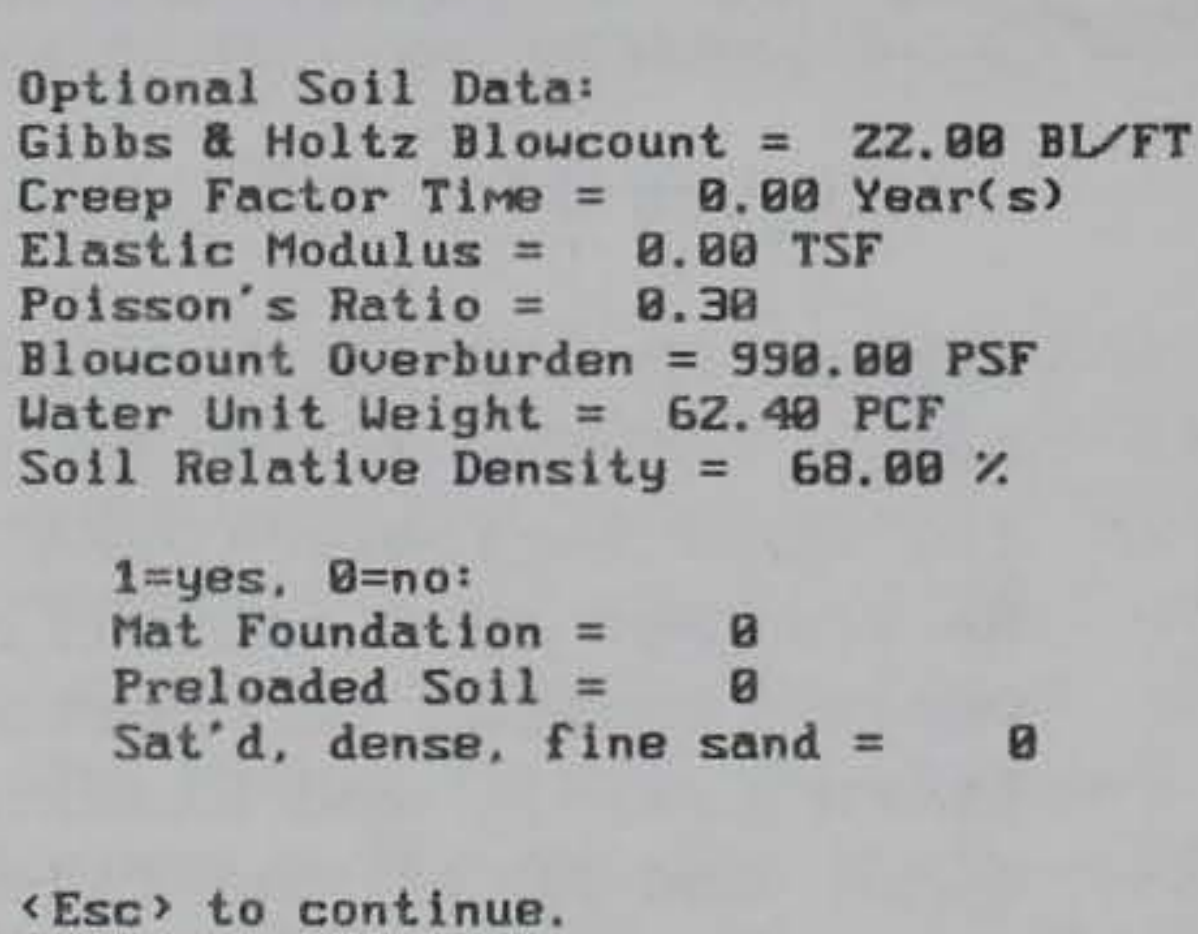 \\
\hline
\end{tabular}

Figure 32. Screen showing 1 ist of current data 
the next screen when the $\langle\mathrm{ESC}>$ key is entered, Figure 33. Otherwise, $<\mathrm{ESC}\rangle$ returns to the main menu.

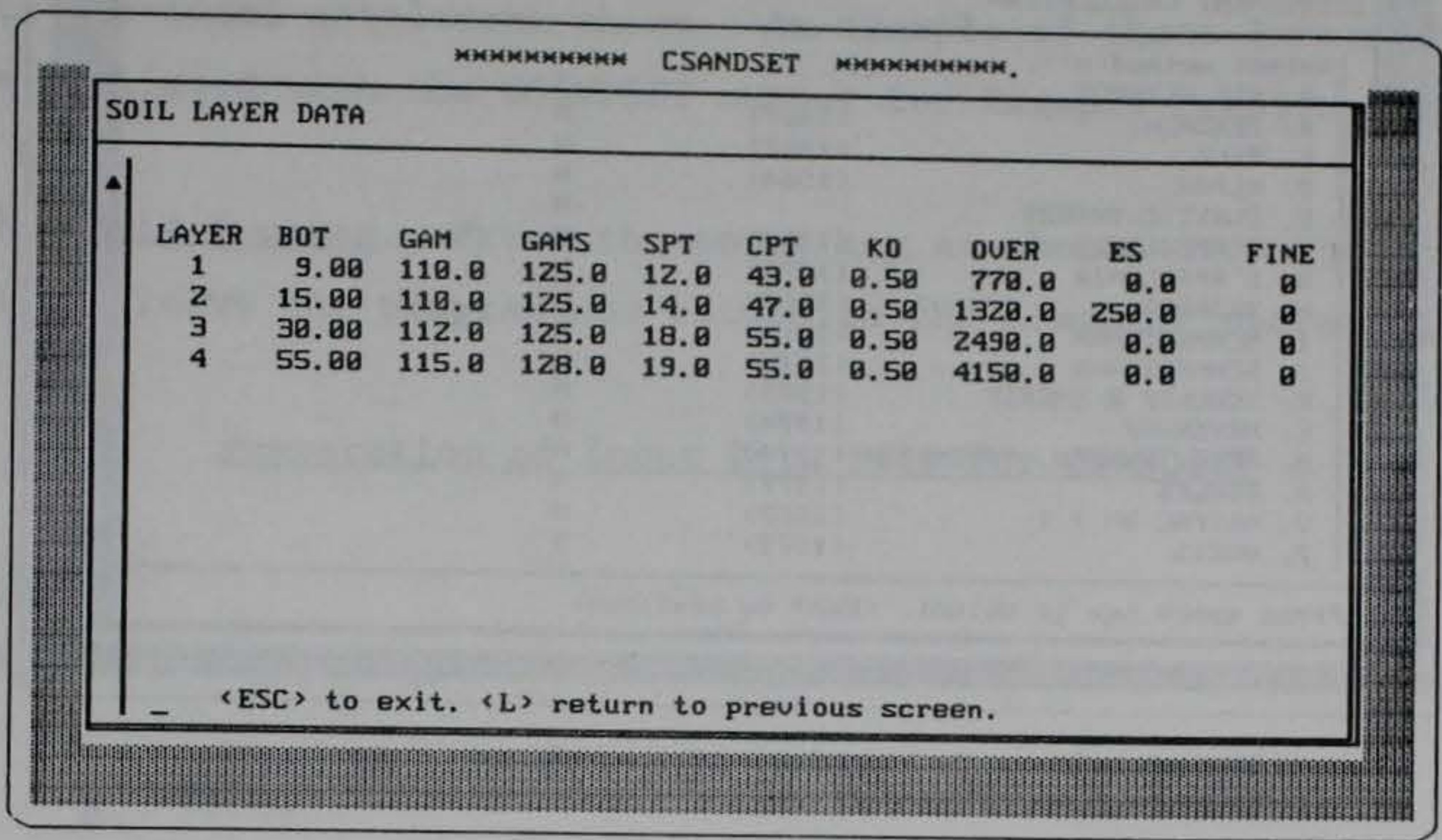

Figure 33. Screen showing current soil layer data

109. Settlement calculations. The selection of choice $D$ on the main menu, Figure 34, brings up the screen shown in Figure 35. The user can select

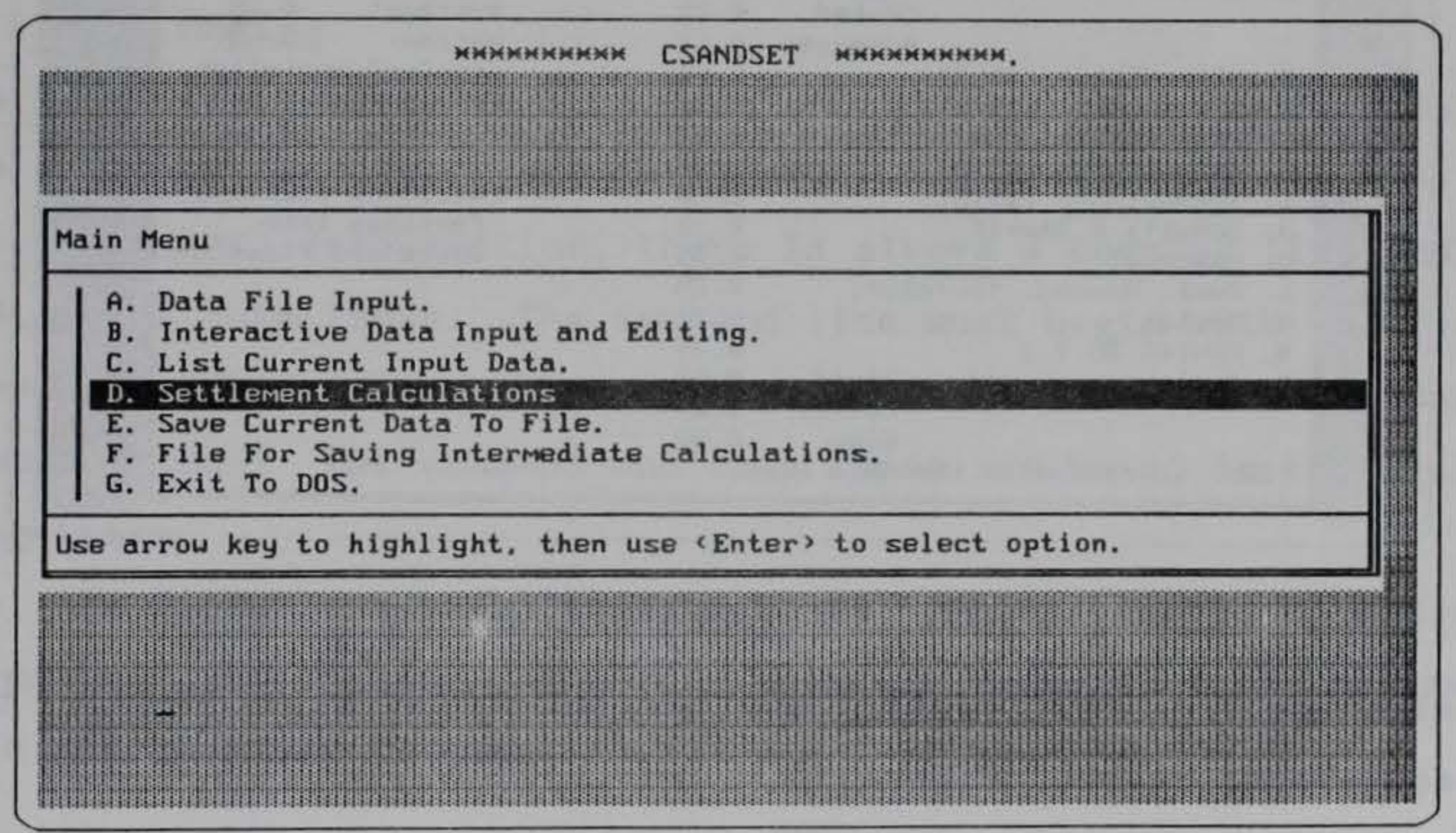

Figure 34. Option to have settlement calculated

individual methods or all the methods to calculate settlement by pressing the spacebar to indicate yes ( $\mathrm{Y}$ ) at the appropriate locations. The <ESC> key is used to enter these selections and produce the calculated settlements screen shown in Figure 36. If all methods are selected (choice A, Figure 35), then a 


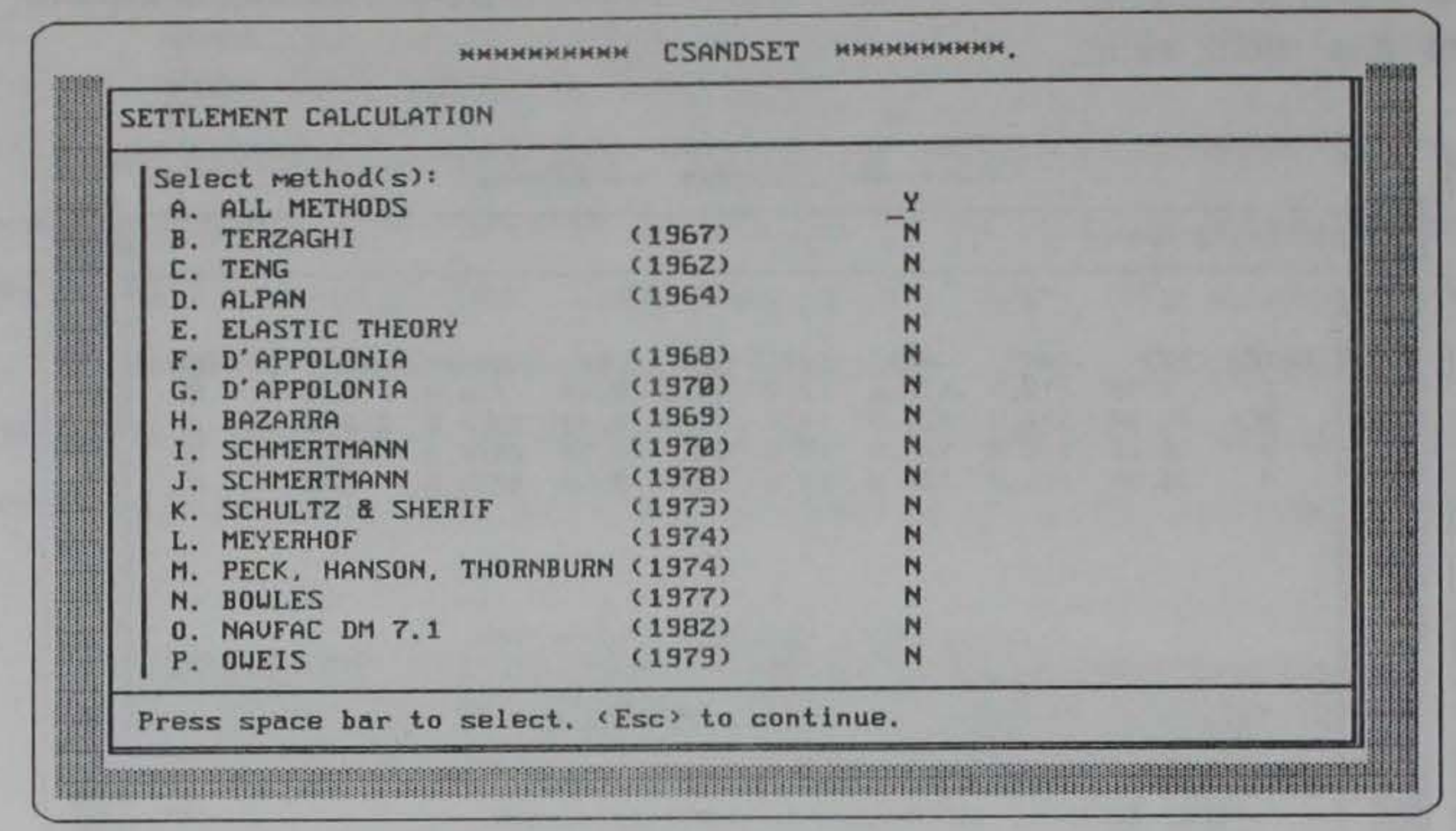

Figure 35. Selection of settlement methods

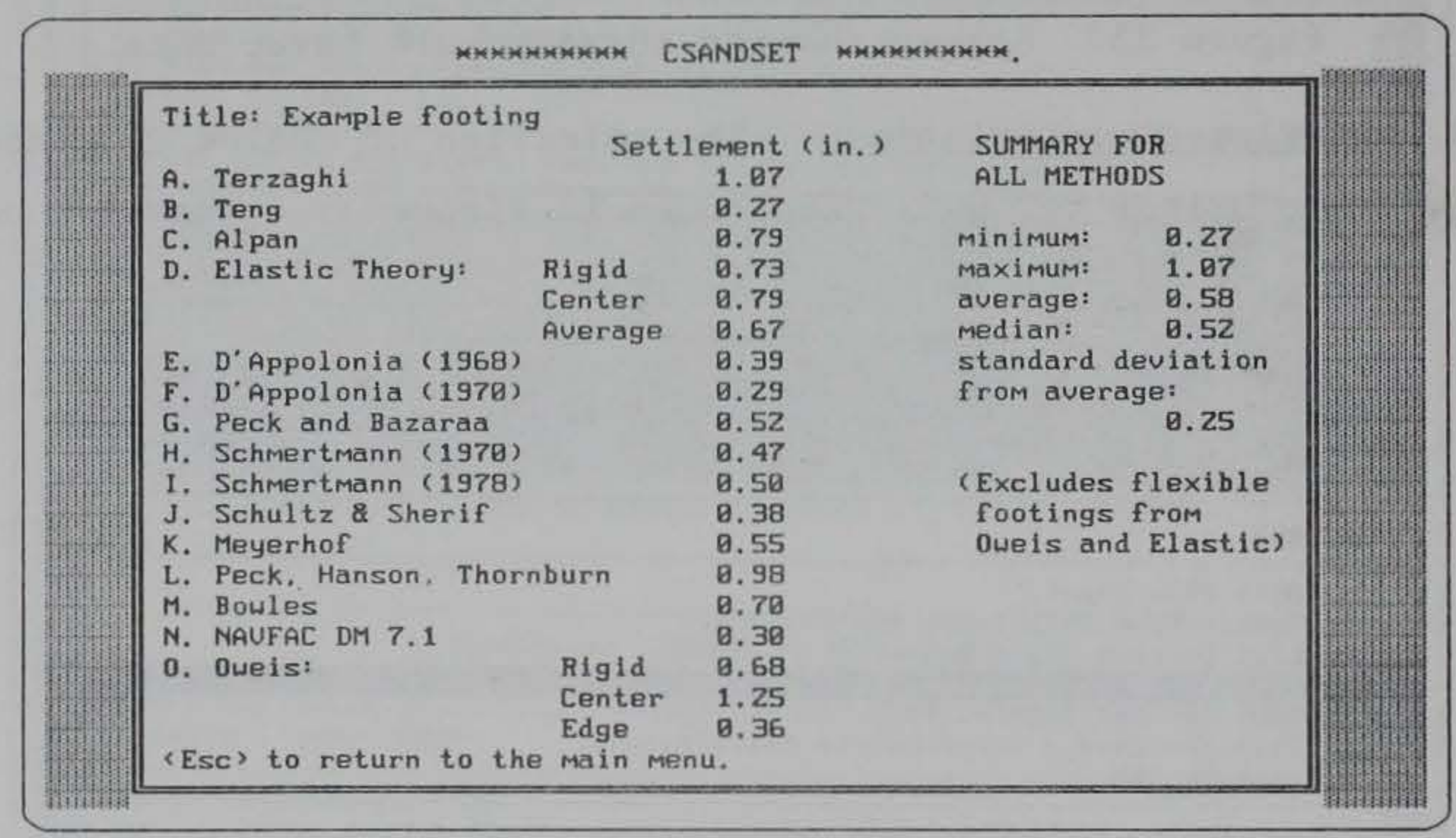

Figure 36. Settlement calculations

statistical summary of the results is displayed on the right side of the calculated settlements screen, Figure 36.

110. Save current data to a file. Selection of the option to save data to a file produces the prompt for a file name similar to the input data file prompt shown in Figure 25. The program will create a new file under the specified name and write the current input data to it, in the correct format for an input data file.

111. Intermediate program calculations. If the option to save intermediate calculations is selected (choice $F$ on the main menu), a file name must 
be entered at the prompt. Into this file will be written the correction factors, chart values, and other calculations used in each settlement method to compute the final settlement shown. An example of these intermediate calculations is listed with the CSANDSET output for Example Problem 1 of Appendix A.

112. Exit program. Press the enter key at choice $G$ on the main menu, Figure 24 , to leave the program and return to the computer operating system.

\section{Preparation of Input Data File for CSANDSET}

\section{Data sections}

113. In the input guide to follow, data is described by the sections 1isted:

a. Title.

b. Footing description.

c. Soil description.

d. Optional data (optional).

e. Soil layer data (optional).

f. Ending.

114. The first three and the last sections are the required data. The other two sections, as noted, are optional.

115. For each data section, there is always a command line and sometimes additional data lines. The command line must begin with the four-letter command word for that data section. There may or may not be other data items on the command line. The command and data lines are boxed in this guide for easy recognition.

116. In CSANDSET, data items which are "depths" should be entered as positive numbers, increasing downward. They are measured from the ground surface to the boundary in question.

\section{Syntax}

117. The data file syntax is the language used in this input guide to describe how the data for a file should be written.

a. Brackets, [ ], are used to indicate that the enclosed characters are optional data items. Therefore, you may choose whether or not to enter the data shown in the brackets. Do not enter the brackets. 
b. Quotation marks, " ", around underscored words indicate that the word is to be typed as shown, without the quotation marks or underscore. These are command words.

c. The data file is typed line-by-line using the command word and data line format shown in this guide. Line numbers are not to be used.

d. All data entry is in free-field format. Enter at least one blank space to separate data items on a line. Do not use commas or any other characters to separate data.

e. English units are used in CSANDSET. Units vary from one data item to another, therefore, be sure to use the proper units for the data as noted in this guide and on the program screens.

f. Notes about specific data items or their entry may be listed below the data line descriptions. This is important information which should be read for proper understanding of the input data.

g. A good way to learn the format for an input data file is to enter data interactively on the menus, then save it to a file.

\section{Input lines}

118. The following subparagraphs give a step-by-step description for writing an input data file.

a. Title

(1) Command Line.

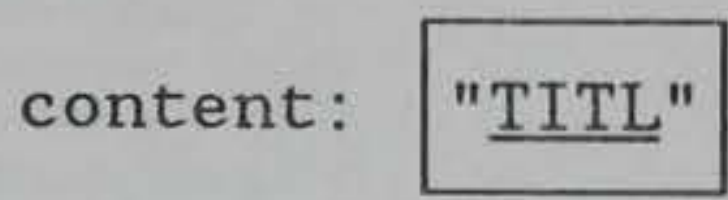

definition: "TITL" = command word for title of analysis.

(2) Data Line.

content: $\operatorname{xxxxxxx\ldots ...}$

definition: any alphanumeric information, up to 65 characters in length

b. Footing Description

(1) Command Line.

content: "FOOT"

definition: "FOOT" = command word for footing data

(2) Data Line.

content: B L D Q 
definition: $B=$ footing width; short dimension ( $f t$ )

$\mathrm{L}=$ footing length; long dimension ( $\mathrm{ft}$ )

$D=$ footing depth from ground surface ( $f t)$

$\mathrm{Q}=$ applied net loading pressure (tsf)

c. Soil Description

(1) Command Line.

content: "SOIL"

definition: "SOIL" = command word for soil data

(2) Data Line.

content: SPT CPT GAM GAMS KO H W

definition: SPT = uncorrected SPT blowcount value, average from $D$ to $D+B$

(blows/ft)

$$
\begin{aligned}
\text { CPT } & =\text { cone penetration test value, average } \\
& \text { from } D \text { to } D+B \text { (tsf) } \\
& =0 \text {, if not available }
\end{aligned}
$$

GAM = total moist or dry soil unit weight (pcf)

GAMS = saturated soil unit weight (pcf)

KO = horizontal at-rest earth pressure coefficient (used in Oweis method)

$\mathrm{H}=$ thickness of compressible soil, measured from the ground surface to the depth of a rigid layer ( $f t$ )

$W=$ depth to the water table from the ground surface ( $f t$ )

d. Optional Data. Default values are given and the results of using the default value are explained.

(1) Command Line.

content: ["OPTN" GHN MAT TIME PRE]

definition: "OPTN" = command word for optional data

GHN = corrected blowcount from Gibbs and Holtz (1957) chart; used in the Alpan (1964) and D'Appolonia, D'Appolonia, and Brissette (1968) methods, (blows/ft) 
$=0$, default: D'Appolonia, D'Appolonia, and Brissette (1968) and Alpan (1964) settlements not computed

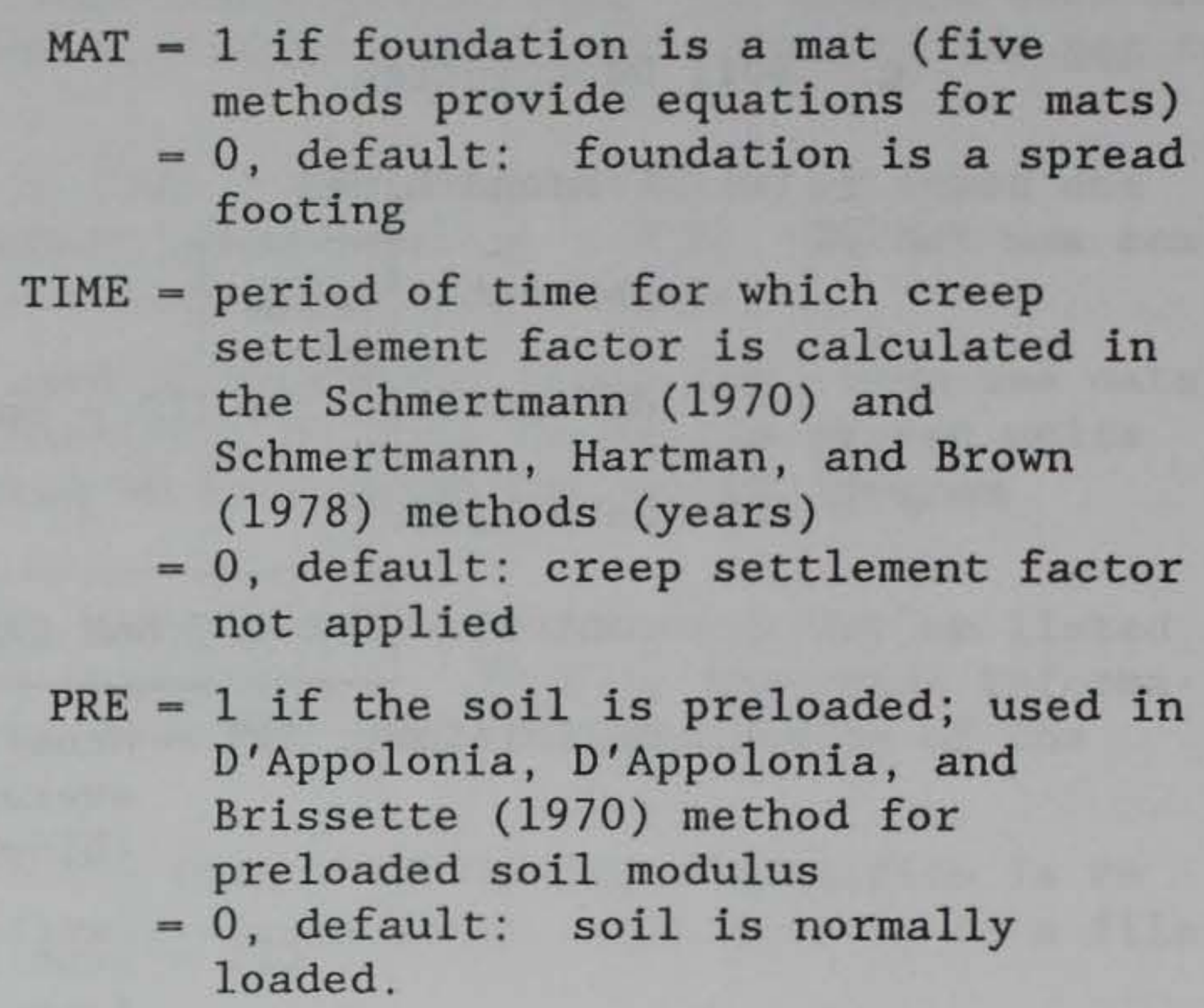

(2) Data Line.

content: [ES PR OVER GAMW DR NCHG]

definition: ES = elastic soil modulus used in Elastic Theory and Schmertmann (1970) and Schmertmann, Hartman, and Brown (1978) methods (tsf)

$=0$, default: $\mathrm{ES}=5(\mathrm{~N}+15)$ tsf

PR $=$ Poisson's Ratio

$=0$, default: $\quad P R=0.30$

OVER = effective overburden pressure corresponding to the SPT blowcount (psf)

$=0$, default: OVER $=\operatorname{GAM}(\mathrm{D}+\mathrm{B} / 2)$

GAMW = unit weight of water or other fluid (pcf)

$=0$, default: GAMW $=62.4$ pcf

$\mathrm{DR}=$ soil relative density (percent)

$=0$, default: computed individually in methods that use DR

NCHG = 1 if sand is silty or very fine, and is saturated and dense; Terzaghi's blowcount correction, $N_{c}=15+0.5(N$ - 15), is applied in methods that use it.

$=0$, default: soil conditions do not apply 
(3) Notes.

(a) If the user desires a default value for any data item, enter zero $(0)$ in the position of that data item on the line. The default value shown above will be internally assigned to that variable.

(b) On the Command Line, only the command word "OPTN" is required. After this, enter up to the last value desired only. Defaults will be assigned to the rest of the data. For example, to indicate a mat foundation with all else default, only the command line with values for GHN and MAT need to be entered:

"OPTN" GHN MAT. The line entered may look like: OPTN 01 . The defaults for TIME and PRE will automatically be set.

(c) If only the optional data items on the Command Line are to be entered, then the entire following Data Line may be omitted. Default values are assigned internally.

(d) If only data on the Data Line is to be entered, the data items following the command word "OPTN" may be omitted from the Command Line.

e. Soil Layer Data (optional, defaults shown. See notes paragraph $118 \mathrm{e} 3$ )

(1) Command Line.

content: "LAYE" NL

definition: "LAYE" = command word for soil layer data

$\mathrm{NL}=$ number of soil layers to be entered (max. 20)

(2) Data Line -- one per layer, repeat NL times.

content: BOT GAM GAMS SPT KO CPT OVER ES NCHG

definition: ВОт $=$ depth from ground surface to bottom of soil layer ( $\mathrm{ft}$ )

GAM = total moist or dry unit weight of soil layer (pcf)

GAMS = saturated unit weight of soil layer (pcf)

SPT $=$ uncorrected SPT blowcount value for the soil layer (blows/ft)

$\mathrm{KO}=$ horizontal at-rest earth pressure coefficient (used in Oweis method) 


$$
\begin{aligned}
\text { CPT }= & \text { cone penetrometer test value for the } \\
& \text { soil layer (tsf) } \\
= & 0 \text {, default: SPT converted to CPT in } \\
& \text { Schmertmann methods } \\
\text { OVER = } & \text { effective overburden pressure for SPT } \\
& \text { value (psf) } \\
= & 0 \text {, default: oVER = effective unit } \\
& \text { weight times depth to midlayer } \\
\text { ES = } & \text { soil modulus for layer; used in } \\
& \text { Schmertmann method if entered (tsf) } \\
= & 0 \text {, default: computed by CPT or SPT } \\
& \text { relation to E in Schmertmann method. } \\
\text { NCHG }= & 1 \text { if layer is silty or very fine sand, } \\
& \text { and is saturated and dense. Used in } \\
& \text { Schmertmann to convert SPT to CPT if } \\
& \text { CPT not entered. } \\
= & 0, \text { default: soil conditions do not } \\
& \text { apply }
\end{aligned}
$$

(3) Notes.

(a) The value of BOT of the last (lowest) soil layer must equal the value $H$, the depth of the compressible zone, entered in the soil data section.

(b) For more accurate results a layer should be defined at:

1. The level of the groundwater table (if $<H$ ).

2. The depth $D+B / 2$.

(c) If all the properties of one soil layer are the same as those of the immediately preceding layer, just enter BOT "SAME", for that line, and all values of the remaining data items for that layer will be equated to the values of the data items for the preceding layer (except for overburden which is calculated). An example is shown in the sample data file of Figure 37.

f. End of Data Entry

Command Line.

content: "END"

definition: "END" = command word for end of data.

119. Figure 37 is an example data file showing the use of different input options.

120. Figure 38 shows an example footing with the general dimensions and terms listed as they are used in the input guide for footing and soil data. Figure 39 shows the terins for a layered soil system. 
TITL $\ldots \ldots \ldots \ldots \ldots \ldots$ (command word)

EXAMPLE DATA FILE FORMAT ...(title information)

FOOT .................... (command word)

$122052.2 \ldots \ldots \ldots \ldots \ldots \ldots$ (B L D $Q$ )

SOIL $\ldots \ldots \ldots \ldots \ldots \ldots \ldots$ (command word)

$\begin{array}{lllllll}18 & 0 & 100 & 116 & 0.5 & 30 & 11 \ldots\end{array}$ (SPT CPT GAM GAMS KO $\mathrm{H} \mathrm{W}$ )

OPTN $420001 \ldots \ldots \ldots \ldots$ (command word, GHN MAT TIME PRE)

$\begin{array}{lllllllll}250 & 0 & 0 & 0 & 67 & 0 & \ldots & \ldots & \text { (ES PR OVER GAMW DR NCHG) }\end{array}$

LAYE $4 \ldots \ldots \ldots \ldots \ldots \ldots$ (command word, NL)

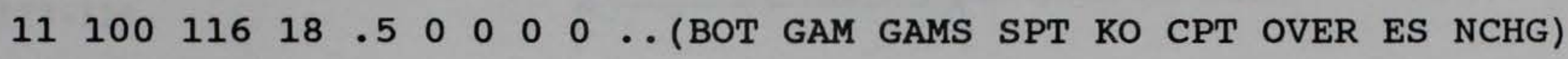

$\begin{array}{lllllllllll}20 & 100 & 116 & 22 & .5 & 0 & 0 & 0 & 1 & \ldots & \text { (layer } 2 \text { ) }\end{array}$

25 SAME ................ (layer 3, same properties as layer 2)

$\begin{array}{llllllllll}30 & 100 & 116 & 21 & .5 & 0 & 0 & 0 & 0 & \ldots\end{array}$ (layer 4 )

END .................. (command word)

Figure 37. Example data file

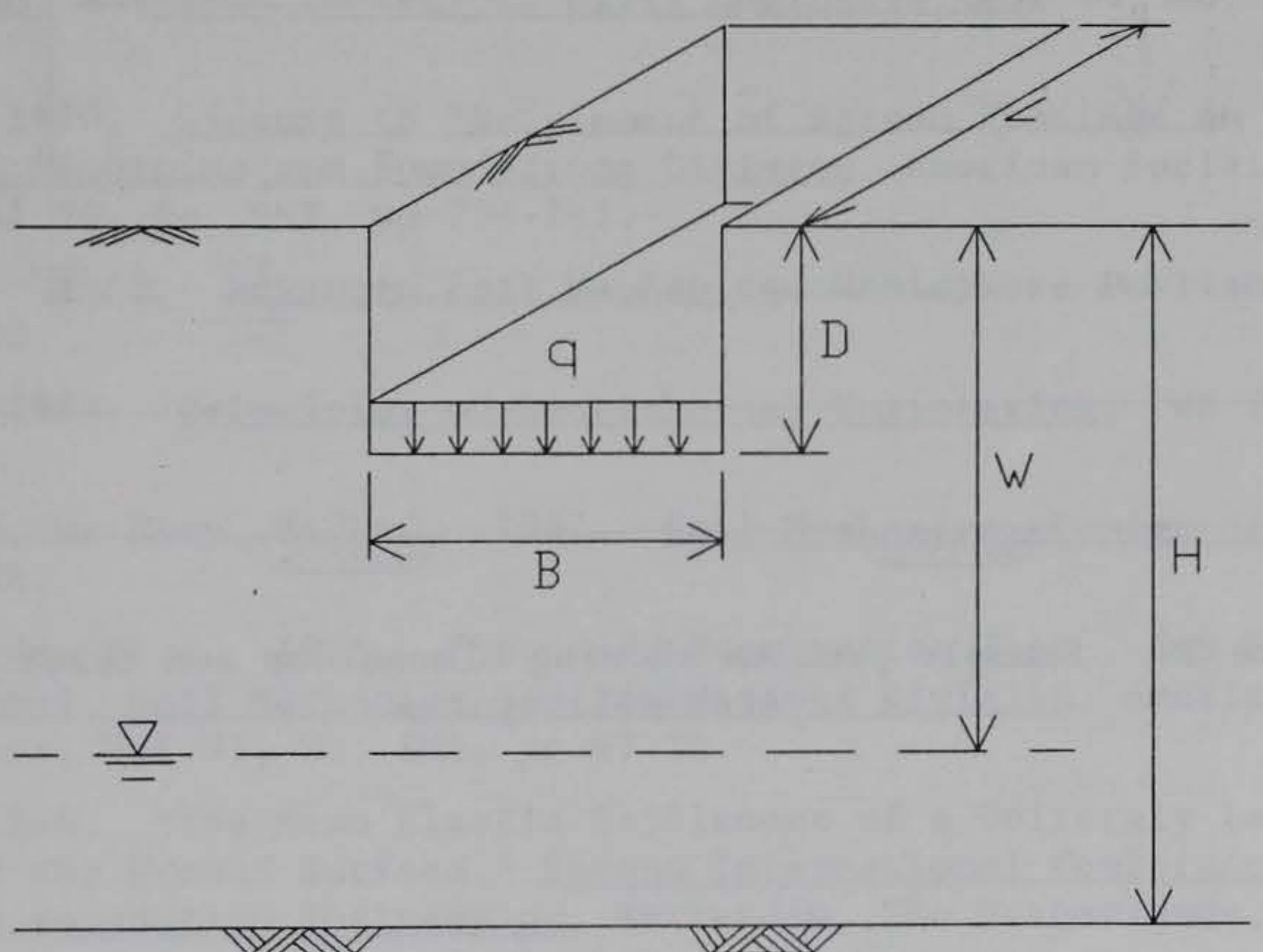

Figure 38. Example footing showing dimensions and terms for required input data 


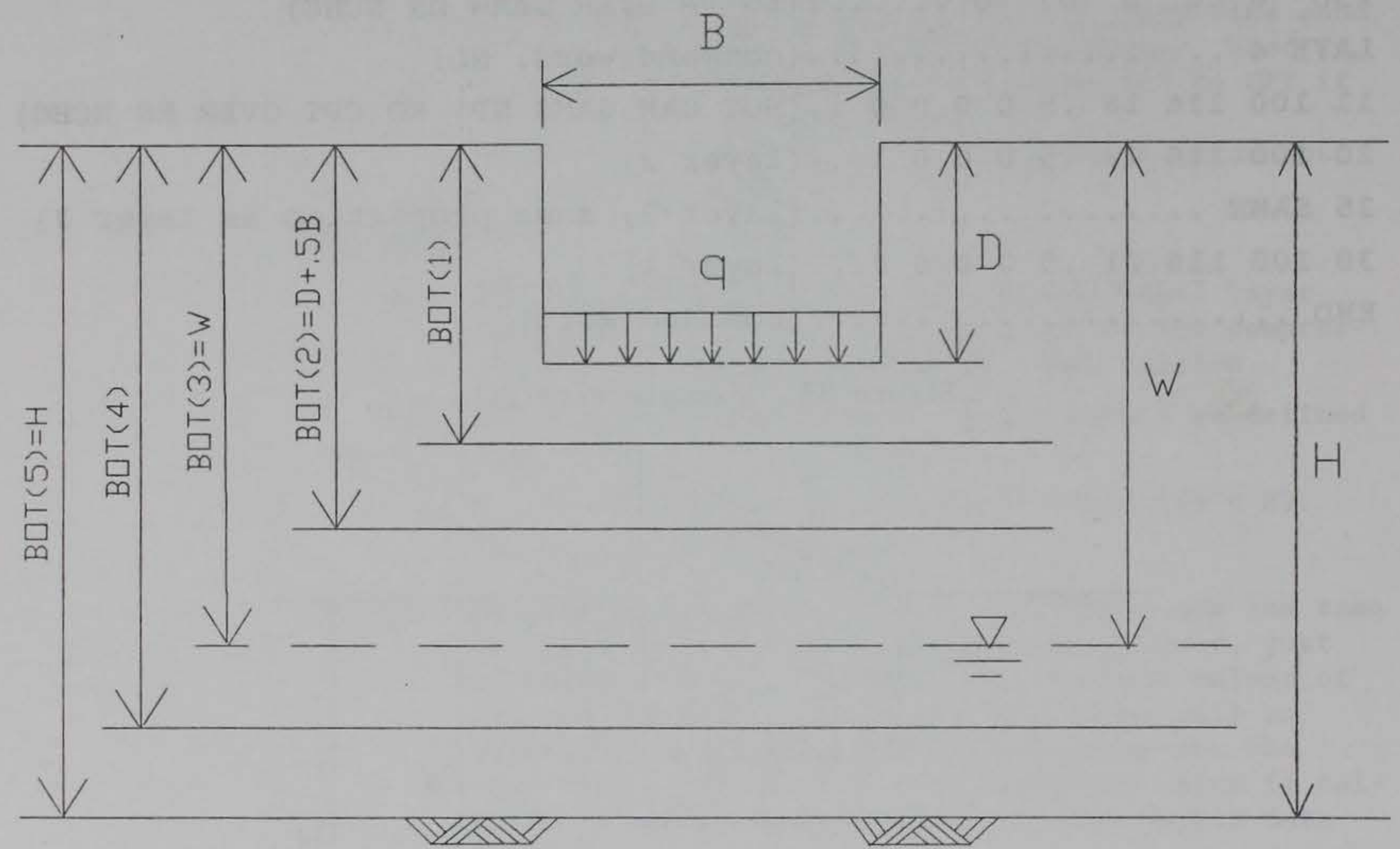

Figure 39. Example problem showing dimensions and terms for a layered soil system 


\section{REFERENCES}

Alpan, I. 1964 (Nov). "Estimating the Settlements of Foundations on Sands," Civil Engineering and Public Works Review, pp 1415-1418.

Bazaraa, Abdel, R. 1967. "Use of the Standard Penetration Test for Estimating Settlements of Shallow Foundations on Sand," Ph.D. Dissertation, Department of Civil Engineering, University of Illinois, Urbana, IL.

Bowles, Joseph E. 1977. Foundation Analysis and Design, 2nd ed., McGrawHill, New York.

\section{New York.}

. 1982. Foundation Analysis and Design, 3rd ed., McGraw-Hill

Christian, John T., and Carrier III, W. David. 1978. "Janbu, Bjerrum and Kjaernsli's Chart Reinterpreted," Canadian Geotechnical Journal, Vol 15, pp $123-128$.

Coffman, B. S. 1960. "Estimating the Relative Density of Sands," Civil Engineering, American Society of Civil Engineers, Vol 30, No. 10, pp 78-79. Consla, John A. 1983. "A Comparison of Sand Settlement Models," M.S. Thesis, Department of Civil Engineering, Massachusetts Institute of Technology, Cambridge, MA.

D'Appolonia, David J., D'Appolonia, Elio, and Brissette, Richard F. 1968. "Settlement of Spread Footings on Sand," Journal, Soil Mechanics and Foundations Division, American Society of Civil Engineers, Vol 94, No. SM3, pp 735-760.

. 1970. Closure to "Settlement of Spread Footings on Sand," Journal, Soil Mechanics and Foundations Division, American Society of Civil Engineers, Vol 95, No. SM2, pp 754-762.

Das, Braja M. 1983. Advanced Soil Mechanics, Hemisphere Publishing Corp., Washington, DC.

$\overline{\text { Boston, MA. }}$.

1985. Principles of Geotechnical Engineering, PWS Publishers,

Department of the Navy, NAVFAC. 1982. Soil Mechanics, Design Manual 7.1, Alexandria, VA.

Fletcher, Gordon F. A. 1965. "Standard Penetration Test: Its Uses and Abuses," Journal. Soil Mechanics and Foundations Division, American Society of Civil Engineers, Vol 91, No. SM4, pp 67-75.

Fox, E. N. 1948. "The Mean Elastic Settlement of a Uniformly Loaded Area at a Depth Below the Ground Surface," Second International Conference, Soil Mechanics and Foundation Engineering, Rotterdam, The Netherlands, Vol 1 , pp 129-132.

Gibbs, H. J., and Holtz, W. G. 1957. "Research on Determining the Density of Sands by Spoon Penetration Testing," Proceedings, 4th International Conference on Soil Mechanics and Foundation Engineering, London, Vol 1, pp 35-39.

Janbu, N., Bjerrum, L., and Kjaernsli, B. 1956. "Veiledning ved lesning av fundamenteringsoppgaver, " Norwegian Geotechnical Institute, Publication No. 16, Oslo, pp 30-32. 
Jeyapalan, Jey K. 1982. "Procedures for Settlement Prediction for Shallow Foundations on Sand," Unpublished report prepared for US Army Engineer Waterways Experiment Station, Vicksburg, MS .

Liao, Samson S. C., and Whitman, Robert V. 1986. "Overburden Correction Factors for SPT in Sand," Journal. Geotechnical Engineering Division, American Society of Civil Engineers, Vol 112, No. 3, pp 373-377.

Mansur, C. I., and Kaufman, R. I. 1958. "Pile Tests, Low-Sill structure, Old River, Louisiana," Transactions of the American Society of Civil Engineers, Vol 123, pp 715-748.

Mansur, C. I., and Hunter, A. H. 1970. "Pile Tests - Arkansas River Project," Journal. Soil Mechanics and Foundations Division, American Society of Civil Engineers, Vol 96, No. SM5, pp 1545-1582.

Marcuson, III, William F., and Bieganousky, Wayne A. 1977a (Jun). "Laboratory Standard Penetration Tests on Fine Sands," Journal. Geotechnical Engineering Division, American Society of Civil Engineers, Vol 103, No. GT6, pp 565-588.

. 1977b (Nov). "SPT and Relative Density in Coarse Sands," Journal, Geotechnical Engineering Division, American Society of Civil Engineers, Vol 103, No. GT11, pp 1295-1309.

Meigh, A. C., and Nixon, I. K. 1961. "Comparison of in Situ Tests for Granular Soils," Proceedings of the European Conference on Soil Mechanics and Foundation Engineering, Paris, Vol 1, pp 499-507.

Meyerhof, G. G. 1956. "Penetration Tests and Bearing Capacity of Cohesionless Soils," Journal, Soil Mechanics and Foundations Division, American Society of Civil Engineers, Vol 82, No. SM1.

- 1965. "Shallow Foundations," Journa1, Soil Mechanics and Foundations Division, American Society of Civil Engineers, Vol 91, No. SM2.

- 1974. "General Report: State-of-the-Art of Penetration Testing in Countries Outside Europe," Proceedings, European Symposium on Penetration Testing, Stockholm, pp 40-48.

Mosher, Reed L. 1984. "Load-Transfer Criteria for Numerical Analysis of Axially Loaded Piles in Sand," Technical Report K-84-1, US Army Engineer Waterways Experiment Station, Vicksburg, MS .

Oweis, Issa S. 1979. "Equivalent Linear Model for Predicting Settlements of Sand Bases," Journal of the Geotechnical Engineering Division, American Society of Civil Engineers, Vol 105, No. GT12, pp 1525-1544.

Palmer, D. J., and Stuart, J. G. 1957. "Some Observations on the Standard Penetration Test and a Correlation of the Test with a New Penetrometer," Proceedings, 4th International Conference on Soil Mechanics and Foundation Engineering, London, Vo1 1, pp 231-236.

Peck, R. B., and Bazaraa, Abdel R. 1969. Discussion of "Settlement of Spread Footings on Sand," Journal, Soil Mechanics and Foundations Division, American Society of Civil Engineers, Vol 95, No. SM3, pp 905-909.

Peck, Ralph B., Hanson, Walter E., and Thornburn, Thomas H. 1974. Foundation Engineering, 2nd ed., Wiley, New York. 
Robertson, P. K., and Campanella, R. G. 1983. "Interpretation of Cone Penetration Tests. Part I: Sand," Canadian Geotechnical Journal, Vol 20, pp $718-733$.

Schmertmann, John H. 1970. "Static Cone to Compute Static Settlement Over Sand," Journal. Soil Mechanics and Foundations Division, American Society of Civil Engineers, Vo1 96, No. SM3, pp 1011-1043.

Schmertmann, John H., Hartman, John Paul, and Brown, Phillip R. 1978.

"Improved Strain Influence Factor Diagrams," Journal, Geotechnical Division, American Society of Civil Engineers, Vol 104, No. GT8, pp 1131-1135.

Schultze, E., and Sherif, G. 1973. "Prediction of Settlements from Evaluated Settlement Observations for Sand," Proceedings, 8th International Conference on Soil Mechanics and Foundation Engineering, Moscow, pp 225-230.

Schultze, E., and Menzenbach, E. 1961. "Standard Penetration Test and Compressibility of Soils," Proceedings, 5th International Conference on Soil Mechanics and Foundation Engineering, Paris, pp 527-532.

Skempton, A. W. 1986. "Standard Penetration Test Procedures and the Effects in Sands of Overburden Pressure, Relative Density, Particle Size, Ageing and Overconsolidation," Geotechnique, Vol 36, No. 3, pp 425-447.

Teng, W. 1962. Foundation Design, Prentice Hall, New Jersey.

Terzaghi, Kar1. 1955. "Evaluation of Coefficients of Subgrade Reaction," Geotechnique, Vol 5, pp 297-326.

Terzaghi, Karl, and Peck, Ralph B. 1948. Soil Mechanics in Engineering Practice, Wiley, New York.

New York.

. 1967. Soil Mechanics in Engineering Practice, 2nd ed., Wiley,

Winterkorn, Hans F., and Fang, Hsai-Yang, Editors. 1975. Foundation

Engineering Handbook, Van Nostrand Reinhold, New York. 


\section{Hand Calculations and Verification of CSANDSET}

1. Three example settlement problems are presented in this appendix. Each is slightly different from the others to show different aspects of settlement calculation. A paragraph and figure describe each example, hand calculations from each of the methods are provided, and the results from the CSANDSET computer program follow. The calculations follow the procedures outlined in Part III of the main text.

2. Problem 1 shows more detailed calculations than Problems 2 and 3 . The charts used to obtain values for certain methods are included in the hand calculations for Problem 1, but are referenced only in Problems 2 and 3 . Some of the hand calculated values are carried out to more decimal places than may be considered practical. This is done only to provide a better comparison with the CSANDSET computer program calculations. Slight differences between hand and computer calculations are mainly due to discrepancies between the values chosen from graphs and curves. Sometimes, small differences in a variable, such as the alpha value in Alpan's (1964)* method, can produce notable changes in the computed settlement. In the Oweis (1979) method many charts and curves are used, thus it is possible for cumulative errors to result if one is not careful and consistent in selecting values.

3. The following symbols used in the problems are assigned the definitions and units listed:

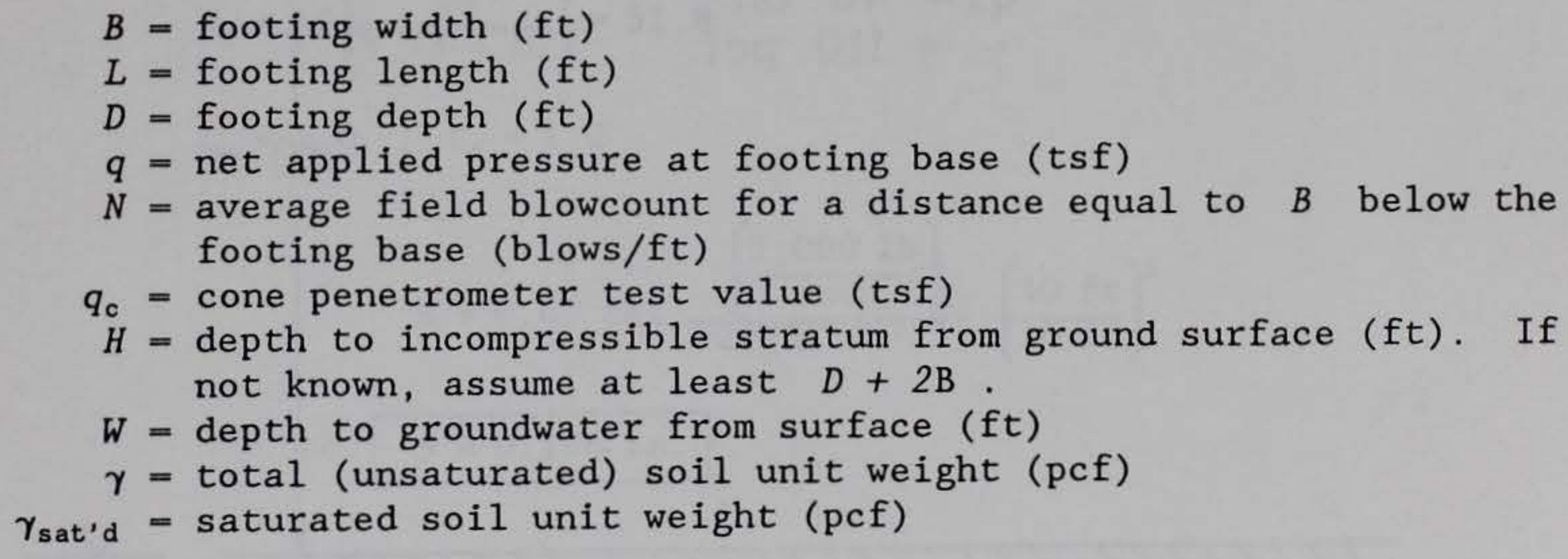

* A list of references follows the main text of this report. 


\section{Problem 1}

4. This is an example of a fairly simple problem. The footing is located at the ground surface (no embedment), and there is no groundwater present within the range of two times the width below the footing. The length is roughly twice the footing width. Dimensions and parameters are shown in Figure A1. Table Al lists the hand-calculated settlements from all the methods. Figures A2 through A7 show screens from the CSANDSET computer program for the input, settlement calculations, and intermediate calculations of Problem 1.

$$
\begin{aligned}
B & =15 \mathrm{ft*} \\
L & =32.8 \mathrm{ft} \\
D & =0.0 \mathrm{ft} \\
q & =0.49 \mathrm{tsf} \\
N & =10 \mathrm{bl} / \mathrm{ft} \\
q_{c} & =40 \mathrm{tsf} \\
\gamma & =110 \mathrm{pcf} \\
H & =40 \mathrm{ft} \\
W & =40 \mathrm{ft} \text { (assumed) }
\end{aligned}
$$
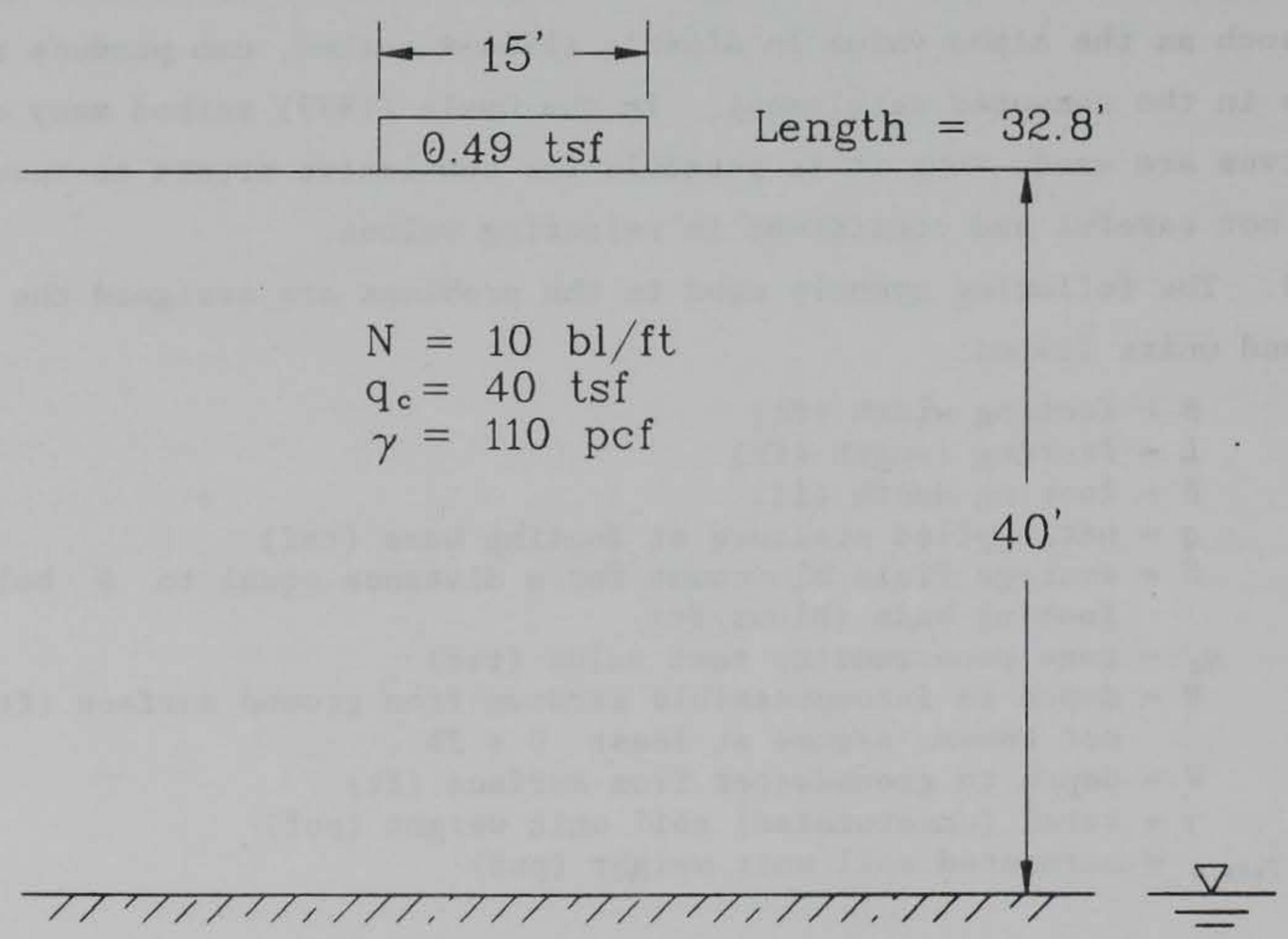

Figure A1. Example problem 1 (Jeyapalen 1982)

* A table of factors for converting non-SI units of measurement to SI (metric) units is on page 6 of the main text. 


$$
\begin{array}{rl}
S & =\frac{12 q}{N}\left(\frac{B}{B+I}\right)^{2}\left(C_{\mathrm{w}} C_{\mathrm{d}}\right) \\
& =\frac{12(0.49 \mathrm{tsf})}{10}\left(\frac{15 \mathrm{ft}}{16 \mathrm{ft}}\right)^{2} \\
C_{\mathrm{w}}=1.0, C_{\mathrm{d}}=1.0 & S=0.517 \mathrm{in} .
\end{array}
$$

b. Teng (1962)

$$
\begin{aligned}
& S=\frac{q}{720\left(N_{\mathrm{C}}-3\right)}\left(\frac{2 B}{B+I}\right)^{2}\left(C_{\mathrm{w}} C_{\mathrm{d}}\right) \\
& N_{\mathrm{c}}=N\left(\frac{50}{p^{\prime}+10}\right) \\
& p^{\prime}=\gamma\left(D+\frac{B}{2}\right)=110 \operatorname{pcf}(0+7.5 \mathrm{ft})=825 \mathrm{psf}=5.73 \mathrm{psi} \\
& N_{\mathrm{c}}=10\left(\frac{50}{5.73+10}\right)=31.8 \\
& C_{\mathrm{w}}=1.0, C_{\mathrm{d}}=1.0 \\
& S=0.49 \operatorname{tsf} \frac{\left(\frac{2,0001 \mathrm{~b}}{\operatorname{ton}}\right)}{720(31.8-3)}\left(\frac{30 \mathrm{ft}}{16 \mathrm{ft}}\right)^{2} \\
& S=0.166 \mathrm{in} .
\end{aligned}
$$

c. Alpan (1964)

$$
S=\alpha q\left(\frac{2 B}{B+1}\right)^{2} m C_{w}
$$


Correct blowcount for overburden pressure with Alpan's form of Gibbs and Holtz (1957) chart. $N=10, p^{\prime}=5.73$ psi (paragraph 4b), use Figure 9a (main text):

SPT Blowcount - N

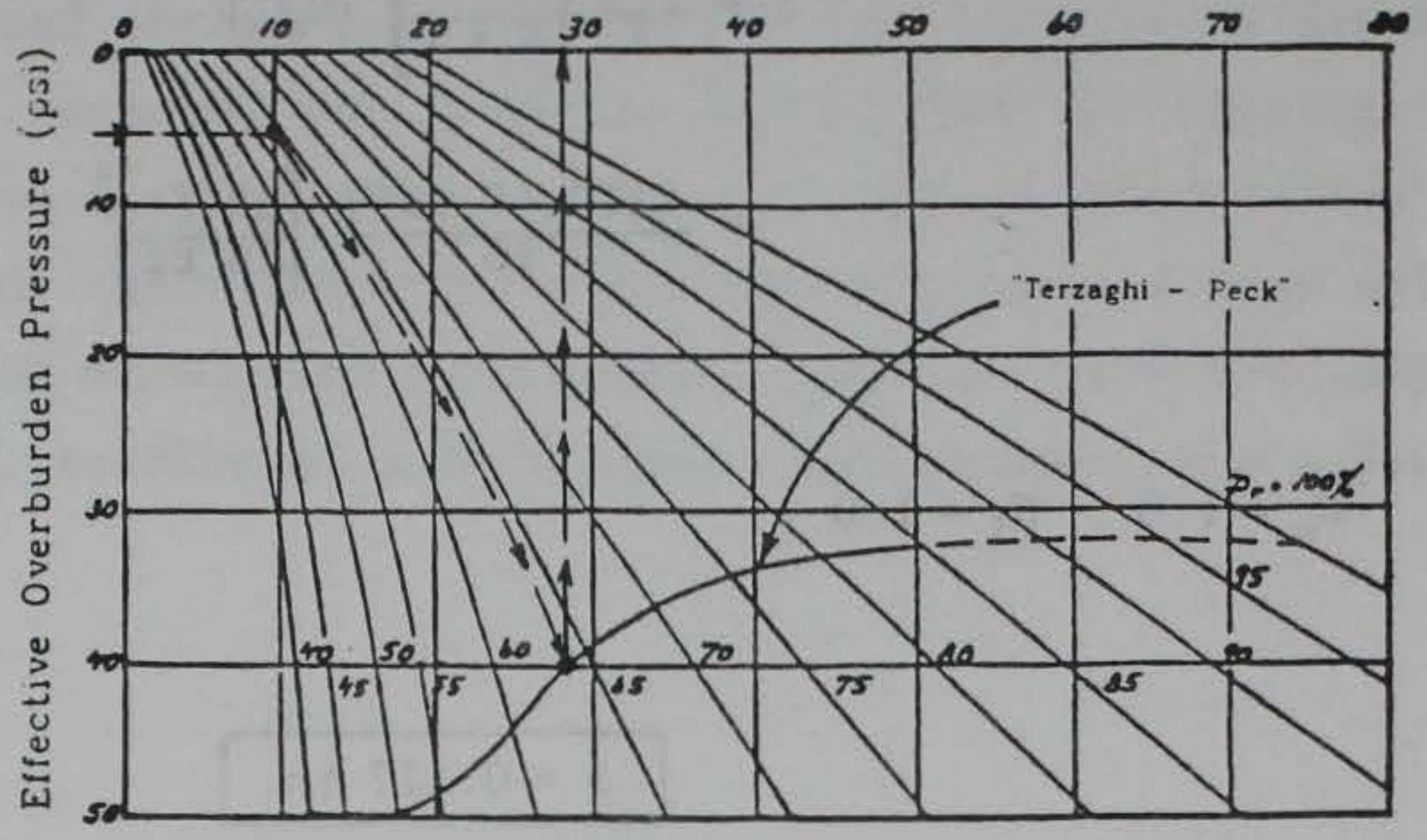

$N_{\mathrm{c}}=28 \mathrm{~b} 1 / \mathrm{ft}$

Use Figure 10a (main text) to get $\alpha$.

$$
\alpha \approx 0.108 \frac{\text { in. }-f t^{2}}{\text { ton }}
$$

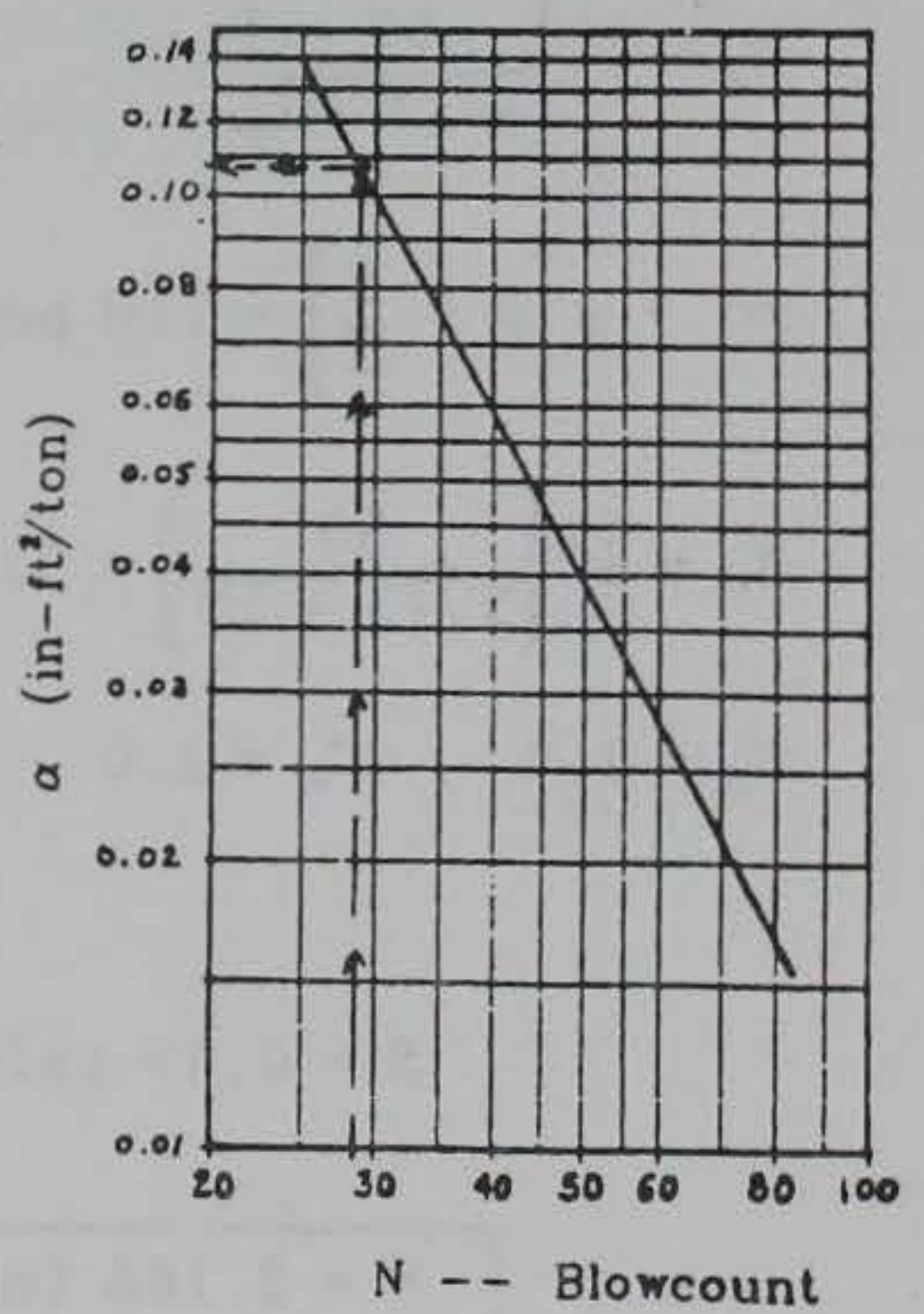


Use Figure 11 (main text) to get shape factor, $m$.

$$
\begin{aligned}
n & =\frac{L}{B}=\frac{32.8 \mathrm{ft}}{15 \mathrm{ft}}=2.187 \\
\frac{m}{n} & =0.64 \\
m & =0.64 \mathrm{n} \\
& =0.64(2.187) \\
& =1.4
\end{aligned}
$$$$
\mathrm{n}=\mathrm{L} / \mathrm{B}
$$

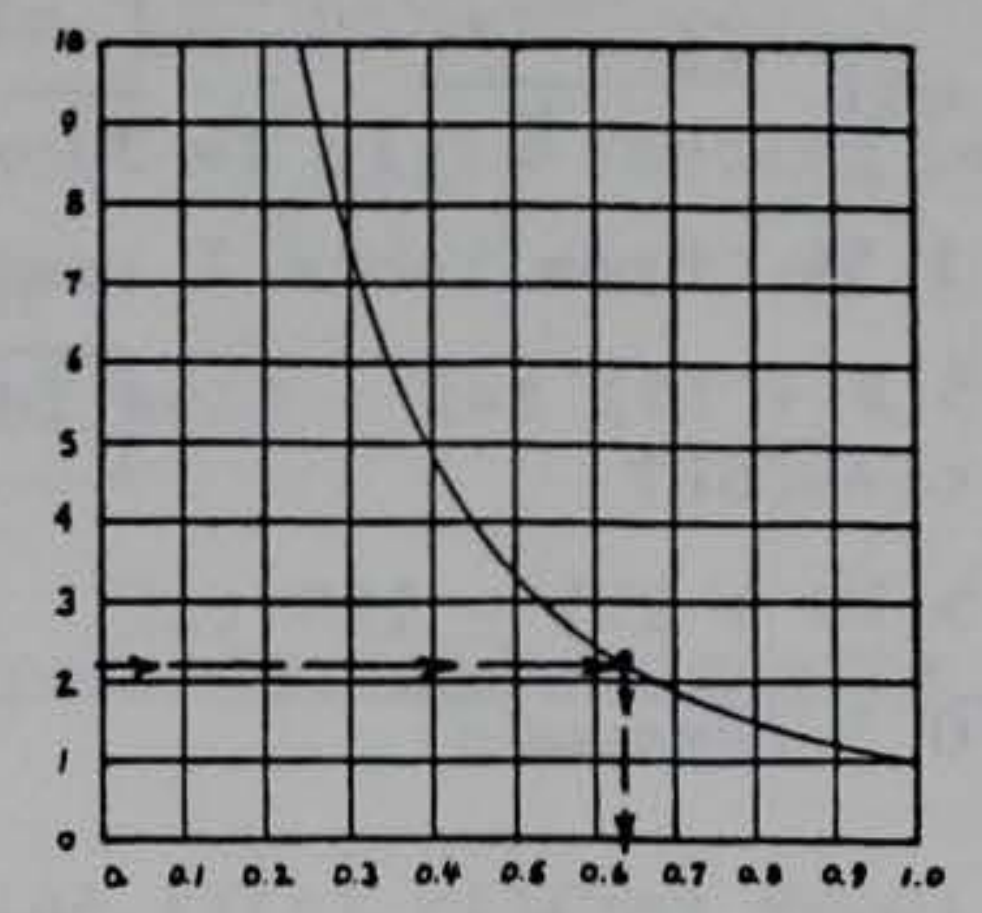

$\mathrm{m} / \mathrm{n}$

$\mathrm{C}_{\mathrm{w}}=1.0$

$$
\begin{aligned}
& S=\alpha q\left[\frac{2 B}{B+1}\right)^{2} m C_{W} \\
& S=\left(0.108 \frac{\text { in. }-\mathrm{ft}^{2}}{\text { ton }}\right)(0.49 \mathrm{tsf})\left(\frac{30 \mathrm{ft}}{16 \mathrm{ft}}\right)^{2}(1.4)(1.0) \\
& S=0.260 \text { in. }
\end{aligned}
$$


d. Elastic theory.

$$
S=q B I \frac{\left(1-\gamma^{2}\right)}{E} C_{\mathrm{d}}
$$

$\frac{H}{B}=\frac{40 \mathrm{ft}}{15 \mathrm{ft}}=2.7<10$, therefore, compute settlement of footing on finite compressible layer, as shown in paragraph 62 in Part III of the main text.

(1) $S_{c}=$ settlement at center of flexible footing on semi-infinite layer

$=q B I \frac{\left(1-\gamma^{2}\right)}{E}$

$I \approx 1.54$, from Table 7 (main text), for $L / B=2.187$

$E=5(N+15)$ tsf - from Table 8 (main text), and used in CSANDSET

$$
=5(10+15)=125 \text { tsf }
$$

$\boldsymbol{\gamma}=0.3$ (assumed)

$$
\begin{aligned}
S_{\mathrm{c}} & =(0.49 \mathrm{tsf})(15 \mathrm{ft})(1.54) \frac{\left(1-0.3^{2}\right)}{125 \mathrm{tsf}}=0.0824 \mathrm{ft} \\
& =0.989 \mathrm{in} .
\end{aligned}
$$

(2) $S_{\mathrm{a}}=$ average settlement $=0.848 S_{\mathrm{c}}=0.839 \mathrm{in}$.

$S_{\mathrm{r}}=$ rigid footing settlement $=0.93 S_{\mathrm{c}}=0.92 \mathrm{in}$.

(3) $S^{\prime}$ = settlement of a corner of the footing at depth $\mathrm{H}=40 \mathrm{ft}$

$=\frac{\mathrm{q} \mathrm{B}^{\prime}}{2 \mathrm{E}}\left(1-\gamma^{2}\right) \quad \mathrm{I}_{3}{ }^{\prime}-\frac{(1-2 \gamma)}{(1-\gamma)} \mathrm{I}_{4^{\prime}}$

$$
B^{\prime}=\frac{B}{2}=7.5 \mathrm{ft}
$$

$I_{3}^{\prime}=0.490$, from paragraph $62, \quad m=\frac{L / 2}{B / 2}=\frac{16.4 \mathrm{ft}}{7.5 \mathrm{ft}}=2.187$

$I_{4}^{\prime}=0.119$, from paragraph 62 , and $n=\frac{H}{B / 2}=\frac{40 \mathrm{ft}}{7.5 \mathrm{ft}}$ 


$$
\begin{aligned}
S^{\prime}= & \frac{(0.49 \mathrm{tsf})(7.5 \mathrm{ft})}{2(125 \mathrm{tsf})}\left(1-0.3^{2}\right) \\
& \times\left\{0.490-\frac{[1-2(0.3)]}{(1-0.3)}(0.119)\right\} \\
= & 0.0056 \mathrm{ft}=0.0677 \mathrm{in} .
\end{aligned}
$$
(4) $S_{c f}=\underset{\text { settlement at center of flexible footing on finite }}{\text { layer }}$

$=S_{c}-\left(4 S^{\prime}\right)=0.989$ in. $-(4)(0.0677$ in. $)$

$$
S_{c f}=0.718 \text { in. }
$$

(5) $S_{a f}=$ average settlement of flexible footing on finite layer

$$
\begin{aligned}
& =0.848 S_{\mathrm{cf}} \\
S_{\mathrm{af}} & =0.609 \mathrm{in} . \\
S_{\mathrm{rf}} & =\text { settlement of rigid footing on finite layer } \\
& =0.93 S_{\mathrm{cf}} \\
S_{\mathrm{rf}} & =0.668 \mathrm{in} .
\end{aligned}
$$

e. D'Appolonia, D'Appolonia, and Brissette (1968).

$$
S=\frac{8 q}{N_{\mathrm{c}}}\left(\frac{B}{B+1}\right)^{2} C_{\mathrm{d}}
$$

$N_{\mathrm{c}}=28$ (Gibbs and Holtz (1957) corrected blowcount)

$C_{\mathrm{d}}=1.0$

$$
S=\frac{8(0.49 \mathrm{tsf})}{28}\left(\frac{15 \mathrm{ft}}{16 \mathrm{ft}}\right)^{2}
$$

$$
S=0.123 \text { in. }
$$

f. D'Appolonia, D'Appolonia, and Brissette (1970).

$$
S=\frac{q B I}{M}
$$

$I=\mu_{\mathrm{o}} \mu_{1}$, from Figure 13 (main text)

$\mu_{\mathrm{o}}=1.0(D / B=0)$ 

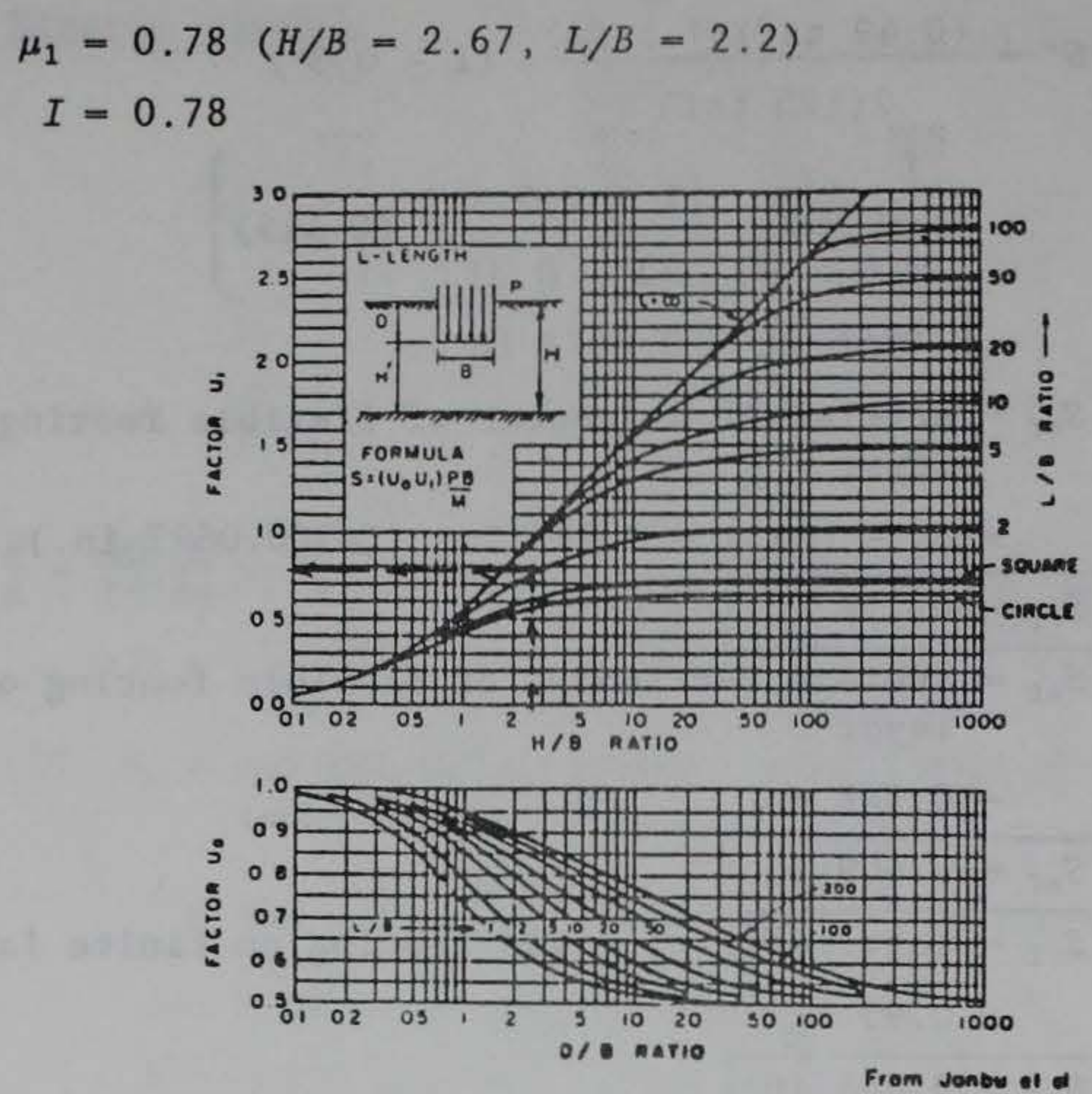

Compressibility Modulus, $M=255$ tsf, for $N=10$, Figure 14 (main text)

$$
S=\frac{q B I}{M}=\frac{(0.49 \mathrm{tsf})(15 \mathrm{ft})(0.78)}{255 \mathrm{tsf}}=0.0225 \mathrm{ft}
$$

$S=0.270 \mathrm{in}$.

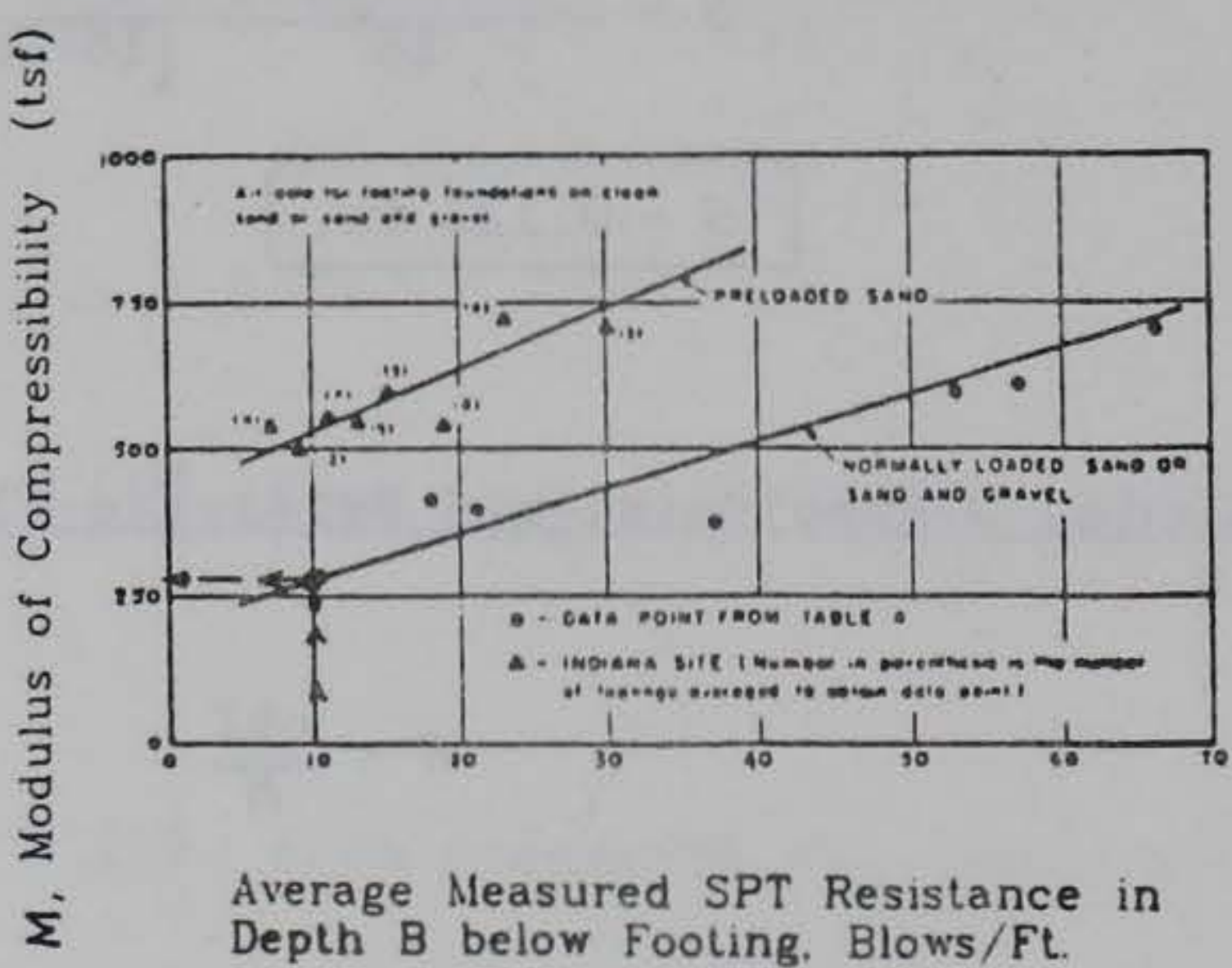


g. Peck and Bazaraa (1969)

$$
S=\frac{8 q}{N_{\mathrm{c}}}\left(\frac{B}{B+\mathrm{I}}\right)^{2} C_{\mathrm{d}} C_{\mathrm{w}}
$$

$$
C_{\mathrm{d}}=1.0, C_{\mathrm{w}}=1.0
$$

Correct blowcount for overburden

$$
\begin{gathered}
p^{\prime}=\gamma\left[p+\frac{B}{2}\right]=110 \mathrm{pcf}(7.5 \mathrm{ft})=825 \mathrm{psf}=0.825 \mathrm{ksf} \\
N_{c}=\frac{4 N}{1+2 p^{\prime}}=\frac{4(10)}{1+2(0.825 \mathrm{ksf})}=15.1 \\
S=\frac{8(0.49 \mathrm{tsf})}{15.1}\left(\frac{15 \mathrm{ft}}{16 \mathrm{ft}}\right)^{2} \\
S=0.228 \mathrm{in} .
\end{gathered}
$$

h. Schmertmann (1970)

$$
S=q C_{\mathrm{d}} C_{\mathrm{t}} \sum_{\mathrm{i}=1}^{\mathrm{n}}\left(\frac{I_{\mathrm{z}}}{E_{\mathrm{s}}}\right)_{\mathrm{i}} z_{\mathrm{i}}
$$

Assume uniform layer - constant $E_{\mathbf{s}}$ over depth of $2 B$. Therefore, the sum of the terms $\frac{I_{\mathrm{z}}}{E_{\mathrm{s}}}{ }_{i} z_{i}=\frac{0.6 B}{E_{\mathrm{s}}}$

$$
\begin{aligned}
& E_{\mathrm{s}}=2 q_{\mathrm{c}}=2(40 \mathrm{tsf})=80 \mathrm{tsf} \\
& C_{\mathrm{d}}=1.0, C_{\mathrm{t}}=1.0
\end{aligned}
$$




$$
S=(0.49 \mathrm{tsf}) \frac{0.6(15 \mathrm{ft})}{80 \mathrm{tsf}}=0.055 \mathrm{ft}
$$

$$
S=0.662 \text { in. }
$$

i. Schmertmann, Hartman, and Brown (1978)

$$
\begin{aligned}
& \qquad S=q C_{\mathrm{d}} C_{\mathrm{t}} \sum_{\mathrm{i}=1}^{\mathrm{n}}\left(\frac{I_{2}}{E_{\mathrm{s}}}\right]_{\mathrm{i}} z_{\mathrm{i}} \\
& \text { Uniform soil, constant } E_{\mathrm{s}}: \sum_{i=1}^{\mathrm{n}}\left(\frac{I_{2}}{E_{\mathrm{s}}}\right]_{\mathrm{i}} z_{\mathrm{i}}=\begin{array}{l}
\text { area under strain } \\
\text { influence diagram }
\end{array}
\end{aligned}
$$

Form the strain influence diagram:

\section{Point 1}

$$
\begin{aligned}
\text { depth, } \frac{Z_{1}}{B} & =\frac{1}{18}\left[\frac{L}{B}-1\right)+0.5 \leq 1.0 \\
& =\frac{1}{18}\left(\frac{32.8 \mathrm{ft}}{15 \mathrm{ft}}-1\right)+0.5=0.566<1.0 \\
\therefore Z_{1} & =0.566 B=8.49 \mathrm{ft} \\
I_{z}-\text { peak } & =0.5+0.1 \sqrt{\frac{q}{p^{\prime}}} \\
p^{\prime} & =\gamma\left(D+Z_{1}\right)=110 \mathrm{pcf}(8.49 \mathrm{ft})=933.90 \mathrm{psf} \\
I_{z}-\text { peak } & =0.5+0.1 \sqrt{\frac{0.49 \operatorname{tsf}(2,000)}{933.90 \mathrm{psf}}} \\
& =0.602
\end{aligned}
$$




\section{Point 2}

$$
\begin{aligned}
I_{z}-\text { intercept } & =\frac{1}{90}\left(\frac{L}{B}-1\right)+0.1 \leq 0.2 \\
& =\frac{1}{90}\left(\frac{32.8 \mathrm{ft}}{15 \mathrm{ft}}-1\right)+0.1=0.113<0.2
\end{aligned}
$$

\section{Point 3}

$$
\begin{aligned}
\frac{Z_{2}}{B} & =\frac{2}{9}\left[\frac{L}{B}-1\right]+2 \leq 4.0 \\
& =\frac{2}{9}\left[\frac{32.8 \mathrm{ft}}{15 \mathrm{ft}}-1\right)+2=2.264<4
\end{aligned}
$$

$$
\begin{aligned}
& \text { Compute } E_{\mathrm{s}}: \\
& \begin{aligned}
E_{\mathrm{s}} & =R q_{\mathrm{c}} \\
R & =\frac{1}{9}\left(\frac{L}{B}-1\right)+2.5 \leq 3.5 \\
& =2.63<3.5 \\
E_{\mathrm{s}} & =2.63(40 \text { tsf })=105.2 \text { tsf }
\end{aligned}
\end{aligned}
$$

Constant $E_{\mathrm{s}}$ with depth, $\therefore$ sum area under curve

$$
\begin{aligned}
& \text { (1) }=0.113(0.566 B)=0.064 B \\
& \text { (2) }=\frac{1}{2}(0.602-0.113)(0.566 B)=0.138 B \\
& \text { (3) }=\frac{1}{2}(2.264-0.566) B(0.602)=0.511 B
\end{aligned}
$$

TOTAL $=0.713 B$ 


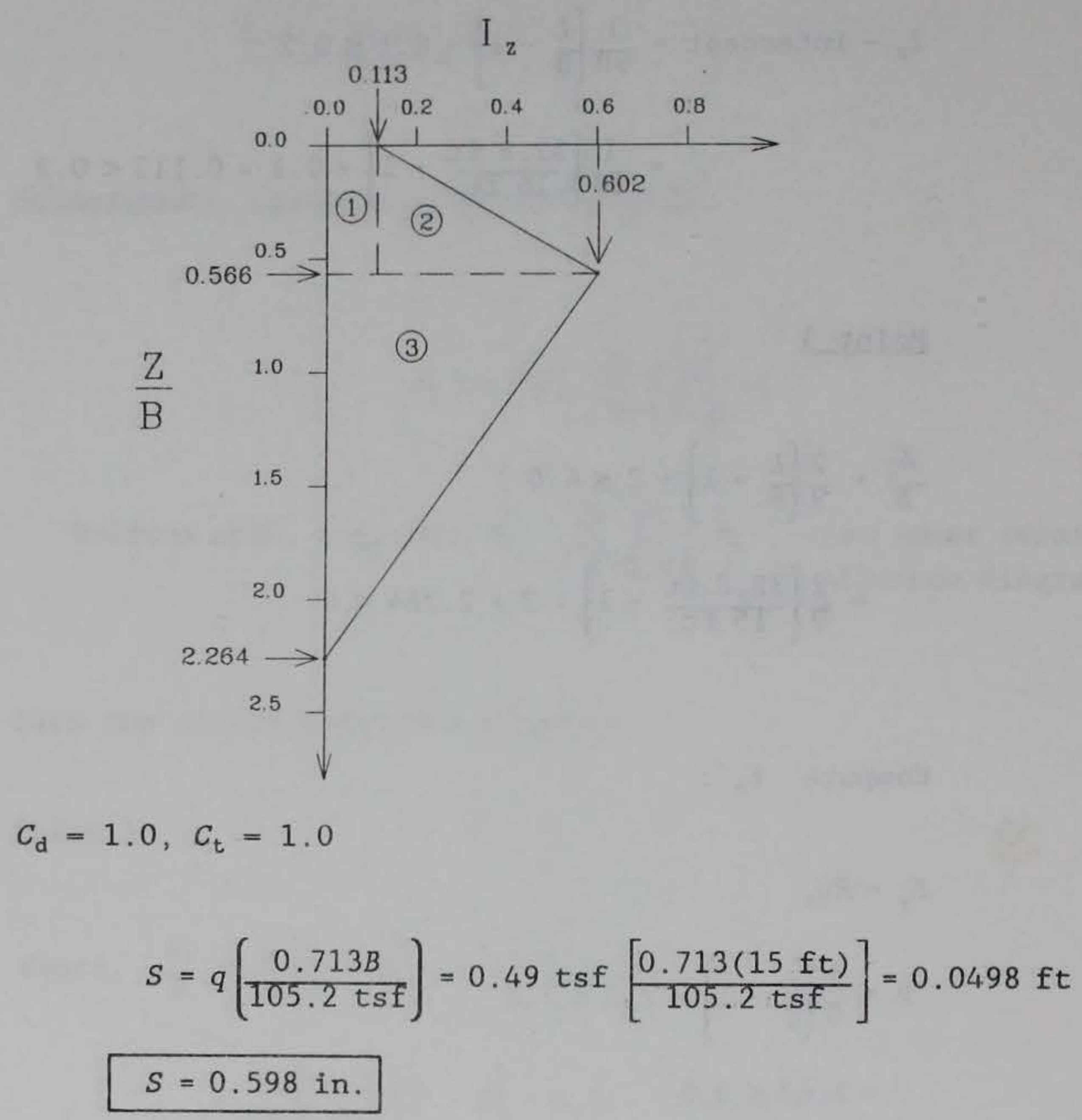

i. Schultze and Sherif (1973)

$$
S=\frac{Q F_{\mathrm{c}}}{N^{0.87} C_{\mathrm{d}}}
$$




$$
\begin{aligned}
Q & =\text { gross contact pressure }=\text { net }+\gamma D \\
q & =0.49 \mathrm{tsf}\left(\frac{0.9764 \mathrm{~kg} / \mathrm{cm}}{1 \mathrm{tsf}}\right)=0.478 \mathrm{~kg} / \mathrm{cm} \\
\gamma D & =0 \\
C_{\mathrm{d}} & =1.0
\end{aligned}
$$

Use Figure 17 (main text), $L / B$, and $B=15 \mathrm{ft}(12 \mathrm{in.} / \mathrm{ft})(2.54 \mathrm{~cm} /$ in. $)=457 \mathrm{~cm}$, to get $F_{\mathrm{c}}$ factor

$$
F_{\mathrm{c}}=9.5 \mathrm{~cm}^{3} / \mathrm{kg}
$$

$$
\begin{aligned}
& S=\frac{\left(0.478 \mathrm{~kg} / \mathrm{cm}^{2}\right)\left(9.5 \mathrm{~cm}^{3} / \mathrm{kg}\right)}{(10)^{0.87}(1.0)}=0.6126 \mathrm{~cm} \\
& S=0.241 \mathrm{in} .
\end{aligned}
$$

Check reduction factor: $D_{\mathrm{s}}=H-D=40 \mathrm{ft}$ $\frac{H}{B}=\frac{40 \mathrm{ft}}{15 \mathrm{ft}}=2.67>2.0 \therefore$ Reduction not needed

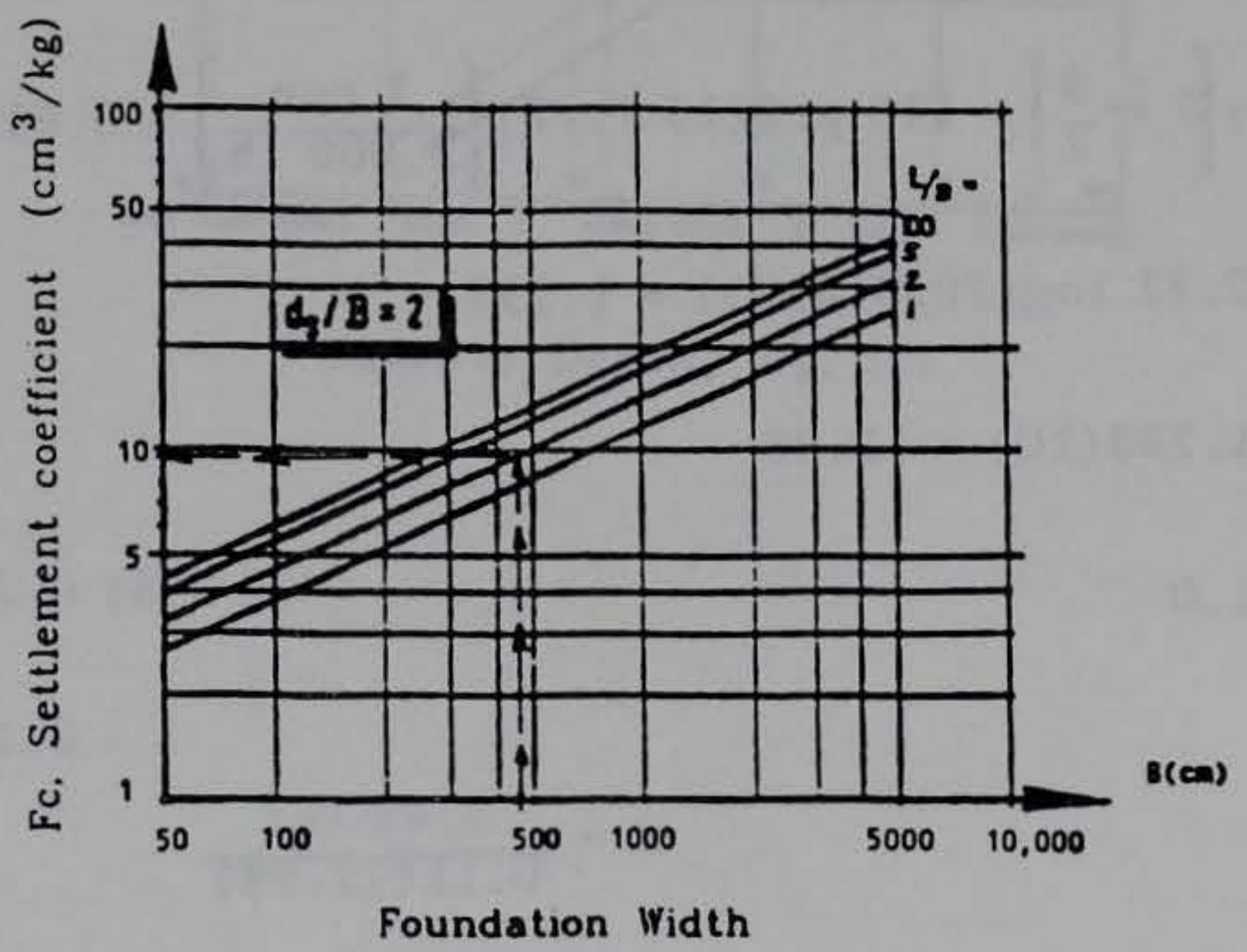


k. Meyerhof (1974).

$$
S=\frac{q \sqrt{B}}{2 N} C_{\mathrm{d}}
$$

$$
\begin{aligned}
B & =15 \mathrm{ft}=180 \mathrm{in} . \\
C_{\mathrm{d}} & =1.0
\end{aligned}
$$

$$
\begin{aligned}
& S=\frac{(0.49 \mathrm{tsf}) \sqrt{180 \mathrm{in.}}}{2(10)} \\
& S=0.329 \mathrm{in} .
\end{aligned}
$$

1. Peck, Hanson, and Thornburn (1974)

$$
S=\frac{q}{0.11 N_{c} C_{w}}
$$

$$
\begin{aligned}
& N_{\mathrm{c}}=C_{\mathrm{N}} N \\
& C_{\mathrm{N}}=0.77 \log \left(\frac{20}{P^{\prime}}\right) \\
& p^{\prime}=\gamma\left(p+\frac{B}{2}\right)=110 \mathrm{pcf}(15 \mathrm{ft} / 2)\left(\frac{1 \text { ton }}{2,0001 \mathrm{~b}}\right)=0.4125 \mathrm{tsf} \\
& C_{\mathrm{N}}=0.77 \log (20 / 0.4125)=1.298 \\
& N_{\mathrm{c}}=1.298(10)=12.98 \\
& C_{\mathrm{w}}=1.0
\end{aligned}
$$

$$
\begin{aligned}
& S=\frac{0.49 \mathrm{tsf}}{0.11(12.98)} \\
& S=0.343 \mathrm{in} .
\end{aligned}
$$


m. NAVFAC (Department of the Navy 1982)

$$
S=\frac{C q}{K_{\mathrm{v}}}\left(\frac{B}{B+I}\right)^{2} C_{\mathrm{w}}
$$

Compute relative density from Bazaraa (1967), paragraph 84, in main text.

$$
\begin{aligned}
& p^{\prime}=\gamma\left(p+\frac{B}{2}\right)=110 \mathrm{pcf}\left(\frac{15 \mathrm{ft}}{2}\right)\left(\frac{1^{\mathrm{K}}}{1,000 \mathrm{lb}}\right)=0.825 \mathrm{ksf} \\
& D_{r}=\sqrt{\frac{N}{20\left(1+2 p^{\prime}\right)}}=\sqrt{\frac{10}{20(1+2(0.825))}}=43.48
\end{aligned}
$$

Use Figure 22 (main text) and $D_{r}=43.48$ to get $K_{v}$ $K_{\mathrm{v}}=105 \mathrm{tcf}$

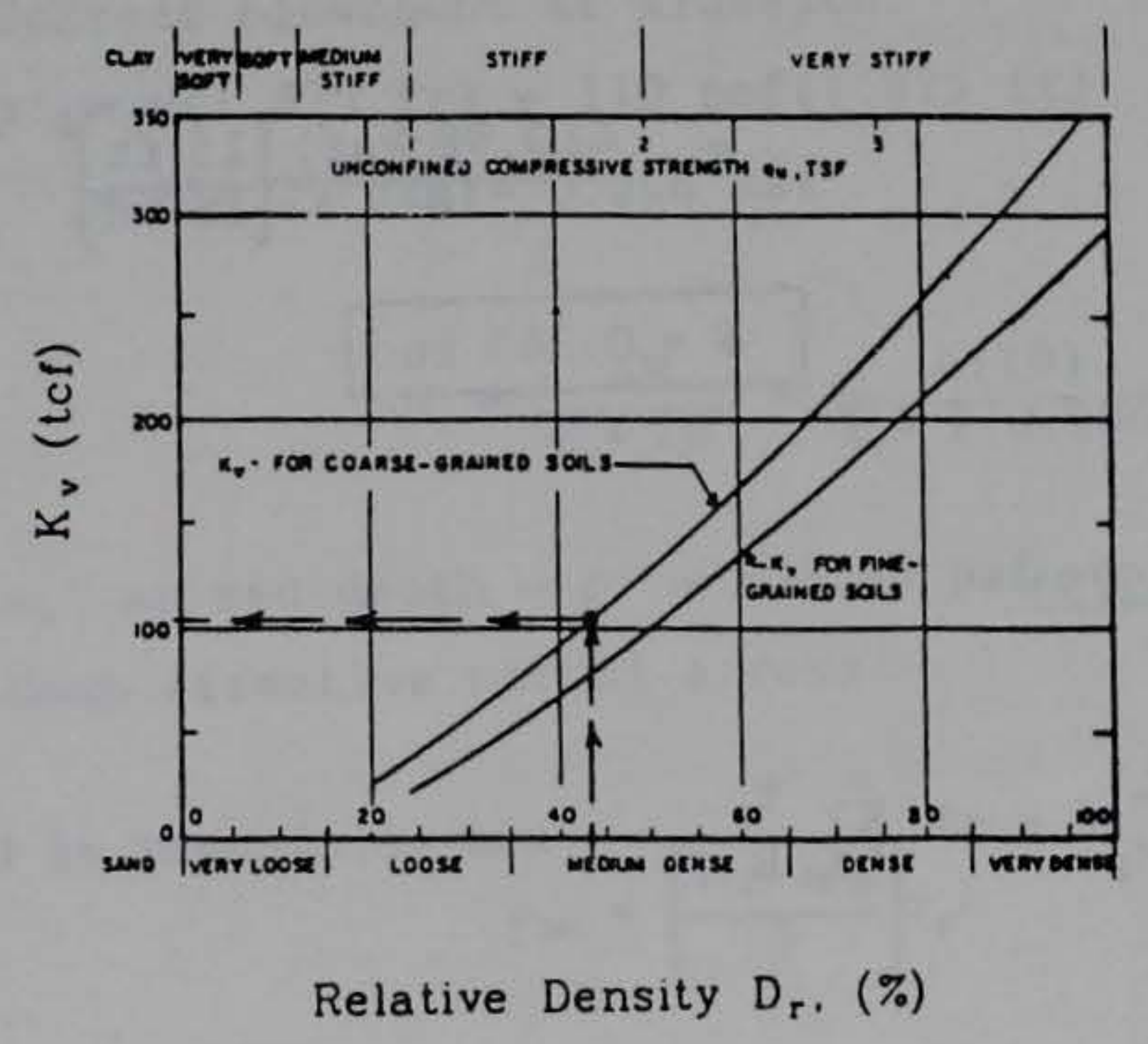

$$
\begin{aligned}
C & =4.0\left(B<20^{\prime}\right) \\
C_{\mathrm{w}} & =1.0
\end{aligned}
$$




$$
\begin{aligned}
& S=\frac{4.0(0.49 \mathrm{tsf})}{105 \mathrm{tsf}}\left(\frac{15 \mathrm{ft}}{16 \mathrm{ft}}\right)^{2}=0.0164 \mathrm{ft} \\
& S=0.197 \mathrm{in} .
\end{aligned}
$$

n. Bowles $(1977 / 82)$

$$
\begin{gathered}
S=\frac{4 q}{N}\left(\frac{B}{B+I}\right)^{2} \frac{C_{\mathrm{w}}}{C_{\mathrm{d}}} \\
q=0.49 \mathrm{tsf}\left(\frac{2^{\mathrm{K}}}{1 \mathrm{ton}}\right)=0.98 \mathrm{ksf} \\
C_{\mathrm{w}}=1.0 \\
C_{\mathrm{d}=1.0}=\frac{4(0.98 \mathrm{ksf})}{10}\left(\frac{15 \mathrm{ft}}{16 \mathrm{ft}}\right)^{2} \\
S=0.345 \mathrm{in} .
\end{gathered}
$$

o. Oweis (1979)

$$
S=\sum_{i=1}^{\mathrm{n}} \delta=q B \sum_{i=1}^{\mathrm{n}} \frac{\Psi_{i}}{E_{\mathrm{i}}}-\text { sum settlement of individual layers }
$$

(1) Subdivide the stratum into layers over a depth of $2 \times B$ below the footing base: 


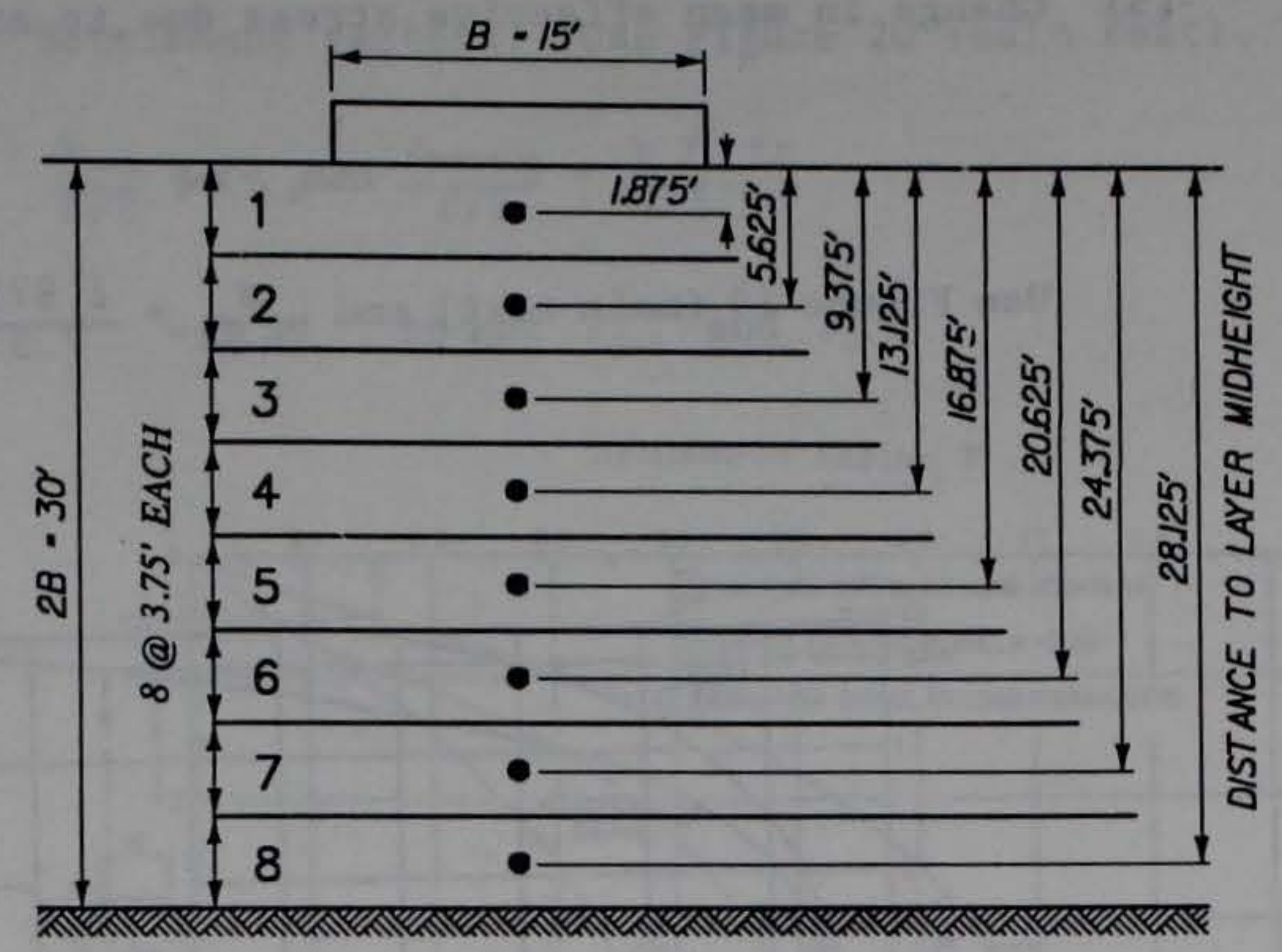

The following steps (2 through 12 ) are performed to calculate settlement of the top sublayer under the center of a flexible footing.

(2) Correct blowcount at middepth:

$$
\begin{aligned}
p^{\prime} & =\gamma(1.875 \mathrm{ft})=110 \mathrm{pcf}(1.875 \mathrm{ft}) \\
& =206.25 \mathrm{psf}=0.206 \mathrm{ksf}
\end{aligned}
$$

$$
N_{c}=\frac{4 N}{1+2 p^{\prime}}=\frac{4(10)}{1+2(0.206)}=28.32
$$

(3) $\sigma_{\mathrm{v}}{ }^{\prime}$ at mid-depth $=p^{\prime}=206.25 \mathrm{psf}$

(4) Mean effective normal stress:

$$
\begin{aligned}
\sigma_{\mathrm{mo}} & =\left(\frac{1+2 K_{\mathrm{o}}}{3}\right) \sigma_{\mathrm{v}^{\prime}} \\
& =\frac{1+2(0.5)}{3}(206.25 \mathrm{psf}) \\
& =137.5 \mathrm{psf}
\end{aligned}
$$


(5) Change in mean effective stress due to applied load: $\Delta \sigma_{\mathrm{m}}$

$$
\Delta \sigma_{\mathrm{m}}=\alpha q
$$

Use Figure 19 (main text) and $\frac{z}{0.5 B}=\frac{1.875 \mathrm{ft}}{7.5 \mathrm{ft}}=0.25$, to get $\alpha$

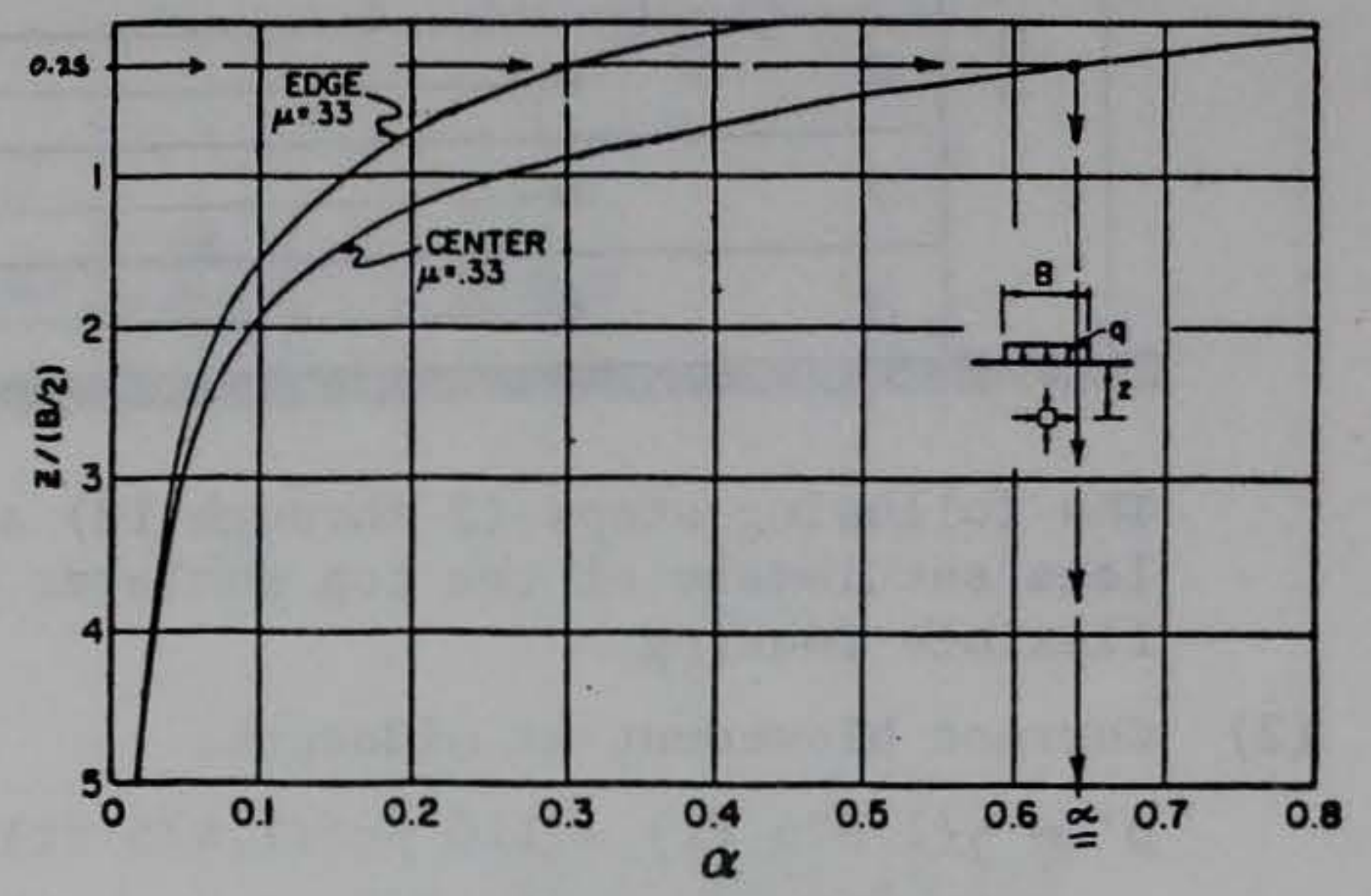

$$
\begin{aligned}
\alpha & \approx 0.64 \\
\Delta \sigma_{\mathrm{m}} & =0.64(0.49 \text { tsf })(2,000) \\
& =627.2 \mathrm{psf}
\end{aligned}
$$

(6) $K_{\max }=17.2\left(N_{\mathrm{c}}\right)^{0.42}=17.2(28.32)^{0.42}$

$$
=70.05
$$

(7) Maximum elastic modulus of layer

$$
\begin{aligned}
E_{\max } & =K_{\max } \sqrt{\sigma_{\mathrm{mo}}+\Delta \sigma_{\mathrm{m}}} \\
& =70.05 \sqrt{(137.5+627.2) \mathrm{psf}} \\
& =1,937.11 \mathrm{ksf}
\end{aligned}
$$


(8) Settlement factors: Use Figure 20 (main text), and

$$
\begin{aligned}
\frac{z_{\text {top }}}{B / 2} & =0, \text { and } \frac{z_{\text {bottom }}}{B / 2}=\frac{3.75 \mathrm{ft}}{7.5 \mathrm{ft}} \\
& =0.50 \text {, to get } F_{1-1} \text { and } F_{i}
\end{aligned}
$$

\section{Settlement Factor, F}

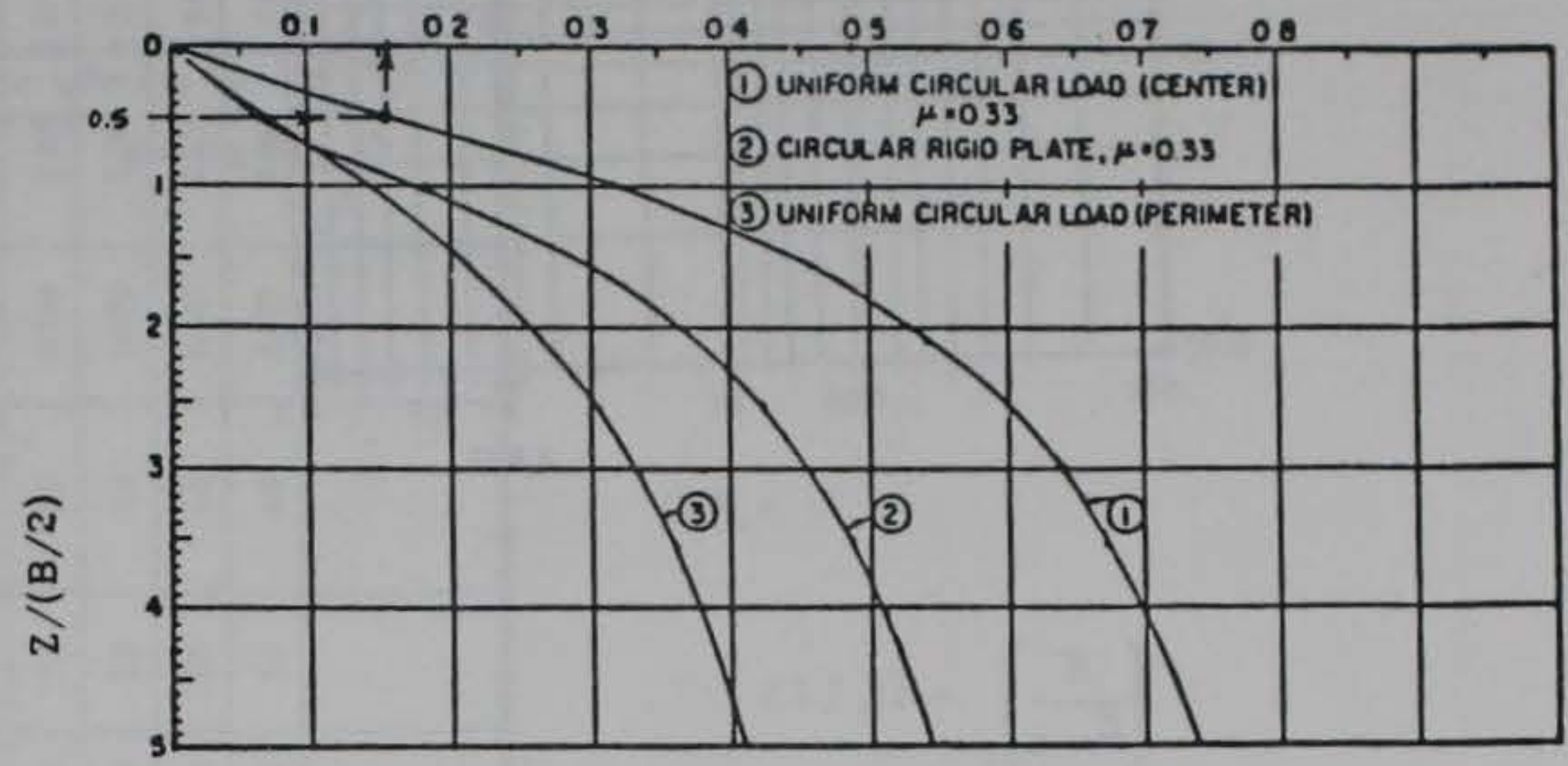

For top layer, $i=1$ :

$F_{i-1}=0$

$$
F_{1}=0.158
$$

(9) $\Psi_{1}=F_{1}-F_{i-1}=0.158-0=0.158$

$$
\lambda_{1}=\frac{\Psi_{1} q B}{h_{1} E_{\max }}=\frac{0.158(0.49 \mathrm{tsf})\left(\frac{2 k}{I}\right)(15 \mathrm{ft})}{(3.75 \mathrm{ft})(1,937.11 \mathrm{ksf})}=0.0003197=0.0328
$$

(10) Use Figure 21 (main text) and $\lambda_{1}$, to get the ratio $\left(\frac{E}{E_{\max }}\right)_{1}$ 


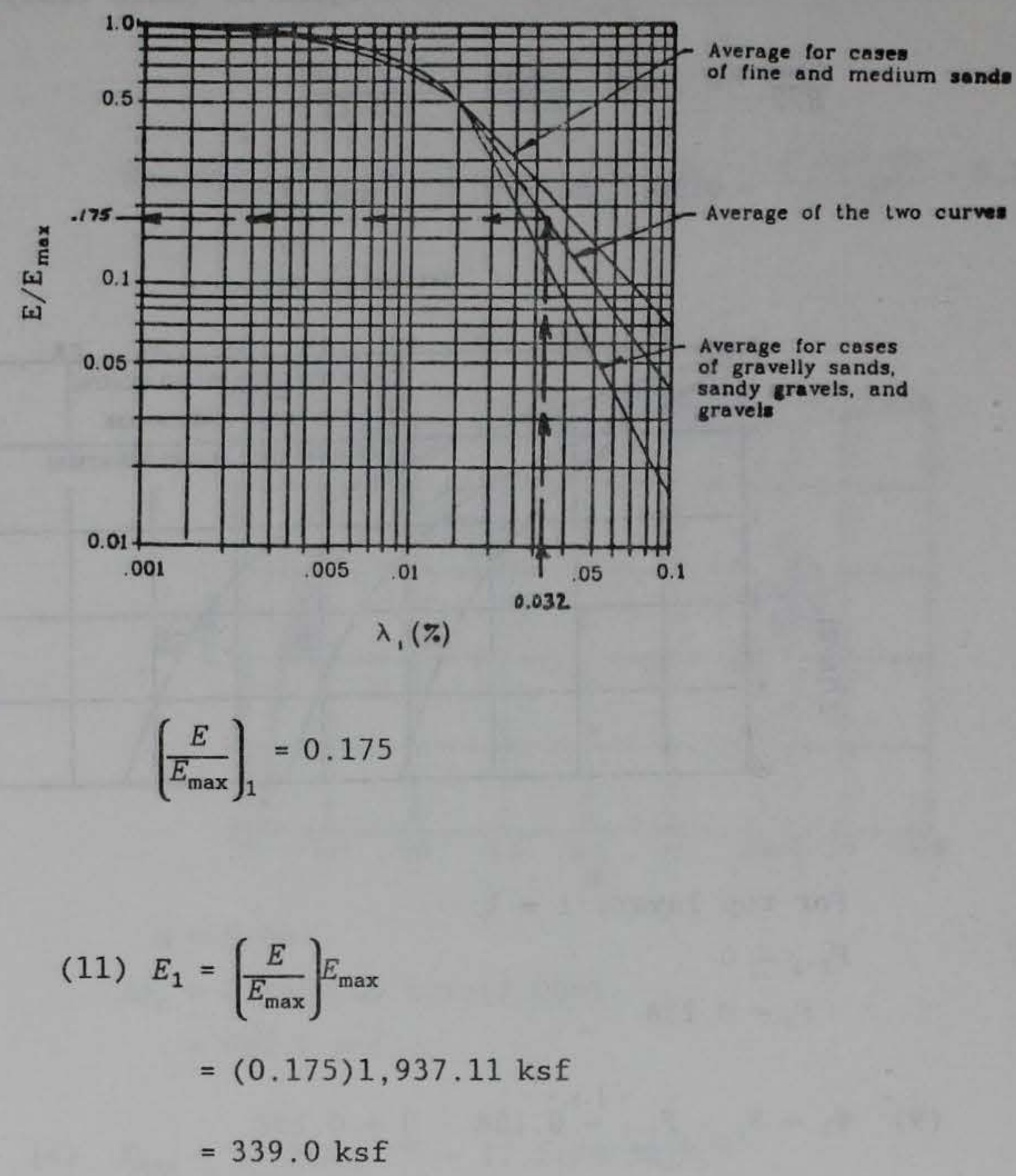

(12) Layer 1 settlement:

$$
\begin{aligned}
\delta_{1} & =\frac{q B \Psi_{1}}{E_{1}}=\frac{0.49 \mathrm{tsf}\left(\frac{2 \text { kips }}{1 \text { ton }}\right)(15 \mathrm{ft}) 0.158}{339 \mathrm{ksf}} \\
& =0.00685 \mathrm{ft} \\
& =0.082 \mathrm{in} .
\end{aligned}
$$

Settlement calculations for the remaining sublayers and for all edge and rigid footing settlement are shown in the following charts. Table 11 (main text) is used to record results from each step of the calculations. 
For: (Center Edge Rigid) Setllement.

\begin{tabular}{|c|c|c|c|c|c|c|c|c|c|c|c|c|c|c|c|c|c|c|c|}
\hline $\begin{array}{l}\text { Layer } \\
\text { No. }\end{array}$ & $\begin{array}{c}\text { Layer } \\
\text { Thickness } \\
h_{\mathrm{i}}\end{array}$ & $\begin{array}{l}\text { Blows } \\
\text { per foot, } \\
N\end{array}$ & $\begin{array}{c}\text { Corrected } \\
\text { Blowcount } \\
N_{\mathrm{c}}\end{array}$ & $\begin{array}{c}\text { Midlayer } \\
\sigma_{v}^{\prime} \\
\text { (psf) }\end{array}$ & $\begin{array}{l}\text { Mean Init. } \\
\text { Stress, } \sigma_{\text {mo }} \\
\text { (psf) }\end{array}$ & $\frac{z \text {-midlayer }}{0.5 B}$ & $\begin{array}{l}\text { Alpha } \\
\text { Factor }\end{array}$ & $\begin{array}{l}\Delta \sigma_{\mathrm{m}} \\
(\mathrm{psf})\end{array}$ & $K_{\max }$ & $\begin{array}{l}E_{\max } \\
(\mathbf{k s f})\end{array}$ & $\frac{z-10 p}{0.5 B}$ & $\frac{\text { 2-bottom }}{0.5 B}$ & $\begin{array}{l}\text { (top) } \\
F_{(0-1)}\end{array}$ & $\begin{array}{c}\text { (bottom) } \\
F_{i}\end{array}$ & $\psi_{1}$ & $\begin{array}{l}\lambda_{1} \\
(\%)\end{array}$ & $\frac{E}{E_{\max }}$ & $\underset{(\mathrm{ksf})}{E_{\mathrm{i}}}$ & $\underset{\text { (feet) }}{\delta_{1}}$ \\
\hline 1 & $3.75^{\circ}$ & 10 & 28.32 & 206.2 & 137.5 & 0.25 & 0.64 & 627.2 & 70.05 & $1,937.1$ & 0 & 0.5 & 0 & 0.158 & 0.158 & 0.032 & 0.175 & 339.0 & 0.00685 \\
\hline 2 & & & 17.88 & 618.8 & 412.5 & 0.75 & 0.355 & 347.9 & 57.74 & $1,592.3$ & 0.5 & 1.0 & 0.158 & 0.320 & 0.162 & 0.040 & 0.140 & 222.9 & 0.01068 \\
\hline 3 & & & 13.06 & $1,031.2$ & 687.5 & 1.25 & 0.190 & 186.2 & 50.61 & $1,495.9$ & 1.0 & 1.5 & 0.320 & 0.448 & 0.128 & 0.034 & 0.165 & 246.8 & 0.00762 \\
\hline 4 & & & 10.29 & $1,443.8$ & 962.5 & 1.75 & 0.115 & 112.7 & 45.78 & $1,501.3$ & 1.5 & 2.0 & 0.448 & 0.530 & 0.082 & 0.021 & 0.330 & 495.4 & 0.00243 \\
\hline 5 & & & 9.57 & $1,856.2$ & $1,237.5$ & 2.25 & 0.080 & 78.4 & 44.42 & $1,611.4$ & 2.0 & 2.5 & 0.530 & 0.600 & 0.070 & 0.017 & 0.440 & 709.0 & 0.00145 \\
\hline 6 & & & 9.12 & $2,268.8$ & $1,512.5$ & 2.75 & 0.055 & 53.9 & 43.53 & $1,722.8$ & 2.5 & 3.0 & 0.600 & 0.640 & 0.040 & 0.009 & 0.700 & $1,206.0$ & 0.000483 \\
\hline 7 & & & 8.71 & $2,681.2$ & $1,787.5$ & 3.25 & 0.041 & 40.18 & 42.70 & $1,825.4$ & 3.0 & 3.5 & 0.640 & 0.672 & 0.032 & 0.007 & 0.750 & $1,369.0$ & 0.000342 \\
\hline 8 & & & 8.35 & $3,093.8$ & $2,062.5$ & 3.75 & 0.032 & 31.36 & 41.92 & $1,918.1$ & 3.5 & 4.0 & 0.672 & 0.698 & 0.026 & 0.005 & 0.850 & $1,630.4$ & 0.000233 \\
\hline & & & & & & & & & & & & & & & & & & \multicolumn{2}{|c|}{$\begin{array}{r}\text { Total }=0.03009 \mathrm{ft} \\
S=0.361 \mathrm{in} . \\
\text { center-flexible }\end{array}$} \\
\hline
\end{tabular}

(Sheet 1 of 3) 
For: (Center Edge Rigid) Settlement.

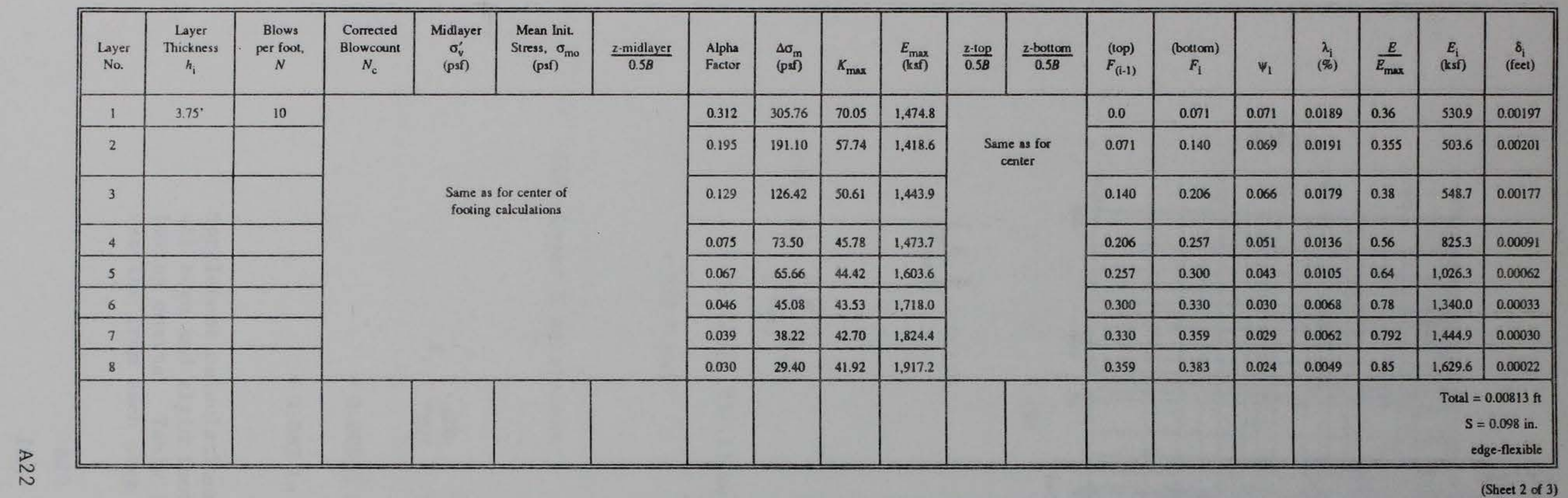


For: (Center Edge Kigid) Settlement.

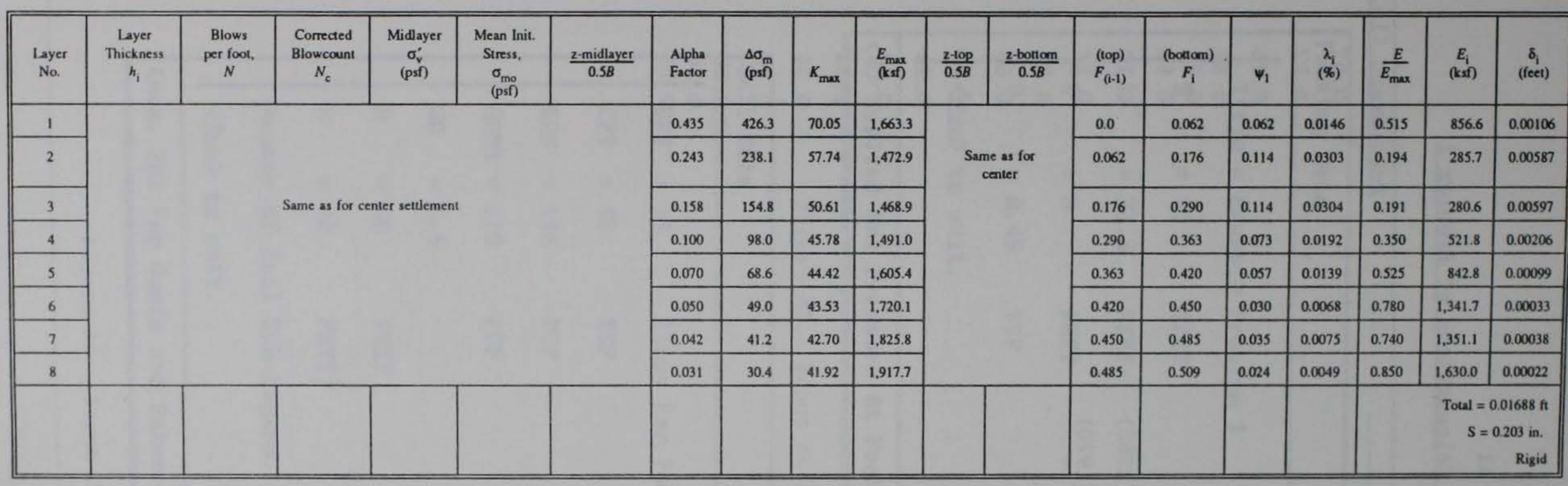


Table A1

Summary of Results from Hand Calculations of Problem 1

Method

Terzaghi and Peck (1948, 1967)

Teng (1962)

Alpan (1964)

Elastic Theory - rigid center (flex.) average (flex.)
Settlement (in.)

0.52

0.17

0.26

0.67

0.72

0.61

0.12

0.27

0.23

0.66

0.60

0.24

0.33

0.34

0.34

0.20

0.20

0.36

0.10 


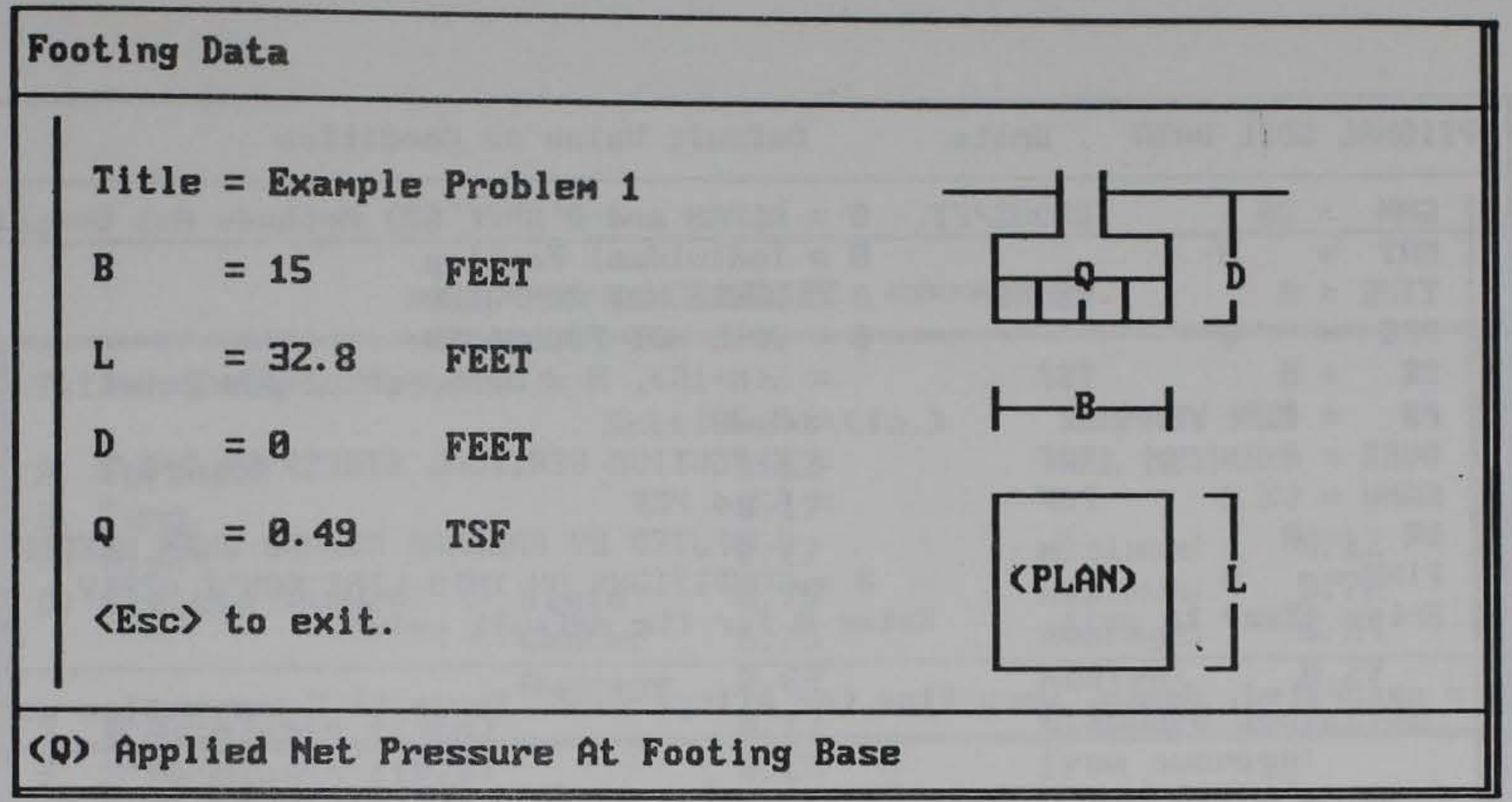

Figure A2. Input data for footing of Problem 1

\begin{tabular}{|ll}
\hline Soil Data & \\
\hline SPT $=10$ & Blows Per Foot \\
CPT $=40$ & TSF \\
GAM $=110$ & PCF \\
GAMS $=110$ & PCF \\
KO $=0.5$ & \\
$H=48$ & FEET \\
$W=40$ & FEET \\
Number of Soil & Sub-Layers \\
$\langle$ Esc to exit. &
\end{tabular}

(max. 20) For Oweis and Schmert. methods. Enter 1 if no layers

Figure A3. Input data for soil of Problem 1 


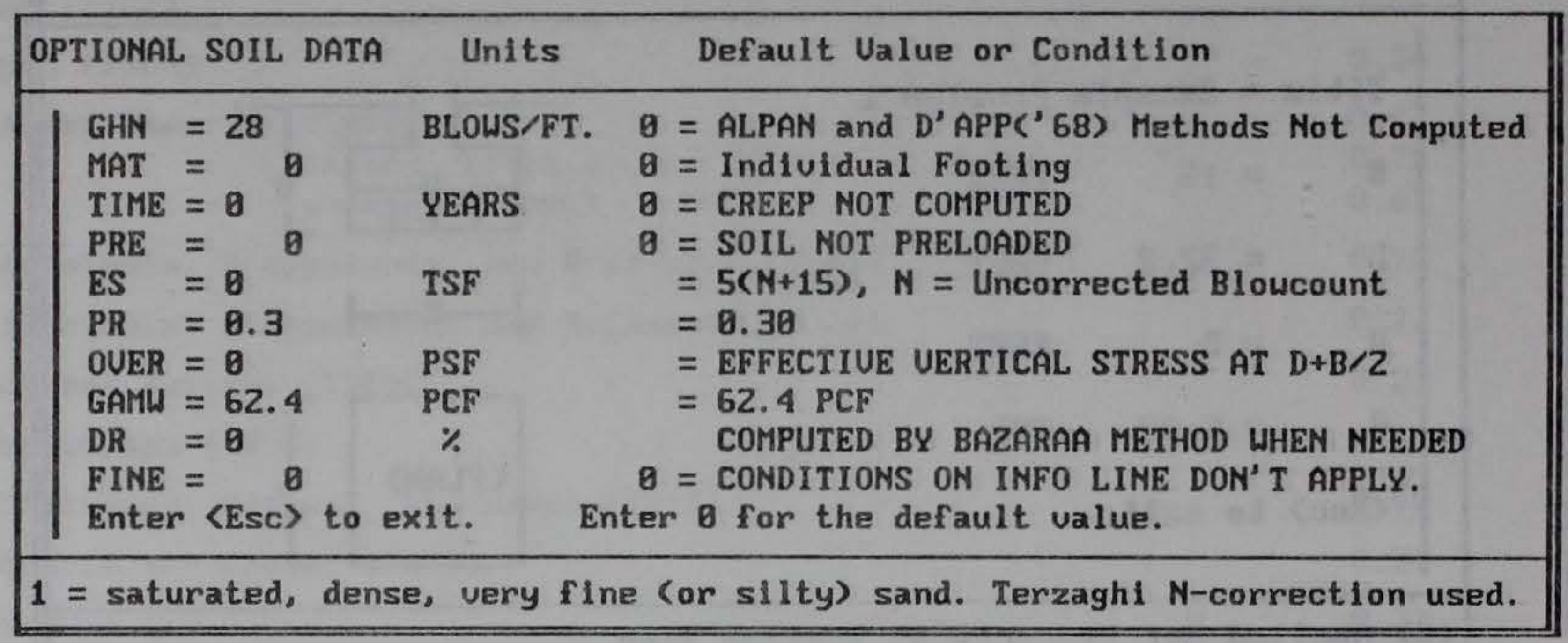

Figure A4. Input of optional soil data for Problem 1

CSANDSET - IMPUT DATA

Title: Example Problem 1

Footing Data:

Width $=15.00 \mathrm{Ft}$

Length $=32.80 \mathrm{Ft}$

Depth $=0.00 \mathrm{Ft}$

Pressure $=0.49 \mathrm{TSF}$

Soll Data:

Blowcount $=10.08 \mathrm{Bl} / \mathrm{Ft}$

Cone Penetrometer $=40.00 \mathrm{TSF}$

Unit Weight $=110.00 \mathrm{PCF}$

Sat'd Unit Weight $=110.00 \mathrm{PCF}$

Horiz. Earth Pressure $=0.50$

Depth To Rigid Layer $=40.00 \mathrm{Ft}$

Depth To Water $=48.00 \mathrm{FT}$

Optional Soil Data:

Gibbs \& Holtz Blowcount $=28.00 \mathrm{BL} / \mathrm{FT}$

Creep Factor Time $=0.00 \operatorname{Year}(s)$

Elastic Modulus $=0.00 \mathrm{TSF}$

Poisson's Ratio $=$ 0. 30

Blowcount Ouerburden $=825$. 00 PSF

Water Unit Weight $=62.40$ PCF

Soll Relative Density $=0.00 \%$

$1=$ yes, $\theta=$ no:

Mat Foundation $=0$

Preloaded Soll = 0

Sat' $d$, dense, fine sand $=0$

〈Esc〉 to continue.

Figure A5. Listing of all input data for Problem 1 


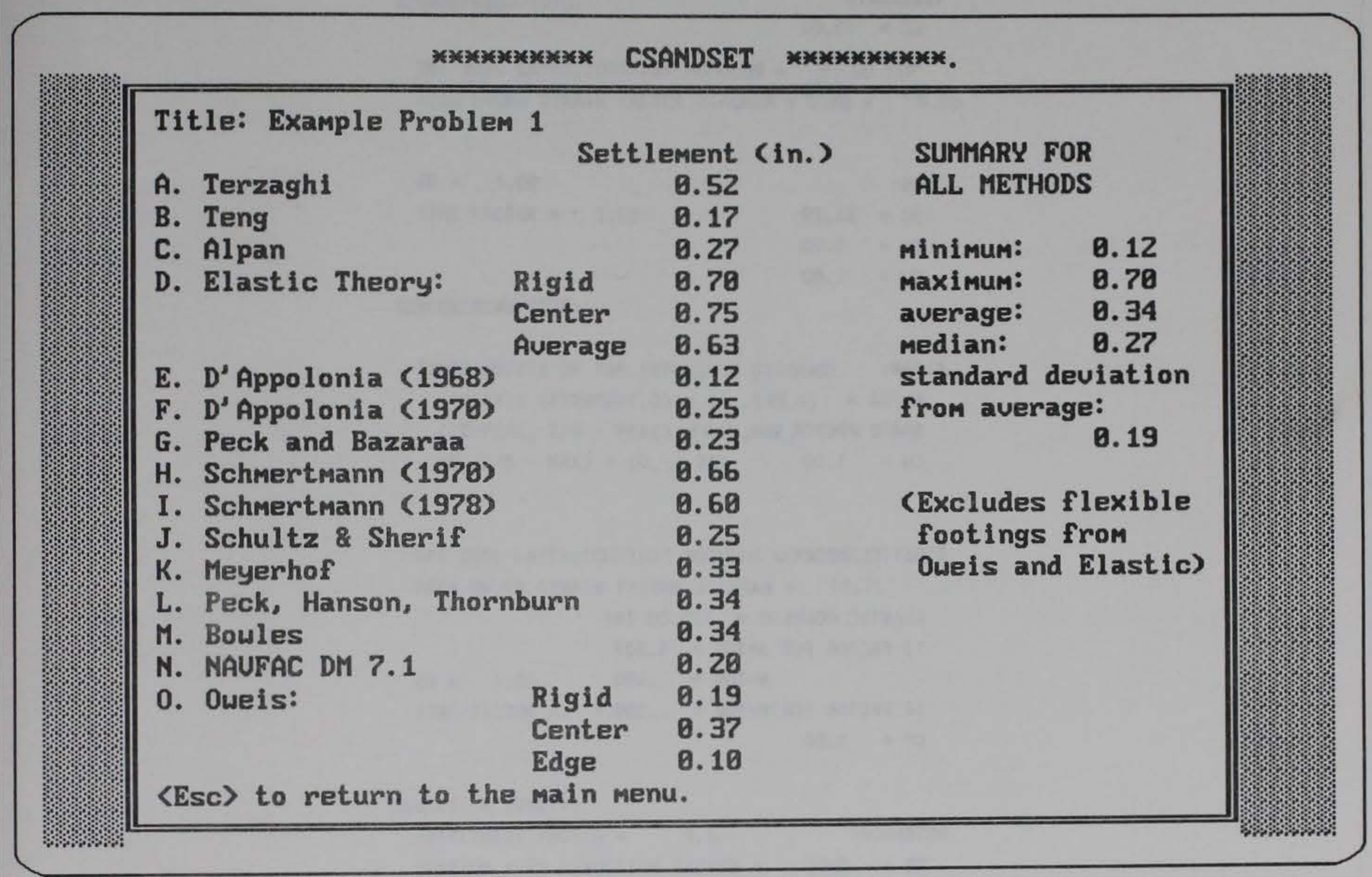

Figure A6. CSANDSET settlement calculations for Problem 1 


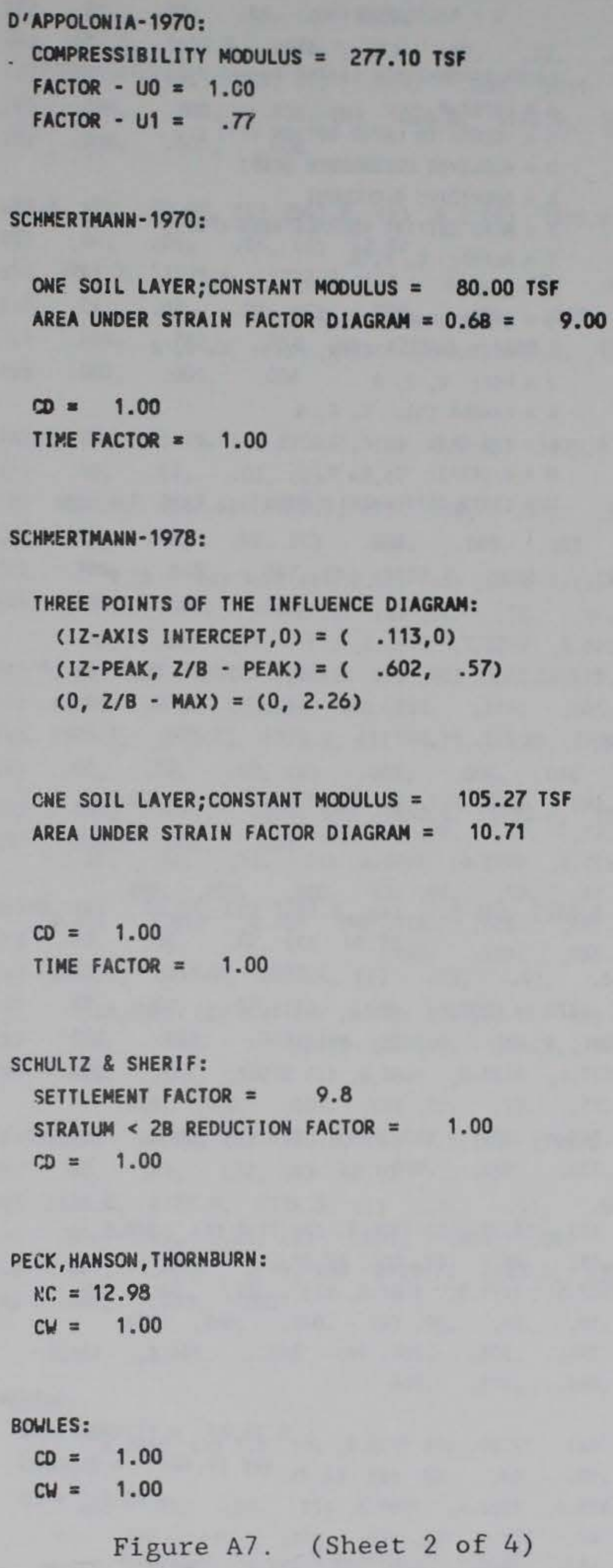


OHEIS

$$
\begin{aligned}
& C=\text { CENTER OF FLEXIBLE FOOTING } \\
& E=\text { EDGE OF FLEXIBLE FOOTING } \\
& R=\text { RIGID FDOTING }
\end{aligned}
$$

LAYER INFORMATION LISTED IN THE FOLLONING ORDER:
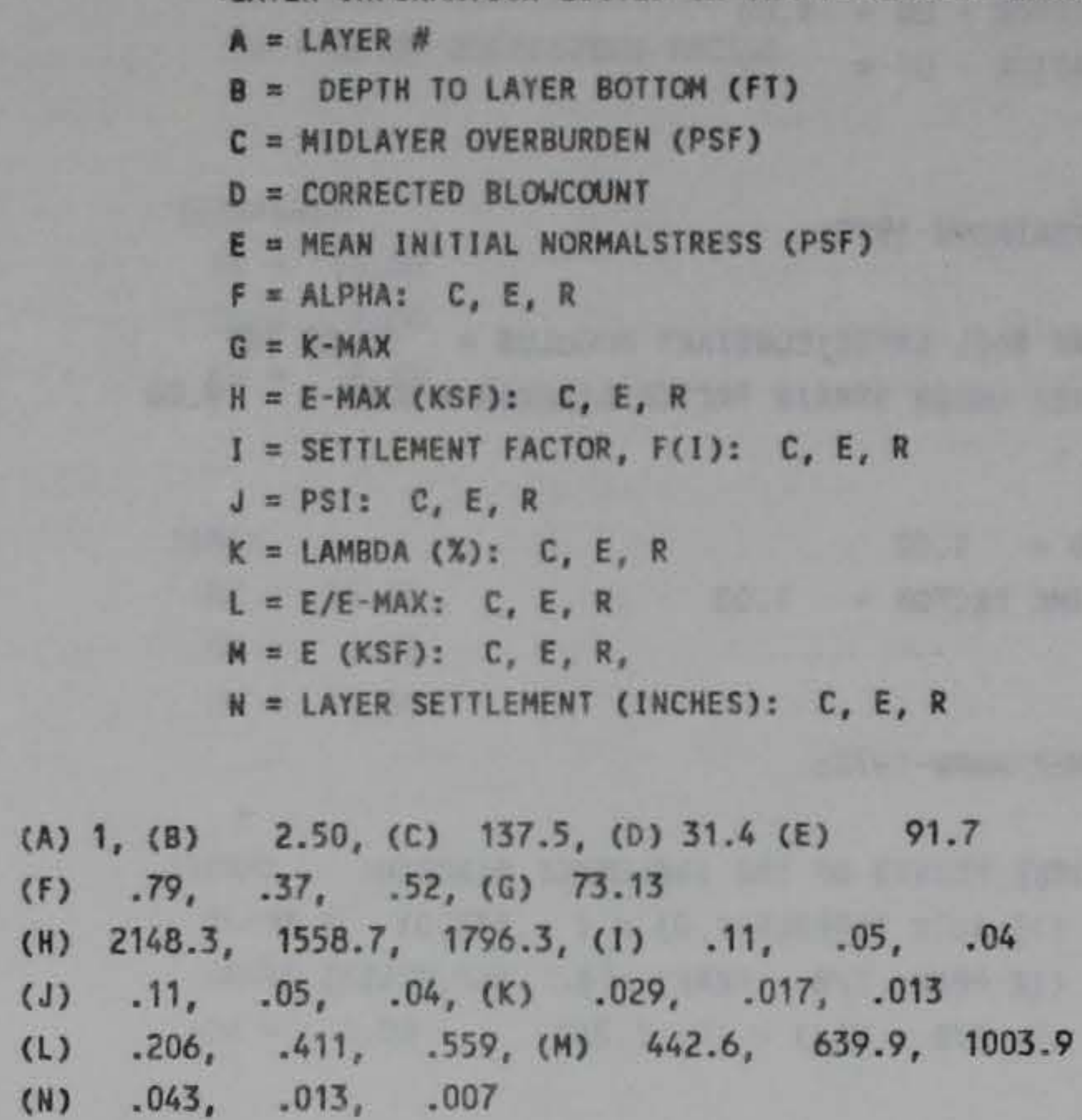

(A) 2, (B) 6.25 , (C) 481.3 , (D) 20.4 (E) 320.8

(F) $.41, .21, .29$, (G) 61.01

(H) $1635.9,1405.6,1496.6$, (1) $.27, .12, .14$

(J) $.16, .07, .10,(\mathrm{~K}) \quad .038, .020, .025$

(L) $.143, .335, .250$, (M) $234.5, \quad 470.3, \quad 374.4$

(N) $.120, .027, .045$

(A) 3, (B) 10.00, (C) 893.8, (D) 14.3 (E) 595.8

(F) $.24, .14, .18$, (G) 52.65

(H) $1517.4,1428.0,1464.0$, (1) .42, .19, .25

(J) $.15, .07, .11$, (K) $.038, .019, .031$

(L) $.143, .375, .192$, (M) $217.5, \quad 535.2,281.5$

(N) $.120, .022, .072$

(A) 4, (B) 13.75 , (C) 1306.3, (D) 11.1 (E) 870.8

(F) $.15, .10, .12$, (G) 47.22

(H) $1507.6,1471.5,1487.0$, (1) .51, .24, .34

(J) $.10, .06, .09,(\mathrm{~K}) .025, .015, .023$

(L) $.254, .506, .284$, (M) $383.0,744.6,422.8$

(N) $.044, .013, .036$

(A) 5 , (B) 17.50 , (C) 1718.8 , (D) 9.7 (E) 1145.8

(F) $.10, .08, .09$, (G) 44.73

(H) $1576.4,1562.4,1569.3$, (I) $.58, .29, \quad .40$

(J) $.07, .04, .06,(\mathrm{~K}) .016, .011, .016$

(L) $\quad .45 ?, \quad .604, \quad .462$, (M) $712.4,944.3,724.9$

(N) $.015, .008, .016$

Figure A7. (Sheet 3 of 4) 


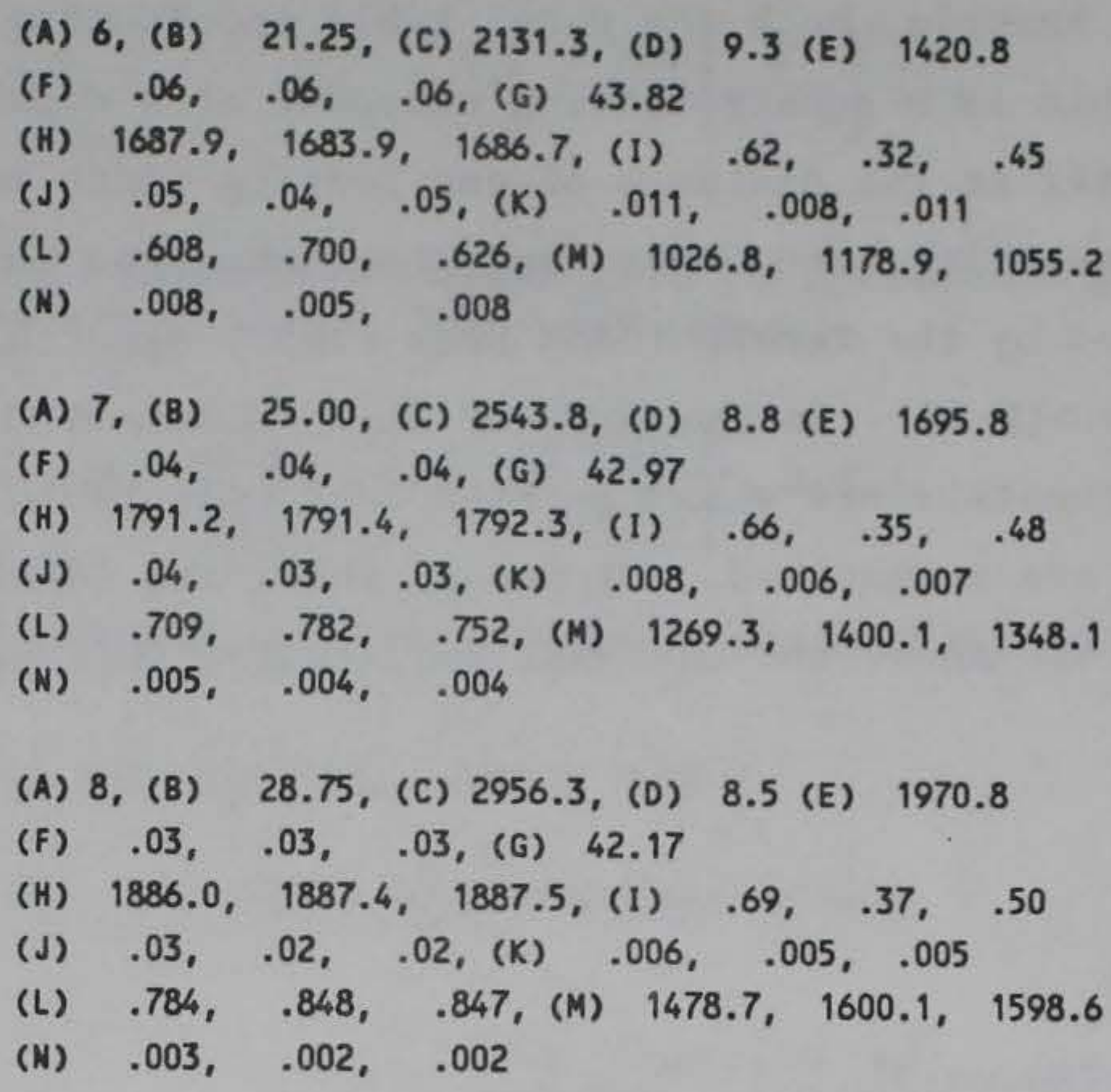

\section{NAVFAC:}

REL. DENSITY $=43.44 \%$

MODULUS $=104.91 \mathrm{TSF}$

$\mathrm{CU}=1.00$

Figure A7. (Sheet 4 of 4 ) 


\section{Problem 2}

5. In this example, both the water table and footing embedment must be accounted for. This is a square footing embedded at a depth half its width, with the groundwater at the distance of one footing width below the surface. The soil is a dense silty sand, therefore, the submerged part should have the blowcount corrected by the Terzaghi and Peck (1967) equation for this type of sand, $N_{c}=15+0.5(N-15)$ in the methods that recommend this correction.

Dimensions and parameters are shown in Figure A8. In Table A2, the resulting hand calculations are summarized. Figure A9 shows the CSANDSET input listing screen and Figure A10 shows the CSANDSET results for this problem.
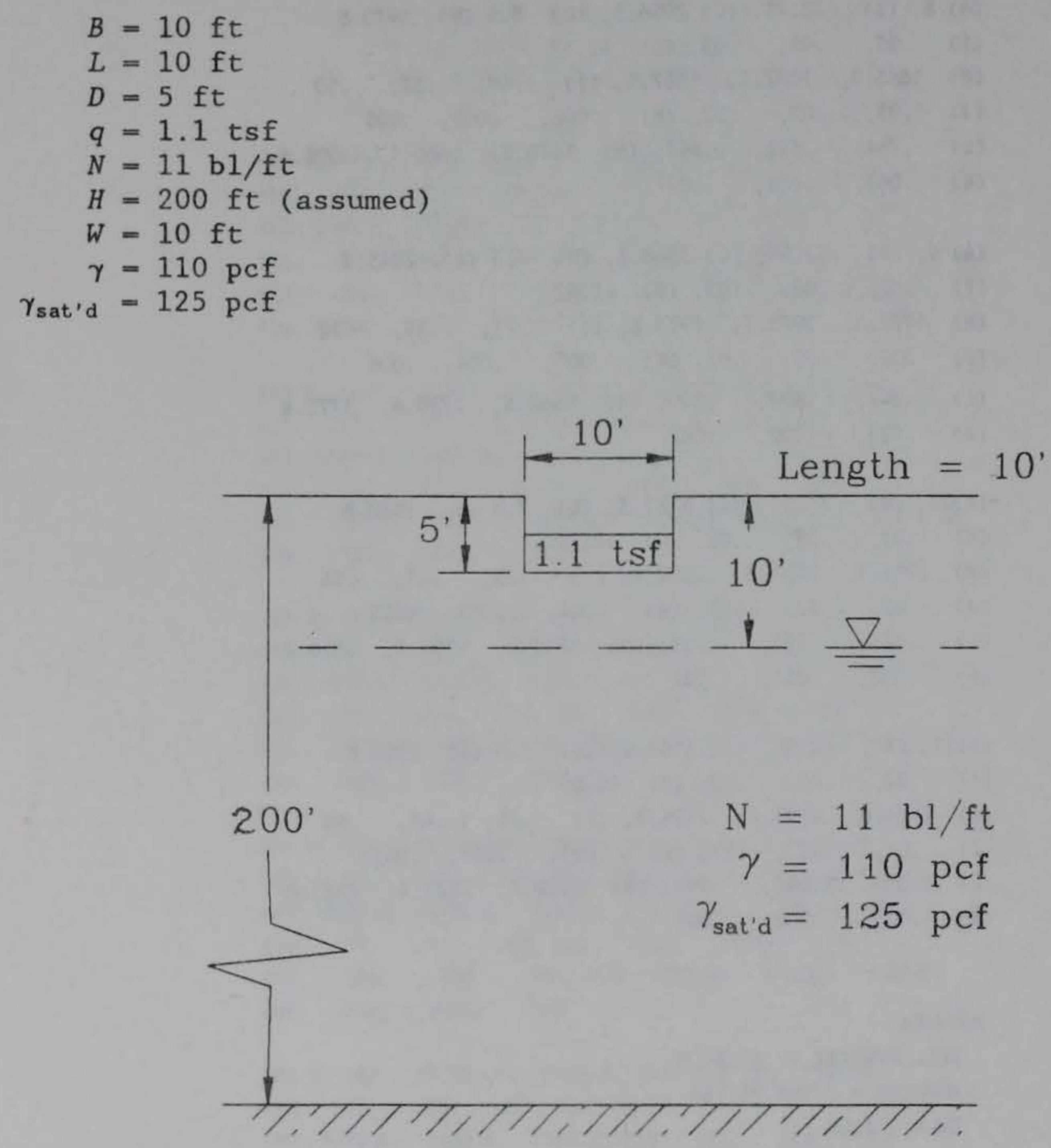

Figure A8. Example Problem 2 


\section{a. Terzaghi and Peck $(1948,1967)$}

$$
S=\frac{12 q}{N}\left(\frac{B}{B+I}\right)^{2} C_{\mathrm{w}} C_{\mathrm{d}}
$$

$C_{\mathrm{w}}=1.0$, footing not submerged. No correction given for embedded footings unless fully submerged.

$$
C_{\mathrm{d}}=1-0.25\left(\frac{D}{B}\right)=1-0.25\left(\frac{5 \mathrm{ft}}{10 \mathrm{ft}}\right)=0.875
$$

Correct blowcount for saturated, dense silty sand at $D+\frac{B}{2}$.

$N_{\mathrm{c}}=15+0.5(N-15)$, for $N>15$.

$N=11$, therefore do not use correction.

$$
S=\frac{12(1.1 \mathrm{tsf})}{11}\left(\frac{10 \mathrm{ft}}{11 \mathrm{ft}}\right)^{2}(0.875)
$$

$$
S=0.868 \mathrm{in}
$$




\section{b. Teng (1962)}

$$
\begin{aligned}
& S=\frac{q}{720\left(N_{c}-3\right)}\left(\frac{2 B}{B+I}\right)^{2}\left(\frac{1}{C_{w} C_{d}}\right) \\
& C_{\mathrm{w}}=0.5+0.5\left(\frac{\mathrm{W}-D}{B}\right) \geq 0.5 \\
& =0.5+0.5\left(\frac{10 \mathrm{ft}-5 \mathrm{ft}}{10 \mathrm{ft}}\right) \\
& =0.75 \\
& C_{\mathrm{d}}=1+\frac{D}{B} \leq 2.0 \\
& =1+\frac{5}{10} \\
& =1.5 \\
& N_{\mathrm{c}}=\frac{N(50)}{\left(p^{\prime}+10\right)} \\
& p^{\prime}=\gamma^{\prime}\left(p+\frac{B}{2}\right)=110 \operatorname{pcf}\left[5 \mathrm{ft}+\frac{10 \mathrm{ft}}{2}\right)=1,100 \operatorname{psf}\left(\frac{1}{144 \text { in. }^{2}}\right) \\
& =7.639 \mathrm{psi} \\
& N_{\mathrm{c}}=\frac{11(50)}{(7.639+10)}=31.2 \\
& S=\frac{1.1 \operatorname{tsf}\left(\frac{2,000 \mathrm{lb}}{1}\right)}{720(31.2-3)}\left(\frac{20 \mathrm{ft}}{11 \mathrm{ft}}\right)^{2} \frac{1}{(0.75)(1.5)} \\
& S=0.319 \text { in. }
\end{aligned}
$$


c. Alpan (1964)

$$
S=\alpha q\left(\frac{2 B}{B+I}\right)^{2} m C_{w}
$$

Corrected Blowcount from Gibbs and Holtz (1957) curve, Figure 11 (main text), $N_{c}=26.5$.

Correct this for saturated, dense, silty sand: $N_{\mathrm{c} 2}=15+0.5\left(N_{\mathrm{c}}-15\right)$

$N_{\mathrm{c} 2}=15+0.5(26.5-15)=20.75$

Use Figure 9 (main text) to get $\alpha . \alpha=0.165$

$\frac{L}{B}=\frac{10 \mathrm{ft}}{10 \mathrm{ft}}=1$, therefore, $m=1.0$

$C_{\mathrm{w}}=1.0$. Correction applies to water at footing base.

$$
S=(0.165)(1.1 \mathrm{tsf})\left(\frac{20 \mathrm{ft}}{11 \mathrm{ft}}\right)^{2}
$$

$$
S=0.600 \text { in. }
$$

\section{d. Elastic Theory}

$$
S=q B \frac{\left(1-\gamma^{2}\right)}{E} I C_{\mathrm{d}}
$$

Use Table 7 (main text), and $\frac{L}{B}=1.0 ; I_{\text {center }}=1.122$

$E=5(N+15)=5(11+15)=130$ tsf

$\gamma=0.30$

$C_{\mathrm{d}}$ from Fox's chart, Figure 12 (main text). $C_{\mathrm{d}}=0.775$

$$
S_{c}=(1.1 \mathrm{tsf})(10 \mathrm{ft}) \frac{\left(1-0.30^{2}\right)}{130 \mathrm{tsf}}(1.122)(0.775)=0.0670 \mathrm{ft}
$$




$$
\begin{aligned}
& S_{\mathrm{c}}=0.803 \mathrm{in} . \\
& S_{\text {average }}=0.848 S_{\mathrm{c}}: S_{\mathrm{a}}=0.681 \mathrm{in} . \\
& S_{\text {rigid }}=0.93 S_{\mathrm{c}}: S_{\mathrm{r}}=0.747 \mathrm{in} .
\end{aligned}
$$

\section{e. D'Appolonia, D'Appolonia, and Brissette (1968)}

$$
S=\frac{8 q}{N_{\mathrm{c}}}\left(\frac{B}{B+1}\right)^{2} C_{\mathrm{d}}
$$

Corrected Blowcount from Gibbs and Holtz (1957) curves. See Alpan calculation, paragraph $5 \underline{c}$ ).

$$
\begin{aligned}
& N_{\mathrm{c}}=26.5 \\
& C_{\mathrm{d}}=1-0.25 \frac{D}{B}=1-0.25\left(\frac{5 \mathrm{ft}}{10 \mathrm{ft}}\right)=0.875 \\
& \quad S=\frac{8(1.1 \mathrm{tsf})}{26.5}\left(\frac{10 \mathrm{ft}}{11 \mathrm{ft}}\right)^{2} 0.875 \\
& \quad S=0.240 \mathrm{in} .
\end{aligned}
$$

f. D'Appolonia, D'Appolonia, and Brissette (1970)

$$
S=\frac{q B I}{M}
$$

$I=\mu_{\mathrm{o}} \mu_{1}$ Figure 13 (main text).

$\mu_{0}=0.86$

$\mu_{1}=0.70$

$I=0.602$

$M=$ compressibility modulus, Figure 14 (main text), and $N=11$

$$
=285 \mathrm{tsf}
$$




$$
S=\frac{(1.1 \mathrm{tsf})(10 \mathrm{ft}) 0.602}{285 \mathrm{tsf}}=0.023 \mathrm{ft}
$$

$$
S=0.279 \text { in. }
$$

\section{g. Peck and Bazaraa (1969)}

$$
S=\frac{8 q}{N_{\mathrm{c}}}\left(\frac{B}{B+1}\right)^{2} C_{\mathrm{d}} C_{\mathrm{w}}
$$

$$
\begin{aligned}
& p^{\prime}=\gamma\left(D+\frac{B}{2}\right)=110 \mathrm{pcf}(5 \mathrm{ft}+5 \mathrm{ft})=1,100 \mathrm{psf}=1.1 \mathrm{ksf} \\
& N_{\mathrm{c}}=\frac{4 N}{1+2 p^{\prime}}=\frac{4(11)}{1+2(1.1 \mathrm{ksf})}=13.75 \\
& C_{\mathrm{d}}=1.0-0.4 \sqrt{\frac{\gamma D}{q}}=1.0-0.4 \sqrt{\frac{(110 \mathrm{pcf})(5 \mathrm{ft})}{(1.1 \mathrm{tsf})\left(\frac{2,000}{1}\right)}}=0.80 \\
& C_{\mathrm{w}}=\frac{\sigma_{\mathrm{v}^{\prime}}(\text { dry })}{\sigma_{\mathrm{v}}^{\prime}(\text { wet })} @ D+\frac{B}{2}=\frac{110(10 \mathrm{ft})}{110(10 \mathrm{ft})}=1.0
\end{aligned}
$$

$$
S=\frac{8(1.1 \mathrm{tsf})}{13.75}\left[\frac{10 \mathrm{ft}}{11 \mathrm{ft}}\right)^{2}(0.80)
$$

$$
S=0.423 \text { in. }
$$


h. Schmertmann (1970)

$$
S=q C_{\mathrm{d}} C_{\mathrm{t}} \sum_{\mathrm{i}=1}^{\mathrm{n}}\left(\frac{I_{\mathrm{z}}}{E_{\mathrm{s}}}\right)_{\mathrm{i}} z_{\mathrm{i}}
$$

$$
\begin{aligned}
& E_{\mathrm{s}}=2 q_{\mathrm{c}} \\
& q_{\mathrm{c}}=2 \mathrm{~N}, \text { for silty sand } \\
& E_{\mathrm{s}}=2(2(11))=44 \mathrm{tsf}
\end{aligned}
$$

$E_{\mathrm{s}}$ is constant with depth to $2 B$ below footing base.

Area under strain-influence diagram (of $2 B-0.6$ distribution) is $0.6 B$.

Therefore, $\sum\left(\frac{I_{z}}{E_{\mathrm{s}}}\right) z=\frac{0.6 \dot{B}}{E_{\mathrm{s}}}=\frac{0.6(10 \mathrm{ft})}{44 \mathrm{tsf}}=0.1364 \frac{\mathrm{ft}}{\mathrm{tsf}}$

$$
C_{\mathrm{d}}=1-0.5\left(\frac{\gamma D}{q}\right) \geq 0.5
$$$$
=1-0.5\left[\frac{110 \operatorname{pcf}(5 \mathrm{ft})}{1.1 \mathrm{tsf}\left(\frac{2,000}{1}\right)}\right]=0.875
$$$$
S=(1.1 \mathrm{tsf})(0.875)\left(0.1364 \frac{\mathrm{ft}}{\mathrm{tsf}}\right)=0.1313 \mathrm{ft}
$$

$$
S=1.575 \mathrm{in} .
$$

i. Schmertmann, Hartman, and Brown (1978)

$$
S=q C_{\mathrm{d}} C_{\mathrm{t}} \sum_{\mathrm{i}=1}^{\mathrm{n}}\left(\frac{I_{\mathrm{z}}}{E_{\mathrm{s}}}\right)_{\mathrm{i}}
$$




$$
\begin{aligned}
E_{\mathrm{s}} & =R q_{\mathrm{c}} \\
R & =\frac{1}{9}\left(\frac{L}{B}-1\right)+2.5 \leq 3.5 \\
& =\frac{1}{9}(0)+2.5=2.5 \\
q_{\mathrm{c}} & =2 N, \text { for silty sand } \\
& =2(11)=22 \\
E_{\mathrm{s}} & =2.5(22)=55 \text { tsf }
\end{aligned}
$$

$E_{\text {s }}$ is constant over depth below the footing, therefore

$\Sigma\left(I_{z}\right) \quad z=$ area under the strain-influence diagram.

Construct strain-influence diagram

\section{Point 1}

$$
\begin{aligned}
\frac{Z_{1}}{B} & =\frac{1}{18}\left(\frac{L}{B}-1\right)+0.5 \leq 1.0 \\
& =0.5 \\
\therefore Z_{1} & =0.5 B=5 \mathrm{ft} \\
I_{z}-\text { peak } & =0.5+0.1] \sqrt{\frac{q}{p^{\prime}}} \\
p^{\prime} & =\gamma\left(D+Z_{1}\right)=110 \mathrm{pcf}(5 \mathrm{ft}+5 \mathrm{ft})=1,100 \mathrm{psf} \\
I_{\mathbf{z}}-\text { peak } & =0.5+0.1] \frac{1.1 \mathrm{tsf}\left(\frac{2,000}{1}\right)}{1100 \mathrm{psf}} \\
& =0.641
\end{aligned}
$$




\section{Point 2}

$$
\begin{aligned}
I_{z}-\text { intercept } & =\frac{1}{90}\left(\frac{L}{B}-1\right)+0.1 \leq 0.2 \\
& =0.1 \\
\frac{Z}{B} & =0
\end{aligned}
$$

\section{Point 3}

$$
\begin{aligned}
x & =0 \\
\frac{Z_{2}}{B} & =\frac{2}{9}\left[\frac{L}{B}-1\right)+2 \leq 4.0 \\
& =2.0
\end{aligned}
$$

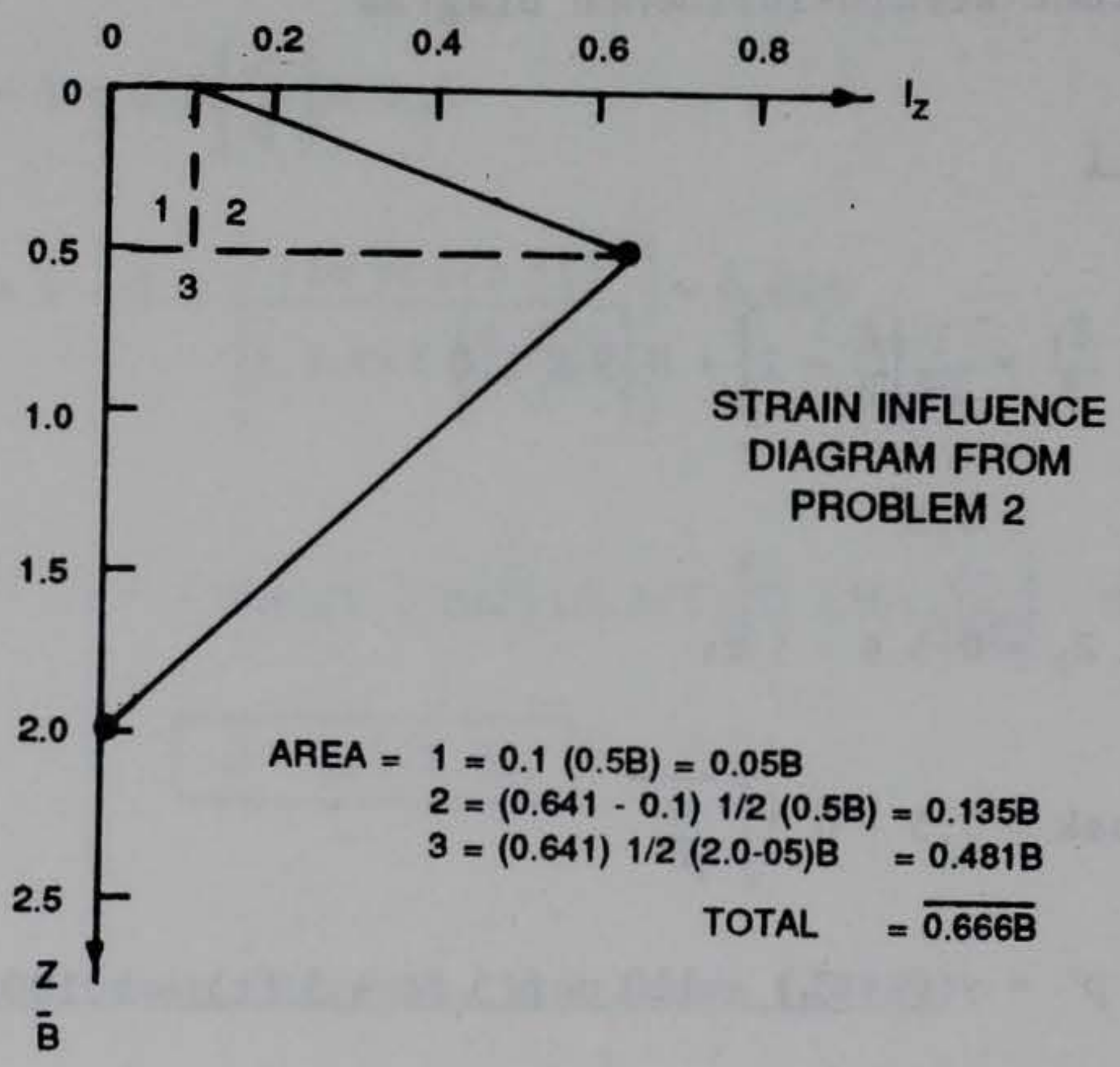

$C_{\mathrm{d}}=0.875$, from 1970 method 


$$
\begin{aligned}
& S=(1.1 \mathrm{tsf})(0.875) \frac{(0.666)(10 \mathrm{ft})}{55 \mathrm{tsf}}=0.1166 \mathrm{ft} \\
& S=1.399 \mathrm{in} .
\end{aligned}
$$

\section{i. Schultze and Sherif (1973)}

$$
\begin{aligned}
& \qquad S=\frac{Q F_{\mathrm{c}}}{N^{0.87} C_{\mathrm{d}}} \\
& Q=\text { gross pressure }=q+\gamma D=1.1 \mathrm{tsf}+(110 \mathrm{pcf})\left(\frac{1}{2,000}\right)(5 \mathrm{ft}) \\
& =1.375 \mathrm{tsf} \\
& =1.375 \mathrm{tsf}\left(\frac{0.976486 \mathrm{~kg} / \mathrm{cm}^{2}}{1 \mathrm{tsf}}\right)=1.343 \mathrm{~kg} / \mathrm{cm}^{2}
\end{aligned}
$$

Use Figure 17 (main text) and $B=10 \mathrm{ft}\left(\frac{12 \mathrm{in} .}{1 \mathrm{ft}}\right)\left(\frac{2.54 \mathrm{~cm}}{1 \mathrm{in} .}\right)$ $=304.8 \mathrm{~cm}$, to get $F_{\mathrm{c}}$

$$
\begin{aligned}
F_{\mathrm{c}} & =6.5 \frac{\mathrm{cm}^{3}}{\mathrm{~kg}} \\
C_{\mathrm{d}} & =1+0.4\left(\frac{D}{B}\right) \leq 1.4 \\
& =1+0.4\left(\frac{5 \mathrm{ft}}{10 \mathrm{ft}}\right)=1.2
\end{aligned}
$$

$$
\begin{aligned}
& S=\frac{1.343 \frac{\mathrm{kg}}{\mathrm{cm}^{2}}\left(6.5 \frac{\mathrm{cm}^{3}}{\mathrm{~kg}}\right)}{(11)^{0.87}(1.2)}=0.9032 \mathrm{~cm} \\
& S=0.356 \mathrm{in} .
\end{aligned}
$$


k. Meyerhof (1974)

$$
\begin{gathered}
S=\frac{q \sqrt{B}}{N} C_{\mathrm{d}} \\
C_{\mathrm{d}}=1-0.25\left(\frac{D}{B}\right) \\
=1-0.25\left(\frac{5 \mathrm{ft}}{10 \mathrm{ft}}\right)=0.875 \\
B=10 \mathrm{ft}\left(\frac{12 \mathrm{in} .}{\mathrm{ft}}\right)=120 \mathrm{in} . \\
S=\frac{1.1 \mathrm{tsf} \sqrt{120 \mathrm{in} .}}{11}(0.875) \\
S=0.959 \mathrm{in} .
\end{gathered}
$$

1. Peck, Hanson, Thornburn (1974)

$$
S=\frac{q}{0.11 N_{\mathrm{c}} C_{\mathrm{w}}}
$$

$$
\begin{aligned}
& N_{\mathrm{c}}=N\left(0.77 \log \frac{20}{p^{\prime}}\right) \\
& p^{\prime}=\gamma\left(p+\frac{B}{2}\right)=110 \mathrm{pcf}\left(\frac{1}{2,000}\right)(5 \mathrm{ft}+5 \mathrm{ft})=0.55 \mathrm{tsf} \\
& N_{\mathrm{c}}=11(0.77) \log \left(\frac{20}{0.55}\right)=13.22 \\
& C_{\mathrm{w}}=0.5+0.5\left(\frac{\mathrm{w}}{D+B}\right)=0.5+0.5\left(\frac{10 \mathrm{ft}}{5 \mathrm{ft}+10 \mathrm{ft}}\right)=0.833
\end{aligned}
$$




$$
S=\frac{1.1 \mathrm{tsf}}{0.11(13.22)(0.833)}
$$

$$
s=0.908 \text { in. }
$$

m. Bowles $(1977,1982)$

$$
\begin{gathered}
\quad S=\frac{4 q}{N}\left(\frac{B}{B+1}\right)^{2} \frac{C_{w}}{C_{d}} \\
C_{w}=2-\left(\frac{w}{D+B}\right) \leq 2.0, \geq 1.0 \\
=2-\left(\frac{10 \mathrm{ft}}{5 \mathrm{ft}+10 \mathrm{ft}}\right)=1.333 \\
C_{\mathrm{d}}=1+0.33 \frac{D}{B} \leq 1.33 \\
=1+0.33\left(\frac{5 \mathrm{ft}}{10 \mathrm{ft}}\right)=1.165 \\
\quad S=\frac{4(1.1 \mathrm{tsf})\left(\frac{2 \mathrm{kips}}{1 \text { ton }}\right)\left(\frac{10 \mathrm{ft}}{11 \mathrm{ft}}\right)^{2}\left(\frac{1.333}{1.165}\right)}{\quad S=0.756 \text { in. }}
\end{gathered}
$$

n. NAVFAC DM 7.1 (Department of the Navy (1982))

$$
S=\frac{C q}{K_{\mathrm{v}}}\left(\frac{B}{B+1}\right)^{2} C_{\mathrm{w}}
$$


$C=4.0$, for $B<20 \mathrm{ft}$

Use Figure 22 (main text) and $D_{\mathrm{r}}$ to get $K_{\mathrm{v} 1}$.

$$
\begin{aligned}
& D_{\mathbf{r}}=\sqrt{\frac{N}{20\left(1+2 p^{\prime}\right)}} \\
& p^{\prime}=\gamma\left(p+\frac{B}{2}\right)=110 \operatorname{pcf}(5 \mathrm{ft}+5 \mathrm{ft})=1,100 \mathrm{psf} \\
& =1.10 \mathrm{ksf} \\
& D_{r}=\sqrt{\frac{11}{20(1+2(1.10 \mathrm{ksf}))}} \\
& =41.5 \% \\
& K_{\mathrm{v}}=97 \text { tsf } \\
& C_{w}=2-\left(\frac{W-D}{1.5 B}\right) \leq 2.0 \\
& =2-\left(\frac{10 \mathrm{ft}-5 \mathrm{ft}}{1.5(10 \mathrm{ft})}\right) \\
& =1.667 \\
& \begin{array}{l}
S=\frac{4.0(1.1 \mathrm{tsf})}{97 \mathrm{tsf}}\left(\frac{10 \mathrm{ft}}{11 \mathrm{ft}}\right)^{2}(1.667)=0.0625 \mathrm{ft} \\
S=0.750 \mathrm{in} .
\end{array}
\end{aligned}
$$

o. Oweis (1979)

$$
S=q B \sum_{i=1}^{\mathrm{n}} \frac{\Psi i}{E_{i}}
$$

Divide stratum into sublayers below footing base to a convenient depth. 


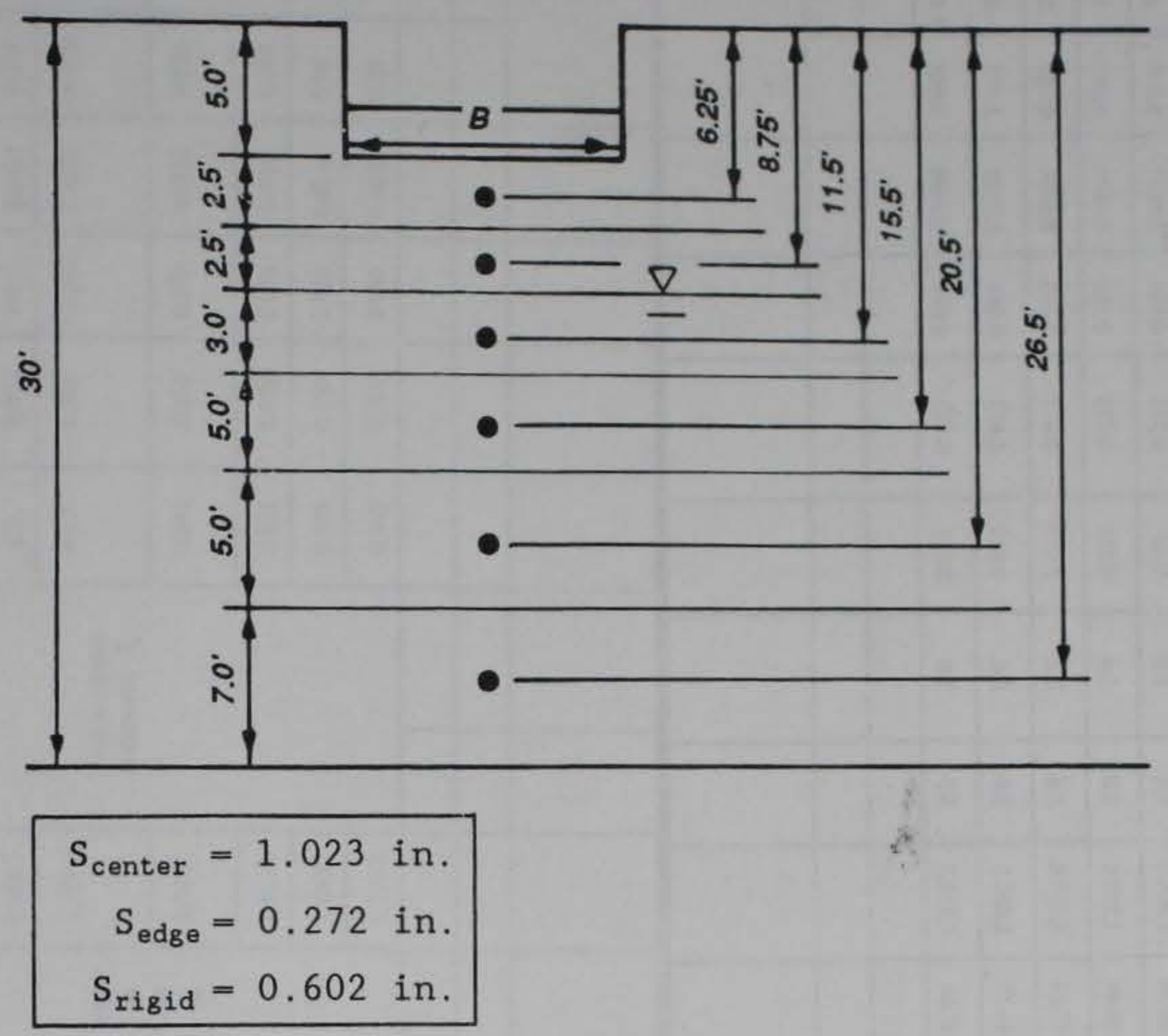

The calculations for this example are recorded on the chart from the main text (Table 11) on the following pages. 
For: (Center Edge Rigid) Settlement.

\begin{tabular}{|c|c|c|c|c|c|c|c|c|c|c|c|c|c|c|c|c|c|c|c|}
\hline $\begin{array}{l}\text { Layer } \\
\text { No. }\end{array}$ & $\begin{array}{c}\text { Layer } \\
\text { Thickness } \\
h_{\mathrm{i}}\end{array}$ & $\begin{array}{c}\text { Blows } \\
\text { per foot, } \\
N\end{array}$ & $\begin{array}{c}\text { Corrected } \\
\text { Blowcount } \\
N_{\mathrm{c}}\end{array}$ & $\begin{array}{c}\text { Midlayer } \\
\sigma_{v}^{\prime} \\
\text { (psf) }\end{array}$ & $\begin{array}{l}\text { Mean Init. } \\
\text { Stress, } \sigma_{\text {mo }} \\
\text { (psf) }\end{array}$ & $\frac{2 \text {-midlayer }}{0.5 B}$ & $\begin{array}{l}\text { Alphs } \\
\text { Factor }\end{array}$ & $\begin{array}{l}\Delta \sigma_{\mathrm{m}} \\
(\mathrm{psf})\end{array}$ & $K_{\max }$ & $\begin{array}{l}E_{\max } \\
(\mathbf{k s f})\end{array}$ & $\frac{2 \cdot \operatorname{top}}{0.5 B}$ & $\frac{z \text {-bottom }}{0.5 B}$ & $\begin{array}{l}\text { (lop) } \\
F_{(6-1)}\end{array}$ & $\begin{array}{c}\text { (bottom) } \\
F_{\mathrm{i}}\end{array}$ & $\psi_{1}$ & $\begin{array}{l}\lambda_{1} \\
(\%)\end{array}$ & $\frac{E}{E_{\max }}$ & $\underset{(k \leq f)}{E_{1}}$ & $\begin{array}{c}\delta_{i} \\
\text { (feet) }\end{array}$ \\
\hline 2 & 2.5 & 11 & 15.04 & 962.5 & 641.7 & 0.75 & 0.36 & 792 & 53.70 & $2,033.3$ & 0.5 & 1.0 & 0.16 & 0.315 & 0.155 & 0.0671 & 0.069 & 140.30 & 0.02431 \\
\hline 3 & $3.0^{\circ}$ & 11 & 12.99 & $1,193.75$ & 795.8 & 1.30 & 0.175 & 385 & 50.49 & $1,735.0$ & 1.0 & 1.6 & 0.315 & 0.475 & 0.160 & 0.0676 & 0.068 & 117.98 & 0.02984 \\
\hline 4 & $5.0^{\circ}$ & 11 & 11.32 & $1,443.75$ & 962.5 & 2.10 & 0.09 & 198 & 47.66 & $1,623.6$ & 1.6 & 2.6 & 0.475 & 0.610 & 0.135 & 0.0366 & 0.158 & 256.53 & 0.01158 \\
\hline 5 & $5.0^{\circ}$ & 11 & 10.66 & $1,756.25$ & $1,170.8$ & 3.10 & 0.048 & 105.6 & 46.47 & $1,660.2$ & 2.6 & 3.6 & 0.610 & 0.678 & 0.068 & 0.0180 & 0.395 & 655.79 & 0.00228 \\
\hline 6 & $7.0^{\circ}$ & 11 & 10.20 & $2,131.25$ & $1,420.8$ & 4.30 & 0.025 & 55 & 45.61 & $1,752.2$ & 3.6 & 5.0 & 0.678 & 0.737 & 0.059 & 0.0106 & 0.640 & $1,121.38$ & 0.00116 \\
\hline & & & & & & & & & & & & & & & & & & & \\
\hline & & & & & & & & & & & & & & & & & & \multicolumn{2}{|c|}{$\begin{array}{c}\text { Total }=0.08524 \mathrm{ft} \\
S_{c}=1.023 \text { in. } \\
\text { center-flexible }\end{array}$} \\
\hline
\end{tabular}

(Sheet 1 of 3) 
For: (Center Edge Rigid) Settlement.

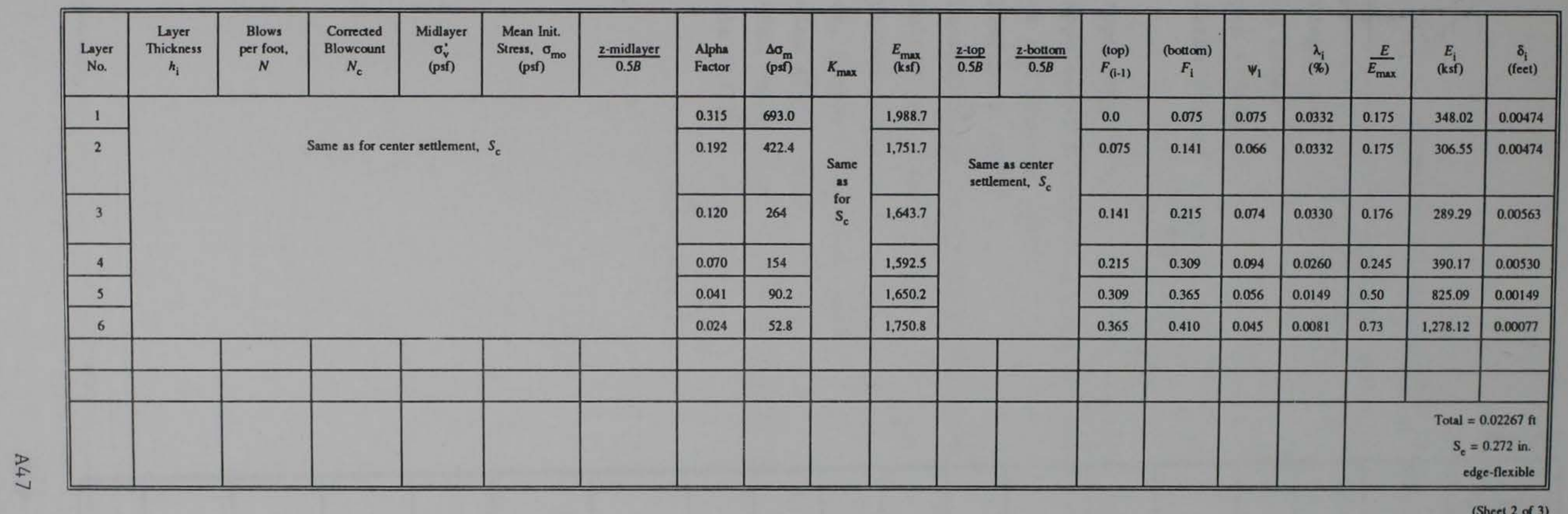


For: (Center Edge Rigid) Settement.

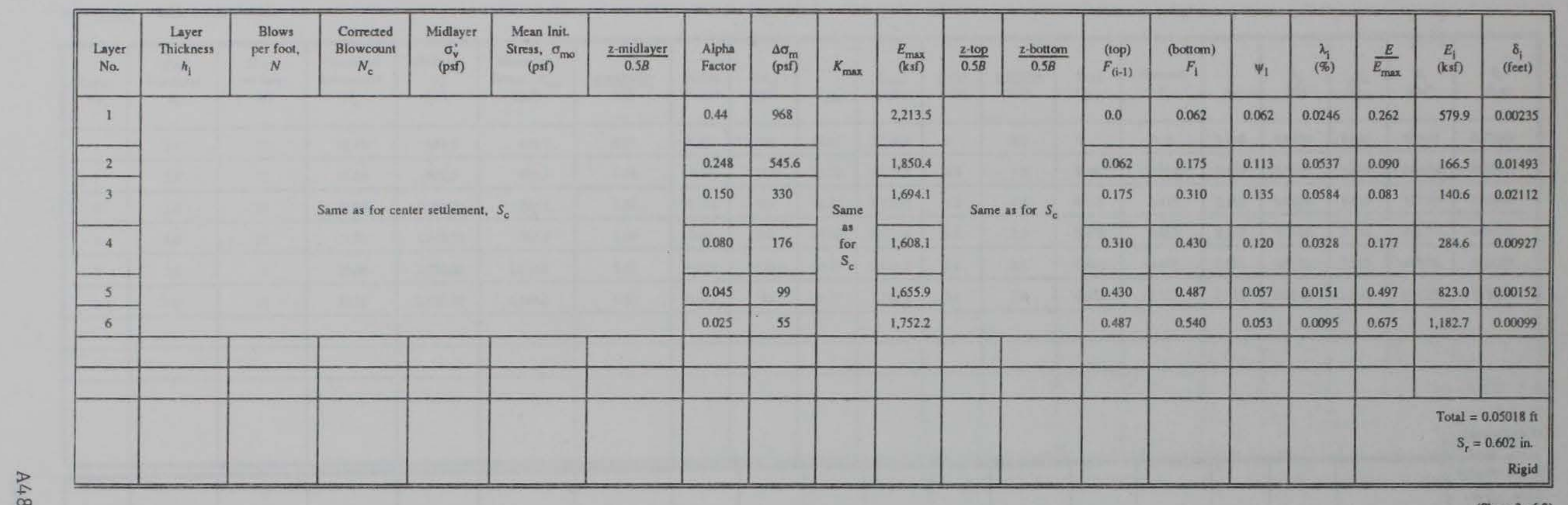

(Sheet 3 of 3 ) 


\section{Summary of Results from Hand Calculations of Problem 2}

\section{Method}

Terzaghi and Peck (1948, 1967)

Teng (1962)

Alpan (1964)

Elastic Theory - rigid center (flex.) average (flex.)

D'Appolonia, D'Appolonia, and Brissette (1968)

D'Appolonia, D'Appolonia, and Brissette (1970)

Peck and Bazaraa (1969)

Schmertmann (1970)

Schmertmann, Hartman, and Brown (1978)

Schultze and Sherif (1973)

Meyerhof (1974)

Peck, Hanson, Thornburn (1974)

Bowles (1977, 1982)

NAVFAC (Department of the Army (1982))

Oweis (1979) - rigid center (flex.) edge (flex.)
Settlement (in.)

0.87

0.32

0.60

0.75

0.80

0.68

0.24

0.28

0.42

1.58

1.40

0.36

0.96

0.91

0.76

0.75

0.60

1.02

0.27 
CSAMDSET - INPUT DATA

Title: Example Problem 2

Footing Data:

Width $=10.00 \mathrm{Ft}$
Length $=10.98 \mathrm{Ft}$
Depth $=5.00 \mathrm{Ft}$
Pressure $=1.10 \mathrm{TSF}$

Optional Soll Data:

Gibbs \& Holtz Bloucount $=26.50 \mathrm{BL} / \mathrm{FT}$

Creep Factor Time =

Elastic Modulus =

0.00 Year(s)

Polsson's Ratio =

$0.00 \mathrm{TSF}$

Soll Data:

Blowcount $=11.00 \mathrm{~B} 1 / \mathrm{Ft}$

Cone Penetrometer $=0.00 \mathrm{TSF}$

Unit Weight $=110.00$ PCF

Sat'd Unit Weight $=125.00 \mathrm{PCF}$

Horiz. Earth Pressure $=0.50$

Blowcount Overburden $=1100.00$ PSF

Water Unit Weight $=62.40 \mathrm{PCF}$

Sol1 Relative Density $=0.00 \%$

$1=$ yes, $\theta=$ no:

Mat Foundation $=\theta$

Preloaded Soll = 0

Depth To Rigid Layer $=200.00 \mathrm{Ft}$

Sat $^{2} d$, dense, fine sand $=1$

Depth To Water $=10.00 \mathrm{FT}$

〈Esc〉 to continue.

Figure A9. Listing of all input data for Problem 2

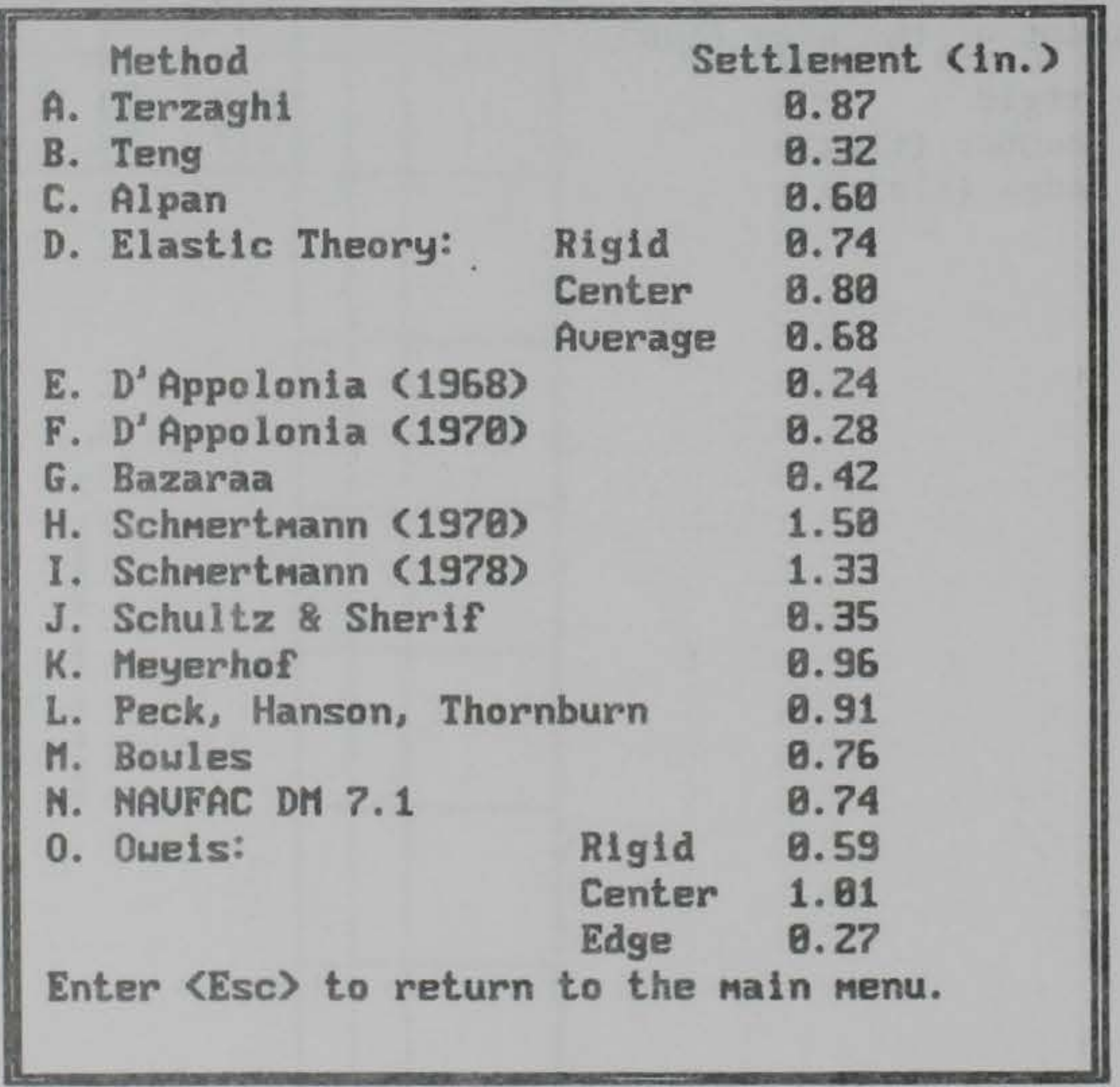

Figure A10. CSANDSET settlement calculations for Problem 2 


\section{Problem 3}

6. This example shows a square footing near the ground surface with a distant water table $(>4 B)$. Three values from the blowcount and cone penetrometer tests are available from three different depths in the soil below the footing. This is useful for describing soil layers in the Schmertmann (1970), Schmertmann, Hartman, and Brown (1978), and Oweis (1979) methods.

However, for the majority of methods which do not use the layer technique, an average value must be used. In this example, weighted values of the SPT and CPT test values are computed for this purpose. Dimensions and parameters are shown in Figure A11. Table A3 lists the hand-calculated settlements for all the methods. Figures A12 through A14 show the CSANDSET input screens for footing, soil, and optional data. The soil layer input shown in Figure Al5, the input listing, in Figure A16, and the output in Figure Al7 correspond to the layers used in the hand calculations for Schmertmann (1970) and Schmertmann, Hartman, and Brown (1978). Figures A18 and Al9 show soil layer input and CSANDSET output for Problem 3 using soil layer data corresponding to the hand calculations for Oweis (1979).

\section{Data for Problem 3}

$$
\begin{aligned}
B & =8.2 \mathrm{ft} \\
L & =8.2 \mathrm{ft} \\
D & =0.23 \mathrm{ft} \\
q & =1.024 \mathrm{tsf} \\
N & =7.5 \mathrm{bl} / \mathrm{ft} \text { at } 3.3 \mathrm{ft} \\
& =12 . \mathrm{bl} / \mathrm{ft} \text { at } 6.6 \mathrm{ft} \\
& =13.5 \mathrm{bl} / \mathrm{ft} \text { at } 9.8 \mathrm{ft} \\
q_{c} & =63.25 \mathrm{tsf} \text { at } 3.3 \mathrm{ft} \\
& =72.41 \mathrm{tsf} \text { at } 6.6 \mathrm{ft} \\
& =63.85 \mathrm{tsf} \text { at } 9.8 \mathrm{ft} \\
H & =40 \mathrm{ft}(\text { assumed) } \\
W & =38.4 \mathrm{ft} \\
\boldsymbol{\gamma} & =96 \mathrm{pcf}
\end{aligned}
$$




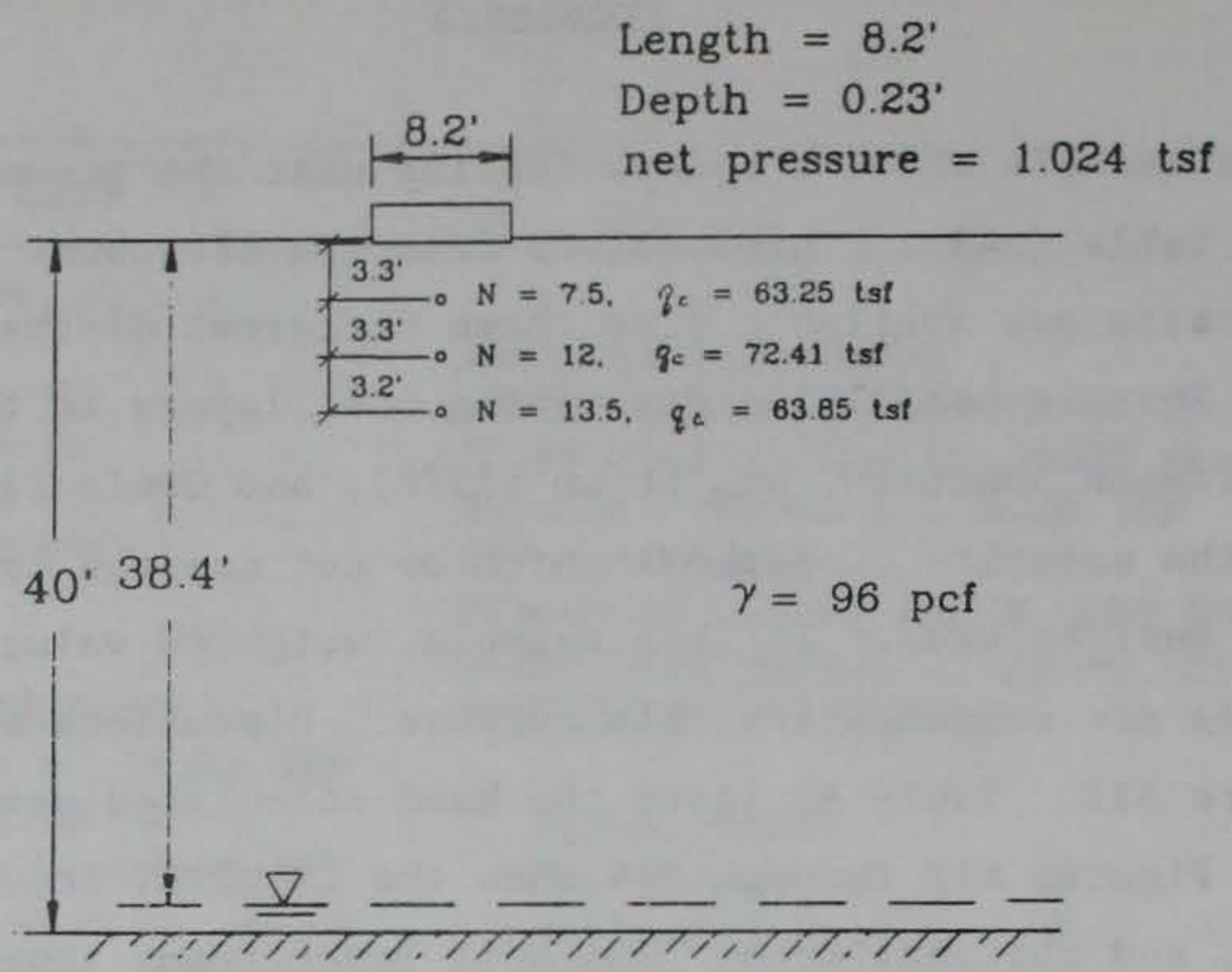

Figure A11. Example Problem 3 (from Consla 1983)

7. For all methods, excluding Oweis (1979), Schmertmann (1970), and Schmertmann, Hartman, and Brown (1978), compute an average blowcount and CPT value for the depth $B$ below the footing. Assume the blowcount and CPT at each given depth ( $3.3 \mathrm{ft}, 6.6 \mathrm{ft}$, and $9.8 \mathrm{ft}$ ) are uniform over a distance extending halfway between each given depth.
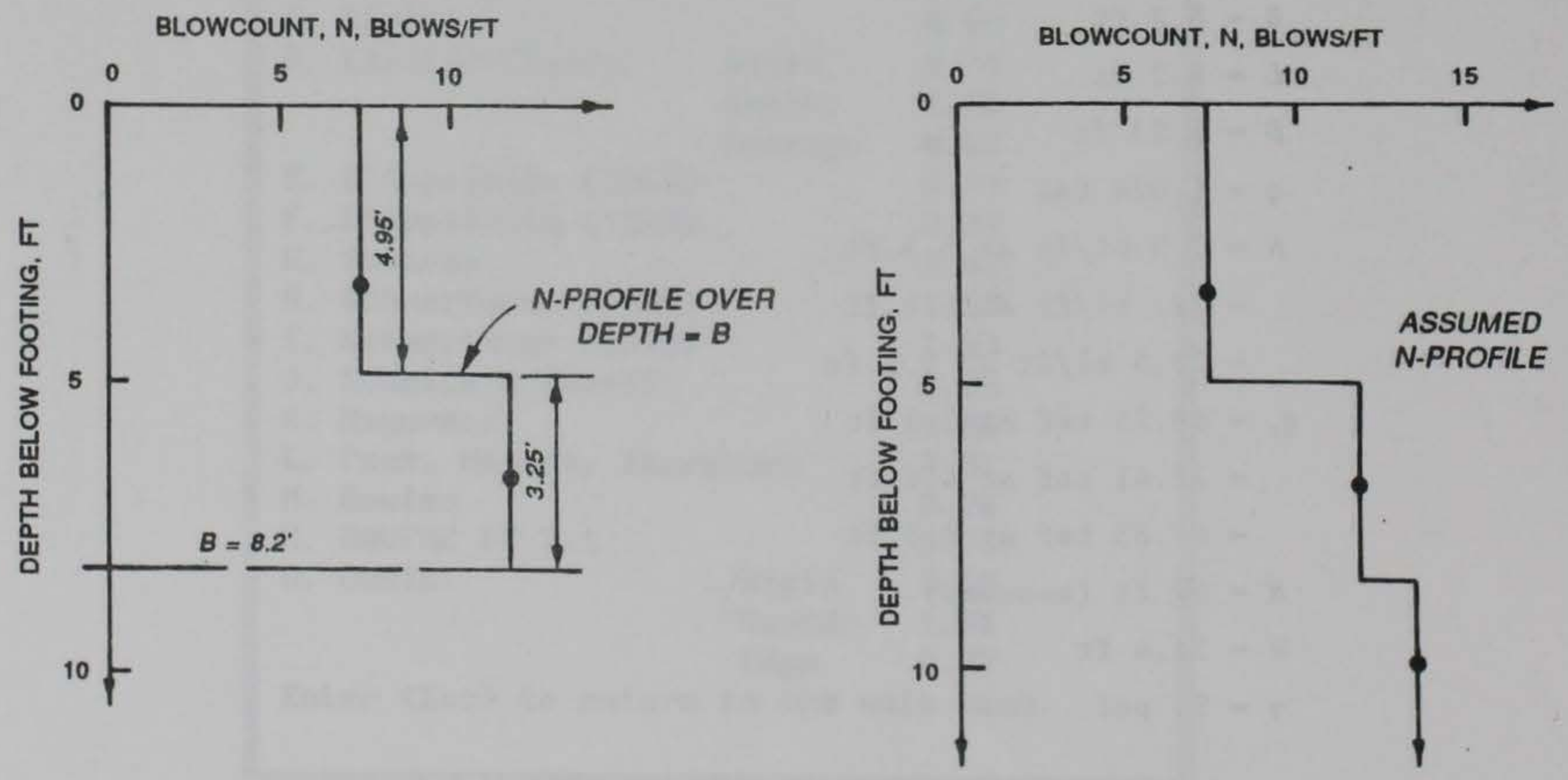
Calculate a weighted N-value from the assumed N-profile over the depth $D=B=8.2 \mathrm{ft}$.

\section{Weighted Average}

$$
\begin{aligned}
& \qquad N \rightarrow \frac{4.95 \mathrm{ft}}{8.2 \mathrm{ft}}\left(7.5 \frac{\mathrm{blow}}{\mathrm{ft}}\right)+\frac{3.25 \mathrm{ft}}{8.2 \mathrm{ft}}\left(12 \frac{\mathrm{blow}}{\mathrm{ft}}\right)=9.3 \frac{\mathrm{blows}}{\mathrm{ft}} \\
& C P T \rightarrow \frac{4.95 \mathrm{ft}}{8.2 \mathrm{ft}}(63.25 \mathrm{tsf})+\frac{3.25 \mathrm{ft}}{8.2 \mathrm{ft}}(72.41 \mathrm{tsf})=66.88 \mathrm{tsf} \\
& \text { Average } N=9.3 \mathrm{blows} / \mathrm{ft} \\
& \text { Average } C P T=66.88 \mathrm{tsf}
\end{aligned}
$$

a. Terzaghi and Peck $(1948,1967)$

$$
S=\frac{12 q}{N}\left(\frac{B}{B+1}\right)^{2} C_{\mathrm{w}} C_{\mathrm{d}}
$$

$$
\begin{aligned}
& C_{\mathrm{w}}=1.0 \\
& C_{\mathrm{d}}=1-0.25\left(\frac{D}{B}\right)=1-0.25\left(\frac{0.23 \mathrm{ft}}{8.2 \mathrm{ft}}\right)=0.993
\end{aligned}
$$




$$
\begin{aligned}
& S=\frac{12(1.024 \mathrm{tsf})}{9.3}\left(\frac{8.2 \mathrm{ft}}{9.2 \mathrm{ft}}\right)^{2}(0.993) \\
& S=1.042 \mathrm{in} .
\end{aligned}
$$

\section{b. Teng (1962)}

$$
S=\frac{q}{720\left(N_{\mathrm{c}}-3\right)}\left(\frac{2 B}{B+1}\right)^{2}\left(\frac{1}{C_{\mathrm{w}} C_{\mathrm{d}}}\right)
$$

$$
\begin{aligned}
& N_{\mathrm{c}}=\frac{N 50}{\left(p^{\prime}+10\right)} \\
& \quad p^{\prime}=\gamma\left(p+\frac{B}{2}\right)=96 \mathrm{pcf}\left[0.23 \mathrm{ft}+\frac{8.2}{2} \mathrm{ft}\right]=415.68 \mathrm{psf}=2,887 \mathrm{psi} \\
& N_{\mathrm{c}}=\frac{9.3(50)}{2.887+10}=36.08 \\
& C_{\mathrm{d}}=1+\frac{D}{B}=1+\frac{0.23 \mathrm{ft}}{8.2 \mathrm{ft}}=1.028 \\
& C_{\mathrm{w}}=1.0
\end{aligned}
$$

$$
\begin{aligned}
& S=\frac{1.024 \operatorname{tsf}\left(\frac{2000}{1}\right)}{720(36.08-3)}\left(\frac{16.4 \mathrm{ft}}{9.2 \mathrm{ft}}\right)^{2}\left(\frac{1}{1.028}\right) \\
& S=0.266 \mathrm{in} .
\end{aligned}
$$

c. Alpan (1964)

$$
S=\alpha q\left(\frac{2 B}{B+1}\right)^{2} m C_{\mathrm{w}-}
$$

Corrected blowcount from Figure 11 (main text) and $p^{\prime}=2,887$ psi, $\quad N_{\mathrm{c}}=31$

From Figure 9a (main text) , $\quad \alpha=0.094$ 


$$
\begin{aligned}
m & =1.0 \quad\left(\frac{L}{B}=1.0\right) \\
C_{\mathrm{w}} & =1.0
\end{aligned}
$$

$$
S=0.094(1.024 \mathrm{tsf})\left(\frac{16.4 \mathrm{ft}}{9.2 \mathrm{ft}}\right)^{2}
$$$$
S=0.306 \mathrm{in} .
$$

\section{d. Elastic theory}

$$
S=q B \frac{\left(1-\gamma^{2}\right)}{E} I C_{\mathrm{d}}
$$

$$
\begin{aligned}
& E=5(N+15)=5(9.3+15)=121 \cdot 5 \text { tsf } \\
& \gamma=0.3
\end{aligned}
$$

$\frac{H}{B}=\frac{40 \mathrm{ft}}{8.2 \mathrm{ft}}=4.88$, Consider layer a finite compressible stratum

$C_{\mathrm{d}} \simeq 1.0$

$I=1.122$ from Table 7 (main text), for center of flexible footing

$$
S_{\mathrm{c}}=1.024 \mathrm{tsf}(8.2 \mathrm{ft}) \frac{\left(1-0.3^{2}\right)}{121.5 \mathrm{tsf}}(1.122)=0.0706 \mathrm{ft}=0.847 \mathrm{in} .
$$

$$
\begin{gathered}
S_{\mathrm{a}}=0.848 S_{\mathrm{c}}=0.848(0.847 \mathrm{in.})=0.718 \mathrm{in} . \\
S_{\mathrm{r}}=0.93 S_{\mathrm{c}}=0.93(0.847 \mathrm{in.})=0.788 \mathrm{in} . \\
S^{\prime}=\frac{q B^{\prime}}{2 E}\left(1-\gamma^{2}\right)\left[I_{3}^{\prime}-\left(\frac{1-2 \gamma}{1-\gamma}\right) I_{4}^{\prime}\right]
\end{gathered}
$$




$$
\begin{gathered}
B^{\prime}=\frac{B}{2}=4.1 \mathrm{ft} \\
I_{3}^{\prime}=0.1296 \text { (from paragraph 62) } \\
I_{4}^{\prime}=0.0323 \text { (from paragraph 62) } \\
S^{\prime}=\frac{(1.024 \mathrm{tsf})(4.1 \mathrm{ft})}{2(121.5 \mathrm{tsf})}\left(1-0.3^{2}\right)\left[0.1296-\left(\frac{1-0.6}{1-0.3}\right)(0.0323)\right] \\
=0.00175 \mathrm{ft} \quad 0.021 \mathrm{in.} \quad S_{\mathrm{cf}}=0.93 S_{\mathrm{cf}}=0.710 \mathrm{in} . \\
S_{\mathrm{aff}}=0.848 S_{\mathrm{cf}}=0.647 \mathrm{in} .
\end{gathered}
$$

Settlements of footings on finite compressible layer:

$$
\left\{\begin{array}{c}
S_{\text {center }}=0.763 \mathrm{in} . \\
S_{\text {avg. }}=0.647 \mathrm{in} . \\
S_{\text {rigid }}=0.710 \mathrm{in} .
\end{array}\right\}
$$

e. D'Appolonia, D'Appolonia, and Brissette (1968)

$$
S=\frac{8 q}{N_{\mathrm{c}}}\left(\frac{B}{B+1}\right)^{2} C_{\mathrm{d}}
$$

$N_{c}$, from Figure 11 (main text), = 31

$$
C_{\mathrm{d}}=1-0.25 \frac{D}{B}=1-0.25\left(\frac{0.23 \mathrm{ft}}{8.2 \mathrm{ft}}\right)=0.993
$$




$$
\begin{aligned}
& S=\frac{8(1.024 \mathrm{tsf})}{31}\left(\frac{8.2 \mathrm{ft}}{9.2 \mathrm{ft}}\right)^{2} 0.993 \\
& S=0.208 \mathrm{in} .
\end{aligned}
$$

f. D'Appolonia, D'Appolonia, and Brissette (1970)

$$
S=\frac{q B I}{M}
$$

$$
I=\mu_{0} \mu_{1}
$$

From Figures $13 \mathrm{a}$ and $\mathrm{b}$ (main text), $\mu_{0}=1.0 \quad\left(\frac{D}{B}=0\right)$

$$
\mu_{1}=0.67 \quad\left(\frac{H}{B}=4.88\right)
$$

$I=0.67$

From Figure 14 (main text), $M=272$ tsf

$$
S=\frac{(1.024 \mathrm{tsf})(8.2 \mathrm{ft})(0.67)}{272 \mathrm{tsf}}=0.0207 \mathrm{ft}
$$

$$
S=0.248 \mathrm{in}
$$

g. Peck and Bazaraa (1969)

$$
S=\frac{8 q}{N_{c}}\left(\frac{B}{B+1}\right)^{2} C_{d} C_{w}
$$




$$
\begin{aligned}
& C_{\mathrm{w}}=1.0 \\
& C_{\mathrm{d}}=1-0.4 \sqrt{\frac{\gamma D}{q}}=1-0.4 \sqrt{\frac{(96 \mathrm{pcf})(0.23 \mathrm{ft})}{(1.024 \mathrm{tsf}) \frac{2,000}{1}}}=0.958 \\
& p^{\prime}=\gamma\left[P+\frac{B}{2}\right]=96 \operatorname{pcf}(0.23+4.1 \mathrm{ft})=415.68 \mathrm{psf}=0.4157 \mathrm{ksf} \\
& N_{\mathrm{c}}=\frac{4 N}{1+2 p^{\prime}}=\frac{4(9.3)}{1+2(0.4157)}=20.31 \quad(\text { Use average } \mathrm{N}) \\
& S=\frac{8(1.024 \mathrm{tsf})}{20.31}\left[\frac{8.2 \mathrm{ft}}{9.2 \mathrm{ft}}\right]^{2}(0.958) \\
& S=0.307 \mathrm{in} .
\end{aligned}
$$

h. Schmertmann (1970)

$$
S=q C_{\mathrm{d}} C_{\mathrm{t}} \sum_{i=1}^{\mathrm{n}}\left(\frac{I_{z}}{E_{\mathrm{s}}}\right)_{i} z_{i}
$$

$E_{\mathrm{s}}=2 q_{\mathrm{c}} \Rightarrow$ different throughout stratum

Subdivide soil into layers over a depth $2 B$ below footing base. $2 B=16.4 \mathrm{ft}$

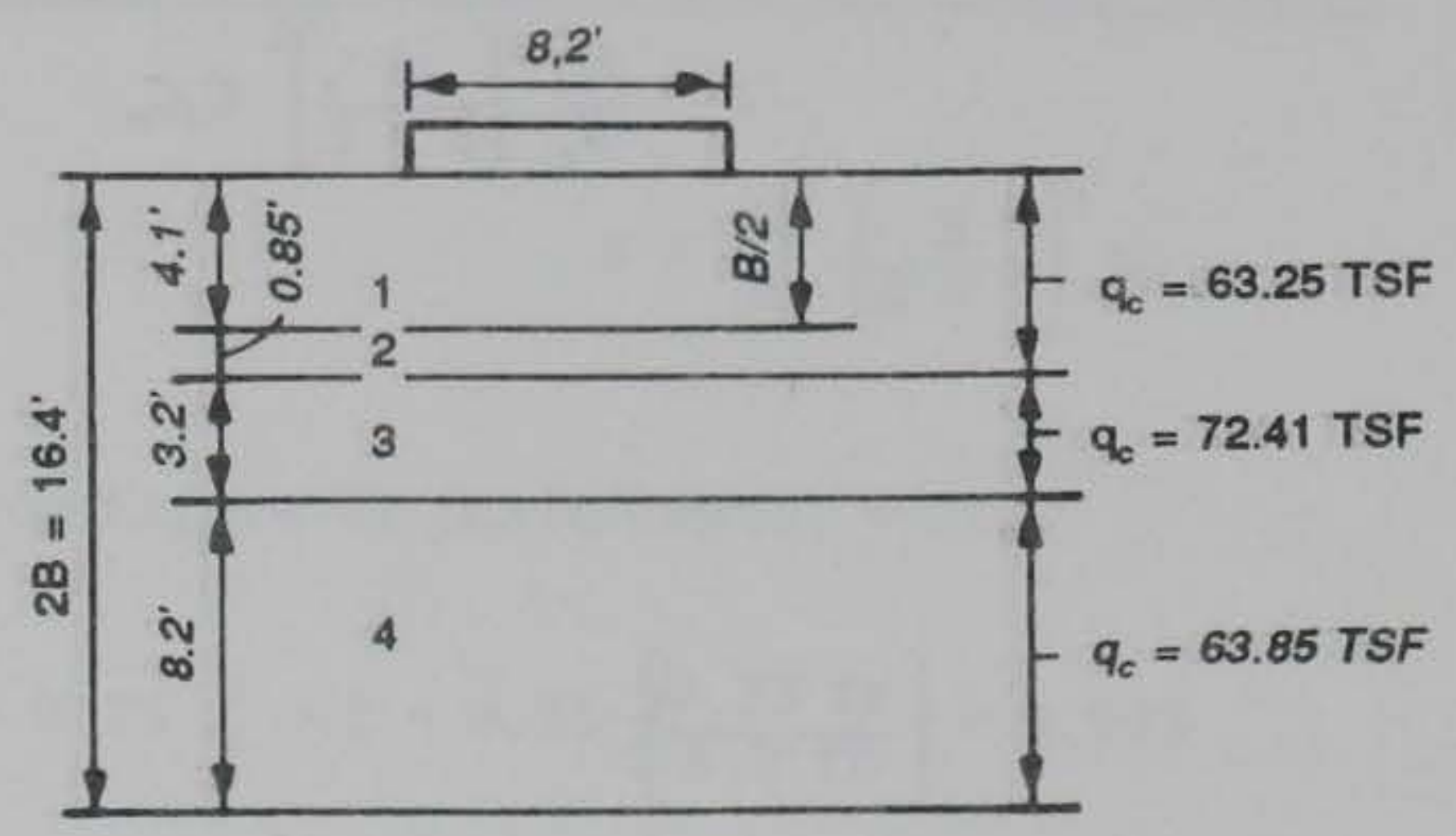




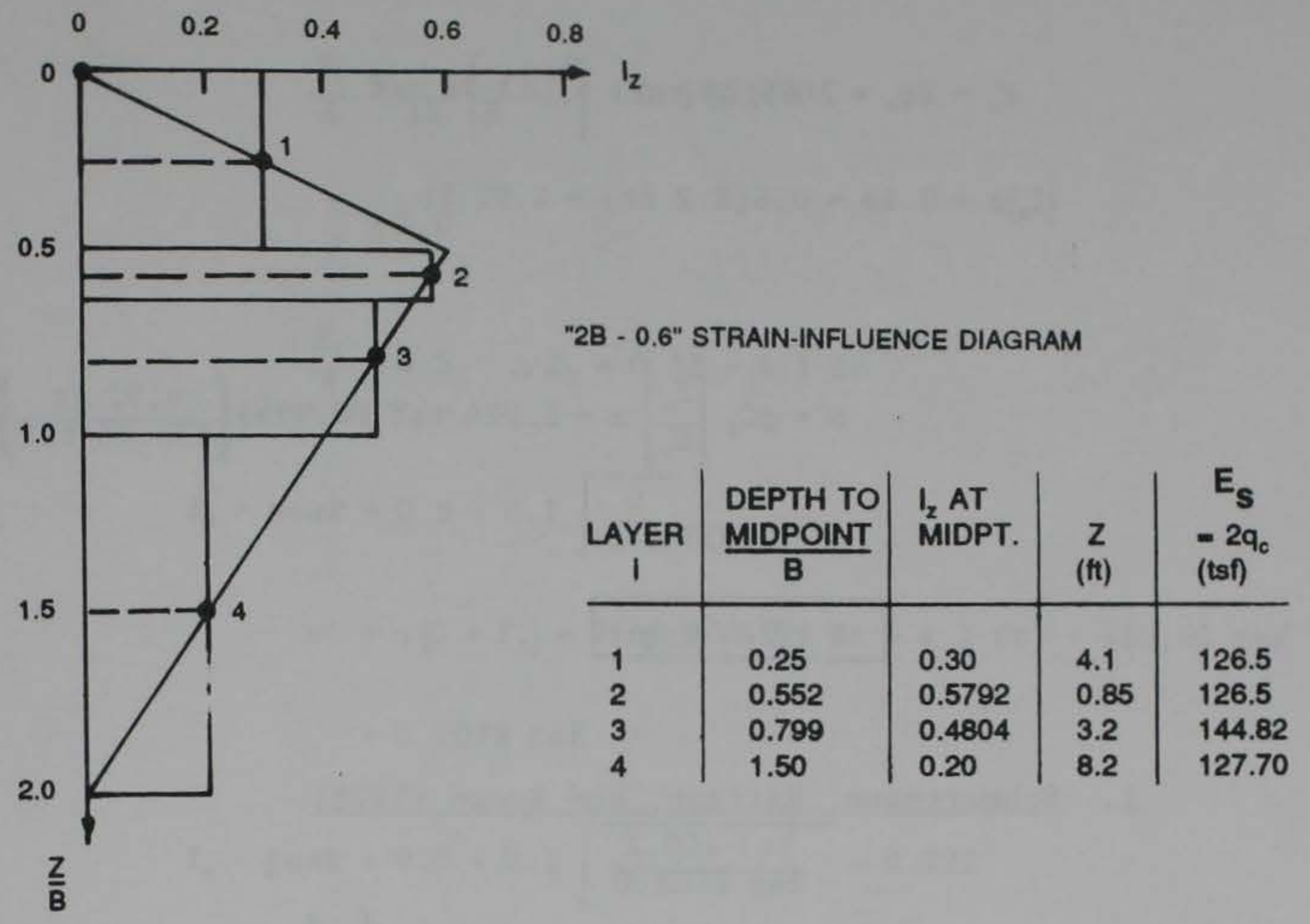

$$
\left.\begin{array}{ll}
\begin{array}{l}
\text { Layer } \\
\frac{1}{1}
\end{array} & \frac{\left(\frac{I_{z}}{E_{\mathrm{s}}}\right)_{i} z_{i}}{0.00972 \mathrm{ft} / \mathrm{tsf}} \\
2 & 0.00389 \\
3 & 0.01062 \\
4 & 0.01284
\end{array}\right\} \sum\left(\frac{I_{z}}{E_{\mathrm{s}}}\right) z=0.03707 \mathrm{ft} / \mathrm{tsf}
$$$$
C_{\mathrm{d}}=1-0.5\left(\frac{\gamma D}{q}\right)=1-0.5\left(\frac{96 \mathrm{pcf}(0.23 \mathrm{ft})}{1.024 \mathrm{tsf} \frac{2,000}{1}}\right)=0.995
$$$$
S=(1.024 \mathrm{tsf})(0.995)\left(0.03707 \frac{\mathrm{ft}}{\mathrm{tsf}}\right)=0.03777 \mathrm{ft}
$$$$
S=0.453 \text { in. }
$$ 
Simplified: Use $q_{c}$ - average $=66.88$ tsf constant over depth $=2 B$

$$
\begin{aligned}
E_{\mathrm{s}} & =2 q_{\mathrm{c}}=2(66.88 \mathrm{tsf})=133.76 \mathrm{tsf} \\
\left(I_{z}\right) z & =0.6 B=0.6(8.2 \mathrm{ft})=4.92 \mathrm{ft}
\end{aligned}
$$

$$
\begin{aligned}
S & =q C_{\mathrm{d}}\left(\frac{I_{\mathrm{z}}}{E_{\mathrm{s}}}\right) z=1.024 \operatorname{tsf}(0.995)\left(\frac{4.92 \mathrm{ft}}{133.76 \mathrm{tsf}}\right) \\
& =0.03748 \mathrm{ft} \\
S & =0.450 \mathrm{in} .
\end{aligned}
$$

i. Schmertmann, Hartman, and Brown (1978)

$$
S=q C_{\mathrm{d}} C_{\mathrm{t}} \sum_{\mathrm{i}=1}^{\mathrm{n}}\left(\frac{I_{\mathrm{z}}}{E_{\mathrm{s}}}\right)_{\mathrm{i}} z_{\mathrm{i}}
$$

Construct strain-influence diagram. 


\section{Point 1}

$$
\begin{aligned}
& \frac{Z_{1}}{B}=\frac{1}{18}\left(\frac{L}{B}-1\right)+0.5 \leq 1.0 \\
& \frac{L}{B}=1.0 \\
& \frac{Z_{1}}{B}=0.5 \quad \therefore Z_{1}=0.5 B=4.1 \mathrm{ft} \\
& I_{z}-\text { peak }=0.5+0.1 \sqrt{\frac{q}{p^{\prime}}} \\
& p^{\prime}=\gamma\left(D+Z_{1}\right)=96 \operatorname{pcf}(0.23 \mathrm{ft}+4.1 \mathrm{ft})=415.68 \mathrm{psf} \\
& =0.2078 \mathrm{tsf} \\
& I_{z}-\text { peak }=0.5+0.1 \sqrt{\frac{1.024 \operatorname{tsf}}{0.2078 \operatorname{tsf}}}=0.722
\end{aligned}
$$

\section{Point 2}

$$
\begin{aligned}
I_{z}-\text { intercept } & =\frac{1}{90}\left(\frac{L}{B}-1\right)+0.1 \leq 0.2 \\
& =0.1 \\
\frac{Z}{B} & =0
\end{aligned}
$$

Point 3

$$
\begin{aligned}
\frac{Z_{2}}{B} & =\frac{2}{9}\left(\frac{L}{B}-1\right)+2 \leq 4.0 \\
& =2 \\
I_{z} & =0
\end{aligned}
$$


$C_{\mathrm{d}}=0.995$, Schmertmann (1970)

$C_{\mathrm{t}}=N \cdot A$.

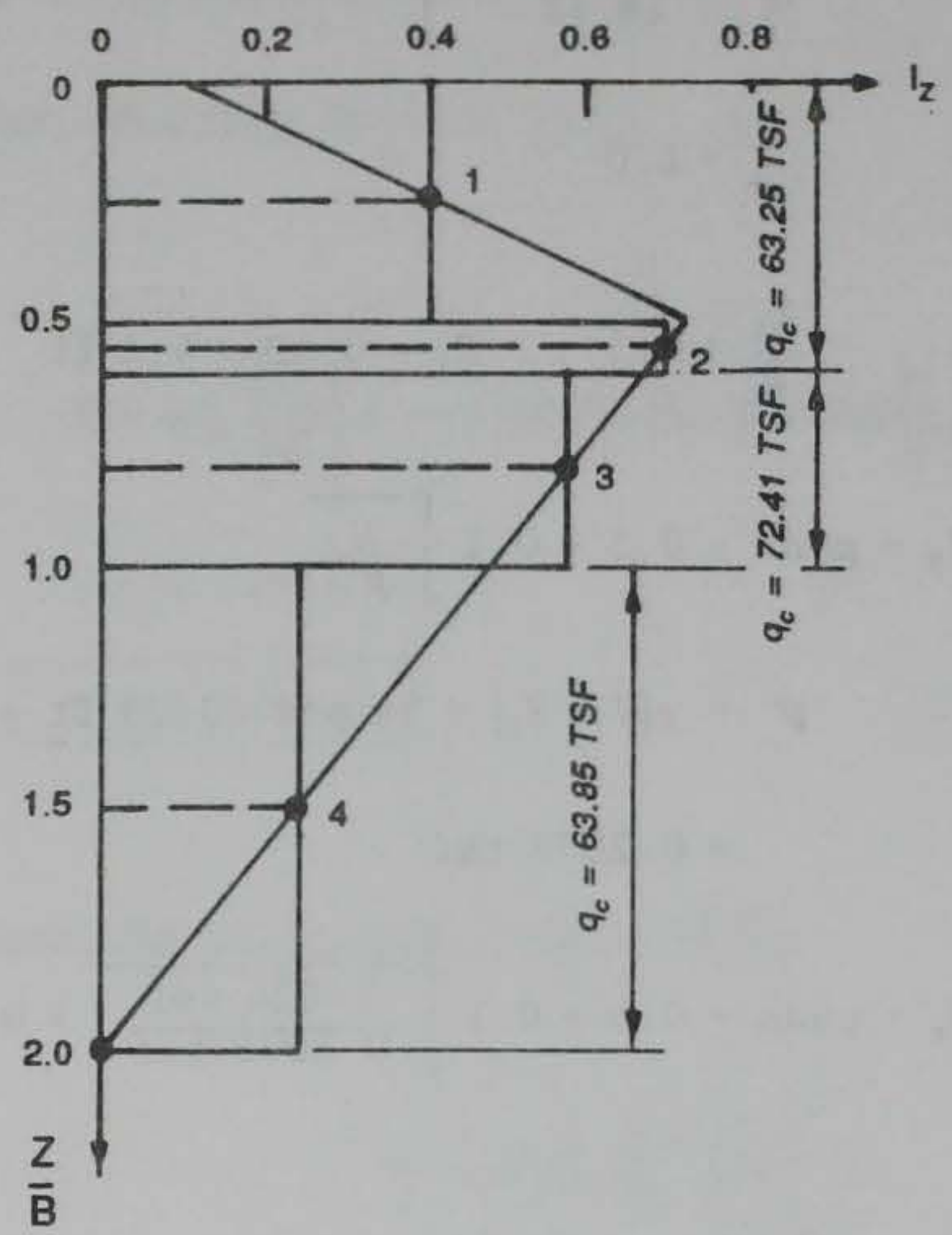

Use same layers as in 1970 calculations.

\begin{tabular}{|c|c|c|c|c|c|}
\hline $\begin{array}{c}\text { Layer } \\
i \\
\end{array}$ & $\left(\frac{\mathrm{Z} \text {-midpoint }}{B}\right.$ & $\begin{array}{l}I_{\mathbf{z}_{i}} \\
\text { at midpoint }\end{array}$ & $\begin{array}{r}z_{i} \\
(\mathrm{ft}) \\
\end{array}$ & $\begin{array}{c}E_{\mathrm{s}_{\mathrm{i}}}=2.5 q_{\mathrm{c}} \\
\quad \text { (tsf) }\end{array}$ & $\begin{array}{l}\left.\frac{I_{z}}{E_{s}}\right)_{i} z_{i} \\
\text { (ft/tsf) }\end{array}$ \\
\hline 1 & 0.25 & $0.411 *$ & 4.1 & 158.125 & 0.01066 \\
\hline 2 & 0.552 & 0.697 & 0.85 & 158.125 & 0.00375 \\
\hline 3 & 0.799 & 0.578 & 3.2 & 181.025 & 0.01022 \\
\hline \multirow[t]{2}{*}{4} & 1.50 & 0.241 & 8.2 & 159.625 & 0.01238 \\
\hline & & & & Total & $\begin{aligned}= & 0.03701 \\
& (\mathrm{ft} / \mathrm{tsf})\end{aligned}$ \\
\hline
\end{tabular}

* $\quad \frac{0.722-0.1}{0.5}=\frac{0.722-I_{\mathrm{z}_{1}}}{0.25}$

$I_{z_{1}}=0.411$ 


$$
\begin{aligned}
S & =q C_{\mathrm{d}}\left(\frac{I_{\mathrm{z}}}{E_{\mathrm{s}}}\right) z \\
& =(1.024 \mathrm{tsf})(0.995)(0.03701 \mathrm{ft} / \mathrm{tsf})=0.03771 \mathrm{ft} \\
S & =0.453 \mathrm{in} .
\end{aligned}
$$

Simplified: Assume $q_{c}$ is constant at average $=66.88$ tsf over the strain-influence diagram.

$$
E_{\mathrm{s}}=2.5 q_{\mathrm{c}}=2.5(66.88 \mathrm{tsf})=167.20 \mathrm{tsf}
$$

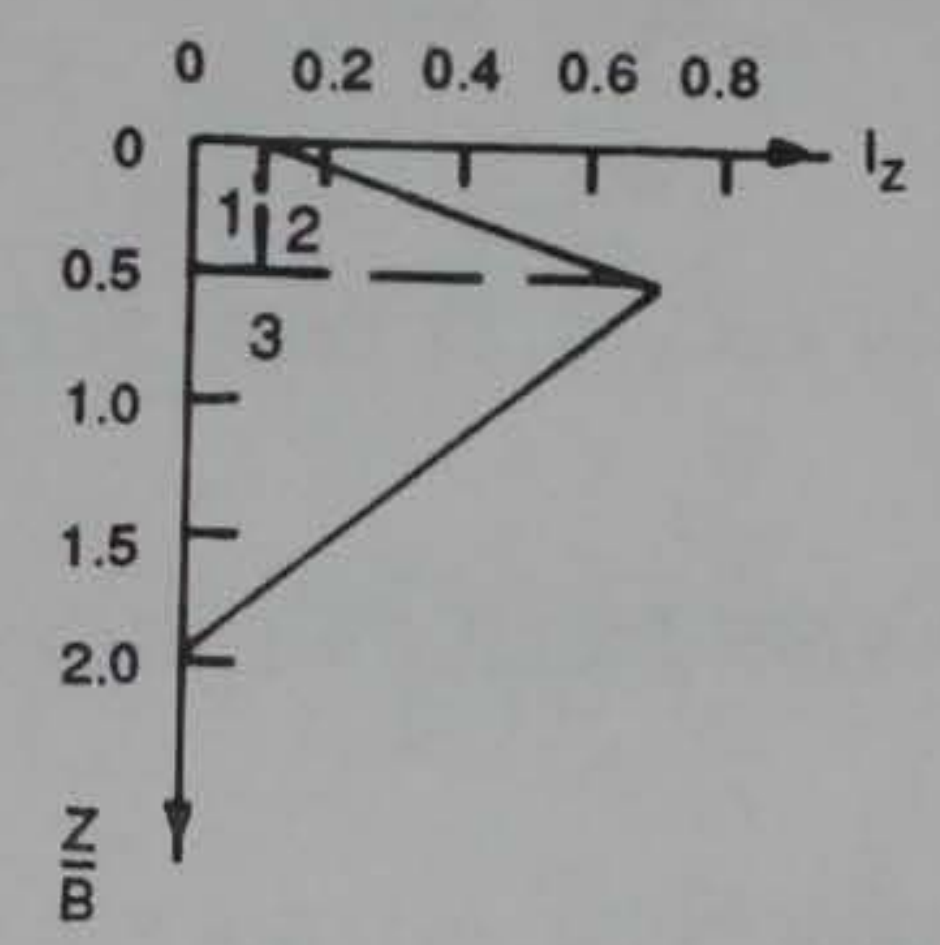

$$
\begin{aligned}
\sum\left(\frac{I_{\mathrm{z}}}{E_{\mathrm{s}}}\right)_{\mathrm{i}} z_{\mathrm{i}} & =\frac{\text { area under curve }}{E_{\mathrm{s}}} \\
\text { (1) } & =0.1(0.5 \mathrm{~B})=0.05 \mathrm{~B} \\
\text { (2) } & =(0.722-0.1)(0.5 B) \frac{1}{2}=0.1555 \mathrm{~B} \\
\text { (3) }=\frac{1}{2}(0.722)(2.0-0.5) B & =\underline{0.5415 \mathrm{~B}} \\
\text { Total } & =0.747 \mathrm{~B} \\
& =6.1254 \mathrm{ft}
\end{aligned}
$$




$$
\begin{aligned}
\left(\frac{I_{z}}{E_{\mathrm{s}}}\right) z=\frac{6.1254 \mathrm{ft}}{167.20 \mathrm{tsf}}=0.03664 \mathrm{ft} / \mathrm{tsf} \\
S=(1.024 \mathrm{tsf})(0.995)(0.03664 \mathrm{ft} / \mathrm{tsf})=0.03733 \mathrm{ft} \\
S=0.448 \mathrm{in} .
\end{aligned}
$$

i. Schultze and Sherif (1973)

$$
S=\frac{Q F_{\mathrm{c}}}{N^{0.87} C_{\mathrm{d}}}
$$

$$
\begin{aligned}
Q & =q+\gamma D=1.024 \operatorname{tsf}+0.23 \mathrm{ft}(96 \mathrm{pcf}) \frac{1}{2,000} \\
& =1.035 \operatorname{tsf}\left(0.9765 \frac{\mathrm{kg} / \mathrm{cm}^{2}}{\mathrm{tsf}}\right)=1.0107 \mathrm{~kg} / \mathrm{cm}^{2}
\end{aligned}
$$

Use Figure 17 (main text) and $B=8.2 \mathrm{ft}(12 \mathrm{in.} / \mathrm{ft})(2.54 \mathrm{~cm} / \mathrm{in}$.) $=250 \mathrm{~cm}$, to get $F_{c}\left(\right.$ for $\left.\frac{L}{B}=1\right)$

$$
\begin{aligned}
F_{\mathrm{c}}= & 6.0 \frac{\mathrm{cm}^{3}}{\mathrm{~kg}} \cdot \frac{H-D}{B}=\left(\frac{40 \mathrm{ft}-0.23}{8.2} \mathrm{ft}\right)=4.85>2, \\
& \therefore \text { Figure } 17 \mathrm{~b} \text { (main text) not required }
\end{aligned}
$$

$$
C_{\mathrm{d}}=1+0.4\left(\frac{D}{B}\right)=1+0.4\left(\frac{0.23 \mathrm{ft}}{8.2 \mathrm{ft}}\right)=1.011
$$

$$
S=\frac{\left(1.0107 \frac{\mathrm{kg}}{\mathrm{cm}^{2}}\right)\left(6 \frac{\mathrm{cm}^{3}}{\mathrm{~kg}}\right)}{(9.3)^{0.87}(1.011)}=0.8619 \mathrm{~cm}
$$

$$
S=0.339 \mathrm{in} .
$$


k. Meyerhof (1974)

$$
\begin{gathered}
S=\frac{q \sqrt{B}}{2 N} C_{\mathrm{d}} \\
B=8.2 \mathrm{ft}(12)=98.4 \mathrm{in.} \\
C_{\mathrm{d}}=1-0.25\left(\frac{D}{B}\right)=1-0.25\left(\frac{0.23 \mathrm{ft}}{8.2 \mathrm{ft}}\right)=0.993 \\
S=\frac{1.024 \mathrm{tsf} \sqrt{98.4 \mathrm{in} .}}{2(9.3)}(0.993) \\
S=0.542 \mathrm{in.}
\end{gathered}
$$

1. Peck, Hanson, and Thornburn (1974)

$$
S=\frac{q}{0.11 N_{\mathrm{c}} C_{\mathrm{w}}}
$$

$$
\begin{aligned}
N_{\mathrm{c}} & =0.77 \log \left(\frac{20}{P},\right)(N) \\
P^{\prime} & =\gamma\left(D+\frac{B}{2}\right)=96 \mathrm{pcf}(0.23 \mathrm{ft}+4.1 \mathrm{ft})=415.68 \mathrm{psf}\left(\frac{1}{2,000}\right) \\
& =0.2078 \mathrm{tsf} \\
N_{\mathrm{c}} & =0.77 \log \left(\frac{20}{0.2078}\right)(9.3) \\
& =14.2 \\
C_{\mathrm{w}} & =N . A .
\end{aligned}
$$




$$
S=\frac{1.024 \operatorname{tsf}}{0.11(14.2)}
$$

$$
S=0.655 \text { in. }
$$

m. Bowles (1977, 1982)

$$
S=\frac{4 q}{N}\left(\frac{B}{B+1}\right)^{2} \frac{C_{\mathrm{w}}}{C_{\mathrm{d}}}
$$

$$
\begin{aligned}
& C_{\mathrm{w}}=1.0 \text { (N.A.) } \\
& C_{\mathrm{d}}=1+0.33 \frac{D}{B}=1+0.33\left(\frac{0.23 \mathrm{ft}}{8.2 \mathrm{ft}}\right)=1.009
\end{aligned}
$$

$$
S=\frac{4(1.024 \mathrm{tsf})\left(\frac{2 \mathrm{kip}}{1 t}\right)}{9.3}\left(\frac{8.2 \mathrm{ft}}{9.2 \mathrm{ft}}\right)^{2}\left(\frac{1}{1.009}\right)
$$

$$
S=0.694 \mathrm{in} .
$$

n. NAVFAC DM 7.1 (Department of the Navy (1982))

$$
S=\frac{C q}{K_{\mathrm{v}}}\left(\frac{B}{B+1}\right)^{2} C_{\mathrm{w}}
$$




$$
\begin{aligned}
C & =4.0, \text { for } B<20 \mathrm{ft} \\
C_{\mathrm{w}} & =1.0 \text { (N.A.) }
\end{aligned}
$$

Use Figure 22 and $D_{r}$ to get $K_{v}$

$$
\begin{array}{rlrl}
D_{\mathrm{r}} & =\sqrt{\frac{N}{20\left(1+2 p^{\prime}\right)}} \quad P^{\prime} & =\gamma\left(D+\frac{B}{2}\right)=96 \operatorname{pcf}(0.23 \mathrm{ft}+4.1 \mathrm{ft}) \\
& =415.68 \mathrm{psf} \\
& =\sqrt{\frac{9.3}{20(1+2(0.416))}} \quad=0.416 \mathrm{ksf} \\
D_{\mathrm{r}}=50.48 &
\end{array}
$$

From Figure 22 (main text), $\quad K_{\mathrm{v}}=126$ tsf

$$
S=\frac{4.0(1.024 \mathrm{tsf})}{126 \mathrm{tcf}}\left(\frac{8.2 \mathrm{ft}}{9.2 \mathrm{ft}}\right)^{2}=0.0258 \mathrm{ft}
$$

$$
S=0.309 \mathrm{in} \text {. }
$$

o. . Owe is (1979)

$$
S=q B \sum_{i=1}^{\mathrm{n}} \frac{\Psi_{i}}{E_{i}}
$$

Divide stratum into ' $n$ ' sublayers for a depth of 2 to $2.5 B$ below the footing. 


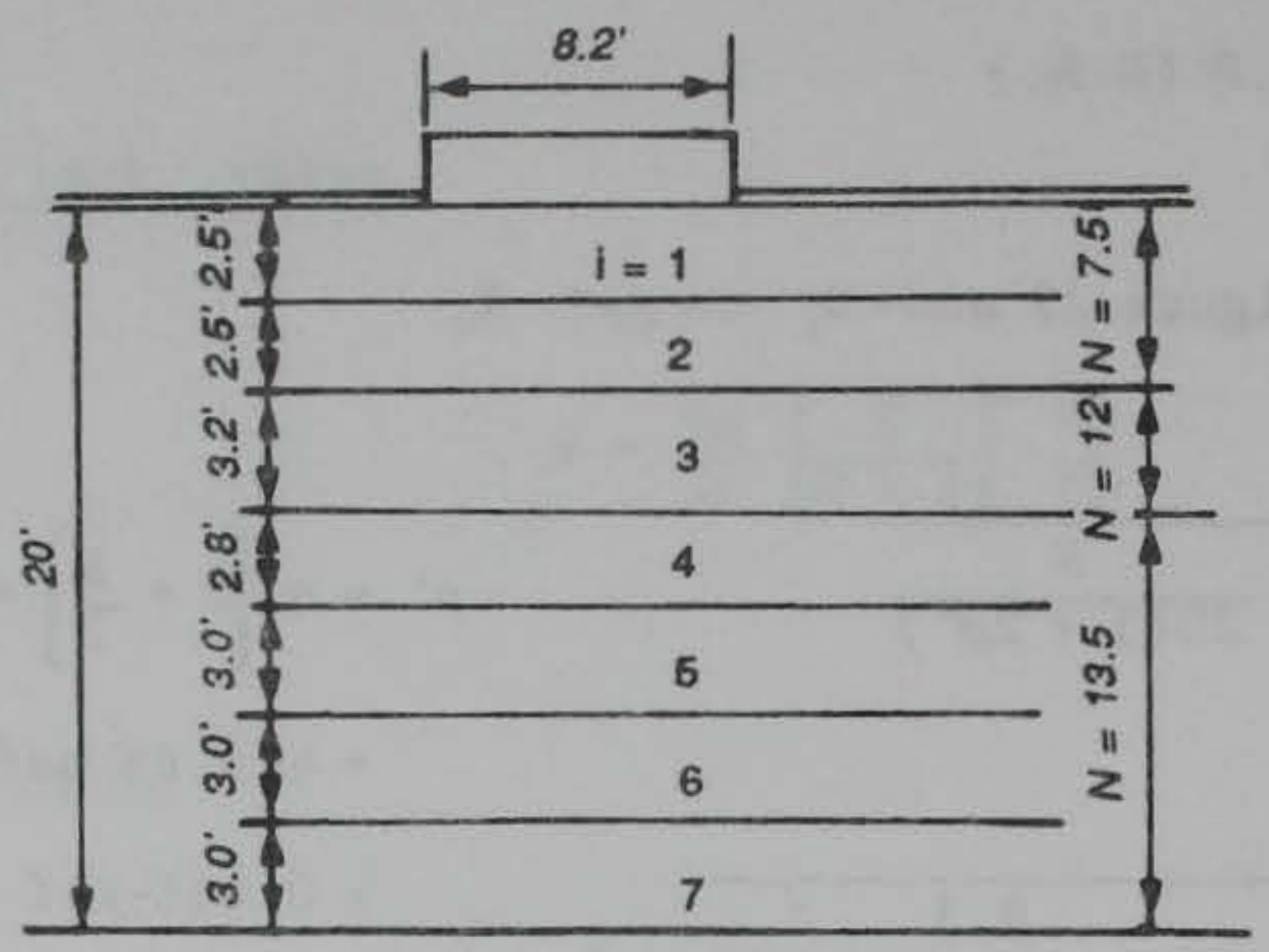

$$
\begin{gathered}
S_{\text {center }}=0.829 \mathrm{in} . \\
S_{\text {edge }}=0.250 \mathrm{in} . \\
S_{\text {rigid }}=0.518 \mathrm{in} .
\end{gathered}
$$

Table 11 from main text is used to record calculations. 
ior: (Center Edge Rigid) Settlement.

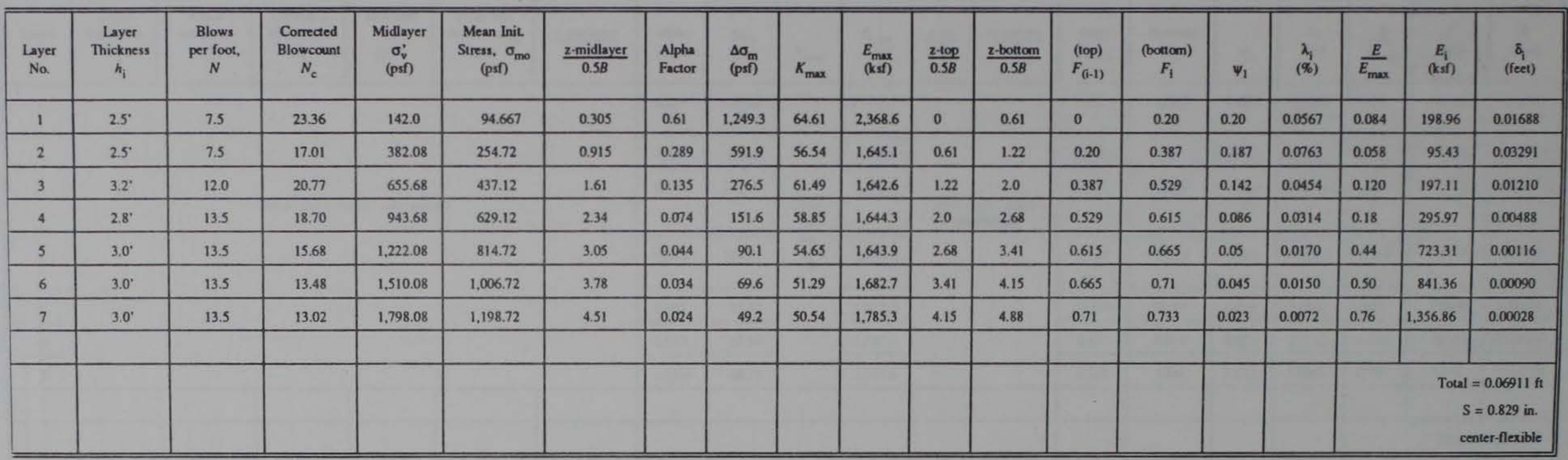


For: (Center Edge Rigid) Setuement.

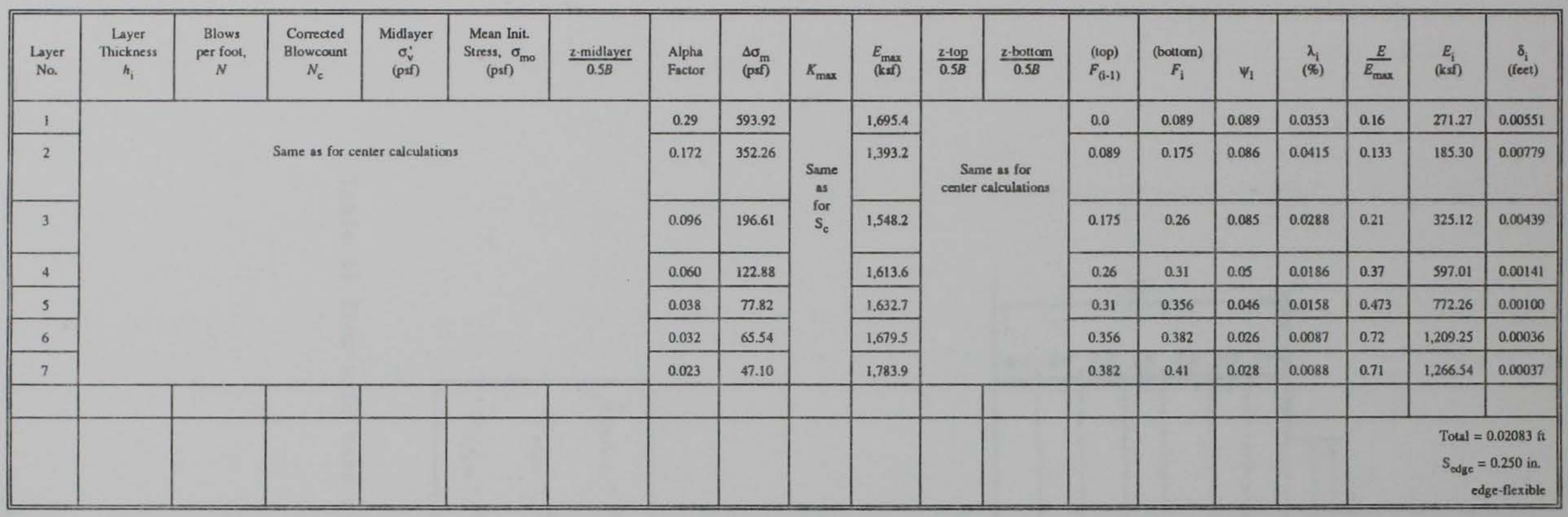


For: (Center Edge Rigid) Settement.

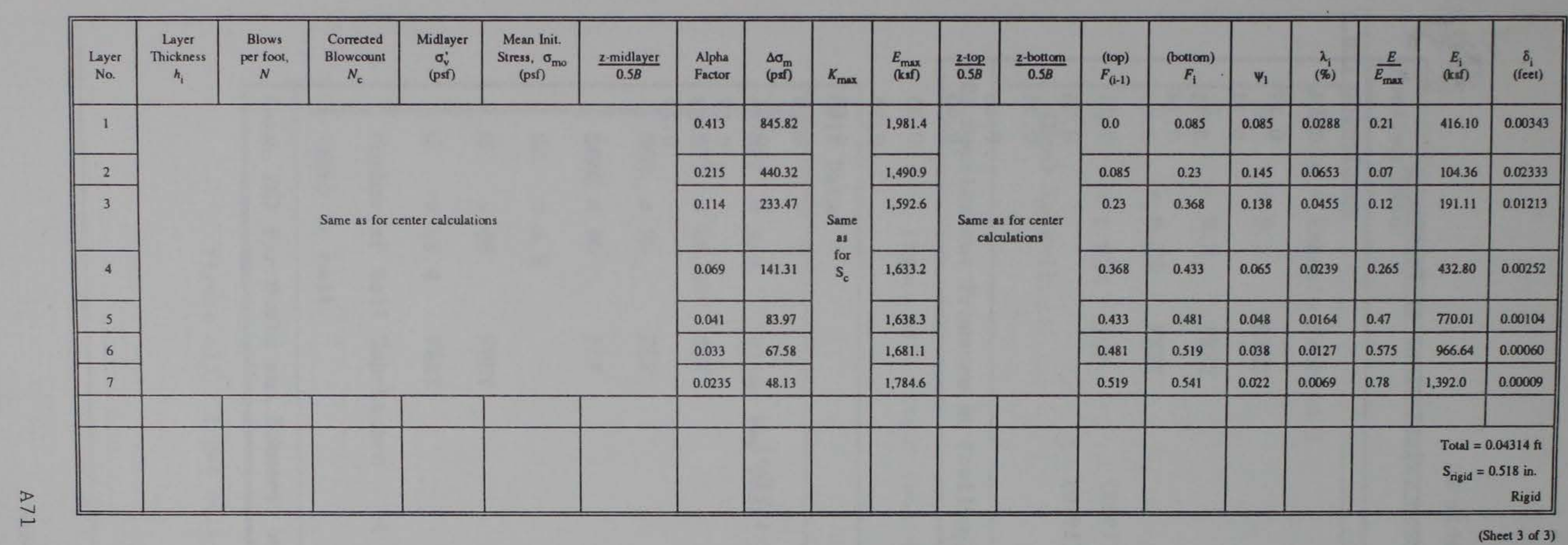


Table A3

Summary of Results from Hand Calculations of Problem 3

\section{Method}

Terzaghi and Peck (1948, 1967)

Teng (1962)

Alpan (1964)

Elastic Theory - rigid center (flex.) average (flex.)

D'Appolonia, D'Appolonia, and Brown (1968)

D'Appolonia, D'Appolonia, and Brown (1970)

Peck and Bazaraa (1969)

Schmertmann (1970)

Schmertmann, Hartman, and Brown (1978)

Schultze and Sherif (1973)

Meyerhof (1974)

Peck, Hanson, Thornburn (1974)

Bowles (1977, 1982)

NAVFAC DM 7.1 (Department of the Navy (1982))

Oweis (1979) - rigid center (flex.) edge (flex.)
Settlement (in.)

1.04

0.27

0.31

0.71

0.76

0.65

0.21

0.25

0.31

0.45

0.45

0.34

0.54

0.66

0.69

0.31

0.52

0.83

0.25 


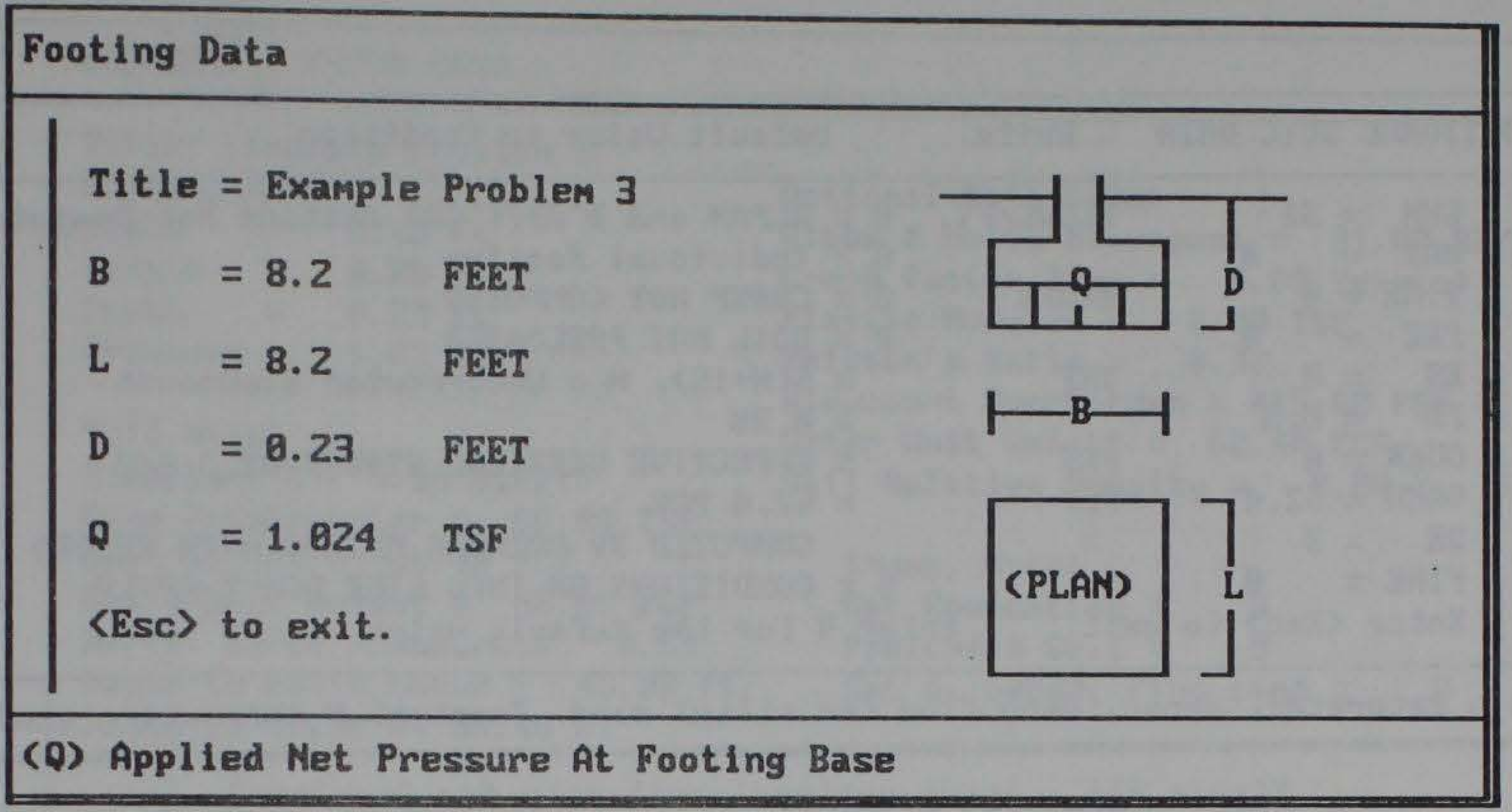

Figure A12. Input footing data for Problem 3

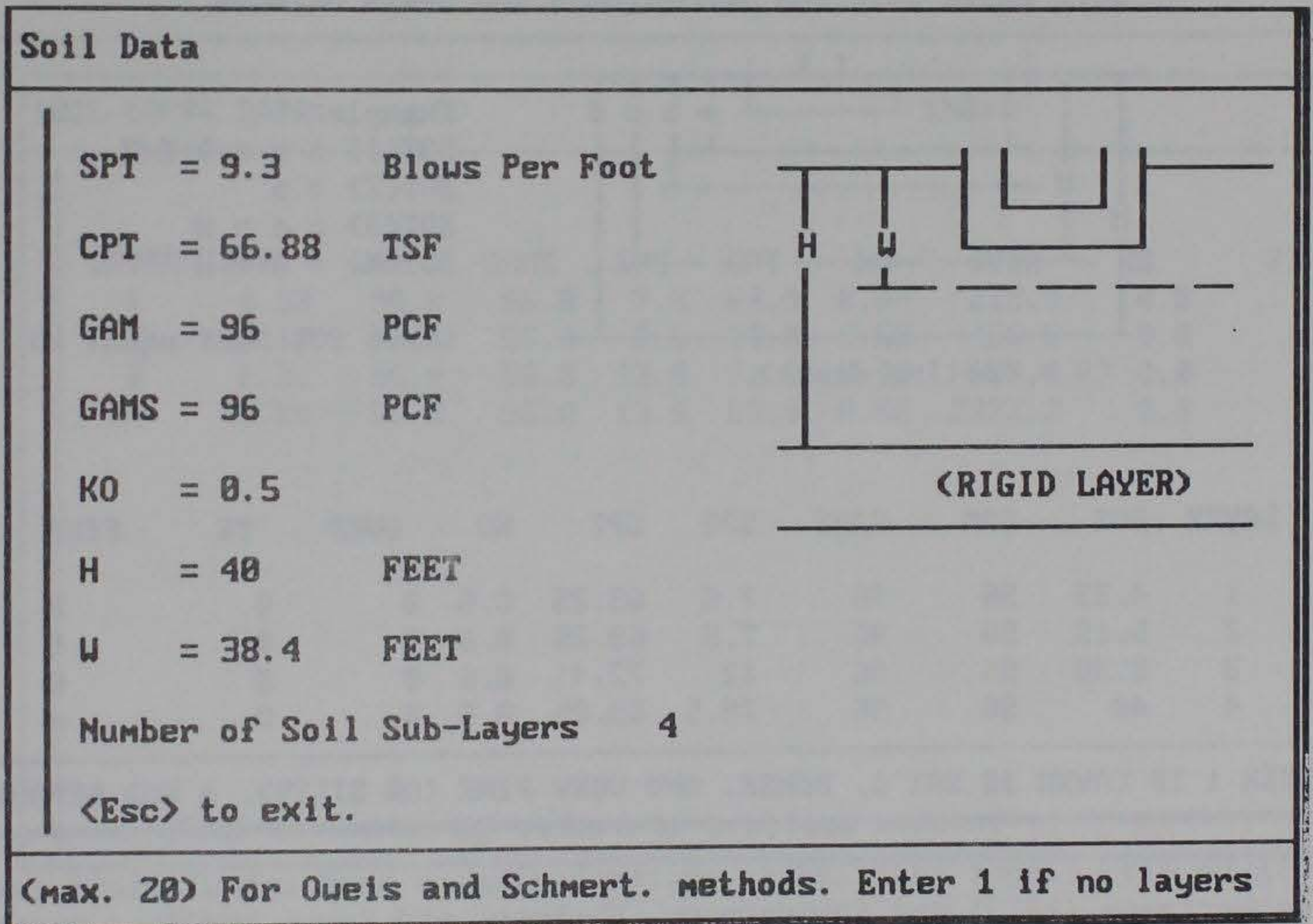

Figure A13. Input soil data for Problem 3 


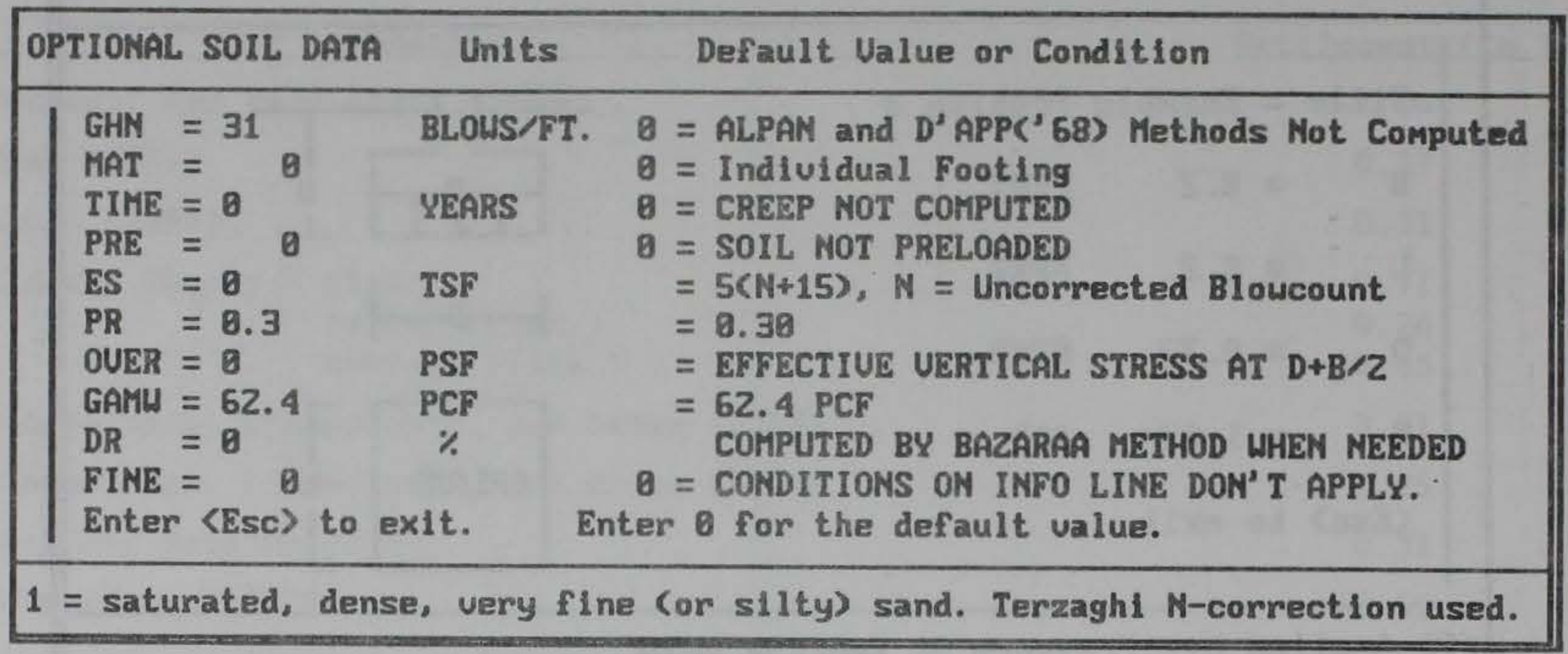

Figure A14. Input optional soil data for Problem 3

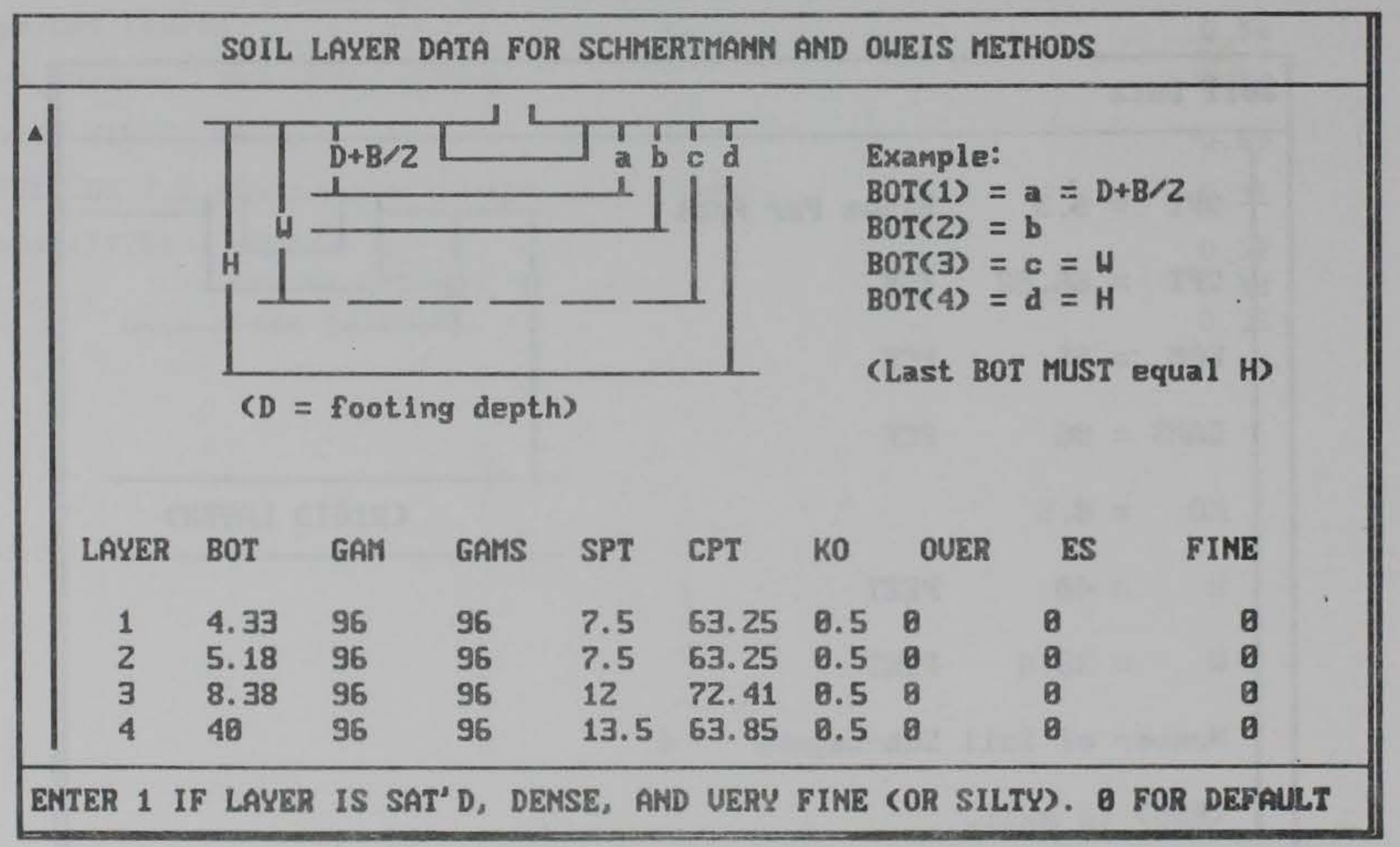

Figure A15. Input soil layers corresponding to hand calculations for Schmertmann (1970) and Schmertmann, Hartman, and Brown (1978). Depths to bottom of each layer include $D=0.23 \mathrm{ft}$ 


\begin{tabular}{|c|c|}
\hline CSANDSET - INPUT DATA & \\
\hline $\begin{array}{l}\text { Title: Example Problem } 3 \\
\text { Footing Data: } \\
\text { Width }=8.20 \mathrm{Ft} \\
\text { Length }=8.26 \mathrm{Ft} \\
\text { Depth }=0.23 \mathrm{Ft} \\
\text { Pressure }=1.02 \mathrm{TSF} \\
\text { Soil Data: } \\
\text { Blowcount }=9.30 \mathrm{Bl} / \mathrm{Ft} \\
\text { Cone Penetrometer }=66.88 \mathrm{TSF} \\
\text { Unit Weight }=96.00 \mathrm{PCF} \\
\text { Sat'd Unit Weight }=96.00 \mathrm{PCF} \\
\text { Horiz. Earth Pressure }=\quad 0.50 \\
\text { Depth To Rigid Layer }=48.80 \mathrm{Ft} \\
\text { Depth To Water }=38.46 \mathrm{FT}\end{array}$ & 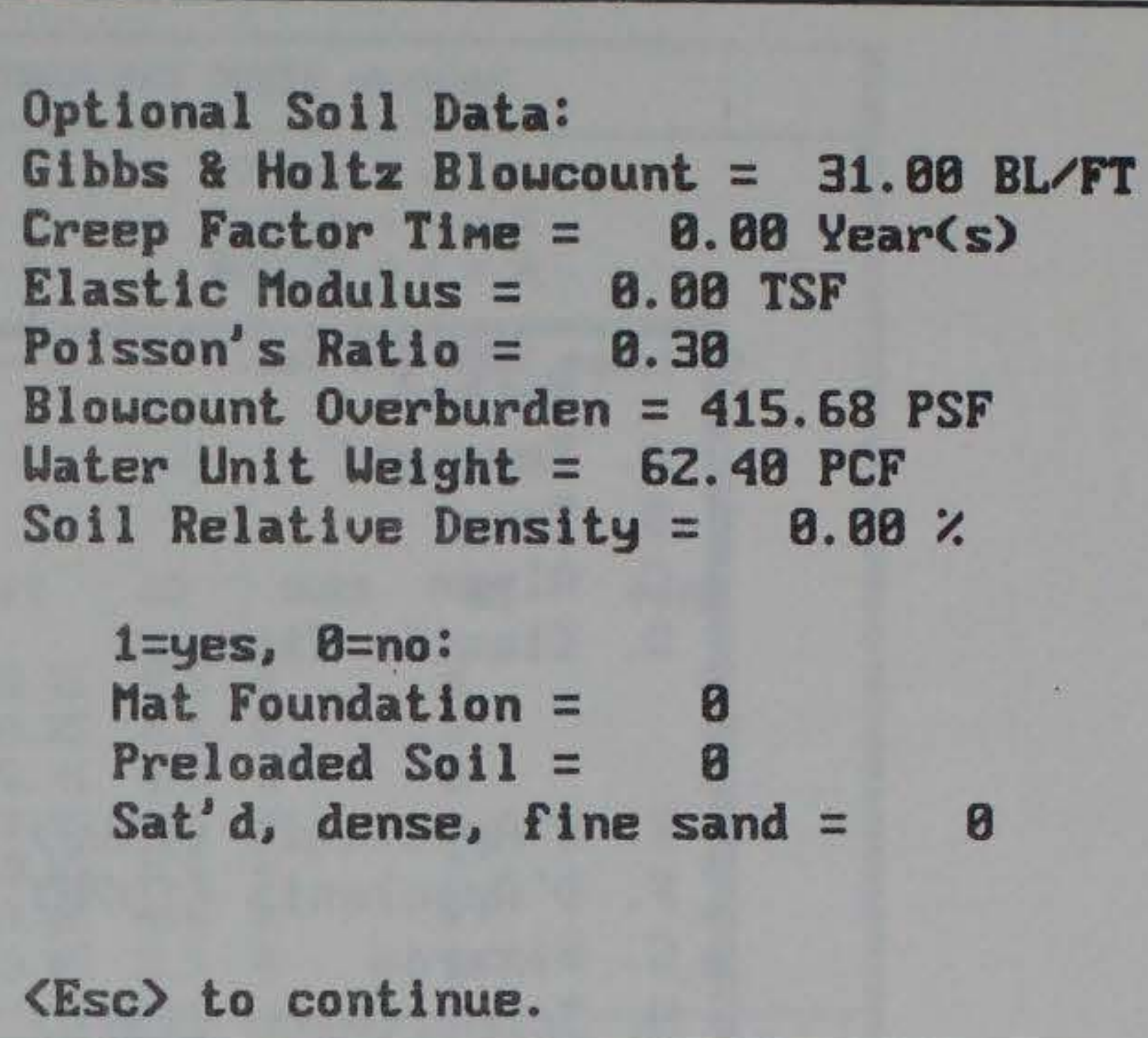 \\
\hline
\end{tabular}

a. Footing, soil, and optional data

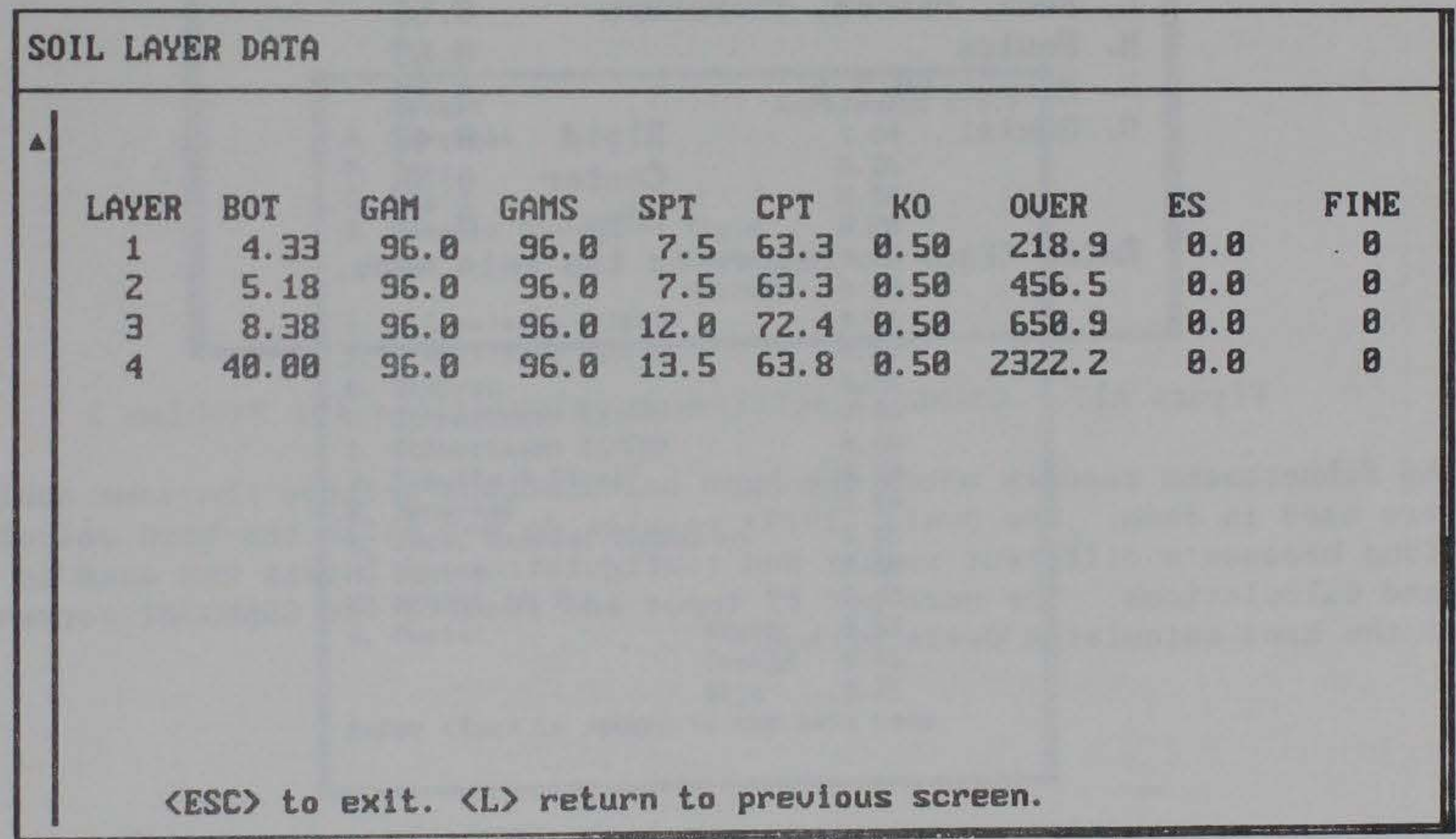

b. Soil layer data

Figure A16. Listing of all input data for Problem 3 


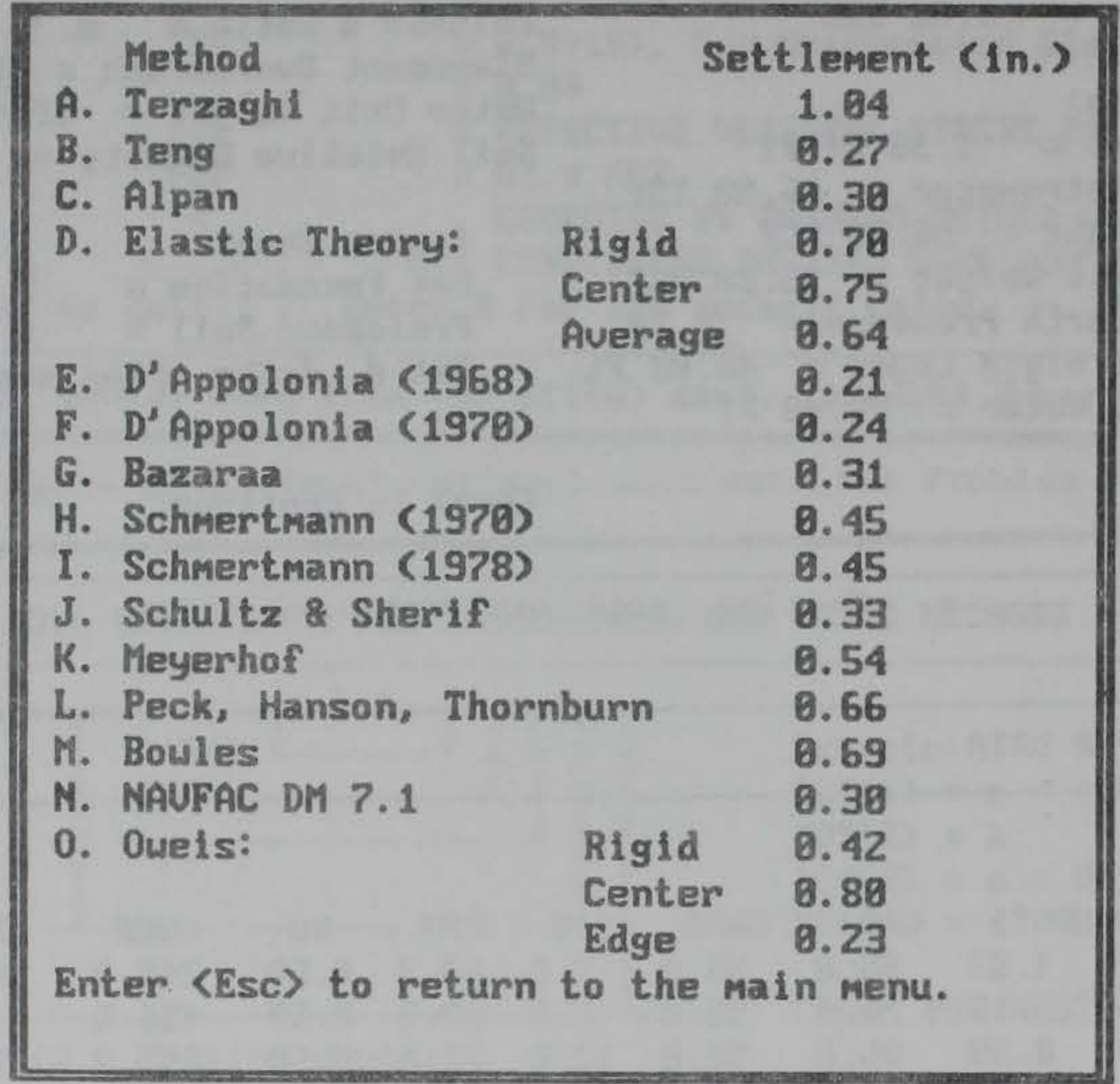

Figure A17. CSANDSET settlement calculations for Problem 3

The Schmertmann results match the hand calculations because the same sublayers were used in each. The Oweis (1979) results do not match the hand calculations because a different number and configuration of layers was used in the hand calculations. The next set of input and results for CSANDSET correspond to the hand-calculated Oweis method. 


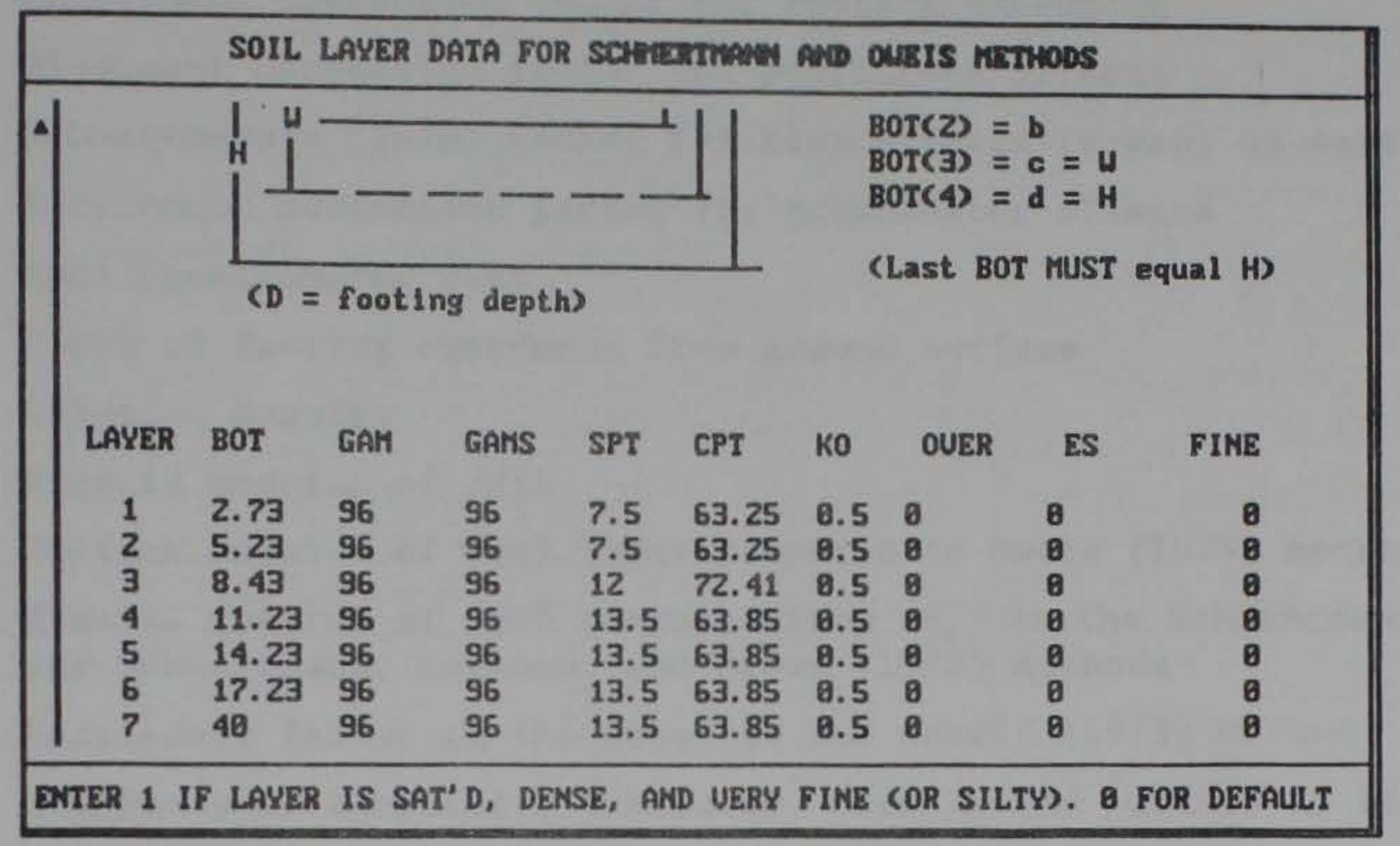

Figure A18. Input soil layer data corresponding to hand calculations for Oweis (1979) method

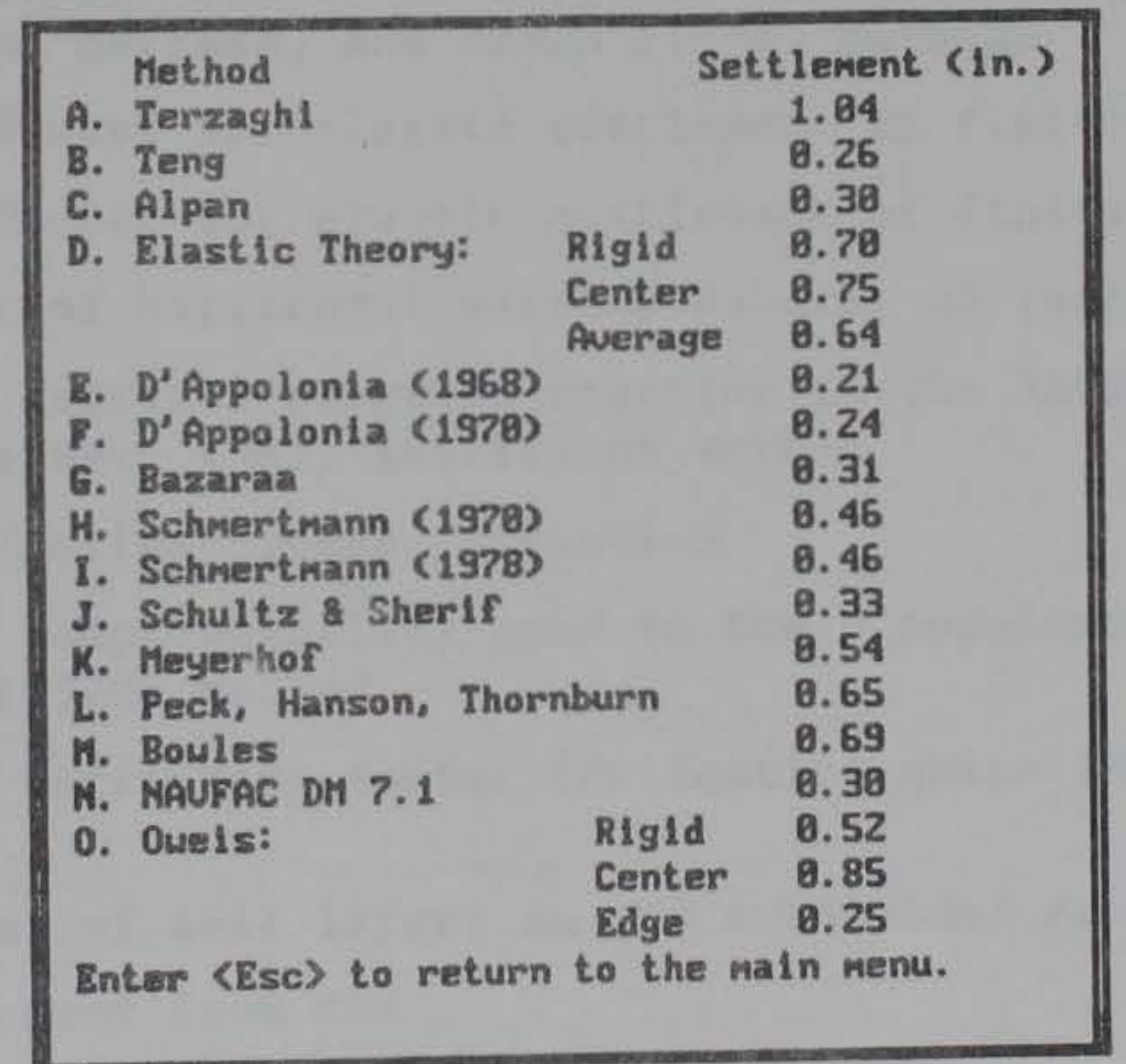

Figure A19. CSANDSET settlement calculations with soil layers input for Oweis (1979) hand calculations 
Width of footing, smaller dimension

Empirical constant used in some settlement equations

$D \quad$ Depth of footing embedment from ground surface

$D_{\mathrm{r}} \quad$ Relative density

E Elastic modulus of soil

Maximum modulus of soil layer computed in Oweis (1979) method

Elastic modulus of soil computed from $q_{c}$ in the Schmertmann (1970) and Schmertmann, Hartman, and Brown (1978) methods

$F_{\mathrm{c}} \quad$ Settlement factor in the Schultze and Sherif (1973) method

$H \quad$ Thickness of compressible stratum, from ground surface to rigid base

$i \quad$ Individual soil layer

I Influence factor used in elastic methods

$I_{2} \quad$ Strain influence factor used in the Schmertmann (1970) and Schmertmann, Hartman, and Brown (1978) methods

$I_{3}{ }^{\prime} \quad$ Influence factor for elastic settlement of finite stratum

$I_{4}{ }^{\prime} \quad$ Influence factor for elastic settlement of finite stratum

$K_{0} \quad$ Coefficient of horizontal earth pressure, at rest

$K_{\mathrm{v}} \quad$ Modulus of vertical subgrade reaction in the NAVFAC DM 7.1 (Department of the Navy 1982) settlement method

$L \quad$ Length of footing, longer dimension

$M \quad$ Modulus of compressibility used in the D'Appolonia, D'Appolonia, Brissette (1970) method

$m$

$n$

$N$

$N_{\mathrm{c}}$

$O C R$

$p^{\prime}$

Settlement correction factor for footing shape in the Alpan (1964) method

Total number of soil layers in the subdivided compressive stratum Field blowcount from SPT

Corrected blowcount

Overconsolidation ratio

Effective overburden pressure usually at depth $D+B / 2$, see context of use

Full (gross) pressure applied to footing

Net applied contact pressure on footing base 
$S$ Total calculated settlement of a shallow foundation

$S_{1} \quad$ Settlement of a 1 -ft square plate from plate load test

$S^{\prime} \quad$ Settlement at the corner of a footing at a depth equal to $H$ in a semi-infinite, homogeneous, elastic half-space

$S_{a} \quad$ Average settlement of a flexible footing on a semi-infinite, homogeneous, elastic half-space

$S_{\text {af }} \quad$ Average settlement of a flexible footing on a finite, homogeneous, compressible elastic stratum

$S_{c} \quad$ Settlement at the center of a flexible footing on a semi-infinite, homogeneous, elastic half-space

$S_{\text {cf }}$ Settlement at the center of a flexible footing on a finite, homogeneous, compressible elastic stratum

$S_{\mathrm{r}} \quad$ Settlement of a rigid footing on a semi-infinite, homogeneous, elastic half-space

$S_{\text {rf }} \quad$ Settlement of a rigid footing on a finite, homogeneous, compressible elastic stratum

SPT Standard Penetration Test

$s_{i} \quad$ Settlement of soil sublayer, $i$

$t$ Time period, used in Schmertmann (1970) and Schmertmann, Hartman, and Brown (1978) creep correction

$\mu_{\circ} \quad J a n b u, B j e r r u m$, and Kjaernsli (1956) correction factor for embedment

$\mu_{1} \quad J a n b u, B j e r r u m$, and Kjaernsli (1956) correction factor for thickness of compressible stratum

$v \quad$ Poisson's ratio

W Depth from ground surface to groundwater table

$z \quad$ Thickness of a soil sublayer

$Z$ Distance from footing base to midpoint, top, or bottom of a soil sublayer, see context of use

$Z_{1} \quad$ Depth below footing base to peak influence-factor value in the Schmertmann, Hartman, and Brown (1978) method

$Z_{2} \quad$ Depth below footing base to the point of zero strain influence in the method of Schmertmann, Hartman, and Brown (1978)

$\alpha \quad$ Subgrade coefficient in the Alpan (1964) method, load factor in the Oweis (1979) method

$\Delta \sigma_{\mathrm{m}} \quad$ Change in mean effective normal stress

$\gamma \quad$ Unit weight of soil

$\lambda \quad$ Strain parameter in the Oweis (1979) method

$\phi \quad$ Internal friction angle of soil

$\sigma_{\text {mo }} \quad$ Initial mean effective normal stress in the Oweis (1979) method 
$\sigma_{\mathrm{v}}{ }^{\prime} \quad$ Effective overburden pressure

$\Psi$ Settlement factor in the Oweis (1979) method 